\title{
GAT-280
}

CHE MISTRY-GENERAL

\section{URANIUM HEXAFLUORIDE: A SURVEY OF THE PHYSICO-CHEMICAL PROPERTIES}

by

R. DeWitt

Information and Records Subdivision

August 12, 1960

GOODYEAR ATOMIC CORPORATION

Portsmouth, Ohio

This document is PUBLICL: from Erifhim Authorizing Onicial

Date: $11 / 21 / 2055$ 


\section{DISCLAIMER}

This report was prepared as an account of work sponsored by an agency of the United States Government. Neither the United States Government nor any agency Thereof, nor any of their employees, makes any warranty, express or implied, or assumes any legal liability or responsibility for the accuracy, completeness, or usefulness of any information, apparatus, product, or process disclosed, or represents that its use would not infringe privately owned rights. Reference herein to any specific commercial product, process, or service by trade name, trademark, manufacturer, or otherwise does not necessarily constitute or imply its endorsement, recommendation, or favoring by the United States Government or any agency thereof. The views and opinions of authors expressed herein do not necessarily state or reflect those of the United States Government or any agency thereof. 


\section{DISCLAIMER}

Portions of this document may be illegible in electronic image products. Images are produced from the best available original document. 


\section{TABLE OF CONTENTS}

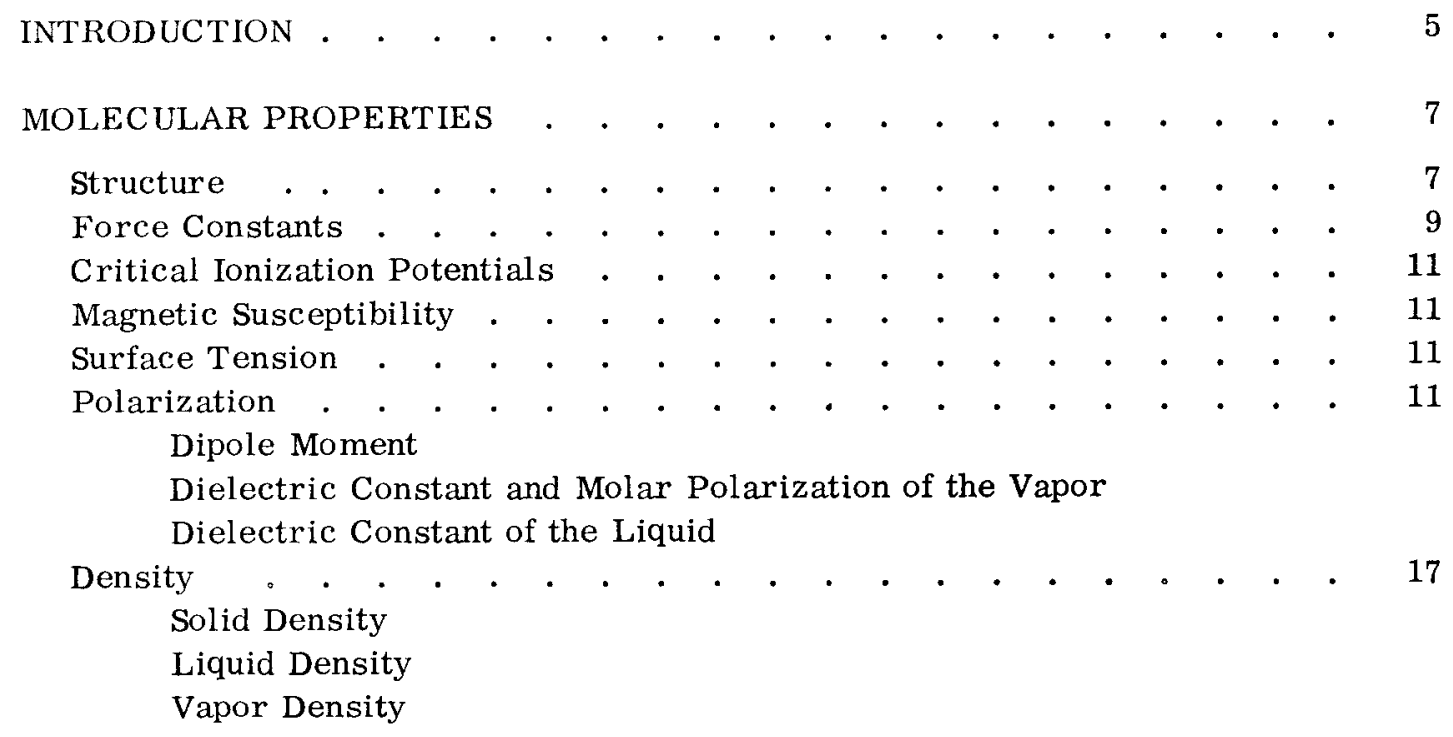

Thermal Conductivity of the Vapor

Thermal Conductivity of the Liquid

Thermal Conductivity of $\mathrm{UF}_{6}-$ Gas Mixtures

Mean Free Path . . . . . . . . . . . . . . . . . . 48

Intermolecular Force Models . . . . . . . . . . . . 52

THERMODYNAMIC PROPERTIES . . . . . . . . . . . . . . 55

Heat Capacity . . . . . . . . . . . . • . . . . . 56 
Heat Capacity of the Solid and the Liquid

Page

Heat Capacity of the Vapor

Heat Capacity Ratio

Enthalpy

Entropy

Entropy of the Solid and of the Liquid

Entropy of the Vapor

Free Energy of the Vapor . . . . . . . . . . . . . . . 70

Heats of Vaporization and of Sublimation . . . . . . . . . . . 72

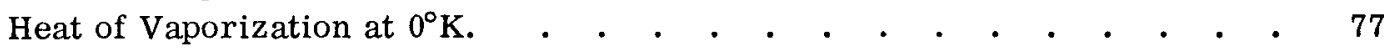

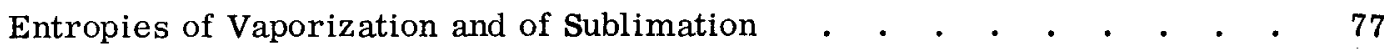

Heat of Fusion . . . . . . . . . . . . . . . . . . . 78

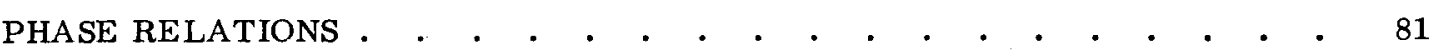

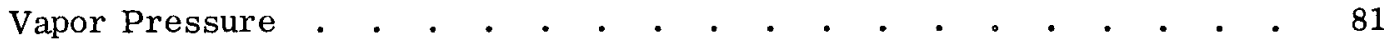

Sublimation Point . . . . . . . . . . . . . . . . .

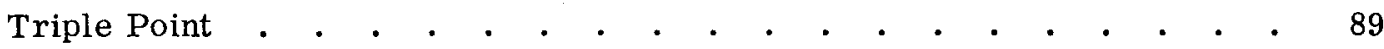

Critical Constants

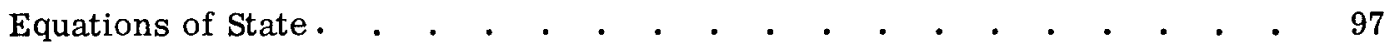

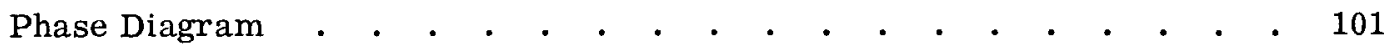

$\mathrm{UF}_{6}$ Binary Equilibrium Systems . • • • . • • • • • • • 101

Solid and Liquid Uranium Hexafluoride in Perfect Solutions

Uranium Hexafluoride in Fluorocarbons GD-727c and GD-727h

Uranium Hexafluoride in Fluorocarbons MFL (Chlorotrifluoroethylene

Liquid Polymer) and C-2144

Uranium Hexafluoride in Dichlorotetrafluoroethane

Uranium Hexafluoride in Perfluorotributylamine

Uranium Hexafluoride in Perfluoroisopropyl Ether

Uranium Hexafluoride in Perfluoro-n-Pentane and in 1,2-Dichloro-

hexafluoropropane

Uranium Hexafluoride in Perfluoroheptane

Uranium Hexafluoride in 2, 2, 3-Trichloroheptafluorobutane

Uranium Hexafluoride in $\mathrm{C}-816$ (Perfluorodimethylcyclohexane)

Uranium Hexafluoride in Hydrogen Fluoride

Uranium Hexafluoride in Bromine Fluorides $\left(\mathrm{BrF}_{3}\right.$ and $\left.\mathrm{BrF}_{5}\right)$

Uranium Hexafluoride in Chlorine Trifluoride $\left(\mathrm{ClF}_{3}\right)$

Miscellaneous Binary Uranium Hexafluoride Phase Relationships

$\mathrm{UF}_{6}$ Ternary Equilibrium Systems 。 . . . . . . . . . . . . . 149

Uranium Hexafluoride - Chlorine Trifluoride - Hydrogen Fluoride

Uranium Hexafluoride - 2, 2,3-Trichloroheptafluorobutane -

Perfluorodimethylcyclohexane

BIBLIOGRAPHY

151

LIST OF SYMBOLS . 


\section{INTRODUCTION}

Although data on the physical properties of $\mathrm{UF}_{6}$ have been compiled in a number of sources, none of the compilations* are both thorough and up-to-date. Most of the available compilations do not cover literature published after 1950. In the last ten years some of the discrepancies in the reported values of various properties of $U_{6} F_{6}$ have been resolved and new, more exact data have been added to the literature. In addition, values of the physical properties taken from different compilations often show striking and unexplained differences. For these reasons this handbook has been compiled in an attempt to collect all of the current physico-chemical data on $\mathrm{UF}_{6}$ in one useful volume and to highlight apparently contradictory results.

It is hoped that this handbook will serve both to acquaint technical personnel with the physico-chemical character of $\mathrm{UF}_{6}$ and to display the status of current knowledge of the values of each physical property. In many cases both preliminary and final values are tabulated herein to facilitate evaluation of the data by the reader, the preliminary values serving also to trace the history of some of the investigations which produced the now accepted values. The more reliable data for most properties are expressed as functions of their variables (e.g., temperature or pressure) to aid the user in quick extraction from the text. These functions are plotted in the form of graphs, given as equations, or both. In the case of most of the reliable data, a brief description is given of the experimental method which the investigator used. The reader is urged, however, to consult the investigator's publications for more complete information on the property reported and for a more authoritative interpretation of the results. Although no special effort was made to correlate all the data reported in this compilation for purposes of intercomparing deduced values of other properties, the data have been correlated for a few properties using various of the well-known empirical relations.

The bibliography near the end of the text is arranged alphabetically according to the first author, and then chronologically. Although every effort has been made to obtain and consider all reports of original data on the physical properties, references to preliminary results were often omitted and the source for the final results given. This avoids many citations to obscure, early progress reports of both the American and British atomic energy projects.

Only those papers published between 1940 and the present were used in the compilation. Data published prior to 1940 are generally considered unreliable because of the crude techniques used in the purification of $\mathrm{UF}_{6}$. However if need be, much of the earlier information can be obtained from the "Uranium" volume of Gmelin's Handbuch der Anorganischen Chemie. Library sources utilized in the present compilation included: Chemical Abstracts, Science Abstracts, Nuclear Science Abstracts, and books of the National Nuclear Energy Series. Bibliographic tools covering classified reports of the U.S. Atomic Energy Commission were also used to supplement the publications mentioned above, as were earlier compilations and bibliographies. In all cases, however, the data incorporated herein was obtained from the original source when it could be obtained.

*See References 9, 17, 20, 28, 46, 65, 82, 87, 88, 93, 107, 111, 115 and 135 . 
The symbols used in this compilation are generally those given in the original sources. When two or more symbols were used in different papers to identify a single property, an arbitrary selection was made. Unfortunately, one symbol may represent more than one property. However, this should not present any real problem since symbol identification is covered in the List of Symbols at the end of the text.

It is hoped that the methods of presenting and correlating data used in this compilation have not distorted any of the experimental data. As it is quite human to initiate and propagate typographical errors, as well as to incorporate some errors stemming from ignorance in compilations of this type, it will be appreciated if these errors are called to the attention of the compiler. 


\section{MOLECULAR PROPERTIES}

\section{STRUCTURE}

The molecular structure of the $\mathrm{UF}_{6}$ molecule has been investigated in the solid state by $\mathrm{x}$-ray crystallography, in the liquid state by Raman spectroscopy, and in the vapor state by infrared spectroscopy, by electron diffraction, and by dipole moment techniques. These data are consistent.

Hoard and Stroupe ${ }^{80,81, ~}{ }^{89}$ used $x$-ray diffraction techniques to determine the parameters of crystalline $U_{6}$ and to reach a somewhat more definite conclusion regarding the configuration of the $\mathrm{UF}_{6}$ molecule. It was found by $\mathrm{x}$-ray analyses that cylindrical single crystals of $U_{6}$ possess an orthorhombic unit structure with the lattice constants $a=9.900 \AA$, $\mathrm{b}=8.962 \AA$, and $\mathrm{c}=5.207 \AA$, each with an estimated probable error of $0.002 \AA$. The orthorhombic unit structure has the space grouping $\mathrm{D}_{2 \mathrm{~h}}^{16}$ Pnma and contains four molecules of $U_{F_{6}}$. The uranium atoms were found to occupy the $4 \mathrm{c}$ positions in the mirror planes of $\mathrm{D}_{2 \mathrm{~h}}^{16}$ with the parameters $\mathrm{X}=0.1295 \pm 0.0005$ and $\mathrm{Z}=0.081 \pm 0.001$.

Hoard and Stroupe also conducted modified Fourier analyses of the (hk0) and (h0l) data and described the geometrical positions of the fluorine atoms. They state that the $x$-ray data do not indicate a completely regular octahedral configuration for the molecule as it exists within the crystal; however, it is quite likely that conditions are modified upon vaporization of the material. None of the U-F bands were found to be larger than $2.0 \AA$ in the case of the crystal, and the authors felt that the slight distortion in the crystal is compatible with a regular configuration for the molecule in the vapor state.

In an effort to resolve the apparent discrepancy which existed at that time between the structure proposed for $\mathrm{UF}_{6}$ as deduced from $\mathrm{x}$-ray analysis of single crystals and that deduced from electron diffraction analysis of the vapor, Bauer and Palter ${ }^{16},{ }^{17}$ investigated $x$-ray powder photographs of crystalline $U F_{6}$. Although the discrepancy was not eliminated, a rather extensive powder diffraction pattern for $U_{6} F_{6}$ was reported. The pattern was obtained by using nickel-filtered copper $\mathrm{K}_{\alpha}$ radiation with a camera having a radius of $57.25 \pm 0.010 \mathrm{~cm}$. The diffraction pattern, consisting of 91 lines, is presented in Table 1.

The structures of the $\mathrm{UF}_{6}$ molecule in the liquid and in the vapor states were determined by an investigation of the Raman spectrum of the liquid and by several individual investigations of the infrared spectrum of the vapor. These investigations yielded data which are completely in accord with each other and which can best be accounted for by assuming regular octahedral symmetry. In addition to these data, an inferred zero dipole moment obtained from dielectric constant measurements (see Dipole Moment, page 16) gives strong evidence in support of the $\mathrm{O}_{\mathrm{h}}$ point group symmetry in which all $\mathrm{U}-\mathrm{F}$ bond distances are the same.

Bigeleisen, Mayer, Stevenson, and Turkevich ${ }^{20}$ were able to interpret the observed vibration spectrum of $\mathrm{UF}_{6}$ vapor on the basis of a totally symmetrical structure. Although the fundamental assignments were slightly different, the interpretation of the infrared spectrum made by Bigeleisen and his co-workers was verified by Burke, Smith, and Nielsen ${ }^{29}$; by Gaunt ${ }^{65}$; and finally by Hawkins, Mattraw and Carpenter ${ }^{74}$ Values of the fundamentals deduced from the infrared spectra compare favorably with those obtained from the Raman spectra ${ }^{20,35}$ 
Table 1

DIFFRACTION PATTERN OF THE CRYSTALLINE POWDER

\begin{tabular}{|c|c|c|c|c|c|c|c|}
\hline $\begin{array}{c}\text { Line } \\
\text { Number }\end{array}$ & $\frac{\operatorname{Sin} \theta^{*}}{\lambda}$ & $\mathrm{d}(\AA)$ & $I / I_{1}$ & $\begin{array}{c}\text { Line } \\
\text { Number }\end{array}$ & $\frac{\operatorname{Sin} \theta^{*}}{\lambda}$ & $\mathrm{d}(\AA)$ & $I / I_{1}$ \\
\hline 1 & .1109 & 4.510 & 113 & 47 & . 3924 & 1.274 & 9 \\
\hline 2 & .1138 & 4. 394 & 75 & 48 & .4021 & 1.243 & 15 \\
\hline 3 & .1172 & 4.266 & 116 & 49 & .4047 & 1.235 & 18 \\
\hline 4 & .1244 & 4.019 & 118 & 50 & .4138 & 1.208 & 9 \\
\hline 5 & .1422 & 3.516 & 22 & 51 & .4186 & 1.195 & 13 \\
\hline 6 & .1577 & 3.171 & 48 & 52 & .4235 & 1. 182 & 8 \\
\hline 7 & .1807 & 2.767 & 36 & $5 \dot{3}$ & .4298 & 1.164 & 8 \\
\hline 8 & .1870 & 2.674 & 33 & 54 & .4341 & 1.152 & 7 \\
\hline 9 & .1943 & 2.573 & 37 & 55 & .4478 & 1.117 & 11 \\
\hline 10 & .1976 & 2.530 & 3 & 56 & .4507 & 1.109 & 7 \\
\hline 11 & .2011 & 2.486 & 22 & 57 & .4552 & 1.098 & 5 \\
\hline 12 & .2051 & 2.438 & 3 & 58 & .4620 & 1.082 & 16 \\
\hline 13 & .2082 & 2.402 & 34 & 59 & .4700 & 1.064 & 6 \\
\hline 14 & .2126 & 2.352 & 24 & 60 & .4743 & 1.054 & 7 \\
\hline 15 & .2195 & 2.278 & 13 & 61 & .4785 & 1.045 & 3 \\
\hline 16 & .2258 & 2.214 & 36 & 62 & .4865 & 1.028 & 5 \\
\hline 17 & .2297 & 2.177 & 32 & 63 & .4910 & 1.018 & 5 \\
\hline 18 & .2332 & 2.144 & 38 & 64 & .5007 & 0.999 & 3 \\
\hline 19 & .2474 & 2.021 & 39 & 65 & .5046 & 0.991 & 3 \\
\hline 20 & .2497 & 2.002 & 7 & 66 & .5130 & 0.975 & 3 \\
\hline 21 & .2532 & 1.975 & 22 & 67 & .5180 & 0.965 & 3 \\
\hline 22 & .2618 & 1.910 & 10 & 68 & .5247 & 0.953 & 9 \\
\hline 23 & .2659 & 1.880 & 5 & 69 & 5271 & 0.949 & 5 \\
\hline 24 & .2705 & 1.848 & 15 & 70 & .5321 & 0.940 & 7 \\
\hline 25 & .2764 & 1.809 & 19 & 71 & .5363 & 0.932 & 5 \\
\hline 26 & .2808 & 1.781 & 13 & 72 & .5416 & 0.923 & 7 \\
\hline 27 & .2880 & 1.736 & 13 & 73 & .5485 & 0.912 & 7 \\
\hline 28 & .2953 & 1.693 & 44 & 74 & .5516 & 0.906 & 3 \\
\hline 29 & .2983 & 1.676 & 21 & 75 & .5593 & 0.894 & 3 \\
\hline 30 & .3016 & 1.658 & 33 & 76 & .5685 & 0.880 & 14 \\
\hline 31 & .3072 & 1.628 & 26 & 77 & .5767 & 0.867 & 12 \\
\hline 32 & .3103 & 1.611 & 3 & 78 & .5795 & 0.863 & 5 \\
\hline 33 & .3193 & 1.566 & 23 & 79 & .5881 & 0.850 & 19 \\
\hline 34 & . 3232 & 1.548 & 7 & 80 & 5911 & 0.846 & 17 \\
\hline 35 & .3270 & 1.529 & 29 & 81 & .5940 & 0.835 & 3 \\
\hline 36 & .3348 & 1.493 & 33 & 82 & .6068 & 0.824 & 3 \\
\hline 37 & . 3384 & 1.478 & 17 & 83 & .6089 & 0.821 & 5 \\
\hline 38 & . 3438 & 1.451 & 11 & 84 & .6104 & 0.819 & 16 \\
\hline 39 & .3481 & 1.436 & 19 & 85 & .6136 & 0.815 & 5 \\
\hline 40 & .3537 & 1.415 & 10 & 86 & .6185 & 0.808 & 5 \\
\hline 41 & .3582 & 1.396 & 22 & 87 & .6212 & 0.805 & 14 \\
\hline 42 & .3638 & 1.374 & 8 & 88 & .6303 & 0.793 & 3 \\
\hline 43 & .3726 & 1.342 & 7 & 89 & .6317 & 0.792 & 11 \\
\hline 44 & .3800 & 1.317 & 16 & 90 & .6358 & 0.786 & 11 \\
\hline 45 & .3846 & 1.301 & 6 & 91 & .6421 & 0.776 & 3 \\
\hline 46 & .3891 & 1.286 & 19 & & & & \\
\hline
\end{tabular}

*A discrepancy exists in the column headings in two similar reports by Bauer, References 16 and 17. In the first the heading is $\operatorname{Sin} \theta / 2$; in the second $\frac{\operatorname{Sin} \theta / 2}{\lambda}$. Experimental data obtained in our laboratory indicates $\frac{\operatorname{Sin} \theta}{\lambda}$ is correct. 
Glauber and Schomaker ${ }^{68}$ eliminated an apparent discrepancy between the interpretation of the structure which was based on vibrational data and that which was based on electron diffraction data by an improvement in the theory of electron diffraction. Bauer ${ }^{18}$, on the basis of available electron diffraction theory, proposed an irregular octahedral structure for $\mathrm{UF}_{6}$ with three short $(1.87 \AA)$ and three long $(2.17 \AA)$ bonds. Upon improving the Born approximation as customarily applied to electron diffraction experiments, Glauber and Schomaker were able to show that $\mathrm{UF}_{6}$ need not be considered as having a distorted structure. Recent electron diffraction studies by Weinstock and $\mathrm{Malm}^{143}$ also provide strong evidence for the octahedral nature of the $\mathrm{UF}_{6}$ vapor molecule.

\section{FORCE CONSTANTS}

Force constants have been calculated from the fundamental vibration frequencies which were proposed on the basis of the regular octahedral symmetry $\left(\mathrm{O}_{\mathrm{h}}\right.$ point group). Values of the calculated force constants are presented in Table 2.

Gaunt ${ }^{66}$ estimated the stretching force constant $\left(\mathrm{k}_{1}=2.47 \times 10^{5}\right.$ dynes $\left./ \mathrm{cm}.\right)$ and bond length of the uranium atom to the fluorine atom (2.04 $\AA$ ) by using the frequency formulae* which were derived by Heath and Linnett. The approximate value of $k_{1}$ is not in agreement with other calculated values. A preliminary value of the U-F bond distance $(1.994 \AA$ ) was obtained from electron diffraction measurements by Schomaker, Kimura, and Weinstock ${ }^{\dagger}$.

Pistorius ${ }^{121}$ calculated the force constants by using Wilson's F-G matrix method, the infrared data which were obtained by Gaunt ${ }^{65}$ and by Hawkins and his co-workers ${ }^{74}$, and the Raman data which were obiained by Claassen and his co-workers ${ }^{35}$. From the vibration data, the following fundamentals were obtained by averaging: $\nu_{1}=666.5 \mathrm{~cm} .^{-1}$, $\nu_{2}=534 \mathrm{~cm} .^{-1}, \nu_{3}=624.5 \mathrm{~cm} .^{-1}, \nu_{4}=187.5 \mathrm{~cm} .^{-1}, \nu_{5}=202 \mathrm{~cm} .^{-1}$ and $\nu_{6}=140 \mathrm{~cm}_{\circ}^{-1}$. Values of the force constants, shown in Table 2, were calculated on the basis of these fundamentals and found to compare favorably with values calculated by Claassen.

Claassen ${ }^{36}$ derived a general quadratic potential function for $\mathrm{UF}_{6}$-type molecules which relates the force constants to the fundamental frequencies. He determined values of the fundamentals $\nu_{1}=667 \mathrm{~cm} .^{-1}, \nu_{2}=535 \mathrm{~cm} .^{-1}, \nu_{3}=623 \mathrm{~cm} .^{-1}, \nu_{4}=181 \mathrm{~cm} .^{-1}, \nu_{5}=202$ $\mathrm{cm} .^{-1}$ and $\nu_{6}=140 \mathrm{~cm} .^{-1}$ from the existing infrared and Raman data and calculated the force constants which are listed in Table 2. Values of the force constants, as well as the formulae derived by Claassen, agree with the data proposed by Linnett and Simpson ${ }^{103}$.

Linnett and Simpson proposed limited ranges for the possible values of the force constants by making various assumptions, whereas both Pistorius and Claassen attempted to set definite values to the constants on the basis of a regularity that appears in the series of molecules they studied. The conditions and the limited range of the values for the various force constants are listed in Table 2.

Califano $^{32}$ used a quadratic potential made up of four-interaction constants to calculate the force constants for $\mathrm{UF}_{6}$. The force constants listed in Table 2 were calculated using the following values for the fundamental vibrational frequencies: $\nu_{1}=665 \mathrm{~cm} .^{-1}$, $\nu_{2}=536 \mathrm{~cm} \cdot .^{-1}, \nu_{3}=623 \mathrm{~cm} \cdot .^{-1}, \nu_{4}=186 \mathrm{~cm} .^{-1}, \nu_{5}=202 \mathrm{~cm} .^{-1}$, and $\nu_{6}=136 \mathrm{~cm} .^{-1}$.

${ }^{*}$ Claassen and his co-workers ${ }^{35}$ reported that Gaunt erred in applying the equations of Heath and Linnett to the data on $\mathrm{UF}_{6}$. The values of the calculated frequencies, $\nu_{3}=626$ $\mathrm{cm} .^{-1}$ and $v_{4}=190 \mathrm{~cm} .^{-1}$, should have been $606 \mathrm{~cm} .^{-1}$ and $265 \mathrm{~cm} .^{-1}$, respectively.

†Unpublished work; see Ref. 143. 
Table 2

FORCE CONSTANTS IN $10^{5}$ DYNES/CM.

\begin{tabular}{|c|c|c|c|c|}
\hline $\begin{array}{c}\begin{array}{c}\text { Force } \\
\text { Constants } \xi \\
\end{array} \\
\end{array}$ & $\begin{array}{c}\begin{array}{c}\text { Linnett et al. * } \\
\text { (Ref. 103) }\end{array} \\
\end{array}$ & $\begin{array}{l}\text { Claassen } \\
\text { (Ref. 36) } \\
\end{array}$ & $\begin{array}{l}\text { Pistorius } \\
\text { (Ref. 121) } \\
\end{array}$ & $\begin{array}{l}\text { Callfano } \\
\text { (Ref. 32) } \\
\end{array}$ \\
\hline$k_{1}$ & $\begin{array}{l}2.07 \text { to } 3.85^{\mathrm{a}} \\
2.07 \text { to } 3.78^{\mathrm{b}} \\
2.07 \text { to } 3.78^{\mathrm{c}} \\
3.78^{\mathrm{d}} \text { or } \\
3.68 \text { to } 3.78^{\mathrm{d}}\end{array}$ & $\begin{array}{l}3.78 \\
3.80^{\dagger}\end{array}$ & 3.78 & 3.795 \\
\hline $\mathbf{k}_{11}$ & $0.30^{a, b}, c, d$ & $\begin{array}{l}0.296 \\
0.296 \dagger\end{array}$ & 0.296 & 0.289 \\
\hline $\mathbf{k}_{11}^{\prime}$ & $\begin{array}{l}-0.07 \text { to } 1.71^{\mathrm{a}} \\
0.00 \text { to } 1.71 \\
0.00 \mathrm{~d}, \mathrm{c} \\
0.00 \text { to } 0.10^{\mathrm{d}}\end{array}$ & $0.00 \dagger$ & & \\
\hline $\mathbf{k}_{\mathrm{a}}$ & & & & 0.129 \\
\hline$k_{1 a}$ & & & & 0.058 \\
\hline kaa & & & & 0.013 \\
\hline $\mathbf{k}_{\mathrm{aa}}^{\prime}$ & & & & 0.007 \\
\hline$\frac{k_{10}-k_{\text {ta }}^{\prime}}{r}$ & $\begin{array}{l}-0.46 \text { to } 0.72^{a, b} \\
0.00 \text { to } 0.72^{c} \\
0.00 \text { to } 0.01^{d} \text { or } \\
0.45 \text { to } 0.55^{d}\end{array}$ & $0.03^{\dagger}$ & $\begin{array}{l}0.426 \\
0.032\end{array}$ & \\
\hline$\frac{k_{a}-k_{a a}}{r^{2}}$ & $\begin{array}{l}0.13 \text { to } 0.52^{\mathrm{a}} \\
0.13 \text { to } 0.52^{\mathrm{b}} \\
0.13^{\mathrm{c}} \text { or } \\
0.18 \text { to } 0.52^{\mathrm{c}} \\
0.13^{\mathrm{d}} \text { or } \\
0.18 \text { to } 0.21^{\mathrm{d}}\end{array}$ & $\begin{array}{l}0.120 \\
0.125 \dagger\end{array}$ & & 0.116 \\
\hline$\frac{k_{a a}-k^{\prime \prime \prime}{ }_{a a}}{r^{2}}$ & $\begin{array}{l}0.01 \text { to } 0.40^{\mathrm{a}} \\
0.01^{\mathrm{b}} \text { or } \\
0.06 \text { to } 0.40^{\mathrm{c}} \\
0.01^{\mathrm{d}} \text { or } \\
0.06 \text { to } 0.10^{\mathrm{d}}\end{array}$ & $0.0111^{\dagger}$ & $\begin{array}{l}-0.119 \\
-0.045\end{array}$ & \\
\hline$\frac{k_{a a}^{\prime}-k_{a a}^{\prime \prime}}{r^{2}}$ & $\begin{array}{l}0.01 \text { to } 0.40^{\mathrm{a}, \mathrm{b}} \\
0.01^{\mathrm{c}} \text { or } \\
0.06 \text { to } 0.40^{\mathrm{c}} \\
0.01^{\mathrm{d}} \text { or } \\
0.06 \text { to } 0.10^{\mathrm{d}}\end{array}$ & $\begin{array}{l}0.009^{\ddagger} \\
0.010^{\dagger}\end{array}$ & $\begin{array}{l}0.096 \\
0.022\end{array}$ & \\
\hline$k_{a}+k_{a a}^{\prime \prime \prime}-2 k_{a n}$ & & & $\begin{array}{l}0.227 \\
0.132\end{array}$ & \\
\hline $\begin{array}{l}k_{a}+k_{a a}^{\prime \prime \prime}-2 k_{a a} \\
k_{a}-k_{a a}^{\prime \prime \prime}-2 k_{a a^{+}}^{\prime} 2 k_{a a}^{\prime \prime}\end{array}$ & & $\begin{array}{l}0.114 \\
0.110\end{array}$ & & \\
\hline
\end{tabular}

*Assumptions: (a) $k_{11}^{\prime}$ positive (b) $\frac{k_{1 a}-k_{1 a}^{\prime}}{r}$ (c) $k_{a a}-k_{a a}^{\prime \prime \prime}$ (d) $k_{11}^{\prime}<k_{11}$.

†Given by Linnett and Simpson (Ref. 103).

FCalculated on basis of values given.

$\xi_{k_{1}}$ bond stretching

$k_{11}$ bond-bond (adjacent) (e.g. between UFx and UFy)

$k_{11}^{\prime}$ bond-bond (opposite) (e.g. between $U F_{X}$ and $U F_{-x}$ )

$k_{a}$ angle bending

$k_{1 a}$ bond-angle (adjacent) (e.g. between $U F_{X}$ and $F_{X} U F_{Y}$ )

$k_{10}^{\prime}$ bond-angle (opposite) (e.g. between $U F_{x}$ and $F_{-x} U F_{y}$ )

$k_{\text {ga }}$ angle-angle (planar-adjacent) (e.g. between $F_{x} U F_{y}$ and $F_{-x} U F_{y}$ )

$k_{a a}^{\prime}$ angle-angle (angled-adjacent) (e.g. between $F_{x} U F_{y}$ and $F_{X} U F_{z}$ )

$k_{a a}^{\prime \prime}$ angle-angle (angled-opposite) (e.g. between $F_{x} U F_{y}$ and $F_{-x} U F_{z}$ )

$k_{a g}^{\prime \prime \prime}$ angle-angle (planar-opposite) (

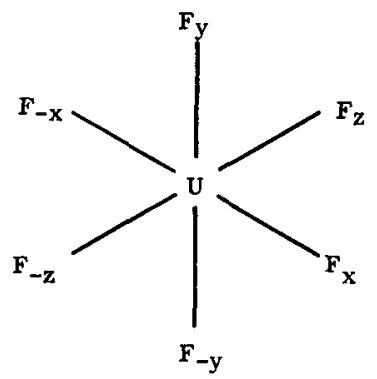

$k_{1} a$ angle-bond (perpendicular) (e.g. between $F_{X} U F_{Z}$ and $F_{-y}$ ) 


\section{CRITICAL IONIZATION POTENTIALS}

Cameron and White ${ }^{146}$ determined the critical ionization potentials of $U_{6}$ with a Niertype mass spectrometer in which the emission regulator unit had been modified to permit variation of electron energy without disturbance to total emission from the filament. The data, which are listed in Table 3, have a probable error range of from 5 percent for the $\mathrm{UF}_{5}^{+}$ion to 15 percent for the $\mathrm{U}^{+}$ion.

Table 3

\section{CRITICAL IONIZATION POTENTIALS}

$\underline{\text { Ion }}$

$\mathrm{UF}_{5}^{+}$

$\mathrm{UF}_{4}^{+}$

$\mathrm{UF}_{3}^{+}$

$\mathrm{UF}_{2}^{+}$

$\mathrm{UF}^{+}$

$\mathrm{U}^{+}$
Critical Ionization Potential (volts)

15.5

20.1

23.5

29.9

37.9

50.3

\section{MAGNETIC SUSCEPTIBILITY}

No recent data on the measurements of the magnetic susceptibility have been reported. The information appearing in previous compilations ${ }^{88,93}$ is all that has been found in literature.

It has been reported that $\mathrm{UF}_{6}$ appears to be paramagnetic. Henkel and Klemm ${ }^{77}$ reported that the specific susceptibility of solid $\mathrm{UF}_{6}$ is $0.12 \times 10^{-6}$ and that the molar susceptibility is $43 \times 10^{-6}$. Correcting the molar susceptibility for diamagnetism, Tilk ${ }^{139}$ obtained a value of $106 \times 10^{-6}$. The paramagnetism seems to be independent of the temperature.

\section{SURFACE TENSION}

The surface tension of liquid $\mathrm{UF}_{6}$ in contact with its vapor was measured in the $70^{\circ}$ to $100^{\circ} \mathrm{C}$. range ${ }^{107}$ and at $65^{\circ}$ and $72.5^{\circ} \mathrm{C} .{ }^{125}$ by the capillary rise method. The latter results are reported with an estimated accuracy of \pm 0.3 dynes $/ \mathrm{cm}$. (between 1.8 and 2.3 percent of the results reported) while the former are reported as accurate to \pm 3 percent of the reported surface tension. The results, which are in agreement with each other, are summarized in Table 4 and pres ented in Figure 1.

\section{POLARIZATION}

The dielectric constant, $\epsilon$, of the vapor has been determined at various temperatures by both the heterodyne beat method and the resonance method. A comparison of the various 
Table 4

SURFACE TENSION OF THE LIQUID

\begin{tabular}{ccc}
$\begin{array}{c}\text { Temperature } \\
\left({ }^{\circ} \mathrm{C} .\right)\end{array}$ & $\begin{array}{c}\text { Surface Tension } \\
\text { (dynes/cm.) }\end{array}$ & $\frac{\text { Reference }}{17.66 \pm 0.5}$ \\
\cline { 2 - 3 } 65 & $16.8 \pm 0.3$ & 125 \\
70 & $16.48 \pm 0.5$ & 107 \\
72.5 & $15.6 \pm 0.3$ & 125 \\
80 & $14.3 \pm 0.3$ & 107 \\
90 & $13.1 \pm 0.3$ & 107
\end{tabular}

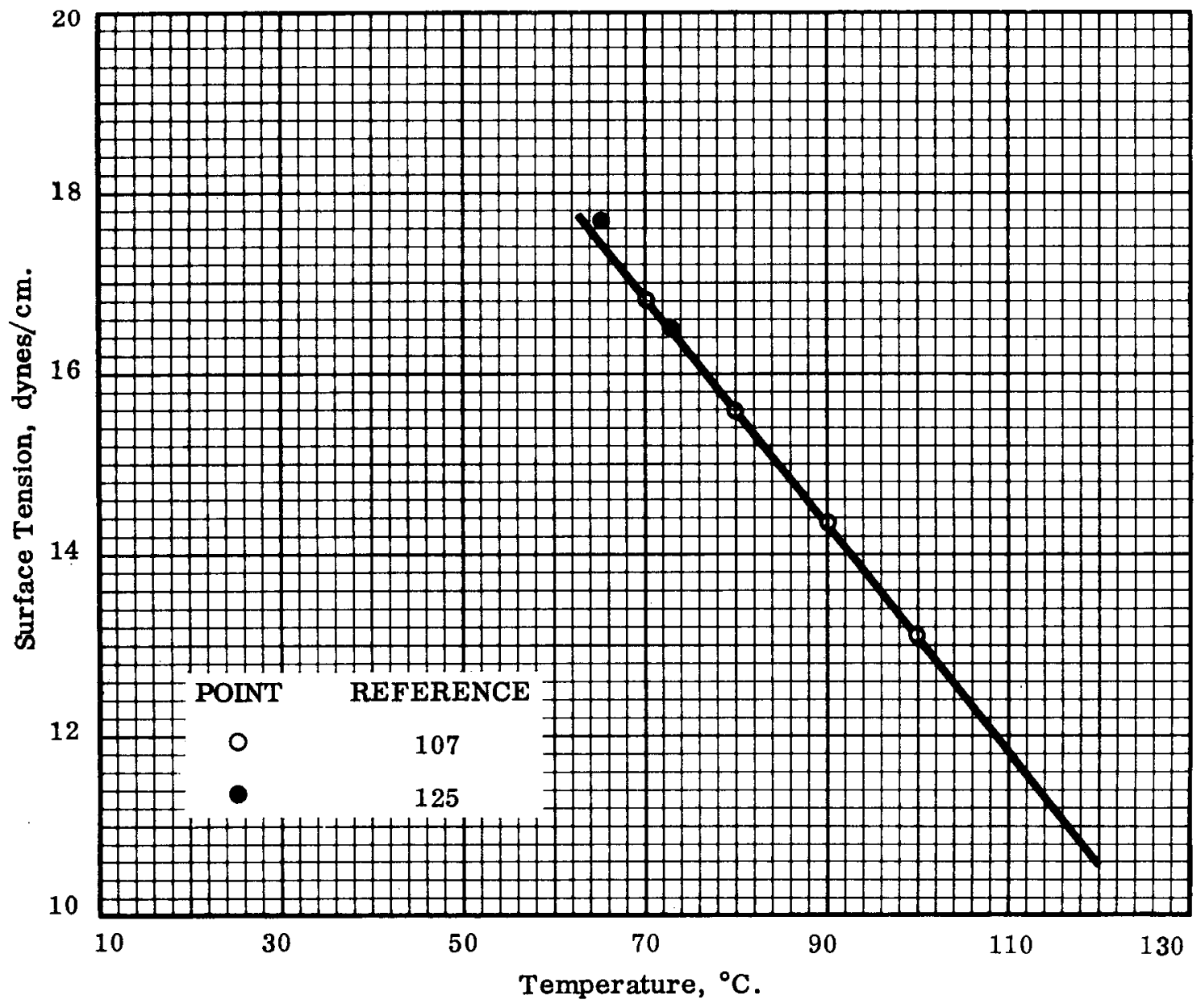

FIG. 1. SURFACE TENSION OF THE LIQUID 
experimental values of the dielectric constant of the vapor is presented in Table 5; some of the more reliable data $\left[(\epsilon-1) \times 10^{6}\right]$ are plotted versus temperature in Figure 2. Molar polarization, $\mathrm{P}_{\mathrm{m}}$, and the dipole moment, $\mu$, have been determined from experimental values of the dielectric constant of the vapor using the Debye equation:

$$
\mathbf{P}_{\mathbf{m}^{\prime}}=\frac{\epsilon-1}{\epsilon+2} \times \mathbf{M} / \rho=\frac{4 \text { д } \mathrm{N}}{3}\left(\alpha+\mu^{2} / 3 \mathrm{kT}\right)
$$

where: $\mathbf{M}=$ the molecular weight

$$
\begin{aligned}
& \rho=\text { the vapor density } \\
& \mathrm{N}=\text { the Avogadro number } \\
& \alpha=\text { the molecular polarizability } \\
& \mathrm{k}=\text { the Boltzmann constant }
\end{aligned}
$$

\begin{tabular}{|c|c|c|c|c|}
\hline \multirow{2}{*}{$\begin{array}{l}\text { Temperature } \\
\left({ }^{\circ} \mathrm{C} .\right) \\
\end{array}$} & \multicolumn{2}{|c|}{ Dielectric Constant, $(\epsilon-1) \times 10^{6}$} & \multirow{2}{*}{$\begin{array}{l}\text { Polarization } \\
\text { (cc.) } \\
\end{array}$} & \multirow[b]{2}{*}{$\underline{\text { Reference }}$} \\
\hline & Obs erved & $\underline{\text { Calculated* }}$ & & \\
\hline 19.6 & $3800 \pm 400$ & & $30.7 \pm 1.0$ & 9 \\
\hline 28.2 & $3815.4 \pm 5.7$ & $(3816)$ & $31.448 \pm 0.047$ & $108,109,110$ \\
\hline 40.0 & $3676.5 \pm 3.8$ & $(3672)$ & $31.490 \pm 0.033$ & $108,109,110$ \\
\hline 50.0 & & $(3558)$ & & \\
\hline 59.5 & 2970 & & $27.0 \pm 0.2$ & 137 \\
\hline 60.0 & & $(3452)$ & & \\
\hline 61.1 & $3441.5 \pm 4.5$ & $(3440)$ & $31.463 \pm 0.041$ & $108,109,110$ \\
\hline 67.4 & 2920 & & $27.2 \pm 0.3$ & 137 \\
\hline 70.0 & & $(3351)$ & & \\
\hline 80.0 & & $(3256)$ & & \\
\hline 83.1 & $\begin{array}{l}3229.5 \pm 3.7 \\
3221.9 \pm 4.1\end{array}$ & $(3228)$ & $\begin{array}{l}31.468 \pm 0.036 \\
31.394 \pm 0.040\end{array}$ & $\begin{array}{l}108,109,110 \\
108,109,110\end{array}$ \\
\hline 89.0 & 2730 & & $27.0 \pm 0.2$ & 137 \\
\hline 90.0 & & $(3166)$ & & \\
\hline 100.0 & & $(3082)$ & & \\
\hline 110.0 & & $(3001)$ & & \\
\hline 120.0 & & (2925) & & \\
\hline 130.0 & & $(2888)$ & & \\
\hline 140.0 & & $(2783)$ & & \\
\hline 150.0 & & $(2718)$ & & \\
\hline
\end{tabular}

Table 5

DIELECTRIC CONSTANT AND MOLAR POLARIZATION OF THE VAPOR

*On the basis of $(\epsilon-1) \times 10^{6} \quad \mathrm{~T} / \mathrm{T}_{\mathrm{o}}=4209.8$ (Ref. 108, 109). 


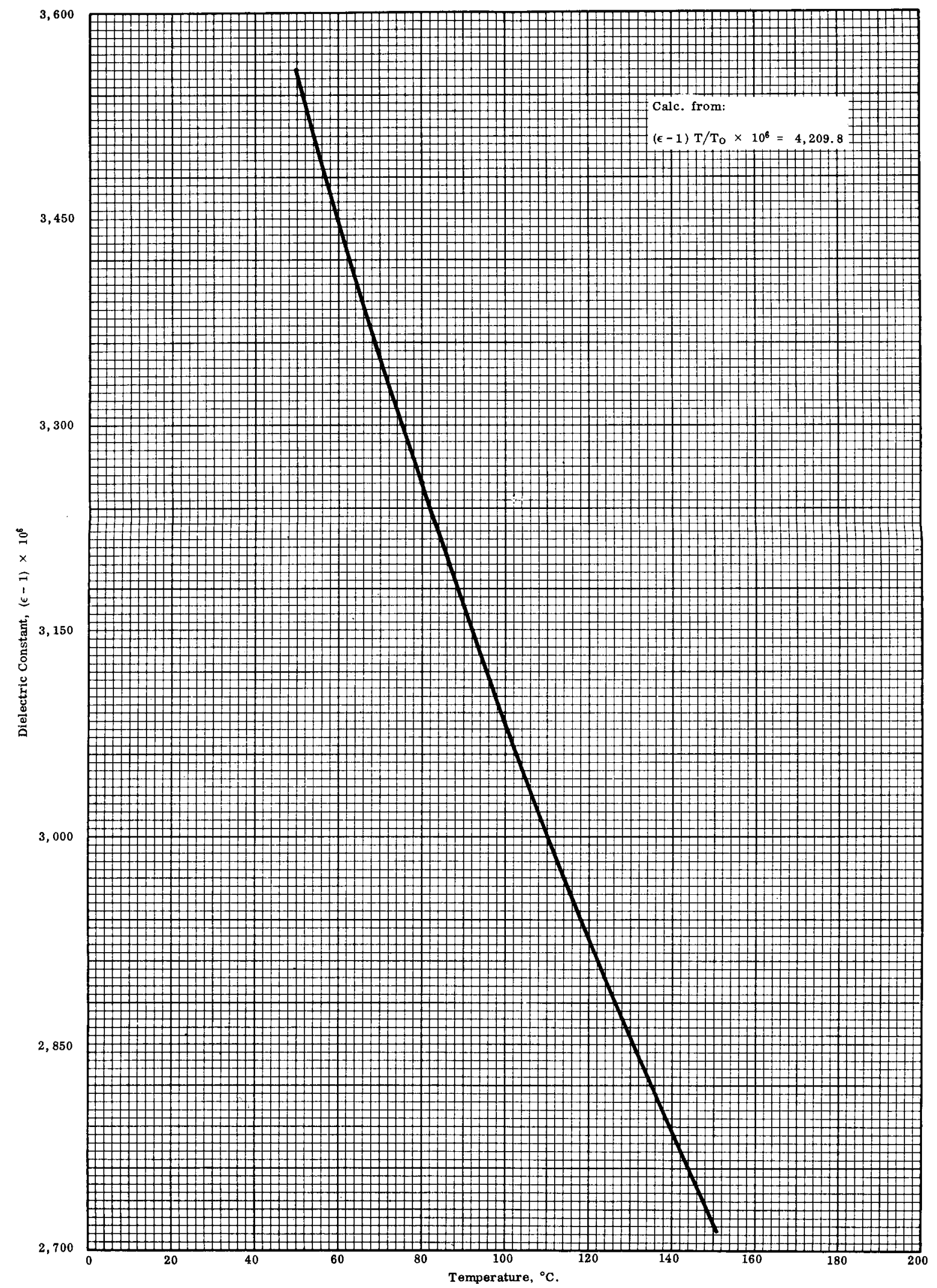

FIG.2. DIELECTRIC CONSTANT OF THE VAPOR 
From the calculated value of $\mathrm{P}_{\mathrm{m}}$, values of the dielectric constant of the liquid were determined. A comparison with the experimental value, which is not very good, is presented in Table 6. The calculated dielectric constant values are plotted in Figure 3.

Table 6

DIELECTRIC CONSTANT OF THE LIQUID

\begin{tabular}{ccc}
\multirow{2}{*}{$\begin{array}{c}\text { Temperature } \\
\left({ }^{\circ} \mathrm{C} .\right)\end{array}$} & \multicolumn{2}{c}{ Dielectric Constant } \\
\cline { 2 - 3 } 65 & $\begin{array}{c}\text { Observed } \\
\text { (Ref. 30) }\end{array}$ & $\frac{\text { Calculated* }}{2.41}$ \\
70 & 2.57 & 2.39 \\
90 & & 2.32 \\
120 & & 2.21 \\
140 & & 2.13 \\
160 & & 2.05
\end{tabular}

*Using Clausius-Mosotti equation, molar polarization value $31.034 \mathrm{cc}$., and Wechsler and Hoge (Ref. 140, 141) liquid density values.

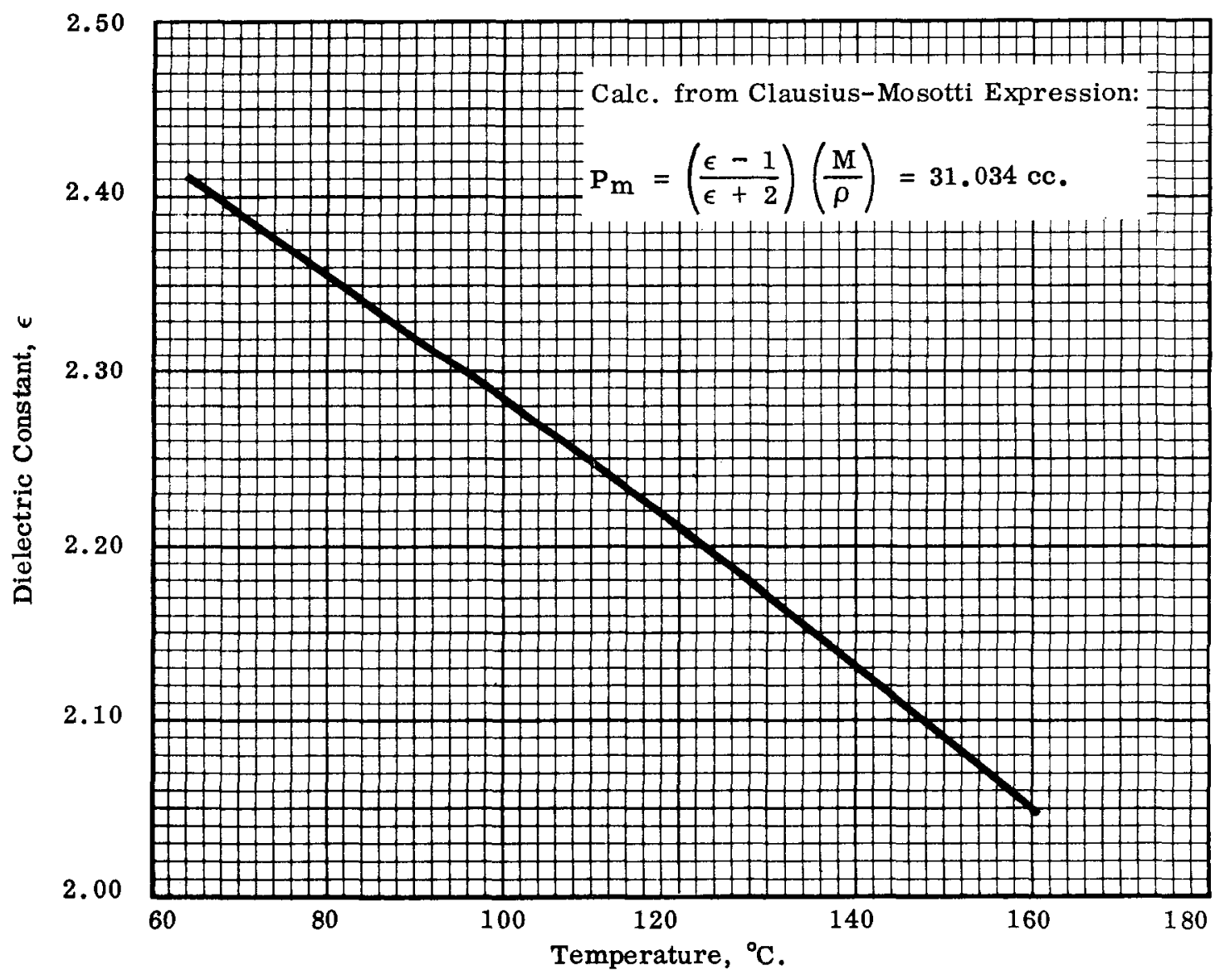

FIG. 3. DIELECTRIC CONSTANT OF THE LIQUID 


\section{DIPOLE MOMENT}

From Equation 1 it is obvious that if the molar polarization does not vary with temperature, the dipole moment must be considered zero. Smyth and Hannay ${ }^{137}$ and later Magnuson ${ }^{110}$ failed to find any detectable variation of the polarization of $\mathrm{UF}_{6}$ with temperature. They reported that the dipole moment of $U F_{6}$ is essentially zero (less than $10^{-18}$ esu., cm.) and therefore the $U_{F}$ molecule could be a regular octahedron. The polarization values were calculated from dielectric constant measurements on the vapor taken at various temperatures and pressures.

\section{DIELECTRIC CONSTANT AND MOLAR POLARIZATION OF THE VAPOR}

The most recent and comprehensive dielectric constant data are those of Magnuson ${ }^{110}$. Dielectric constants were obtained from a ratio of the measured resonant frequency of an evacuated cavity to that of the cavity when filled with $U_{6} F_{6}$ vapor. The Debye equation was then used to determine the molar polarization, $P_{m}$, and the dipole moment, $\mu$. Since the variation of vapor density with pressure, $P$, was not well known, a non-ideality parameter (see Non-ideality of $\mathrm{UF}_{6}$ Vapor, page 98 ) as well as the above-mentioned properties were calculated from a series of dielectric measurements taken at a constant temperature and at different pressures. The quantity $[(\epsilon-1) /(\epsilon+2)][1 / P]$ was plotted against $P$ and a straight line was fitted to the experimental data. The slope of the straight line defined the non-ideality parameter, $\mathrm{A}$, and the intercept defined the molar polarization, $\mathrm{Pm}$. All pressure measurements were corrected to the density of mercury at $0^{\circ} \mathrm{C}$. and the limit of error of the results is stated as being at the 95 percent confidence interval. Magnuson reported the results as follows:

$$
\begin{gathered}
(\epsilon-1)=4202.8 \times 10^{-6} \text { per atm. at } 61.1^{\circ} \mathrm{C} . \\
P_{\mathrm{m}} \text { (av.) }=31.034 \mathrm{cc} .
\end{gathered}
$$

(averaged over the range $53^{\circ}$ to $153^{\circ} \mathrm{C}$.)

Other dielectric constant investigations ${ }^{108,109}$ which were previously conducted by Magnuson at lower pressures $(<40 \mathrm{~cm}$. $\mathrm{Hg})$ did not reveal the effects of non-ideality because of the low pressure. He measured the dielectric constants at five temperatures and made corrections to standard conditions by means of the general gas laws. He averaged the results and reported them as follows:

$$
\begin{gathered}
{\left[(\epsilon-1) \mathrm{T} / \mathrm{T}_{0}\right] \times 10^{6}=4209.8 \pm 3.4 \text { (corrected to standard conditions) }} \\
\mathrm{P}_{\mathrm{m}}=31.453 \pm 0.025 \mathrm{cc} .
\end{gathered}
$$

The slight discrepancy between these results and those previously given by Magnuson can be attributed to the different calculating procedures he used in each case. Magnuson's later results are listed in Table 5 along with earlier data obtained by other investigators. Values of $(\epsilon-1) \times 10^{6}$ were calculated from Equation 3 and are shown plotted against temperature in Figure 2.

Some of the earlier dielectric constant measurements made by other investigators do not compare favorably with those of Magnuson. Amphlett, Mullinger and Thomas ${ }^{9}$ measured the dielectric constant by the heterodyne beat method and reported a value of $\epsilon=1.0038$ \pm 0.0001 at $19.6^{\circ} \mathrm{C}$. and $760 \mathrm{~mm}$. $\mathrm{Hg}$. They determined the total polarization from the Clausius-Mosotti relationship:

$$
P_{m}=[(\epsilon-1) /(\epsilon+2)] \times M / P=[(\epsilon-1) / 3] \times(R T / P)=30.7 \pm 1.0 \mathrm{cc} .
$$


The value of $\epsilon$ thus obtained is slightly higher than that obtained by Magnuson. Smyth and Hannay ${ }^{89,}{ }^{137}$ measured the dielectric constant with an apparatus similar to that used by McAlpine and Smyth*. Five measurements of the dielectric constant of $\mathrm{UF}_{6}$ made at each of three temperatures, $59.5^{\circ}, 67.4^{\circ}$ and $89.0^{\circ} \mathrm{C}$., were us ed to calculate the molar polarization. Smyth and Hannay's results, also listed in Table 5, are lower than those of Amphlett and his co-workers as well as those of Magnuson ${ }^{110}$.

\section{DIELECTRIC CONSTANT OF THE LIQUED}

The dielectric constant of the liquid has not been very throughly investigated. The only study found in the literature was that reported by Burns, McKown, and Asbury ${ }^{30}$. From resistance measurements at $70^{\circ} \mathrm{C}$., they found that the coefficient of electrical resistance was of the order of $10^{14} \mathrm{ohms}$ and that the dielectric constant was 2.57 at 500, 1000 and 2000 cycles per second. Their molar polarization value $(33.6 \mathrm{cc}$.$) calculated from the$ dielectric constant does not appear to be in agreement with that $(31.034 \mathrm{cc}$.) obtained from the dielectric constant measurements on the vapor by Magnuson.

The dielectric constant of a non-polar liquid such as $U_{6} F_{6}$ can also be obtained from the Clausius-Mosotti equation (Equation 4) if the molar polarization and the liquid density at a given temperature are known. Smyth and Hannay ${ }^{89,}{ }^{137}$ made such a calculation using their average molar polarization value of $27.1 \mathrm{cc}$. and found the dielectric constant of the liquid at $65^{\circ} \mathrm{C}$. to be 2.18 . They considered this value typical for non-polar liquids.

Using the average molar polarization value (31.034 cc.) obtained by Magnuson and the liquid density values obtained by Hoge and Wechsler ${ }^{140,141}$ approximate dielectric constants of the liquid for various temperatures were calculated for this report. These are presented in Table 6 and Figure 3.

\section{DENSITY}

The density values of solid $\mathrm{UF}_{6}$ which have been determined by various methods appear to vary linearly with temperature in the $20^{\circ}$ to $62.5^{\circ} \mathrm{C}$. range. These values, which are given in Table 7 and Figure 4, indicate a rather high coefficient of expansion for the

Table 7

DENSITY OF THE SOLID

\begin{tabular}{|c|c|c|c|}
\hline $\begin{array}{l}\text { Temperature } \\
\left({ }^{\circ} \mathrm{C} .\right)\end{array}$ & $\begin{array}{l}\text { Density } \\
\text { (g./cc.) }\end{array}$ & Remarks & Reference \\
\hline 20.7 & $5.09 \pm 0.06$ & From British tube alloy data sheets & 46 \\
\hline $24 \pm 1$ & $(4.95)$ & $\begin{array}{l}\text { Preliminary value calculated from } \\
\text { lattice constants }\end{array}$ & 80 \\
\hline 25 & $5.06 \pm 0.005$ & $\begin{array}{l}\text { Final value calculated from lattice } \\
\text { constants }\end{array}$ & 81 \\
\hline 62.5 & $(4.93)$ & $\begin{array}{l}\text { Preliminary value calculated from ratio } \\
\text { of liquid volume to solid volume }\end{array}$ & 140 \\
\hline 62.5 & 4.87 & $\begin{array}{l}\text { Final value calculated from ratio of } \\
\text { liquid volume to solid volume }\end{array}$ & 141 \\
\hline
\end{tabular}

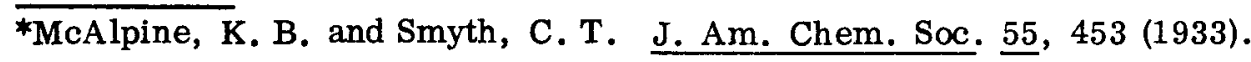




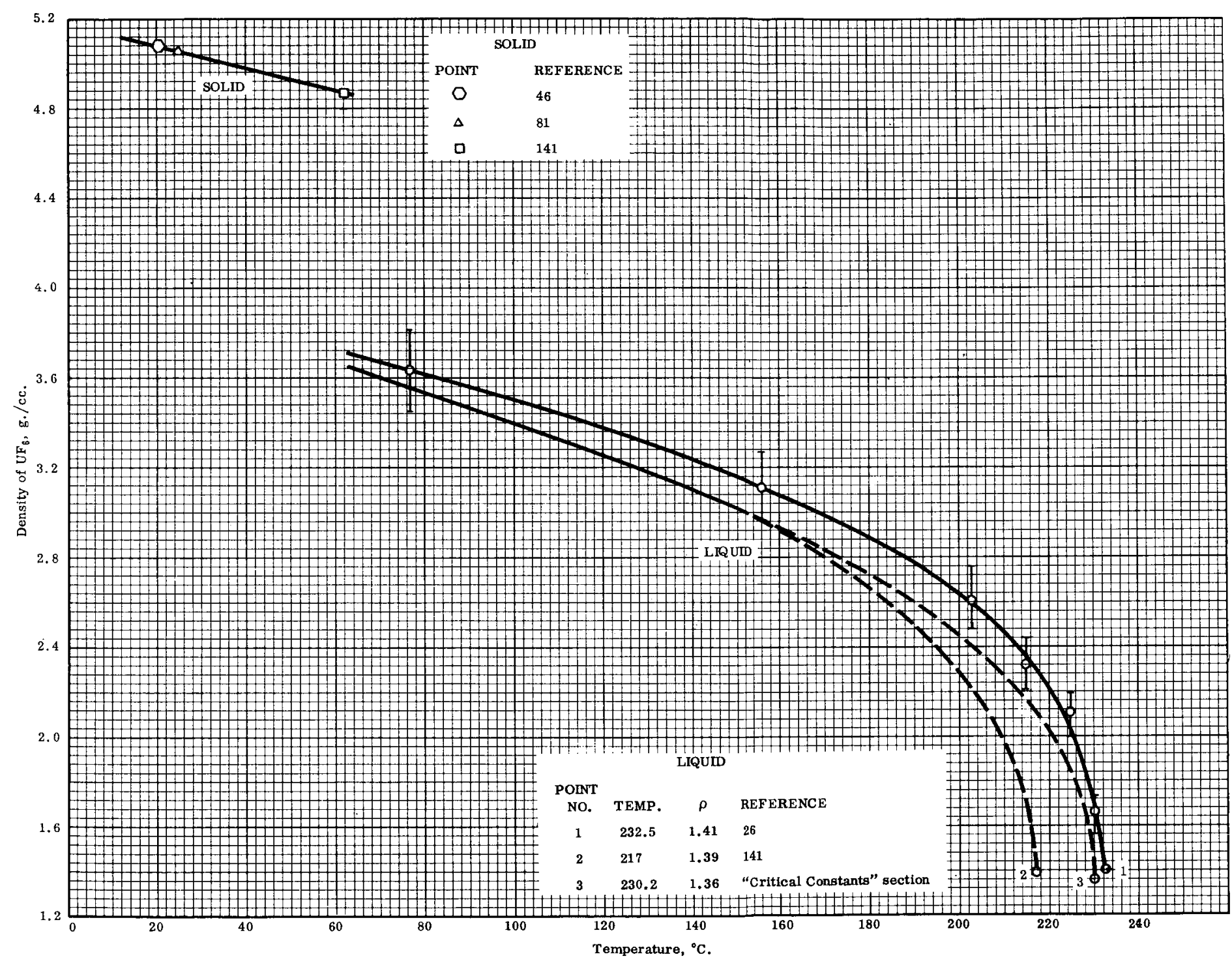

FIG. 4. DENSITIES OF THE SOLID AND THE LIQUID 
solid. Reliable density values of the liquid have been determined in the $65^{\circ}$ to $163^{\circ} \mathrm{C}$. range and are presented in Table 8 and in Figure 4.

Reasonably accurate vapor density values can be calculated either from the equation of state proposed by Magnuson or the one proposed by Weinstock (see Equations of State, page 97). The data presented in Tables 9 and 10 and Figures 5 and 6 can be used in comparing the density values of the vapor calculated from both equations of state with those values derived from the ideal gas law.

\section{SOLID DENSITY}

British data sheets ${ }^{46}$ give a solid density value of $5.09 \pm 0.06 \mathrm{~g}$. $/ \mathrm{cc}$. at $20.7^{\circ} \mathrm{C}$. Hoard and Stroupe ${ }^{80}$ estimated a value of $4.95 \mathrm{~g} . / \mathrm{cc}$. at $24^{\circ} \mathrm{C}$. from approximate lattice constants of the orthorhombic unit structure of the $\mathrm{UF}_{6}$ molecule. From more accurately determined constants ${ }^{81}$, they recalculated the density at $25^{\circ} \mathrm{C}$. and found it to be $5.06 \pm 0.005$ g. /cc.

Wechsler and $\mathrm{Hoge}^{140}$ reported a preliminary density value of $4.93 \mathrm{~g}$. $/ \mathrm{cc}$. at $62.5^{\circ} \mathrm{C}$. This value was based on their observation of the ratio of the liquid volume at $65.1^{\circ} \mathrm{C}$. to the solid volume at $62.5^{\circ} \mathrm{C}$. and upon Priest's value ${ }^{123}(3.667 \mathrm{~g}$. $/ \mathrm{cc}$.) for the density of the liquid. The ratio of the liquid volume to the solid volume at the previously mentioned temperatures was reported as $1.343 \pm 0.002$. The authors ${ }^{141}$ later redetermined the value for the density of the liquid at $65.1^{\circ} \mathrm{C}$. and reported it as $3.624 \mathrm{~g}$. $/ \mathrm{cc}$. Using this value for the density of the liquid, they recalculated the density of the solid and found it to be $4.87 \mathrm{~g}$. $/ \mathrm{cc}$. at $62.5^{\circ} \mathrm{C}$.

It is interesting to note that the final values of the density at $20.7^{\circ}, 25^{\circ}$, and $62.5^{\circ} \mathrm{C}$., which were obtained in three independent investigations, form a straight line, vaguely indicating that these data are in agreement and that $U_{6}{ }_{6}$ solid has a ratherhigh coefficient of expansion (see Figure 4).

\section{LIQUID DENSITY}

The density of liquid $U F_{6}$ has been determined by a number of different investigators, and the reported values are in fair agreement. Hoge and Wechsler ${ }^{141}$ determined the absolute densities of the saturated liquid in the $65^{\circ}$ to $162^{\circ} \mathrm{C}$. range. Measurements were made by immersing glass bobbins of known density into liquid UF ${ }_{6}$. The bobbin densities were corrected for thermal expansion. The temperature was recorded just when a bobbin would start to sink and just when it would start to rise. The average of the two temperatures represents the point at which the density of the liquid and that of the glass bobbins became equal. The results are represented by the equation:

$$
\rho(\text { g. } / \text { cc. })=3.630-5.805 \times 10^{-3}\left(t-t_{f}\right)-1.36 \times 10^{-5}\left(t-t_{f}\right)^{2}
$$

where $\rho$ (g./cc.) is the density at a stated temperature and where $t$ values are in degrees centigrade $\left(t_{f}\right.$ is taken as $64.052^{\circ} \mathrm{C}$. $)$. Previously Hoge and Wechsler ${ }^{140}$ determined liquid densities from measurements of the ratio of the volume of the saturated liquid at temperatures ranging from $64.052^{\circ}$ to $92^{\circ} \mathrm{C}$. to the volume at the triple point, $t_{f}\left(64.052^{\circ} \mathrm{C}\right.$. $)$. This ratio was expressed by the equation:

$$
\mathrm{v} / \mathrm{v}_{\mathrm{f}}=1+1.727 \times 10^{-3}\left(\mathrm{t}-\mathrm{t}_{\mathrm{f}}\right)+3.59 \times 10^{-6}\left(\mathrm{t}-\mathrm{t}_{\mathrm{f}}\right)^{2}
$$

where the subscripts indicate values at the triple point.

Llewellyn ${ }^{107}$ determined the liquid density from $70^{\circ}$ to $100^{\circ} \mathrm{C}$. by sealing $\mathrm{UF}_{6}$ of a known weight in a calibrated tube and measuring the volume at various temperatures. Results are given in Table 8. These values are within 0.5 percent of those given by Hoge and Wechsler also appearing in this table. 
Table 8

DENSITY OF THE LIQUID

Density (g./cc.)

\begin{tabular}{|c|c|c|c|c|c|}
\hline $\begin{array}{c}\text { Temperature } \\
\left({ }^{\circ} \mathrm{C} .\right)\end{array}$ & $\begin{array}{l}\text { Hoge and } \\
\text { Wechsler } \\
\text { (Ref. 141) }\end{array}$ & $\begin{array}{l}\text { Llewellyn } \\
\text { (Ref. 107) }\end{array}$ & $\begin{array}{c}\text { Priest } \\
\text { (Ref. 123) }\end{array}$ & $\begin{array}{c}\text { Abelson } \\
\text { et al. } \\
\text { (Ref. 1, 128) }\end{array}$ & Calculated $\sharp$ \\
\hline 64.052 & & & 3. 674 & & \\
\hline 65 & 3.624 & $3.63 \dagger$ & & & \\
\hline 65.1 & & & $3.667 \pm 0.05$ & & \\
\hline 68 & & 3.620 & & & \\
\hline 68.66 & 3. $604 *$ & & & & \\
\hline 70 & 3.595 & $3.60 \dagger$ & & & \\
\hline 71.6 & & 3.582 & & & \\
\hline 72.91 & $3.576 *$ & & & & \\
\hline 74 & & 3.581 & & & \\
\hline 75 & 3.565 & & & & \\
\hline 76 & & 3.560 & & & \\
\hline 77 & & & & 3.63 & \\
\hline 78.2 & & 3.542 & & & \\
\hline 80 & 3.532 & $3.54^{\dagger}$ & & & \\
\hline 81 & & 3.525 & & & \\
\hline 84 & & 3.520 & & & \\
\hline 85 & 3.502 & & & & \\
\hline 87.8 & & 3. 484 & & & \\
\hline 90 & 3. 470 & $3.48 \dagger$ & & & \\
\hline 91.6 & & 3.455 & & & \\
\hline 92.65 & $3.452 *$ & & & & \\
\hline 93.8 & & 3. 448 & & & \\
\hline 95 & 3.437 & & & & \\
\hline 98.6 & & 3. 427 & & & \\
\hline 98.9 & & 3. 416 & & & \\
\hline 100 & 3.404 & $3.41 \dagger$ & & & \\
\hline 112.67 & $3.316 *$ & & & & \\
\hline 120 & 3.263 & & & & \\
\hline 131.12 & $3.183 *$ & & & & \\
\hline 140 & 3.111 & & & & \\
\hline 156 & & & & 3. 11 & \\
\hline 160 & 2.948 & & & & \\
\hline 162.59 & $2.920 *$ & & & & \\
\hline 203 & & & & 2.62 & \\
\hline 215 & & & & 2.32 & \\
\hline 225 & & & & 2.09 & \\
\hline 230 & & & & 1.63 & \\
\hline 232.5 & & & & 1.41 & 1.373 \\
\hline \multicolumn{6}{|c|}{ *Experimental value. } \\
\hline Value rounde & & & & & \\
\hline
\end{tabular}


Table 9

COMPARISON OF VAPOR DENSITIES AT $49.2{ }^{\circ} \mathrm{C}$.

Density

(g. /cc. $\left.\times 10^{3}\right)$

\begin{tabular}{|c|c|c|c|c|}
\hline \multirow{2}{*}{$\begin{array}{l}\text { Pressure } \\
\text { (mm. Hg) }\end{array}$} & \multicolumn{3}{|c|}{ Equation of State } & \multirow{2}{*}{$\begin{array}{c}\text { Experimental } \\
\text { (Ref. 9) }\end{array}$} \\
\hline & Weinstock & Magnuson & Ideal Gas Law & \\
\hline 523 & 9.425 & 9.391 & 9. 1585 & 9.016 \\
\hline 470 & 8.445 & 8.418 & 8.2306 & 8.119 \\
\hline 350.0 & 6.247 & 6.233 & 6.1292 & $\cdots-\cdots$ \\
\hline 259.3 & 4. 627 & 4.598 & 4. 5408 & 4.278 \\
\hline 186.4 & 3.297 & 3.294 & 3.2642 & 3.130 \\
\hline
\end{tabular}

Table 10

VAPOR DENSITY CALCULATED ON THE BASIS OF THE PROPOSED EQUATION OF STATE

\begin{tabular}{|c|c|c|c|c|}
\hline \multicolumn{2}{|c|}{ Temperature } & \multicolumn{3}{|c|}{ Density, $\rho$ (g./cc.) } \\
\hline$\left({ }^{\circ} \mathrm{C}.\right)$ & ( $\left.{ }^{\circ} \mathrm{K}_{.}\right)$ & Weinstock & Magnuson & $\begin{array}{c}\text { Ideal Gas } \\
\text { Law }\end{array}$ \\
\hline 50 & 323.2 & 0.01384 & 0.01376 & 0.01328 \\
\hline 60 & 333.2 & 0.01338 & 0.01335 & 0.01288 \\
\hline 80 & 353.2 & 0.01254 & 0.01249 & 0.01215 \\
\hline 100 & 373.2 & 0.01180 & 0.01176 & 0.01149 \\
\hline 120 & 393.2 & 0.01116 & 0.01113 & 0.01091 \\
\hline 140 & 413.2 & 0.01059 & 0.01056 & 0.01038 \\
\hline \multicolumn{5}{|c|}{$\begin{array}{l}\text { Priest }{ }^{123} \text { determined the liquid density by using a glass apparatus consisting of a calibrated } \\
\text { Pyrextube of uniform bore. The tube, containing accurately weighed UF } \text {, was sealed } \text {, The } \\
\text { and immersed in a bath at } 65.1^{\circ} \mathrm{C} \text {. The height of the column of liquid was measured } \\
\text { with a precision cathetometer. The density was reported as } 3.667 \pm 0.05 \mathrm{~g} . / \mathrm{cc} \text {. Using } \\
\text { this value and Equation } 6 \text {, Brickwedde, Hoge and Scott }{ }^{24} \text { calculated the density of the liquid } \\
(3.674 \mathrm{~g} . / \mathrm{cc} \text { ) at the triple point. A comparison of the experimental density values of } \\
\text { the saturated liquid with those calculated from Equation } 5 \text { as well as the density values } \\
\text { reported by Abelson and his co-workers }{ }^{1} \text { can be made from the data presented in Table } \\
8 \text { and Figure } 4 \text {. Details of the density investigations of Abelson and his co-workers were } \\
\text { not available, and the density values given in this report were obtained from secondary } \\
\text { literature sources }{ }^{1,26}\end{array}$} \\
\hline
\end{tabular}




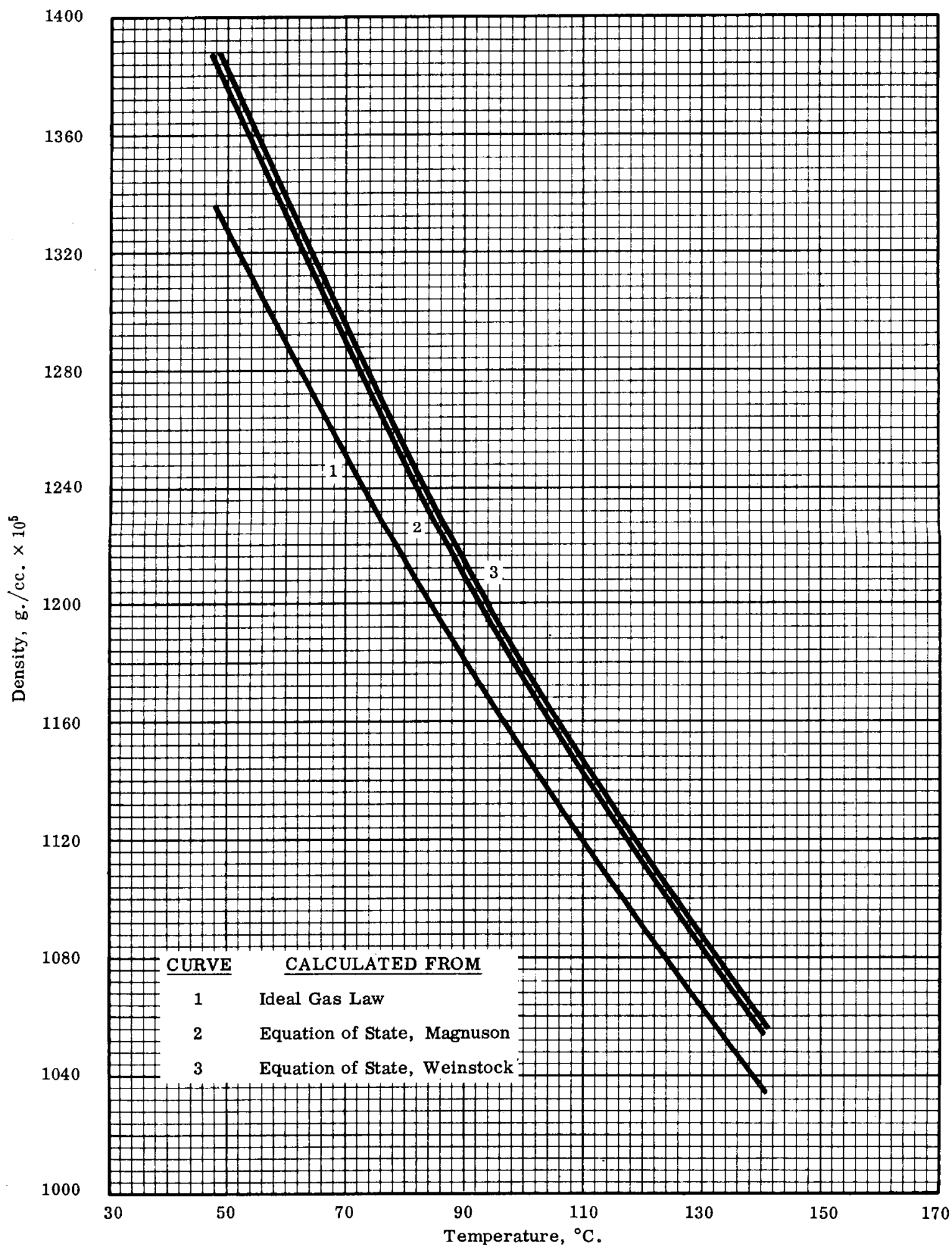

FIG. 5. VAPOR DENSITY CALCULATED AT ATMOSPHERIC PRESSURE 


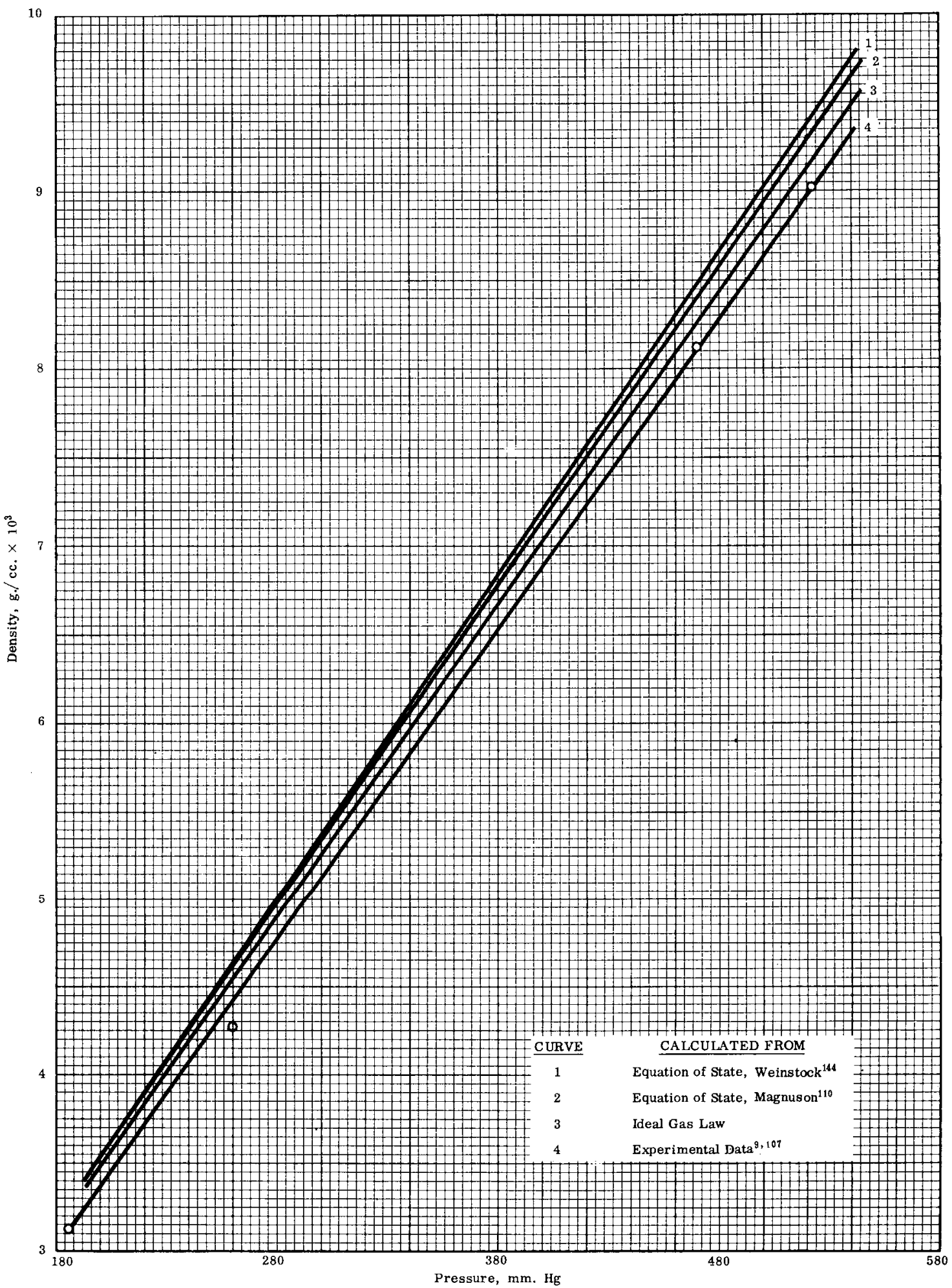

FIG. 6. VAPOR DENSITIES - CALCULATED COMPARED WITH EXPERIMENTAL AT $49.2^{\circ} \mathrm{C}$. 


\section{VAPOR DENSITY}

Amphlett, Mullinger, and Thomas $^{9}$ (see also Llewellyn ${ }^{107}$ ) reported that at $49.2^{\circ} \mathrm{C}$. and at low pressures, $\mathrm{UF}_{6}$ vapor is essentially ideal, at least within the presumed experimental error (one percent) of their measurements. Therefore the density of vapor should be approximately derived by using the ideal gas law:

$$
\rho=\mathrm{MP} / \mathrm{RT}=4.291 \mathrm{P} / \mathrm{T}(\mathrm{g} . / \mathrm{cc} \text {. })
$$

where $P$ is in units of atmospheres and $T$ is in degrees Kelvin. However, at pressures slightly higher than those used in the earlier investigations, it was definitely established by accurate pressure-volume-temperature measurements and by studies of the dielectric constant and thermodynamic properties that $U_{F}$ does not behave as an ideal gas. From the dielectric constant studies a non-ideality parameter was proposed by Magnuson 110 which yields thefollowing expression for the density of vapor for the $50^{\circ}$ to $140^{\circ} \mathrm{C}$. range:

$$
\rho=4.291(\mathrm{P} / \mathrm{T})\left(1+1.2328 \times 10^{6} \mathrm{P} / \mathrm{T}^{3}\right) \mathrm{g} \cdot / \mathrm{cc} .
$$

From studies of the thermodynamic properties, Weinstock and his co-workers ${ }^{144}$ proposed a non-ideality parameter which yields the following vapor density expression:

$$
\rho=\frac{4.291 \mathrm{P}}{\mathrm{T}\left[1+\left(-1.3769 \times 10^{6} \mathrm{P} / \mathrm{T}^{3}\right)\right]} \mathrm{g} \cdot / \mathrm{cc} .
$$

Comparison of the values of the vapor densities at one atmosphere calculated on the basis of Equations 7, 8, and 9 are presented in Table 10 and in Figure 5. Comparis on of the density values calculated on the basis of Equations 7, 8 and 9 with the experimental values obtained by Amphlett and his co-workers are presented in Table 9 and Figure 6. 


\section{OPTICAL PROPERTIES}

\section{REFRACTIVE INDEX}

Both Llewellyn ${ }^{107}$ and Simon ${ }^{135}$ have reported index of refraction values of liquid $\mathrm{UF}_{6}$ in the $70^{\circ}$ to $100^{\circ} \mathrm{C}$. range. These values, which are listed in Table 11 , were determined from measurements of the angle of total reflection and are estimated to be accurate within 0.4 percent. Values of the molecular refraction at $85^{\circ} \mathrm{C}$. calculated from these index values were determined as $22.59 \pm 0.1$ at the $4360 \AA$ wave length and as $21.83 \pm$ 0.1 at the $5890 \AA$ wave length. Assuming that the molecular refraction of the vapor is the same as that of the liquid, both authors reported an expression for the refractive index of the vapor:

$$
\left.\eta-1=5.2 \times 10^{-4} \frac{\mathrm{P}(\mathrm{mm} . \mathrm{Hg})}{\mathrm{T}\left({ }^{\circ} \mathrm{K} .\right)} \text { (at } 5100 \AA\right)
$$

\section{Table 11}

\section{REFRACTIVE INDEX OF THE LIQUID}

Temperature

$\left({ }^{\circ} \mathrm{C}.\right)$

66.0

68.0

69.4

70.0

72.2

72.3

73.5

75.2

77.5

79.2

80.0

84.0

84.7

85.2

87.2

90.0

90.5

91.0

95.1

100.0
Refractive Index $\underline{4360 \AA}$

$\underline{5890 \AA}$

1.385

1.386

1.383

1.367

1.367

1.366

1.382

1.367

1.377

1.360

1.376

1.374

1.371

1.369

$\begin{array}{ll} & 1.353 \\ & 1.354 \\ 1.365 & 1.342 \\ 1.364 & 1.350 \\ 1.364 & \end{array}$

1.347

1.355

1.342 
The refractive index of a $\mathrm{UF}_{6}-\mathrm{BrF}_{5}$ mixture has been determined with the hollow prism spectrometer described by Stein and Vogel ${ }^{138}$ as a function of composition. The refractive index values obtained at $70^{\circ} \mathrm{C}$., using the $\mathrm{Na}$ line, for the entire range of concentration of the $\mathrm{UF}_{6}-\mathrm{BrF}_{5}$ system are listed in Table 12. These are represented by the equation:

$$
\eta_{\mathrm{D}}^{70}=1.3275+0.0380 \mathrm{~N}-0.065 \mathrm{~N}^{2}-0.0010 \mathrm{~N}^{3}
$$

where $\mathrm{N}$ is the mole fraction of $\mathrm{UF}_{6}$ in $\mathrm{BrF}_{5}$.

Table 12

REFRACTIVE INDEXES OF URANIUM HEXAFLUORIDE BROMINE PENTAFLUORIDE MIXTURES AT $70^{\circ} \mathrm{C}$.

\begin{tabular}{cc}
$\begin{array}{c}\text { Mole Fraction } \\
\mathrm{UF}_{6} \text { in } \mathrm{BrF}_{5}\end{array}$ & $\begin{array}{c}\text { Refractive } \\
\text { Index }\end{array}$ \\
\hline 0.0000 & 1.3275 \\
0.1684 & 1.3338 \\
0.3153 & 1.3388 \\
0.4354 & 1.3428 \\
0.5134 & 1.3449 \\
0.5965 & 1.3477 \\
0.7607 & 1.3522 \\
0.9069 & 1.3560 \\
1.0000 & 1.3580
\end{tabular}

\section{MOLECULAR SPECTRA}

VIBRATIONAL SPECTRA

The infrared and Raman spectra of $\mathrm{UF}_{6}$ have been studied rather intensively by several investigators. The data obtained indicate that the $\mathrm{UF}_{6}$ molecule has an $\mathrm{O}_{\mathrm{h}}$ point group symmetry (regular octahedral symmetry). The $O_{h}$ group possesses six fundamental modes of which only two are active in the infrared*. Values of the other fundamentals were obtained either from the Raman spectrum, in which three are active, or by deduction from the binary and ternary combinations of the infrared bands. A summary of the various reported values of the fundamentals which have been assigned by the various investigators is given in Table 13 . Values assigned by Gaunt ${ }^{65}$ compare favorably to those deduced by Hawkins and his co-workers ${ }^{74}$. These values are in agreement with findings in the latest Raman investigations ${ }^{35}$. Summaries of the observed infrared spectrum and the observed Raman spectrum are given in Tables 14 and 15, respectively.

\section{Infrared Spectrum}

The infrared spectrum of $\mathrm{UF}_{6}$ vapor has been investigated recently by Hawkins, Mattraw, and Carpenter ${ }^{74}$ at temperatures up to $100^{\circ} \mathrm{C}$. Originally the spectrum was studied at

*Herzberg, G. Infrared and Raman Spectra. New York, Van Nostrand Co., Inc., 1945. 
Table 13

FUNDAMENTAL VIBRATION FREQUENCIES

\begin{tabular}{|c|c|c|c|c|c|c|c|}
\hline \multirow[b]{2}{*}{ Assignment } & \multirow[b]{2}{*}{ Symmetry } & \multirow[b]{2}{*}{ Activity } & \multirow[b]{2}{*}{ Degeneracy } & \multicolumn{4}{|c|}{ Frequencies, $\mathrm{cm} .^{-1}$} \\
\hline & & & & $\begin{array}{c}\text { Hawkins, } \\
\text { et al. } \\
\text { (Ref. 74) }\end{array}$ & $\begin{array}{r}\text { Weinstock } \\
\text { (Ref. 144) }\end{array}$ & $\begin{array}{c}\text { Gaunt } \\
\text { (Ref. 65) }\end{array}$ & $\begin{array}{l}\text { Bigeleisen } \\
\text { (Ref. 20) }\end{array}$ \\
\hline$\nu_{1}$ & $A_{1} g$ & Raman & 1 & 665 & 667 & 668 & 656 \\
\hline$\nu_{2}$ & $\mathbf{E g}$ & Raman & 2 & 536 & 535 & 532 & 511 \\
\hline$\nu_{3}$ & $\mathrm{~F}_{1} \mathrm{u}$ & Infrared & 3 & 623 & 623 & 626 & 640 \\
\hline$\nu_{4}$ & $F_{1} \mathrm{u}$ & Infrared & 3 & 186 & 181 & 189 & 200 \\
\hline$\nu_{5}$ & $\mathrm{~F}_{2} \mathrm{~g}$ & Raman & 3 & 202 & 202 & 202 & 200 \\
\hline$\nu_{6}$ & $\mathrm{~F}_{2} \mathrm{u}$ & Inactive & 3 & 136 & 140 & 144 & 130 \\
\hline
\end{tabular}

room temperature by Bigeleisen, Mayer, Stevenson, and Turkevich ${ }^{20}$. It was reinvestigated by Burke, Smith, and Nielsen ${ }^{29}$ and by Gaunt ${ }^{65}$. The findings in the investigations at elevated temperatures are much the same as the findings in investigations at room temperature, except that six new bands were revealed in the former case. Assignments of the fundamental vibrations were made on the assumption that the structure of the $\mathrm{UF}_{6}$ molecule is that of a regular octahedron.

Hawkins and his co-workers ${ }^{74}$ studied the infrared spectrum from 2 to 23 microns with a Baird double-beam model AB2-195 spectrometer which employed sodium chloride and potassium bromide optics. The cell was constructed of copper and contained silver chloride windows which apparently did not change in transmissive properties at $100^{\circ} \mathrm{C}$. The recorded spectra were calibrated with polystyrene in the sodium chloride region and with 1, 2, 4-trichlorobenzene in the potassium bromide region. The results obtained by Hawkins and his co-workers are summarized in Table 14. In addition to the six new bands reported in the spectrum made at the elevated temperatures, they found all the bands reported by Burke and his co-workers but did not find the 547 and $587 \mathrm{~cm}$. $^{-1}$ bands reported by Gaunt. However, they felt that the band at $587 \mathrm{~cm} . .^{-1}$ was real and believed that Gaunt was able to detect this weak band by using a long path technique. The fundamental vibrations of $U_{F}$ which they assigned on the basis of regular octahedral structure and the observed infrared spectrum are presented in Table 13. These values compare favorably with the values previously proposed by Gaunt ${ }^{65}$.

Gaunt studied the infrared spectrum at room temperature from 2 to 25 microns with a Hilger D 209 single-beam spectrometer which employed lithium fluoride, sodium chloride, and potassium bromide prisms as its optics ${ }^{65}$. The cells, which ranged from 10 to 186 centimeters in length, were fitted with windows of potassium bromide. The results summarized in Table 14 fully confirm the original measurements of Bigeleisen and his co-workers and agree with the reinvestigation by Burke and his co-workers ${ }^{29}$. The interpretation of the spectrum made by Gaunt differs slightly from the interpretation made by Bigeleisen and his co-workers ${ }^{20}$. The assignments of the fundamentals made by Gaunt are shown in Table 13. 
Table 14

\section{INFRARED SPECTRUM OF THE VAPOR}

\begin{tabular}{|c|c|c|c|c|c|c|c|}
\hline \multicolumn{4}{|c|}{ Frequencies $\left(\mathrm{cm} .{ }^{-1}\right) *$} & & \multirow[b]{2}{*}{$\begin{array}{c}\text { Symmetry } \\
\text { (Ref, 20,74) }\end{array}$} & \multicolumn{2}{|c|}{$\begin{array}{l}\text { Intenaity, Percent Absorption } \\
\text { (Ref. 74) }\end{array}$} \\
\hline $\begin{array}{c}\text { A } \\
\text { (Ref. } 74) \\
\end{array}$ & $\begin{array}{c}\text { B } \\
\text { (Ref. 29) }\end{array}$ & $\begin{array}{c}\text { C } \\
\text { (Ref. 65) }\end{array}$ & $\begin{array}{c}\text { D } \\
\text { (Ref. 20) }\end{array}$ & Assignments & & $\begin{array}{c}\text { Room } \\
\text { Temperature } \\
\end{array}$ & $100^{\circ} \mathrm{C}$ \\
\hline $\begin{array}{c}1869 \\
(1869)\end{array}$ & & & & $3 \nu_{3}^{(A)}$ & $A_{2}+2 F_{1}+F_{2}$ & & 3 \\
\hline $\begin{array}{l}1808 \\
(1782) \text { or } \\
(1824)\end{array}$ & & & & $\begin{array}{l}2 \nu_{3}+\nu_{2}^{(\mathrm{A})} \text { or } \\
\nu_{1}+\nu_{2}+\nu_{3}^{(\mathrm{A})}\end{array}$ & $\begin{array}{l}\mathrm{A}_{1}+\mathrm{A}_{2}+2 \mathrm{E}+\mathrm{F}_{1}+\mathrm{F}_{2} \text { or } \\
\mathrm{F}_{1}+\mathrm{F}_{2}\end{array}$ & & 3 \\
\hline $\begin{array}{l}1684 \\
(1695)\end{array}$ & & & & $2 \nu_{2}+\nu_{3}^{(A)}$ & $2 F_{1}+F_{2}$ & & 8 \\
\hline $\begin{array}{l}1337 \\
(1337) \text { or } \\
(1345)\end{array}$ & & & & $\begin{array}{l}\nu_{1}+\nu_{2}+\nu_{5}^{(\mathrm{A})} \text { or } \\
\nu_{2}+\nu_{3}+\nu_{4}^{(\mathrm{A})}\end{array}$ & $\begin{array}{l}F_{1}+F_{2} \\
A_{1}+A_{2}+2 E+2 F_{1}+2 F_{2}\end{array}$ & & 9 \\
\hline 1288 & $\begin{array}{c}1288 \\
(1296)\end{array}$ & $\begin{array}{c}1294 \\
(1294)\end{array}$ & $\begin{array}{c}1295 \\
(1295)\end{array}$ & $\begin{array}{l}\nu_{1}+\nu_{3}(\mathrm{~A}, \mathrm{~B}, \mathrm{C}) \\
\nu_{6}+\nu_{1}(\mathrm{D})\end{array}$ & $F_{1}$ & 52 & $90-100$ \\
\hline 1159 & $\begin{array}{c}1159 \\
(1151)\end{array}$ & $\begin{array}{c}1158 \\
(1158)\end{array}$ & $\begin{array}{l}1163 \\
(1151)\end{array}$ & $\begin{array}{l}\nu_{2}+\nu_{3}(\mathrm{~A}, \mathrm{~B}, \mathrm{C}) \\
\nu_{6}+\nu_{2}(\mathrm{D})\end{array}$ & $F_{1}+F_{2}$ & 59 & $90-100$ \\
\hline $\begin{array}{c}852 \\
(851)\end{array}$ & $\begin{array}{c}850 \\
(856)\end{array}$ & $\begin{array}{c}854 \\
(857)\end{array}$ & $\begin{array}{c}850 \\
(856)\end{array}$ & $\begin{array}{l}\nu_{1}+\nu_{4}(A, B, C) \\
\nu_{5}+\nu_{1}(D)\end{array}$ & $F_{1}$ & 12 & 59 \\
\hline 82.5 & $\begin{array}{c}825 \\
(840)\end{array}$ & $\begin{array}{c}825 \\
(828)\end{array}$ & $\begin{array}{c}825 \\
(840)\end{array}$ & $\begin{array}{l}\nu_{3}+\nu_{5}{ }^{(A, B, C)} \\
\nu_{6}+\nu_{3}(D)\end{array}$ & & 33 & $90-100$ \\
\hline $\begin{array}{c}755 \\
(752)\end{array}$ & & $\begin{array}{l}756 \\
762\end{array}$ & & $v_{1}-\nu_{2}+v_{3}^{(\mathrm{A}, \mathrm{C})}$ & $F_{1}+F_{2}$ & & 14 \\
\hline $\begin{array}{c}715 \\
(722)\end{array}$ & $\begin{array}{c}715 \\
(711)\end{array}$ & $\begin{array}{c}717 \\
(721)\end{array}$ & $\begin{array}{l}713-719 \\
(711)\end{array}$ & $\begin{array}{l}\nu_{2}+v_{4}{ }^{(\mathrm{A}, \mathrm{B}, \mathrm{C})} \\
\nu_{5}+\nu_{2}{ }^{(\mathrm{D})}\end{array}$ & $F_{1}+F_{2}$ & 16 & 67 \\
\hline 672 & $\begin{array}{l}674 \\
641\end{array}$ & $\begin{array}{l}676 \\
676\end{array}$ & $\begin{array}{l}641 \\
675\end{array}$ & $\begin{array}{l}\nu_{2}+\nu_{8}(\mathrm{~A}, \mathrm{~B}, \mathrm{C}) \\
\nu_{4}+\nu_{2}{ }^{(\mathrm{D})}\end{array}$ & $F_{1}+F_{2}$ & 73 & $90-100$ \\
\hline 623 & 623 & 626 & $\begin{array}{l}623 \\
640\end{array}$ & $\begin{array}{l}v_{3}^{(\mathrm{A}, \mathrm{B}, \mathrm{C})} \\
v_{6}^{(\mathrm{D})}\end{array}$ & $\mathrm{F}_{\mathrm{t}}$ & $90-100$ & $90-100$ \\
\hline & & $\begin{array}{l}587 \\
593\end{array}$ & & $2 \nu_{5}+v_{4}^{(\mathrm{C})}$ & & & \\
\hline & & $\begin{array}{l}574 \\
581\end{array}$ & & $\nu_{3}+\nu_{B}-\nu_{4}^{(C)}$ & & & \\
\hline $\begin{array}{c}571 \\
(558)\end{array}$ & & $\begin{array}{l}547 \\
567\end{array}$ & & $3 \nu_{4}^{(A, C)}$ & $A_{1}+2 F_{1}+F_{2}$ & & $\begin{array}{l}67 \\
\text { Broad }\end{array}$ \\
\hline $\begin{array}{l}533 \\
(524) \text { or } \\
(540)\end{array}$ & & & & $\begin{array}{l}\nu_{4}+\nu_{5}+\nu_{6} \text { or } \\
2 \nu_{5}+\nu_{8}\end{array}$ & $\begin{array}{l}A_{1}+A_{2}+2 E+4 F_{1}+3 F_{2} \text { or } \\
A_{1}+E+2 F_{1}+3 F_{2}\end{array}$ & & \\
\hline $\begin{array}{r}479 \\
(479)\end{array}$ & & & & $\nu_{\mathrm{t}}-\nu_{\mathrm{d}}$ or & $F_{1}$ & & 14 \\
\hline $\begin{array}{l}(388) \text { or } \\
(400)\end{array}$ & $\begin{array}{c}392 \\
(400)\end{array}$ & $\begin{array}{c}394 \\
(391)\end{array}$ & $(400)$ & $\begin{array}{l}v_{4}+v_{5}^{(\mathrm{A}, \mathrm{B}, \mathrm{C})} \\
v_{2}-v_{6}^{(\mathrm{A})} \\
v_{5}+v_{3}^{(\mathrm{D})}\end{array}$ & $\begin{array}{l}A_{2}+E+F_{1}+F_{2} \text { or } \\
F_{1}+F_{2}\end{array}$ & & \\
\hline $\begin{array}{l}(350)^{\dagger} \text { or } \\
(338)\end{array}$ & $\begin{array}{c}350 \\
(330)\end{array}$ & & $(330)$ & $\begin{array}{l}\nu_{2}-\nu_{4}^{(\mathrm{A})} \text { or } \\
\nu_{5}+\nu_{6} \\
\nu_{4}+\nu_{6}{ }^{(\mathrm{B})} \\
\nu_{4}+\nu_{3}^{(\mathrm{D})}\end{array}$ & $\begin{array}{l}F_{1}+F_{2}^{\dagger} \text { or } \\
A_{1}+E+F_{1}+F_{2}\end{array}$ & & \\
\hline $\begin{array}{l}(273) \text { or } \\
(289) \text { or } \\
(268)\end{array}$ & $\begin{array}{c}279 \\
(270)\end{array}$ & & $(200)$ & $\begin{array}{l}-\nu_{2}+\nu_{3}+\nu_{4}^{(\mathrm{A})} \text { or } \\
\nu_{2}+\nu_{3}+\nu_{5}^{(\mathrm{A})} \text { or } \\
2 \nu_{5}-\nu_{6}^{(\mathrm{A})} \text { or } \\
2 \nu_{4}-\nu_{6}^{(\mathrm{B})} \\
\nu_{5}^{(\mathrm{D})}\end{array}$ & $\begin{array}{l}A_{2}+A_{2}+2 E+2 F_{1}+2 F_{2} \text { or } \\
A_{1}+A_{2}+2 E+2 F_{1}+2 F_{2} \text { or } \\
A_{1}+E+2 F_{1}+3 F_{2}\end{array}$ & & \\
\hline
\end{tabular}


Table 15

\section{OBSERVED RAMAN SPECTRUM}

\begin{tabular}{|c|c|c|c|c|}
\hline \multirow[b]{3}{*}{ Designation } & \multicolumn{4}{|c|}{ Frequencies $\left(\mathrm{cm} .{ }^{-1}\right)$} \\
\hline & \multirow[b]{2}{*}{$\begin{array}{c}\text { Duncan (Ref. 44) } \\
\text { Liquid }\end{array}$} & \multirow{2}{*}{$\begin{array}{c}\text { Claassen et al. (Ref. 35) } \\
\text { Vapor }-1200 \mathrm{~mm} . \mathrm{Hg} \\
\left(70^{\circ} \mathrm{C} .\right)\end{array}$} & \multicolumn{2}{|c|}{ Bigeleisen et al. (Ref. 20) } \\
\hline & & & $\begin{array}{l}\text { Liquid } \\
\left(70^{\circ} \mathrm{C} .\right)\end{array}$ & $\begin{array}{c}\text { Solution in } \mathrm{C}_{7} \mathrm{~F}_{16} \\
\left(20^{\circ} \mathrm{C} .\right)\end{array}$ \\
\hline$\nu_{1}$ & 603 & $666.6 \pm 0.3$ & $656 \pm 3$ & $666 \pm 3$ \\
\hline$\nu_{2}$ & & $535 \pm 5$ & $511 \pm 3$ & \\
\hline$\nu_{5}$ & 228 & & & $202 \pm 3$ \\
\hline
\end{tabular}

Burke, Smith, and Nielsen ${ }^{29}$ observed the infrared spectrum from 2 to about 40 microns with Perkin-Elmer spectrometer models $12 \mathrm{C}$ and 21 equipped with sodium chloride, potassium bromide, and KRS-5 prisms. The cell was constructed of fluorothene and contained windows of silver chloride, potassium bromide, or KRS-5 depending upon the region investigated. A modified Perkin-Elmer one-meter cell was also used, but no additional information was obtained. The results, which are summarized in Table 14, were found to be virtually identical with the measurements of Bigeleisen and his coworkers except that three new bands at $279 \mathrm{~cm} .^{-1}, 350 \mathrm{~cm} .^{-1}$ and $392 \mathrm{~cm} .^{-1}$ were located in the extended 17-to-40 micron region.

Bigeleisen, Mayer, Stevenson and Turkevich ${ }^{20}$ conducted the original study of the inirared spectrum in the region between 2 and 17 microns at room temperature. A rock-salt spectrometer and a 20-centimeter cell fitted with rock-salt windows were used to obtain the spectrum at several pressures. The results are summarized in Table 14. The fundamentals, which were assigned on the basis of the $\mathrm{O}_{\mathrm{h}}$ point symmetry, are listed in Table 13.

\section{Raman Spectrum}

The Raman spectrum was studied by Duncan ${ }^{44}$ and by Bigeleisen, Mayer, Stevenson, and Turkevich ${ }^{20}$ and rather recently by Claassen, Weinstock, and Malm ${ }^{35}$. These studies, the results of which are given in Table 15, revealed only three Raman lines. This is in agreement with the number of Raman lines predicted if it is assumed that $\mathrm{UF}_{6}$ has an $\mathrm{O}_{\mathrm{h}}$ point symmetry. The fundamentals $\nu_{1}$ and $\nu_{2}$, which were observed by Claass en and his co-workers, compare very well with those deduced from the observed combination bands of the infrared spectrum, especially those reported by Gaunt ${ }^{65}$ and by Hawkins and his co-workers ${ }^{74}$.

In the investigation of the Raman spectrum of $\mathrm{UF}_{6}$ vapor at $70^{\circ} \mathrm{C}$. and $1200 \mathrm{~mm}$. $\mathrm{Hg} \mathrm{by}$ Claassen and his co-workers ${ }^{35}$, the Raman tube, 20 centimeters long and made of 14millimeter pyrex tubing, contained a plane window on one end and a break seal on the other. The tube was irradiated (4358 $\AA$ ) by an Applied Research Laboratories excitation unit and the spectrum was obtained using a Hilger E 612 instrument with two $63^{\circ}$ glass prisms, a camera aperture of $\mathrm{f} / 6.7$, and an inverse dispersion of $16 \AA$ per millimeter at $4358 \AA$. The results, with estimated uncertainties, are in agreement with the values chosen on the basis of infrared combination bands and compare favorably with other observed values. Using the frequency values obtained from the Raman spectrum and assuming that the $\mathrm{UF}_{6}$ molecule has octahedral symmetry, Weinstock ${ }^{144}$ later calculated values of the other four fundamental vibrational frequencies. These values are listed in Table 13 . 
Duncan ${ }^{44}$ obtained the Raman spectrum of liquid $\mathrm{UF}_{6}$ using a glass Raman tube 6 millimeters in diameter and 20 centimeters long, with a flat end window. The tube containing the liquid $\mathrm{UF}_{6}$ was irradiated at $4358.34 \AA$ with the mercury line filtered by cobalt blue. Two "strong" Raman lines, the more intense one at $603 \mathrm{~cm} .^{-1}$ and the other at 228 $\mathrm{cm} .^{-1}$, were observed.

Bigeleisen and his co-workers ${ }^{20}$ reported that their Raman spectrum values for liquid $\mathrm{UF}_{6}$ at $70^{\circ} \mathrm{C}$. were obtained using $4358 \AA$ excitation. In addition to the Raman spectrum of liquid $\mathrm{UF}_{6}$, the Raman spectrum of a solution of $\mathrm{UF}_{6}$ in $\mathrm{C}_{7} \mathrm{~F}_{16}$ was obtained by using both $4358 \AA$ and $5461 \AA$ excitations. The Raman lines obtained from these studies also are summarized in Table 15.

\section{VISIBLE AND NEAR - ULTRAVIOLET SPECTRA}

The ultraviolet absorption spectrum of $\mathrm{UF}_{6}$ has been studied by Lipkin and Weisman ${ }^{104}$, by Duncan ${ }^{43}$, by Martin and Amphlett ${ }^{55}, 112$ and by Amphlett, Mullinger, and Thomas ${ }^{9}$. Most of their data, which are presented in Tables 16 and 17, have been summarized in a number of earlier compilations ${ }^{45}, 88,93,115,135$ Recently an article concerning the absorption spectrum in the visible and near-ultraviolet region has appeared in the Russian literature ${ }^{136}$. The author of the Russian article, Sheremet'ev, stated that the absorption spectra of $\mathrm{UF}_{6}$ are considerably more complicated than those reported as a result of the previously mentioned investigations. His data are presented in Tables 18,19, 20, and 21.

Amphlett, Mullinger, and Thomas ${ }^{9}$ obtained a qualitative picture of the absorption of $\mathrm{UF}_{6}$ vapor between $2000 \AA$ and $4000 \AA$. A medium-sized Hilger quartz spectrograph with a hydrogen lamp as source and a copper arc for producing reference lines of known wave length was used to obtain the spectra. Two cells were used, a 15-centimeter pyrex cell with silica windows and a 5-centimeter cell of fused silica. The cells were attached by $\mathrm{a} \mathrm{T}$-piece to a bulb which contained the sample.

Preliminary results obtained by these investigators are somewhat different from those obtained earlier by Lipkin and Weisman ${ }^{104}$. The data of Amphlett and his co-workers indicate continuous absorption with complete extinction below $3100 \AA$; the extinction wave lengths of the vapor at various temperatures and pressures are listed in Table 16.

Lipkin and Weisman ${ }^{104}$ obtained the absorption spectrum of $\mathrm{UF}_{6}$ at room temperature by use of a large Hilger instrument (dispersion $5 \AA$ per millimeter). They found a region of strong continuous absorption at about $3300 \AA$ and a region of structure absorption at about $3400 \AA$ to $3800 \AA$. No detailed analysis of the spectrum was made.

Duncan $^{43,45}$ reinvestigated the absorption spectrum of $\mathrm{UF}_{6}$ at a pressure of $36 \mathrm{~mm}$. $\mathrm{Hg}$. The spectrum was studied in the $4000 \AA$ to $3400 \AA$ region using a cell of 1 -meter path length. It was found that the spectrum of $\mathrm{UF}_{6}$ vapor contained ultraviolet edges which appeared slightly sharper than the long wave-length edges. The position of these absorption bands, which are rather diffuse, are listed in Table 17. Duncan expressed the belief that in addition to the strong continuous absorption below $3300 \AA$ there probably exists a continuum underlying the diffuse bands. The absorption spectrum of $U_{6}$ in Indies oil (a branched-chain fluorinated hydrocarbon) at $77^{\circ} \mathrm{K}$. showed essentially the same structure as the spectrum of the vapor except for a uniform shift by about 450 $\mathrm{cm} .^{-1}$ of all bands to lower frequencies.

Sheremet' ${ }^{136}$ obtained the absorption of $\mathrm{UF}_{6}$ vapor in the visible and neighboring regions of the spectrum. The material used in the experiments was separated from volatile impurities by sublimation in a vacuum, first at $-70^{\circ} \mathrm{C}$. and then at $-50^{\circ} \mathrm{C}$, , and by gradually passing the vapor through a 1-meter-long quartz column filled with recrystallized 
Table 16

EXTINCTION WAVE LENGTHS OF THE VAPOR

Bulb

Temperature

( $\left.{ }^{\circ} \mathrm{C}.\right)$

17

$-18$

$-48$

$-58$

$-77$

$-180$
Vapor

Pressure

(mm. Hg)*

65

3.8

0.17

0.05

0.003
Extinction

Wave Length

(A)

3100

2400

2270

2180

2130

2130

* Obtained by extrapolation from the vapor pressure equation:

$\log _{10} P(\mathrm{~mm})=.10.74-2592 / \mathrm{T}$

Table 17

ABSORPTION SPECTRUM OF THE VAPOR*

(Reference 45)

Wave Number, $\left(\mathrm{cm} .^{-1}\right)$

24364

24440

24504

24794

24860

24972

25108

25211

25344

25478

25538

25720

26031

26175

26277
Wave Number,

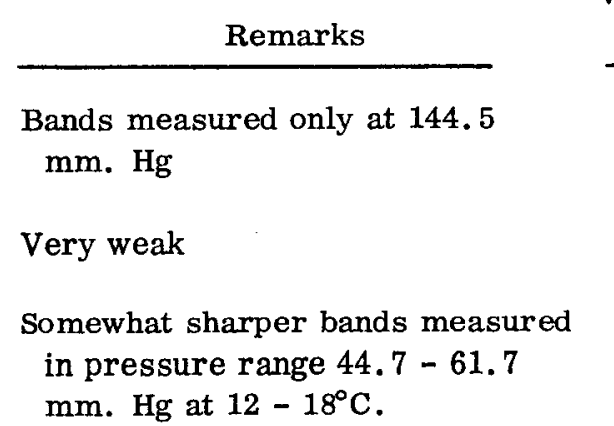

27135

27134

27334

27342

27420

27490

27568

27655

27820

27907

28080

28415

Violet edge of strong absorption

Center

*Measured at $293^{\circ} \mathrm{K}$. with a Hilger E-1 spectrograph. 
Table 18

VISIBLE AND ULTRAVIOLET ABSORPTION SPECTRUM OF THE VAPOR (Reference 136)

\begin{tabular}{|c|c|c|c|c|}
\hline \multirow[b]{2}{*}{ Band } & \multirow[b]{2}{*}{ Wavelength, $\AA$} & \multirow[b]{2}{*}{ Frequency $\left(\mathrm{cm} .^{-1}\right)$} & \multicolumn{2}{|c|}{ Frequency Difference } \\
\hline & & & $\mathrm{cm} .^{-1}$ & Between Bands \\
\hline $1 \mathrm{a}$ & 4068 & 24582 & 513 & $1 \mathrm{a}$ and $3 \mathrm{~b}$ \\
\hline $1 b$ & & 24661 & & \\
\hline $2 \mathbf{a}$ & & 24746 & & \\
\hline $2 b$ & 4040 & 24875 & 570 & $2 b$ and $4 b$ \\
\hline $2 \mathrm{c}$ & & 24981 & & \\
\hline $3 a$ & & 25031 & & \\
\hline $3 b$ & & $25095^{*}$ & 645 & $3 b$ and $5 b$ \\
\hline $3 c$ & & 25220 & & \\
\hline $4 a$ & & 25348 & & \\
\hline $4 b$ & 3930 & 25445 & 583 & $4 b$ and $6 b$ \\
\hline $4 \mathrm{c}$ & & 25510 & & \\
\hline $5 a$ & & 25608 & & \\
\hline $5 b$ & & $25740^{*}$ & 645 & $5 b$ and $7 b$ \\
\hline $5 c$ & & 25839 & & \\
\hline $6 a$ & & 25966 & & \\
\hline $6 b$ & 3842 & 26028 & 603 & $6 b$ and $8 b$ \\
\hline $6 \mathrm{c}$ & & 26178 & & \\
\hline $7 \mathrm{a}$ & & 26281 & & \\
\hline $7 \mathbf{b}$ & & $26385^{*}$ & 533 & $7 b$ and $9 b$ \\
\hline $7 \mathrm{c}$ & & 26490 & & \\
\hline $7 \mathrm{~d}$ & & 26560 & & \\
\hline $8 a$ & & 26595 & & \\
\hline $8 b$ & 3755 & 26631 & 617 & $8 b$ and $10 b$ \\
\hline $9 \mathrm{a}$ & & 26845 & & \\
\hline $9 b$ & & $26918^{*}$ & 630 & $9 b$ and $11 b$ \\
\hline $9 c$ & & 27027 & & \\
\hline $10 a$ & & $27134^{*}$ & 576 & $10 \mathrm{~b}$ and $12 \mathrm{~b}$ \\
\hline $10 \mathrm{~b}$ & 3690 & $27248^{*}$ & & \\
\hline $11 a$ & & 27462 & & \\
\hline $11 b$ & & $27548^{*}$ & 636 & $11 b$ and $13 c$ \\
\hline $11 \mathrm{c}$ & & 27662 & & \\
\hline $12 \mathrm{a}$ & & 27754 & & \\
\hline $12 b$ & 3594 & $27824^{*}$ & 585 & $12 \mathrm{~b}$ and $14 \mathrm{~b}$ \\
\hline $12 \mathrm{c}$ & & 27932 & & \\
\hline $13 a$ & & 28050 & & \\
\hline $13 b$ & & 28074 & & \\
\hline $13 c$ & & $28184^{*}$ & 634 & $13 c$ and $15 c$ \\
\hline $14 \mathrm{a}$ & & 28272 & & \\
\hline $14 \mathrm{~b}$ & 3520 & $28409^{*}$ & & \\
\hline $14 \mathrm{c}$ & & 28530 & & \\
\hline $15 a$ & & 28637 & & \\
\hline $15 b$ & & 28710 & & \\
\hline $15 \mathrm{c}$ & 3470 & $28818^{*}$ & & \\
\hline
\end{tabular}

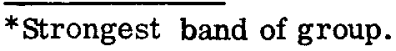


Table 19

FREQUENCY DIFFERENCES NEAR 200 AND 104 CM. $^{-1}$

(Reference 136)

\begin{tabular}{|c|c|c|c|}
\hline Frequency $\left(\mathrm{cm} .^{-1}\right)$ & Difference $\left(\mathrm{cm} .{ }^{-1}\right)$ & Frequency $\left(\mathrm{cm} .^{-1}\right)$ & Difference $(\mathrm{cm}$ \\
\hline 24528 & & 25095 & \\
\hline 24746 & $\begin{array}{l}218 \\
235\end{array}$ & 25220 & 125 \\
\hline 24981 & $\begin{array}{l}235 \\
239\end{array}$ & 25348 & \\
\hline 25220 & $\begin{array}{l}239 \\
225\end{array}$ & 25445 & 97 \\
\hline 25445 & $\begin{array}{l}225 \\
163\end{array}$ & 25608 & \\
\hline 25608 & $\begin{array}{l}163 \\
231\end{array}$ & 25740 & 132 \\
\hline 25839 & $\begin{array}{l}231 \\
189\end{array}$ & 25839 & 99 \\
\hline 26028 & $\begin{array}{l}189 \\
253\end{array}$ & 26028 & \\
\hline 26281 & $\begin{array}{l}253 \\
209\end{array}$ & 26178 & 150 \\
\hline 26490 & $\begin{array}{l}209 \\
141\end{array}$ & 26281 & \\
\hline 26631 & $\begin{array}{l}141 \\
214\end{array}$ & 26385 & 104 \\
\hline 26845 & $\begin{array}{l}214 \\
182\end{array}$ & 26490 & 105 \\
\hline 27027 & $\begin{array}{l}182 \\
221\end{array}$ & 26918 & \\
\hline 27248 & $\begin{array}{l}221 \\
214\end{array}$ & 27027 & 109 \\
\hline 27462 & $\begin{array}{l}214 \\
200\end{array}$ & 27134 & \\
\hline 27662 & $\begin{array}{l}200 \\
162\end{array}$ & 27248 & 114 \\
\hline 27824 & $\begin{array}{l}162 \\
226\end{array}$ & 27548 & \\
\hline 28050 & $\begin{array}{l}226 \\
222\end{array}$ & 27662 & 114 \\
\hline 28272 & $\begin{array}{l}222 \\
258\end{array}$ & 27824 & \\
\hline 28530 & $\begin{array}{l}258 \\
180\end{array}$ & 27932 & 108 \\
\hline 28710 & 180 & 28074 & \\
\hline 24582 & 79 & 28184 & 110 \\
\hline 24661 & 79 & 28409 & \\
\hline 24756 & & 28530 & 121 \\
\hline 24875 & $\begin{array}{l}119 \\
106\end{array}$ & 28710 & \\
\hline 24981 & 106 & 28818 & 108 \\
\hline
\end{tabular}

potassium bifluoride which had been dried at $150^{\circ} \mathrm{C}$. The $\mathrm{UF}_{6}$ purified in this manner consisted of colorless 3-to 4-millimeter orthorhombic crystals. Sheremet' ev reported a melting point of $69.2^{\circ} \mathrm{C}$. at approximately 2 atmospheres. (At approximately 2 atmospheres the melting point is $64.02 \pm 0.05^{\circ} \mathrm{C}$., [see Triple Point of UF $F_{6}$, page 89] .) The spectra were obtained by use of a quartz spectrograph ISP-22 with an average linear dispersion of $25 \AA$ per millimeter in the interval of the wave length from $4100 \AA$ to $3400 \AA$. The absorption cells were made of quartz (100 millimeters long and 400 millimeters in diameter) with parallel optical grade quartz windows. Sheremet'ev obtained the absorption spectra of $\mathrm{UF}_{6}$ vapor in the 5 to $94 \mathrm{~mm}$. $\mathrm{Hg}$ pressure range. He determined the vapor pressure by extrapolation from the experimental values obtained by Amphlett and his co-workers 9 (see Vapor Pressure, page 87, Equation 86).

The spectrogram obtained by Sheremet'ev indicates that there is continuous absorption which begins near $3341 \AA$ and proceeds toward the shorte' wave lengths. It also indicates that there is an absorption zone in the interval from $4050 \AA$ to $3470 \AA$. The whole absorption zone was measured from negatives with a Zeiss microphotometer. Results are given in Table 18. Sheremet'ev states that the most intense absorption in the vapors takes place near the $27,134 \mathrm{~cm} .^{-1}$ frequency, while other comparatively intense absorptions take place near the $26,631 \mathrm{~cm} .^{-1} ; 26,918 \mathrm{~cm} .^{-1} ; 27,548 \mathrm{~cm}^{-1} ; 27,824 \mathrm{~cm} .^{-1}$; 
Table 20

VISIBLE AND ULTRAVIOLET ABSORPTION OF THE SOLID AT $88^{\circ} \mathrm{K}$.

(Reference 136)

\begin{tabular}{|c|c|c|c|c|c|c|c|}
\hline \multirow[b]{2}{*}{ Band } & \multirow[b]{2}{*}{ Frequency $\left(\mathrm{cm} .^{-1}\right)$} & \multicolumn{2}{|c|}{ Frequency Difference } & \multirow[b]{2}{*}{ Band } & \multirow[b]{2}{*}{ Frequency $\left(\mathrm{cm} .^{-1}\right)$} & \multicolumn{2}{|c|}{ Frequency Difference } \\
\hline & & $\mathrm{cm}^{-1}$ & Between Bands & & & $\mathrm{cm}^{-1}$ & Between Bands \\
\hline $1 \mathrm{a}$ & 24539 & & & $9 a$ & 26809 & & \\
\hline $1 \mathrm{~b}$ & $24606^{*}$ & 614 & $1 b$ and $3 c$ & $9 \mathrm{~b}$ & $26980^{*}$ & & \\
\hline $1 \mathrm{c}$ & 24636 & & & $9 c$ & 27041 & 551 & $9 e$ and $11 e$ \\
\hline $2 a$ & $24721^{*}$ & & & $9 d$ & 27071 & & \\
\hline $2 b$ & 24764 & & & $9 e$ & $27134^{\dagger}$ & & \\
\hline $2 c$ & 24844 & 638 & $2 d$ and $4 c$ & $10 \mathrm{a}$ & 27172 & & \\
\hline $2 d$ & $24937 *$ & & & $10 \mathrm{~b}$ & $27322^{*}$ & 650 & $10 \mathrm{~b}$ and $12 \mathrm{~d}$ \\
\hline $\mathbf{3 a}$ & 25029 & & & $11 a$ & 27397 & & \\
\hline $\mathbf{3 b}$ & $25150 *$ & & & $11 b$ & $27510^{\dagger}$ & & \\
\hline $3 c$ & $25220^{*}$ & 566 & $3 c$ and $5 c$ & $11 \mathrm{c}$ & 27548 & 643 & $11 \mathrm{e}$ and $13 \mathrm{e}$ \\
\hline $3 d$ & 25316 & & & 11d & 27586 & & \\
\hline $4 a$ & 25393 & & & $11 \mathrm{e}$ & $27685^{*}$ & & \\
\hline $4 b$ & 25412 & & & $12 \mathrm{a}$ & $27772 \dagger$ & & \\
\hline $4 \mathrm{c}$ & $25575^{*}$ & 616 & $4 c$ and $6 d$ & $12 b$ & 27840 & & \\
\hline $5 a$ & 25608 & & & $12 \mathrm{c}$ & 27894 & 665 & $12 d$ and $14 c$ \\
\hline $5 \mathbf{b}$ & 25693 & & & $12 d$ & $27972^{*}$ & & \\
\hline $5 c$ & $25786^{*}$ & 634 & $5 c$ and $7 b$ & $13 a$ & 28034 & & \\
\hline $5 d$ & 25808 & & & $\mathbf{1 3 b}$ & $28105^{*}$ & & \\
\hline $6 \mathrm{a}$ & 25987 & & & $13 \mathrm{c}$ & 28231 & 574 & $13 d$ and $15 c$ \\
\hline $6 \dot{\mathrm{b}}$ & $26055^{*}$ & & & $13 d$ & $28328^{\dagger}$ & & \\
\hline $6 c$ & 26144 & 582 & $6 \mathrm{~d}$ and $8 \mathrm{~b}$ & $13 e$ & $28425^{*}$ & & \\
\hline $6 d$ & $26191^{*}$ & & & $14 \mathrm{a}$ & 28490 & & \\
\hline $7 \mathbf{a}$ & 26315 & & & $14 b$ & $28520^{*}$ & & \\
\hline $7 \mathbf{b}$ & $26420^{*}$ & & & $14 \mathrm{c}$ & $28637^{*}$ & & \\
\hline $7 c$ & 26455 & 572 & $7 e$ and $9 e$ & $15 a$ & $28752^{*}$ & & \\
\hline $7 d$ & 26476 & & & $15 \mathrm{~b}$ & 28776 & & \\
\hline 71 & $26562^{\dagger}$ & & & $15 \mathrm{c}$ & $28902^{*}$ & & \\
\hline $8 a$ & 26666 & & & $15 \mathrm{~d}$ & 29070 & & \\
\hline $8 b$ & $26773^{*}$ & 549 & $8 \mathrm{~b}$ and $10 \mathrm{~b}$ & $15 \mathrm{e}$ & 29200 & & \\
\hline
\end{tabular}

*Relatively strong bands.

${ }^{\dagger}$ Very strong bands. 
Table 21

THE VISIBLE AND ULTRAVIOLET ABSORPTION OF THE SOLID AT $293^{\circ} \mathrm{K}$.

(Absorption Zone 4070-3470 ̊)

(Reference 136)

\begin{tabular}{llll}
\multicolumn{3}{c}{ Frequency $\left(\mathrm{cm}^{-1}\right)$} \\
\hline 25297 & 26095 & $26918^{*}$ & 27800 \\
25384 & 26178 & 26976 & 27894 \\
25477 & 26246 & 27063 & 28050 \\
25542 & 26385 & 27134 & 28090 \\
25608 & 26455 & 27249 & 28129 \\
25693 & 26574 & 27322 & 28288 \\
25813 & 26631 & 27510 & 28441 \\
25839 & 26737 & 27548 & 28612 \\
25927 & 26773 & 27700 & 28653
\end{tabular}

* Strong band.

$28,184 \mathrm{~cm}^{-1}$ and $28,409 \mathrm{~cm} .^{-1}$ frequencies. He also states that "most of the intervals between neighboring groups (even as well as uneven) of bands represent the differences of frequencies, which differ from $603 \mathrm{~cm}^{-1}$ by no more than a double error of measure$\left( \pm 2.15 \mathrm{~cm} .{ }^{-1}\right)$ " and that "the differences of frequencies near 200 and $104 \mathrm{~cm}^{-1}$ are also systematically found." The regularity which is mentioned in the latter statement is supposedly shown in the differences which are listed in Table 19. This regularity indicates that there is well-expressed harmony only in regard to the frequency $100 \mathrm{~cm}^{-1}$. For the frequencies $600 \mathrm{~cm} .^{-1}$ and $200 \mathrm{~cm} .^{-1}$, many values were observed which ranged between $570 \mathrm{~cm} .^{-1}$ and $650 \mathrm{~cm} .^{-1}$ and between $180 \mathrm{~cm} .^{-1}$ and $260 \mathrm{~cm} .^{-1}$, respectively. On the basis of these findings, Sheremet'ev concluded that the structure of the $\mathrm{UF}_{6}$ molecule does not completely correspond to the model of a regular octahedron.

Dieke and Duncan ${ }^{45}$ reported that the absorption spectra of thin films of solid $\mathrm{UF}_{6}$ showed no discrete bands, although the film may not have been of a favorable thickness.

Sheremet'ev obtained an absorption spectrum of solid $\mathrm{UF}_{6}$ in the visible and in the neighboring ultraviolet regions at $88^{\circ}$ and $293^{\circ} \mathrm{K}$. using thin (about 0.1 millimeter) films. The results of the measurement at $88^{\circ} \mathrm{K}$. are presented in Table 20 in which the second column gives the maximal frequencies of separate bands. The results of the measurements at $293^{\circ} \mathrm{K}$. are listed in Table 21 . At $88^{\circ} \mathrm{K}$. the absorption spectrum consists of about 60 narrow bands of which nearly half are rather intense. At $293^{\circ} \mathrm{K}$. the spectrum begins to blur, yielding only about 36 narrow bands. The strongest band at $88^{\circ} \mathrm{K}$. is found near the $27,134 \mathrm{~cm} .^{-1}$ frequency, while at $293^{\circ} \mathrm{K}$. the most intense band is found near the $26,918 \mathrm{~cm} \cdot{ }^{-1}$ frequency. The visible and ultraviolet absorption spectra of fused $\mathrm{UF}_{6}$ at $353^{\circ} \mathrm{K}$. obtained using a layer of fused $\mathrm{UF}_{6} 1$ millimeter thick were reported as a continuum with a clear long wave border near $4210 \AA$. 


\section{FLUORESCENCE SPECTRA OF THE SOLID}

The powder fluorescence spectrum (unpolarized) of the $\mathrm{UF}_{6}$ solid was obtained by Dieke and Duncan ${ }^{45}$ with a Hilger E-1 prism spectrograph at $77^{\circ} \mathrm{K}$. At this temperature, solid $\mathrm{UF}_{6}$ which has been excited chiefly by the mercury $3660 \AA$ line shows a bright violet fluorescence. At room temperature the fluorescence disappears. No fluorescence was observed in the vapor after even very long exposures. The fluorescence spectrum reported is presented in Table 22.

Table 22

FLUORESCENCE SPECTRUM OF THE SOLID AT $77^{\circ} \mathrm{K}$.

Bands $\left(\mathrm{cm}^{-1}\right)$

22230

23319

22450

23537

22662

23739

22883

23994

23098

24166 


\section{TRANSPORT PHENOMENA}

\section{DIFFUSION COEFFICIENTS}

\section{SELF-DIFFUSION COEFFICIENT OF THE VAPOR}

Ney and Armistead ${ }^{117}$ determined the quantity $\rho \mathrm{D}$ at $30^{\circ} \mathrm{C}$. in which $\rho$ is the vapor density and $D$ is the diffusion coefficient of material enriched in one isotope which diffuses into normal material contained in an apparatus of known geometry. The enrichment of the vapor was measured with a mass spectrometer. Although $D$ as determined by Ney and Armistead cannot be rigorously defined as a self-diffusion coefficient, it does approximate it. The value of $\rho D$ at $30^{\circ} \mathrm{C}$. was calculated from the experimental $\rho D$ values which were obtained at temperatures between $23.9^{\circ}$ and $27.6^{\circ} \mathrm{C}$. by utilizing a relationship between viscosity and temperature. The authors justified the use of. the viscosity-temperature relationship on the basis of the small size of the correction necessary. The value of $\rho D$ at $30^{\circ} \mathrm{C}$. was reported as $234 \pm 9$ micropoises. Since the investigations were conducted at $30^{\circ} \mathrm{C}$. and approximately $10 \mathrm{~mm}$. $\mathrm{Hg}$ pressure, the approximate density of the vapor under these conditions may be calculated from the ideal gas law (see page 49). The self-diffusion coefficient at $30^{\circ} \mathrm{C}$. and $10 \mathrm{~mm}$. $\mathrm{Hg}$ is then:

$$
\mathrm{D}=\frac{2.34 \times 10^{-1}}{1.86 \times 10^{-4}}=1.26 \mathrm{~cm} .{ }^{2} / \mathrm{sec} \text {. at } 30^{\circ} \mathrm{C} \text {. and } 10 \mathrm{~mm} . \mathrm{Hg}
$$

Using the value 1.32 as the "dimensionless quantity", $\epsilon$, which is equivalent to $\rho \mathrm{D} / \eta$ (kinetic theory) as derived by DeMarcus and Starnes ${ }^{42}$ (see page 49), the quantity $\rho D$ can be determined from the equation:

$$
\rho \mathrm{D} / \eta=1.32
$$

where viscosity, $\eta,=0.6163 \mathrm{~T}^{0.933} \times 10^{-6}$ poise. Values of $\rho \mathrm{D}$ calculated from Equation 13 for temperatures ranging from $30^{\circ}$ to $200^{\circ} \mathrm{C}$. are listed in column 4 of Table 23. Values of $\rho D$ calculated by McMillan ${ }^{114}$ are listed in column 3. Jacobsohn ${ }^{82}$ showed that the

Table 23

\begin{tabular}{|c|c|c|c|}
\hline \multirow[b]{2}{*}{$\begin{array}{l}\text { Temperature } \\
\text { ('K.) }\end{array}$} & \multicolumn{3}{|c|}{$\rho \mathrm{D} \times 10^{6}$ (poise) } \\
\hline & $\begin{array}{l}\text { Observed } \\
\text { (Ref. 117) }\end{array}$ & $\begin{array}{l}\text { Mc Millan* } \\
\text { (Ref. 114) }\end{array}$ & $\begin{array}{c}\text { Calculated } \\
\text { Values } \dagger\end{array}$ \\
\hline 303 & 234 & 265 & 236 \\
\hline 313 & & 274 & \\
\hline 333 & & 290 & 250 \\
\hline 353 & & 306 & 264 \\
\hline 383 & & 330 & 285 \\
\hline 413 & & 352 & 305 \\
\hline 443 & & 378 & 326 \\
\hline 473 & & 402 & 347 \\
\hline
\end{tabular}

\section{SELF-DIFFUSION COEFFICIENT VALUES}

${ }^{*}$ Calculated from $\rho \mathrm{D}=(1.529)\left(0.6163 \mathrm{~T}^{0.933}\right)$

$\dagger$ Calculated from $p D=(1.32)\left(0.6163 \mathrm{~T}^{0.933}\right)$ 
relationship $\mathrm{D}=\epsilon \eta / \rho$ and the assumption $\epsilon=1.50$ were used to derive an expression for the diffusion coefficient $\mathrm{D}$ :

$$
\mathrm{D}=0.0606 \frac{20 \mathrm{~cm} .}{\mathrm{P}(\mathrm{cm} .)}\left[1+6.29\left(\mathrm{t} \times 10^{-3}\right)+9.6\left(\mathrm{t} \times 10^{-3}\right)^{2}\right] \mathrm{cm} \cdot{ }^{2} / \mathrm{sec} .
$$

However, the uncertainty of the viscosity-temperature relationship and of the value of $\epsilon$ used in the Equation 14 limit its usefulness.

\section{DIFFUSION COE F FICIENT INTO AIR}

The coefficient of diffusion of $\mathrm{UF}_{6}$ into air at atmospheric pressure was measured by British workers in $1944 .{ }^{53}$ The $\mathrm{UF}_{6}$ was allowed to diffuse upwards through air in a straight vertical tube and was carried away by a steady flow of air across the top of the tube. The rate of flow was determined and the concentrations at two points of the tube were measured by Katharometers. The diffusion coefficient reported at $19^{\circ} \mathrm{C}$. for concentrations between 3.5 and 6.5 mole percent $U_{6}$ was $0.072 \pm 0.006 \mathrm{~cm}^{2} / \mathrm{sec}$.

\section{SELF-DIFFUSION COEFFICIENT OF THE LIQUID}

Rosen and Whybrew ${ }^{128}$ determined the diffusion coefficient of liquid $\mathrm{UF}_{6}$ at approximately $70^{\circ} \mathrm{C}$. in a manner similar to that used by Ney and Armistead to determine the diffusion coefficient of $\mathrm{UF}_{6}$ vapor. Two halves of a long narrow tube were filled with material having two different concentrations of light constituent, and diffusion was allowed to take place for a definite period of time at a constant temperature. The diffusion coefficient was calculated from the change in mean concentration in each half of the tube. Mass spectrometer techniques were used to measure the change. The result, $1.90 \pm 0.13 \times$ $10^{-5} \mathrm{~cm} .{ }^{2} / \mathrm{sec}$., was reported at a mean temperature of $69.5^{\circ} \mathrm{C}$. The authors state that if the coefficient is in error, "it is more likely to be too high than too low, because, if any disturbing factor were present that tended to bring about mixing, its effect on the concentration distribution would be more or less equivalent to that of an increase in the rate of diffusion." The authors also noted that Cohen's calculated value ${ }^{38}$ for the diffusion coefficient of the liquid is about $5 \times 10^{-5} \mathrm{~cm} .^{2} / \mathrm{sec}$. , which is in the same order of magnitude as the experimental results. The diffusion coefficient was calculated by using an approximate formula given by Powell, Roseveare and Eyring. *

\section{THERMAL DIFFUSION COEFFICIENT}

Nier ${ }^{118}$ attempted to determine the thermal diffusion coefficient in the range between $65^{\circ}$ and $480^{\circ} \mathrm{C}$. by means of a Clausius-type thermal diffusion column. As no appreciable separation was observed, he concluded that the method was not sensitive enough for separation of quantities of $U^{235}$.

That this conclusion is questionable is proved by the temporary use in the United States of a full-scale thermal diffusion plant in the mid-1940's. Some of the major results of the work required to design this plant are referred to elsewhere in this compilation.

\section{VISCOSITY}

\section{VISCOSITY OF THE VAPOR}

The viscosity of $\mathrm{UF}_{6}$ vapor has been investigated a number of times by the capillary flow and the oscillating disk methods. Early reports of viscosity measurements which were obtained by the capillary flow method showed large discrepancies (10 to 20 percent) between the values obtained by the different investigators. After these discrepancies

*Powell, R. E., Roseveare, W. E. and Eyring, H. Ind. Eng. Chem. 33, 430 (1941). 
were resolved, fairly accurate viscosity data in the $40^{\circ}$ to $200^{\circ} \mathrm{C}$. range were obtained by this method. The experimental results are in fair agreement with viscosity data obtained by the oscillating disk method, although the slopes of the viscosity versus temperature curves obtained by the two different methods do not agree. Summaries of the viscosity data are presented in Table 24 and in Figure 7. Some of the details of the various investigations are discussed below.

Fowler ${ }^{61}$ determined the viscosity of $\mathrm{UF}_{6}$ vapor by capillary flow measurements at pressures greater than $760 \mathrm{~mm}$. $\mathrm{Hg}$, whereas Llewellyn and Swaine ${ }^{54}$, Llewellyn ${ }^{106}$, and Roberts ${ }^{127}$ determined its viscosity by the same method but at pressures less than $50 \mathrm{~mm}$. Hg. The results of the investigations conducted at different pressure levels are not in agreement. Fowler's results are considerably higher than those of Llewellyn and Swaine and others.

Cohen ${ }^{37}$ attempted to resolve the differences between the results obtained by Fowler and those of Llewellyn and Swaine. He summarized their data using the following empirical formulae:

$$
\begin{aligned}
& \text { For Llewellyn's data:* } \\
& \eta=2.10 \times 10^{-6} \mathrm{~T}^{0.779}\left(0 \text { to } 200^{\circ} \mathrm{C} \text {. }\right) \\
& \text { For Fowler's data: } \\
& \eta=2.46 \times 10^{-6} \mathrm{~T}^{0.772}\left(85 \text { to } 165^{\circ} \mathrm{C} .\right) \text { (calibrated with air) } \\
& \eta=1.78 \times 10^{-6} \mathrm{~T}^{0.827}\left(150 \text { to } 260^{\circ} \mathrm{C} \text {.) (calibrated with } \mathrm{N}_{2}\right. \text { ) }
\end{aligned}
$$

Upon correlating the two sets of viscosity data with the thermal conductivity and the selfdiffusion coefficients, he found that Llewellyn's results formed a picture more in conformity with what was known about the two mentioned properties. However, since Fowler's data were examined rather rigorously and no systematic errors could be found, Cohen recommended further investigation of all three fundamental constants.

Only after an intensive investigation of the viscosity were Myerson and Eicher ${ }^{116}$ able to determine the cause of the large discrepancies in the viscosity data. They showed that the viscosity of the vapor is essentially independent of pressure under the conditions prevailing during the various investigations, while the Reynolds number is a direct function of pressure. They attributed Fowler's high results to the effect of non-laminar flow. Upon further investigation with a platinum capillary of small diameter, they found that the Reynolds number varies linearly with the time ratio of the flow. Therefore, they determined the viscosities using a platinum capillary, 75 centimeters in length with an inside diameter of 0.03 centimeters. These determinations were made at a Reynolds number less than 100 and in regions of experimentally established non-turbulent flow over the 40 to $200^{\circ} \mathrm{C}$. range. McMillan ${ }^{114}$ expressed Myerson and Eicher's results as:

$$
\eta=0.6163 \mathrm{~T}^{0.933} \text { mic ropoise }
$$

DeMarcus and Starnes ${ }^{42}$, in their report on the intermolecular action of $\mathrm{UF}_{6}$, commented on Myerson and Eicher's viscosity data. They stated that since the capillary flow method does not provide a direct measurement of viscosity, but instead gives a measure of viscosity which is relative to that of air as the standard, the viscosity data of air which was used by Myerson and Eicher should also have been screened according to the Reynolds number criterion. They felt that the reported viscosities of $\mathrm{UF}_{6}$ vapor might have systematic errors because of some uncertainity in the values for the viscosity of air which

\footnotetext{
*Llewellyn's formula for his own data: $\eta=1.67(1+0.0026 \mathrm{t}) \times 10^{-4}$ poise $\left(0\right.$ to $200^{\circ} \mathrm{C}$. $)$
} 


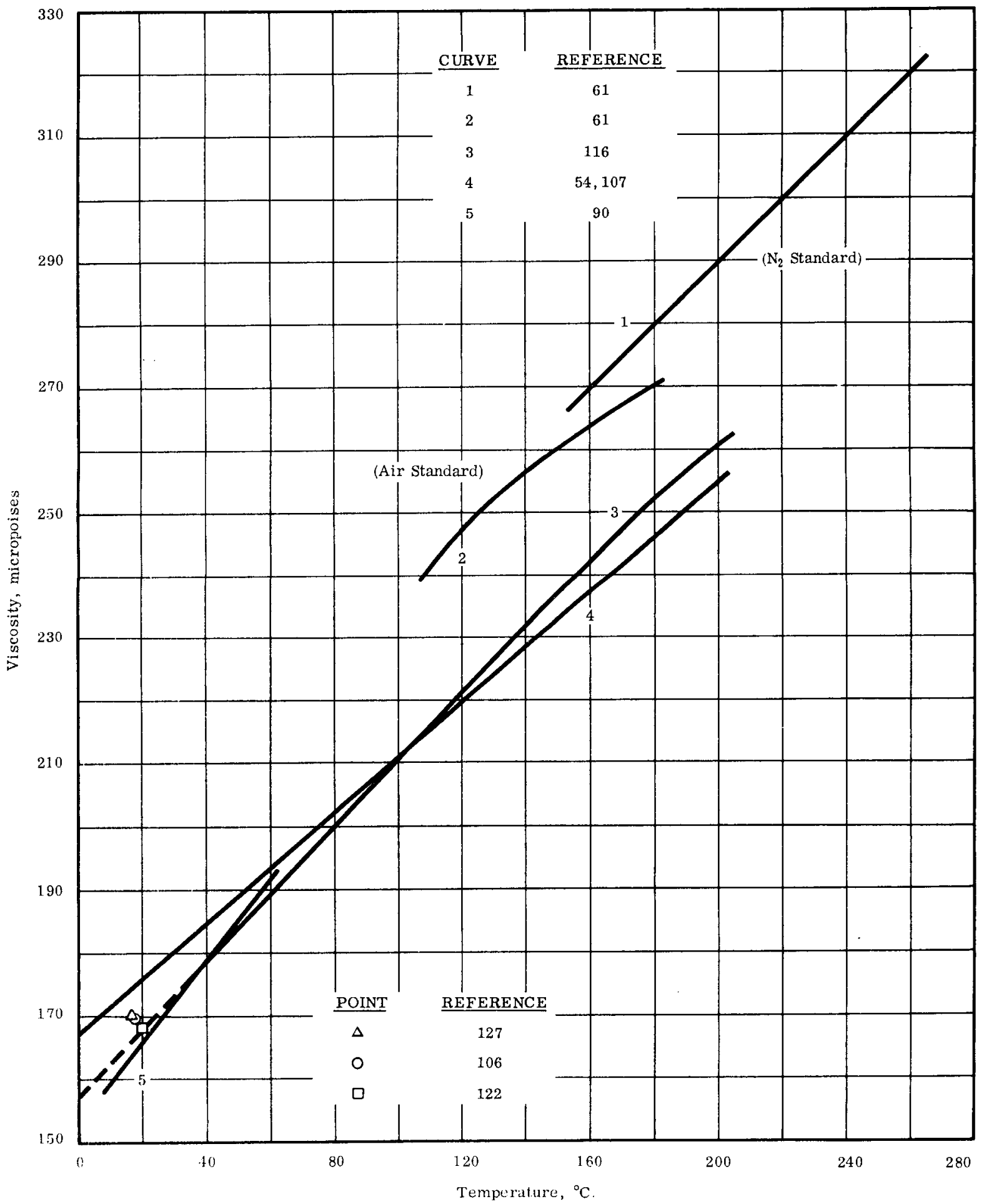

FIG. 7. VISCOSITY OF THE VAPOR 
Table 24

VISCOSITY OF THE VAPOR

$\eta$ (micropoises)

\begin{tabular}{|c|c|c|c|c|c|c|c|c|}
\hline \multirow[b]{2}{*}{$\begin{array}{c}\text { Temperature } \\
\text { (C).) }\end{array}$} & \multirow{2}{*}{$\begin{array}{c}\text { Myerson } \\
\text { and Eicher } \\
\text { (Ref. 116) }\end{array}$} & \multirow[b]{2}{*}{$\begin{array}{l}\text { Kigoshi } \\
\text { (Ref. 90) }\end{array}$} & \multirow{2}{*}{$\begin{array}{c}\text { Liwellyn } \\
\text { and Swaine } \\
\text { (Ref. 54, 107) }\end{array}$} & \multicolumn{2}{|c|}{$\begin{array}{c}\text { Fowler } \\
\text { (Ref. 61) }\end{array}$} & \multirow[b]{2}{*}{$\begin{array}{c}\text { Present } \\
\text { (Ref. 122) }\end{array}$} & \multirow[b]{2}{*}{$\begin{array}{c}\text { Roberts } \\
\text { (Ref. 127) }\end{array}$} & \multirow[b]{2}{*}{$\begin{array}{l}\text { Llwellyn } \\
\text { (Ref. 106) }\end{array}$} \\
\hline & & & & $\begin{array}{l}\text { Air } \\
\text { Std. }\end{array}$ & $\begin{array}{l}\mathrm{N}_{2} \\
\text { Std. }\end{array}$ & & & \\
\hline 0 & & & 167 & & & & & \\
\hline 14.5 & & 162.4 & & & & & & \\
\hline 17 & & & & & & & $170 \pm 3$ & \\
\hline 18 & & & & & & & & $169 \pm 3$ \\
\hline 20 & & & & & & 168 & & \\
\hline 25 & & & 176 & & & & & \\
\hline 26.3 & & 170.1 & & & & & & \\
\hline 35.2 & & 176.0 & & & & & & \\
\hline 40 & 178.7 & & & & & & & \\
\hline 44.7 & & 182.2 & & & & & & \\
\hline 50 & & & 189 & & & & & \\
\hline 60 & 189.0 & & & & & & & \\
\hline 80 & 199.9 & & & & & & & \\
\hline 84.9 & & & & 239.8 & & & & \\
\hline 100.0 & & & 211 & & & & & \\
\hline 104 & & & & 239.9 & & & & \\
\hline 110 & 216.1 & & & & & & & \\
\hline 123.9 & & & & 249.6 & & & & \\
\hline 140 & 231.9 & & & & & & & \\
\hline 144.5 & & & & 258.8 & & & & \\
\hline 150 & & & 233 & & & & & \\
\hline 153.9 & & & & & 266.7 & & & \\
\hline 164.5 & & & & & 271.9 & & & \\
\hline 165.8 & & & & 269.0 & & & & \\
\hline 170 & 248.0 & & & & & & & \\
\hline 186 & & & & & 283.1 & & & \\
\hline 196.3 & & & & & 288.4 & & & \\
\hline 200 & 261.1 & & 255 & & & & & \\
\hline 210 & & & & & 295.6 & & & \\
\hline 219 & & & & & 299.7 & & & \\
\hline 232.2 & & & & & 305.6 & & & \\
\hline 248.0 & & & & & 315.0 & & & \\
\hline 263.0 & & & & & 321.6 & & & \\
\hline
\end{tabular}


were used as standards. Upon comparing the viscosity of air values used by Myerson and Eicher against more recent values which have appeared in the literature, they found agreement up to about $300^{\circ} \mathrm{K}$.; however, values ranged generally between 0.5 percent low at $300^{\circ} \mathrm{K}$. and possibly 1.5 percent high at the upper temperature limit of about $400^{\circ} \mathrm{K}$. They consider it reasonable to assume that the slope of the Myerson-Eicher viscositytemperature curve might be in error by as much as 1.4 percent.

Although Myerson and Eicher's results are in agreement with the results of Fleischman 122 which were determined by the oscillating disc method, they do not compare as favorably with the results of Kigoshi ${ }^{9 \theta}$, which were also determined by the oscillating disc method. Disagreement between the data of Kigoshi and those of Myerson and Eicher is especially apparent in the slopes of the viscosity-temperature curves, which are shown in Figure 7. Since it is not known which of the slopes is the more accurate, the related physical properties of the $U F_{6}$ molecule, such as molecular diameter, rigidity, etc., which were calculated from the viscosity data by Kigoshi must be considered to be somewhat uncertain .

\section{VISCOSITY OF THE LIQUID}

The data on the viscosity of liquid $\mathrm{UF}_{6}$ in the literature are rather scanty and not in agreement. A summary of the viscosity values of the liquid, some which were calculated for this report from proposed viscosity-temperature relationships, is presented in Table 25 and in Figure 8.

Table 25

VISCOSITY OF THE LIQUID

\begin{tabular}{|c|c|c|c|c|c|}
\hline \multirow[b]{2}{*}{$\begin{array}{l}\text { Temperature } \\
\left({ }^{\circ} \mathrm{C} .\right) \\
\end{array}$} & \multicolumn{5}{|c|}{$\eta$ (centipoises) } \\
\hline & $\begin{array}{l}\text { Kirshenbaum* } \\
\text { (Ref. 92) }\end{array}$ & $\begin{array}{c}\text { Simon } \\
\text { (Ref. 135) } \\
\end{array}$ & $\begin{array}{c}\begin{array}{c}\text { Blatt } \\
\text { (Ref. 21) }\end{array} \\
\end{array}$ & $\begin{array}{l}\text { Llewellyn } \\
\text { (Ref. 107) } \\
\end{array}$ & Calculated ${ }^{\dagger}$ \\
\hline 67.2 & $0.731^{*}$ & & & & \\
\hline 67.9 & & & & 0.924 & \\
\hline 70.0 & & 0.91 & & 0.910 & 0.84 \\
\hline 71.5 & & & & 0.902 & \\
\hline 72.5 & $0.692^{*}$ & & & & \\
\hline 72.6 & $0.687 \pm 0.007$ & & & & \\
\hline 72.9 & $0.685^{*}$ & & & & \\
\hline 73.4 & $0.679^{*}$ & & & & \\
\hline 73.9 & & & & 0.892 & \\
\hline 74.5 & & & & 0.880 & \\
\hline 74.6 & & & 0.788 at $347 \mathrm{psi}$. & & \\
\hline 74.7 & $0.669^{*}$ & & & & \\
\hline 75.0 & $0.663^{*}$ & & & & \\
\hline 75.8 & & & 1.035 at 3000 psi.* & & \\
\hline 76.5 & & & & 0.876 & \\
\hline 78.8. & & & & 0.870 & \\
\hline 80.0 & & 0.85 & & & \\
\hline 83.3 & & & & 0.834 & \\
\hline 84.9 & & & & 0.832 & \\
\hline 88.3 & & & & 0.815 & \\
\hline 90.0 & & 0.80 & & & 0.77 \\
\hline 92.2 & & & & 0.794 & \\
\hline 95.7 & & & & 0.770 & \\
\hline 97.8 & & & & 0.766 & \\
\hline 99.0 & & & & 0.752 & \\
\hline 100.0 & & 0.75 & & & \\
\hline 110.0 & & & & & 0.71 \\
\hline 130.0 & & & & & 0.66 \\
\hline 150.0 & & & & & 0.61 \\
\hline 153.0 & & & 0.668 at $400 \mathrm{psi}$ & & \\
\hline 153.5 & & & 0.689 at $3200 \mathrm{psi}$ & & \\
\hline 170.0 & & & & & 0.57 \\
\hline 190.0 & & & & & 0.54 \\
\hline 210.0 & & & Critical point $230.2^{\circ} \mathrm{C}$. & & 0.51 \\
\hline 248.0 & & & 0.552 at $3000 \mathrm{psi}$ & & \\
\hline 250 & & & 0.505 at 1000 psi. & & \\
\hline
\end{tabular}




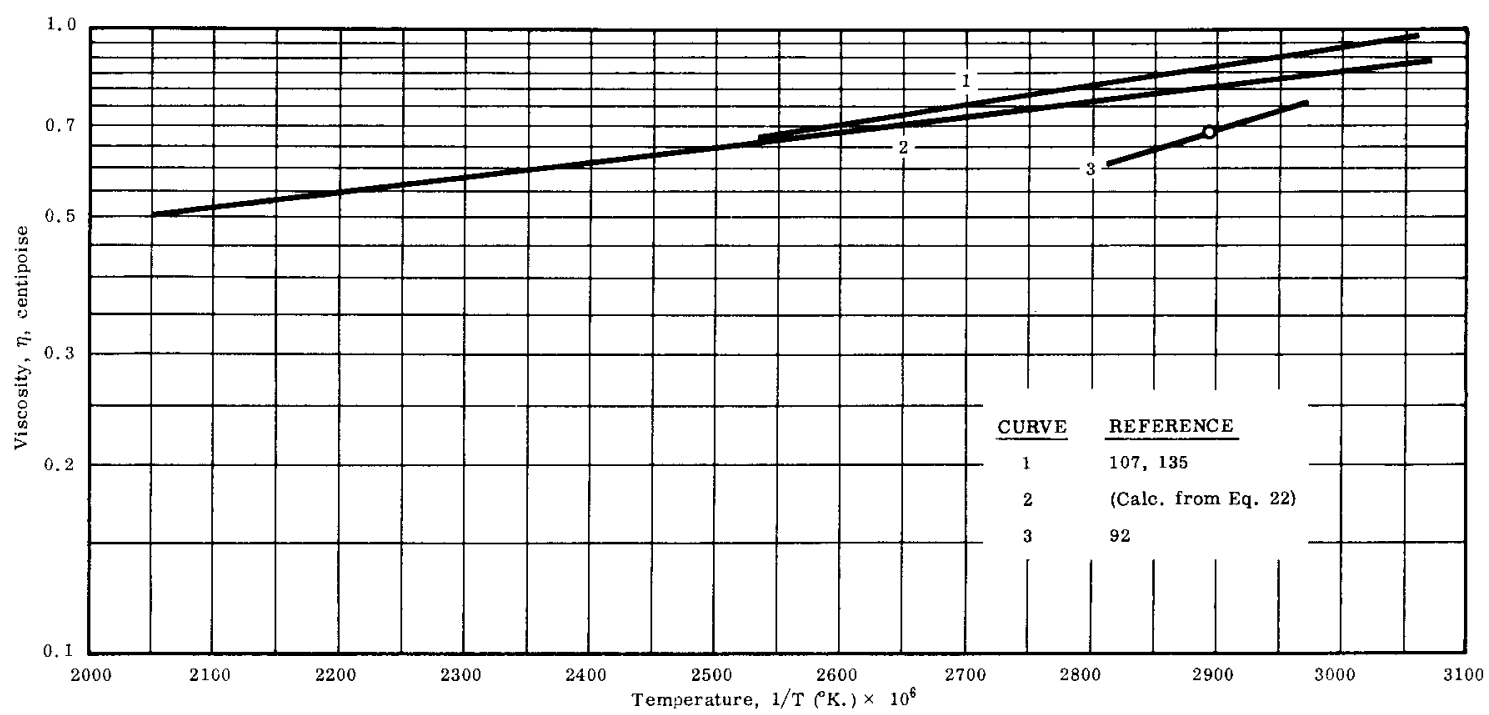

FIG. 8. VISCOSITY OF THE LIQUD

Kirshenbaum ${ }^{92}$ determined the viscosity of liquid $\mathrm{UF}_{6}$ in the $67^{\circ}$ to $75^{\circ} \mathrm{C}$. range by using a modified Ostwald viscosimeter. He stated that since the temperature measurements were uncertain and the total temperature range was small, only a single value of the viscosity at the average temperature should be considered as the final result. The absolute viscosity at $72.6^{\circ} \mathrm{C}$. was reported as $0.687 \pm 0.007$ centipoise. He checked the validity and accuracy of his measurements using the same apparatus to determine the viscosity of known liquids.

Cohen ${ }^{38}$ used an expression:

$$
\eta=A e^{\left(\Delta H_{(v)} / T\right) B}
$$

and assumed that the viscosity of $\mathrm{UF}_{6}$ vapor at its boiling point is the same as that of carbon tetrachloride at its boiling point. From this assumption, he determined the constants $A$ and $B$ for liquid $\mathrm{UF}_{6}$ and obtained the following expression from which he calculated the viscosities of liquid $\mathrm{UF}_{6}$ :

$$
\eta=0.1271 \times 10^{-3} \mathrm{e}^{\left(1.217 \times 10^{3} / \mathrm{T}^{\circ} \mathrm{K} .\right)} \text { poise }
$$

According to Kirshenbaum ${ }^{93}$, this expression gives a viscosity value of 0.43 centipoise at $72.6^{\circ} \mathrm{C}$. compared to the experimental value of 0.687 centipoise.

Blatt ${ }^{21}$ measured the viscosity of theliquid by passing $\mathrm{UF}_{6}$ through a tube of known length and diameter. The material was drawn through the tube by a thermal syphon, and the rate of flow measured by heating the material to a constant temperature and extracting the heat in a calorimeter bath. Blatt discussed the Cohen expression of the data:

$$
\eta=A e^{(\Delta F-P \Delta V) / R T}
$$

where: $\mathrm{A}=1.67 \times 10^{-3}$ poise

$$
\begin{aligned}
& \Delta \mathrm{F}=1100 \mathrm{cal} . / \mathrm{mole} \\
& \Delta \mathrm{V}=28 \mathrm{cc} .
\end{aligned}
$$


Blatt put the expression into the form:

$$
\eta=1.67 \times 10^{-3} \mathrm{e}^{\left(\frac{554-0.023 \mathrm{P}}{\mathrm{T}^{\circ} \mathrm{K} .}\right)}
$$

where $P$ is in pounds per square inch.

Equation 22 was used to calculate viscosity values of the liquid between $70^{\circ}$ and $210^{\circ} \mathrm{C}$. using the vapor pressure values of Oliver and his co-workers ${ }^{119}$. They are presented in Table 25 and in Figure 8 . Viscosity values for the temperatures between $70^{\circ}$ and $100^{\circ} \mathrm{C}$. were reported by $\operatorname{Simon}^{135}$ and are presented in the same table. These values also were later included by Llewellyn ${ }^{107}$.

\section{KINEMATIC VISCOSITY OF MIXTURES OF URANIUM HEXAFLUORIDE AND $\mathrm{C}_{8} \mathrm{~F}_{16}$}

DeMarcus and Hopper ${ }^{41}$ used Eyring's viscosity formula:

$$
\eta=\frac{\mathrm{hN}}{\mathrm{V}} \mathrm{e}^{(\Delta \mathrm{F} / \mathrm{RT})}
$$

where: $h$ is Planck's constant

$\mathrm{N}$ is the Avogadro number

$\mathrm{V}$ is the molar volume

$R$ is the gas constant

$\mathrm{T}$ is the absolute temperature

to derive an expression for determining the kinematic viscosity of $\mathrm{UF}_{6}-\mathrm{C}_{8} \mathrm{~F}_{16}$ mixtures. By converting viscosity to kinematic viscosity and using Eyring's viscosity formula for ideal mixtures, the authors showed that the kinematic viscosity can be represented by:

$$
\eta \text { (mixture) }=\eta_{1}^{\mathbf{x}_{1}} \eta_{2}^{\mathrm{x}_{2}}\left(\frac{\mathrm{M}_{1}^{\mathrm{x}_{1}} \mathrm{M}_{2}^{\mathrm{x}_{2}}}{\mathrm{X}_{1} \mathrm{M}_{1}+\mathrm{X}_{2} \mathrm{M}_{2}}\right)
$$

where subscripts 1 and 2 refer to the pure liquids, $\mathrm{X}_{1}$ and $\mathrm{X}_{2}$ being the respective mole fractions. Since the necessary data for calculating the kinematic viscosities from the above equation were not available, calculation of actual kinematic viscosity values of the mixtures was not attempted.

\section{THERMAL CONDUCTIVITY}

\section{THERMAL CONDUCTIVITY OF THE VAPOR}

The thermal conductivity values of $\mathrm{UF}_{6}$ vapor have been determined by various investigators with respect to known conductivities of other vapors at temperatures ranging between $0^{\circ}$ and $125^{\circ} \mathrm{C}$. The experimental values, most of which were obtained by the "hot wire" method, were reported to compare favorably with the values calculated from viscosity and heat-capacity data. The average of the experimental and calculated values, which was taken on an equal-weight basis, is represented by the following equation:

$$
\mathrm{K}_{\mathrm{av}}=1.46\left(1+0.0042 \mathrm{t}^{\circ} \mathrm{C} .\right) \times 10^{-5} \mathrm{cal} . / \mathrm{cm} \text {. sec. }{ }^{\circ} \mathrm{C} \text {. }
$$

Equation 25 was reported as representing the most reliable thermal conductivity values for temperatures between $0^{\circ}$ and $100^{\circ} \mathrm{C}$. A summary of all the reported experimental and calculated results is presented in Table 26 and Figure 9. The individual thermal conductivity investigations are discussed in more detail below. 
Table 26

THERMAL CONDUCTIVITY OF THE VAPOR

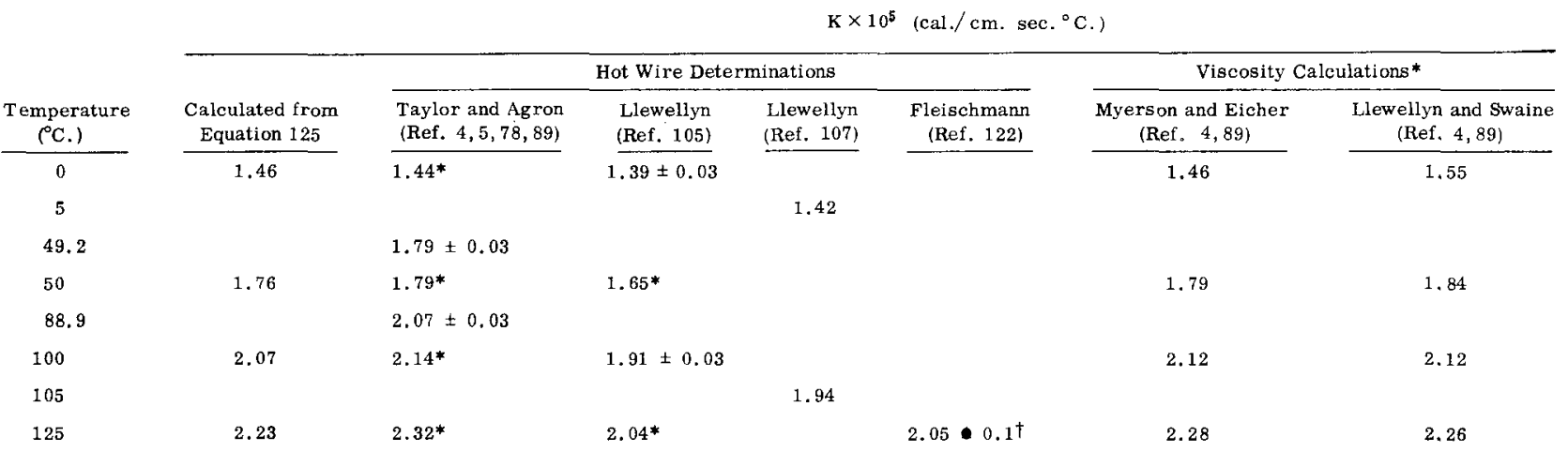

* Calculated from the representative equations.

†obtained by R. D. Present.

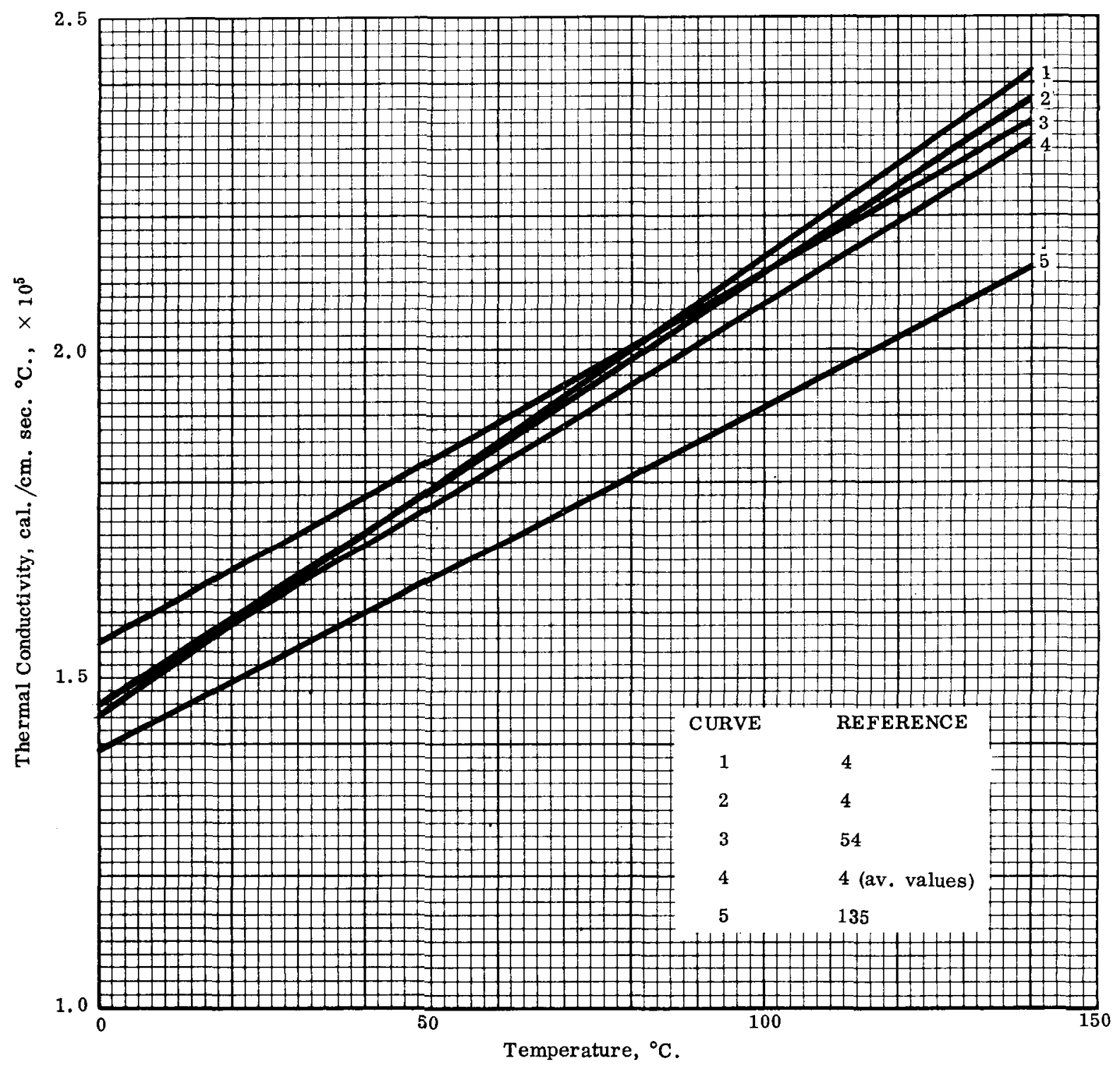

FIG. 9. THERMAL CONDUCTIVITY OF THE VAPOR 
Agron and Taylor 4, 5, 78, 89 found, by the "hot wire" method, that the thermal conductivities of $\mathrm{UF}_{6}$ vapor measured relative to argon and nitrogen at $49.2^{\circ}$ and $88.9^{\circ} \mathrm{C}$. were $1.79 \pm 0.03 \times 10^{-5}$ and $2.07 \pm 0.03 \times 10^{-5} \mathrm{cal} . / \mathrm{cm}$. sec. ${ }^{\circ} \mathrm{C}$., respectively. The thermal conductivity values of the standards, argon and nitrogen, which were used in these determinations were $K=3.850\left(1+0.0031 t^{\circ} \mathrm{C}.\right)$ and $K=5.760\left(1+0.0027 t^{\circ} \mathrm{C}.\right)$, respectively. The authors expressed their results for temperatures between $0^{\circ}$ and $100^{\circ} \mathrm{C}$. by the following equation:

$$
\mathrm{K}=1.45\left(1+0.0048 \mathrm{t}^{\circ} \mathrm{C} .\right) \times 10^{-5} \mathrm{cal} . / \mathrm{cm} \text {. sec. }{ }^{\circ} \mathrm{C} \text {. }
$$

The results of Llewellyn ${ }^{107,135}$ which were $1.42 \pm 0.03$ and $1.94 \pm 0.03 \mathrm{cal} . / \mathrm{cm}$. sec. ${ }^{\circ} \mathrm{C}$. at $5^{\circ}$ and $105^{\circ} \mathrm{C}$., respectively, are somewhat lower than those of Agron and Taylor. Since the method of measurement is the same in each case, the discrepancy between the results of Llewellyn and those of Agron and Taylor may have been caused by a different choice of thermal conductivity values for the standards. Agron and Taylor represented Llewellyn's results ${ }^{107}$ (see also Simon ${ }^{135}$ ) by the following expression:

$$
\mathrm{K}=1.39\left(1+0.0037 \mathrm{t}^{\circ} \mathrm{C} .\right) \times 10^{-5} \mathrm{cal} . / \mathrm{cm} \text {. sec. }{ }^{\circ} \mathrm{C} \text {. }
$$

Present ${ }^{122}$, in his report on Fleischmann's measurement of thermal conductivity, showed that Fleischmann's reported value is in error because of the temperature and pressure corrections and the neglect of convection losses. With the proper correction and with $7.3 \times 10^{-5} \mathrm{cal}$. $/ \mathrm{cm}$. sec. ${ }^{\circ} \mathrm{C}$. as the thermal conductivity of the $\mathrm{N}_{2}$ standard, the thermal conductivity of $\mathrm{UF}_{6}$ at $100^{\circ} \mathrm{C}$. was established as $2.05 \pm 0.10 \times 10^{-5} \mathrm{cal} . / \mathrm{cm}$. sec. ${ }^{\circ} \mathrm{C}$. and found to compare favorably with other values of the vapor from viscosity values, heat capacity values which were obtained from spectroscopic data ${ }^{2 a}$, and the Eucken equation:

$$
\mathrm{K}=\frac{1}{4}\left(9 \mathrm{C}_{\mathrm{p}} / \mathrm{C}_{\mathrm{v}}-5\right) \eta \mathrm{C}_{\mathrm{V}}
$$

Conductivity values obtained from Myerson and Eicher's Viscosity data ${ }^{116}$ and the Eucken equation are in agreement with Agron and Taylor's experimental results. The results calculated from viscosity data are given in Table 26 and are expressed by the following equations :

$$
\begin{aligned}
& \mathbf{K}=1.46\left(1+0.0045 \mathrm{t}^{\circ} \mathrm{C} .\right) \times 10^{-5} \mathrm{cal} . / \mathrm{cm} \text {. sec. }{ }^{\circ} \mathrm{C} \text {. (Myerson and Eicher }{ }^{116} \\
& \left.\mathbf{K}=1.55\left(1+0.0037 \mathrm{t}^{\circ} \mathrm{C} .\right) \times 10^{-5} \mathrm{cal} . / \mathrm{cm} \text {. sec. }{ }^{\circ} \mathrm{C} \text {. (Llewellyn and Swaine }{ }^{54}\right)
\end{aligned}
$$

Taylor and Agron averaged Equations 26, 27, 29 and 30 on an equal-weight basis to obtain the most probable values for the thermal conductivity of $\mathrm{UF}_{6}$ vapor between $0^{\circ}$ and $100^{\circ} \mathrm{C}$. (see Equation 25).

\section{THERMAL CONDUCTIVITY OF THE LIQUD}

Priest ${ }^{123}$ found that the thermal conductivity of liquid $\mathrm{UF}_{6}$ at $72^{\circ} \mathrm{C}$. was $3.83 \times 10^{-4}$ cal. /cm. sec. ${ }^{\circ} \mathrm{C} . \pm 3$ percent. This value was obtained by averaging the results calculated from heat input over a temperature range the midpoint of which was $72^{\circ} \mathrm{C}$. A liquid, said by Priest to have properties known to be similar to those of $U_{6}$, was used to check the apparatus.

Cohen $^{38}$ used the Bridgeman-Eyring formula to represent the thermal conductivity of the liquid. He found that the thermal conductivity of the liquid varied linearly with temperature.

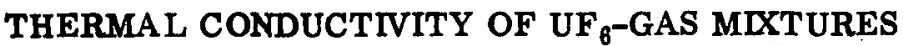

Llewellyn ${ }^{105}$ determined the variation of thermal conductivity with composition of $\mathrm{UF}_{6^{-}}$ air mixtures at $5^{\circ} \mathrm{C}$. by a "hot wire" method. The results, which were read from a smooth curve, are shown in Table 27 and plotted in Figure 10. 
Table 27

THERMAL CONDUCTIVTTY OF URANIUM HEXAFLUORIDE - AIR MIXTURES

Percent $\mathrm{UF}_{6}$

0

20

40

60

80

100
Conductivity (cal./cm. sec. $\left.{ }^{\circ} \mathrm{C}.\right)$

$5.90 \times 10^{-5}$

$4.50 \times 10^{-5}$

$3.45 \times 10^{-5}$

$2.60 \times 10^{-5}$

$2.00 \times 10^{-5}$

$1.42 \times 10^{-5}$

5

6

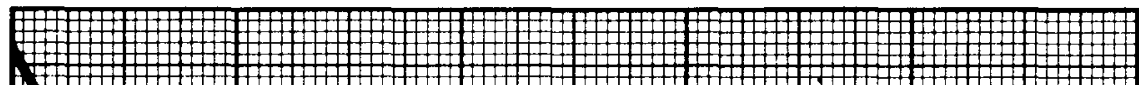

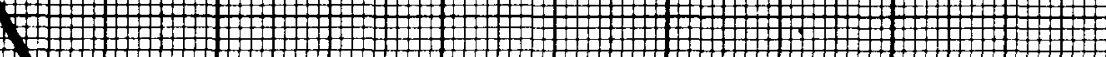

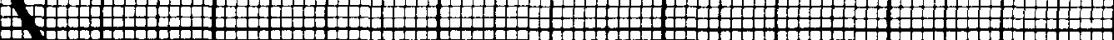

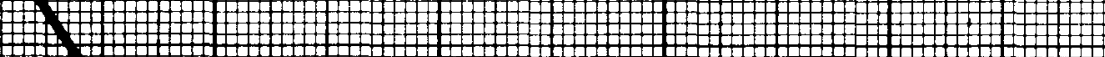
(แ)

\begin{tabular}{c|}
0 \\
0 \\
$\times$ \\
0 \\
0 \\
0
\end{tabular}

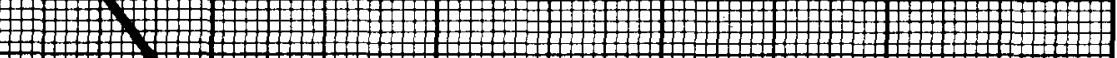

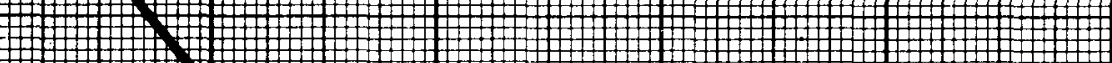
\)

\&

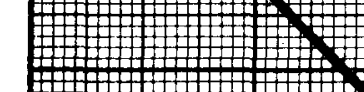
红

घं

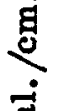
(1)

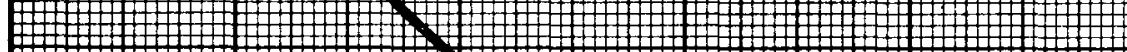
(๒)

3

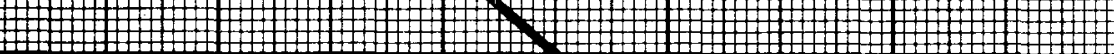

营

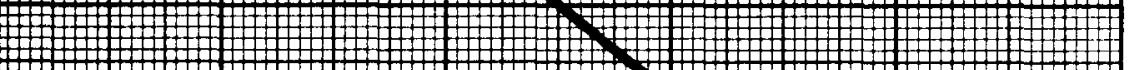

줄

2

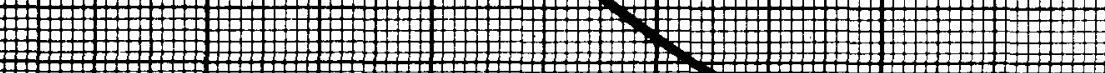

-

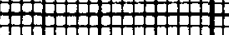

(2)

I

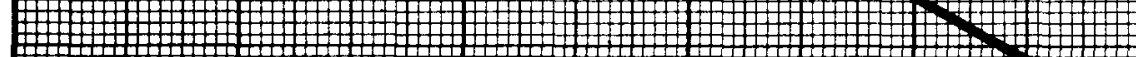

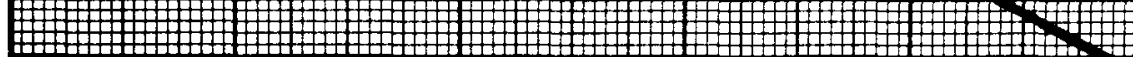
\

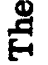

1 (K)

1

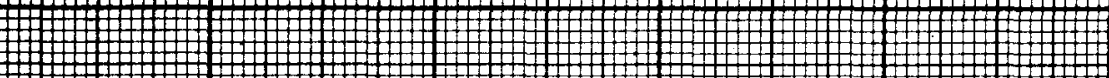

\\

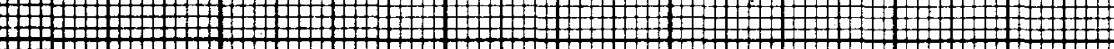
(ֻ)

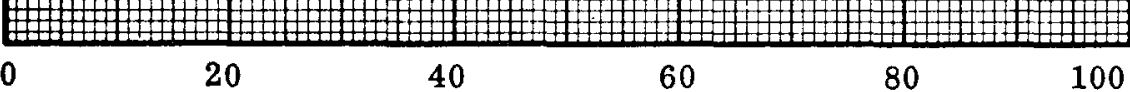

Mole Percent $\mathrm{UF}_{6}$

FIG. 10. THERMAL CONDUCTIVITY OF URANIUM HEXAFLUORIDE AIR MIXTURES 
Greenspan, Roach, and Riseman ${ }^{69}$ found that thermal conductivity of $\mathrm{UF}_{6}$-nitrogen mixtures could be used to make continuous analyses of flowing $U_{F_{6}}$-nitrogen mixtures. For the pure components they obtained a reproducibility of at least 0.1 mole percent. They did not report actual thermal conductivity values.

\section{MEAN FREE PATH}

An expression has been reported ${ }^{88}$ from which values of the mean free path at various temperatures and pressures can be calculated, although no reference is given to indicate the source. Approximate values of the mean free path which were independently calculated from related physical properties are presented at various temperatures and pressures. The values presented here were calculated to establish the order of magnitude of the mean free path. Values calculated at standard temperatures and pressures are given in Table 28. Values calculated at temperatures of $0^{\circ}, 30^{\circ}$ and $130^{\circ} \mathrm{C}$. and at pressures from 0.2 to 2.0 atmospheres are presented in Table 29 and in Figure 11.

Table 28

\section{CALCULATED MEAN FREE PATHS AT STANDARD PRESSURE AND TEMPERATURE*}

\begin{tabular}{llc}
\multicolumn{1}{c}{ Relationship } & \multicolumn{1}{c}{ Values at $0^{\circ} \mathrm{C}}$. & $\begin{array}{c}\text { Mean Free } \\
\text { Path } \\
\left(\times 10^{6}\right)\end{array}$ \\
Viscosity & $1.55 \times 10^{-4} \mathrm{~g} \cdot / \mathrm{cm}$. sec. ${ }^{*}$ & 2.31 \\
Thermal conductivity & $1.46 \times 10^{-5} \mathrm{cal} . / \mathrm{cm}$. sec. ${ }^{\dagger}$ & 2.70 \\
Thermal diffusion & $1.59 \times 10^{-2} \mathrm{~cm} .^{2} / \mathrm{sec} . \ddagger$ & 3.73 \\
Molecular diameter & $4.20 \times 10^{-8} \mathrm{~cm} . \xi$ & 4.73 \\
Dimensionless quantity & $\epsilon=1.32 / /$ & 3.05 \\
Equation 31 & & 1.66
\end{tabular}

* Obtained by averaging the viscosity value of Myerson and Eicher with that of Kigoshi.

†Obtained from the equation: $K_{(a v)}=1.46\left(1+0.0042 \mathrm{t}^{\circ} \mathrm{C}.\right) 10^{-5} \mathrm{cal} . / \mathrm{cm} . \mathrm{sec} .{ }^{\circ} \mathrm{C}$.

$¥$ Obtained from equation: $D=0.0606 \frac{20 \mathrm{~cm} \text {. }}{\mathrm{p} \mathrm{cm} \text {. }}\left[1+6.29\left(\mathrm{t} \times 10^{-3}\right)+9.6\left(\mathrm{t} \times 10^{-3}\right)^{2}\right]$ cm. $2 /$ sec.

$\xi$ Obtained from Kigoshi. ${ }^{90}$

/Suggested by DeMarcus and Starnes (Ref. 42). Values of the other constants used in

$$
\text { the calculations are: } \begin{aligned}
\bar{c} & =1.281 \times 10^{4} \mathrm{~cm} . / \mathrm{sec} . \\
\rho & =1.57 \times 10^{-2} \mathrm{~g} . / \mathrm{cm}^{3} \\
\mathrm{C}_{\mathrm{v}} & =28.3 \mathrm{cal} . / \mathrm{g} .
\end{aligned}
$$


Table 29

MEAN FREE PATHS CALCULATED ON THE BASIS OF THE TRANSPORT PROPERTIES

\begin{tabular}{|c|c|c|c|c|c|}
\hline \multirow[b]{2}{*}{$\begin{array}{c}\text { Temperature } \\
\left({ }^{\circ} \mathrm{C} .\right)\end{array}$} & \multirow[b]{2}{*}{$\begin{array}{c}\text { Pressure } \\
\text { (atm.) }\end{array}$} & \multicolumn{4}{|c|}{$1 \times 10^{6}(\mathrm{~cm} .)^{*}$} \\
\hline & & $\begin{array}{c}\text { Dimensionless } \\
\text { Quantity }^{\dagger}\end{array}$ & $\begin{array}{c}\text { Thermal } \\
\text { Conductivity }\end{array}$ & Viscosity $\xi$ & $\begin{array}{c}\rho D=234 \\
\text { Micropoise }\end{array}$ \\
\hline \multirow[t]{5}{*}{0} & 0.2 & 15.26 & 13.49 & 11.56 & \\
\hline & 0.6 & 5.09 & 4.49 & 3.85 & \\
\hline & 1.0 & 3.05 & 2.29 & 2.31 & \\
\hline & 1.4 & 2.18 & 1.97 & 1.65 & \\
\hline & 2.0 & 1.53 & 1.38 & 1.16 & \\
\hline \multirow[t]{5}{*}{30} & 0.2 & 17.13 & 14.76 & 12.94 & 17.55 \\
\hline & 0.6 & 5.54 & 4.77 & 4.18 & 5.67 \\
\hline & 1.0 & 3.27 & 2.81 & 2.47 & 3.35 \\
\hline & 1.4 & 2.29 & 1.98 & 1.73 & 2.35 \\
\hline & 2.0 & 1.57 & 1.35 & 1.18 & 1.61 \\
\hline \multirow[t]{5}{*}{130} & 0.2 & 26.99 & - & 20.40 & \\
\hline & 0.6 & 8.93 & -- & 6.76 & \\
\hline & 1.0 & 5.32 & -- & 4.03 & \\
\hline & 1.4 & 3.75 & -- & 2.84 & \\
\hline & 2.0 & 2.61 & -- & 1.98 & \\
\hline
\end{tabular}

*Density of $\mathrm{UF}_{6}$ vapor at $0^{\circ}$ calculated from ideal gas law. Density of $\mathrm{UF}_{6}$ vapor at $30^{\circ}$ and $130^{\circ}$ calculated from Magnuson equation of state (Ref. 110).

$\dagger \frac{\mathrm{D}}{\eta}=1.32$ value suggested by DeMarcus and Starnes (Ref. 42).

$\mathrm{f}_{\mathrm{K}}$ values obtained from the equation: $\mathrm{K}_{(\mathrm{av})}=1.46\left(1+0.0042 \mathrm{t}^{\circ} \mathrm{C}.\right) \times 10^{-5} \mathrm{cal} . / \mathrm{cm} . \mathrm{sec} .{ }^{\circ} \mathrm{C}$.

$\xi_{\eta}$ values at $0^{\circ}$ and $30^{\circ}$ are averages of Myerson and Eicher data with those of Kigoshi. $\eta$ values at $130^{\circ}$ are Myerson and Eicher data.

Values of the mean free path are reported in the Kellex Corporation Technical Data Book and the Carbide and Carbon Chemicals Corporation Technical Data Book. ${ }^{120}$ No information is given in either book to indicate where or how the figures were obtained. Jacobsohn ${ }^{82}$ reported the following equation which represents the mean free path values for temperatures from $0^{\circ}$ to $200^{\circ} \mathrm{C}$.:

$$
1=\frac{20 \mathrm{~cm} .}{\mathrm{p} \mathrm{cm} .} \quad(6.32)\left[1+4.45\left(\mathrm{t} \times 10^{-3}\right)+3.1\left(\mathrm{t} \times 10^{-3}\right)^{2}\right] \times 10^{-6} \mathrm{~cm} .
$$




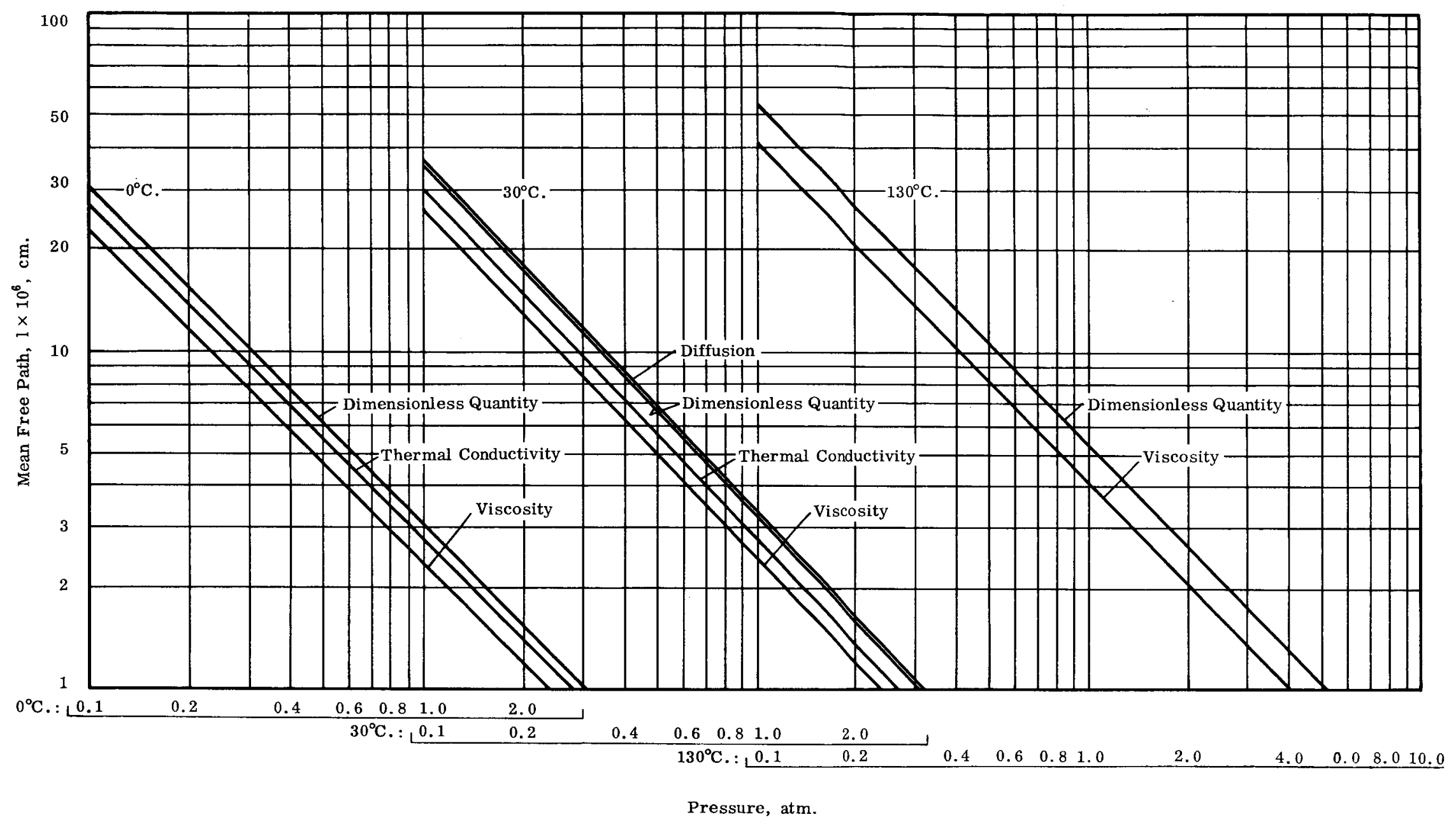

FIG. 11. ESTIMATED MEAN FREE PATHS AT VARIOUS TEMPERATURES 
Values of the mean free path calculated from this equation are lower than the estimates given in this report but are of the same order of magnitude.

The mean free path can be related to the viscosity, $\eta$; the thermal conductivity, $K$; the coefficient of self-diffusion, $\mathrm{D}$; and the molecular diameter, $\sigma$; by application of the kinetic theory as shown by Jeans.* The relationships, which are only first approximations, are as follows:

$$
\begin{array}{ll}
\text { Viscosity } & \eta=1 / 3 \rho \overline{\mathrm{c}} \mathrm{l} \\
\text { Thermal conductivity } & \mathrm{K}=1 / 3 \rho \overline{\mathrm{c}} \mathrm{l} \mathrm{C}_{\mathrm{v}} \\
\text { Diffusion } & \mathrm{D}=1 / 3 \overline{\mathrm{c}} \mathrm{l} \\
\text { Molecular diameter } & \sigma^{2}=1 / \sqrt{2} \pi \eta \mathrm{l}
\end{array}
$$

where $\rho$ is the density of the gas, $\bar{c}$ is the mean velocity which can be calculated from the equation:

$$
\overline{\mathrm{c}}=\sqrt{8 \mathrm{RT} / \pi \mathrm{M}}
$$

$\eta$ is the number of molecules in a unit volume, and $\mathrm{C}_{\mathrm{v}}$ is the heat capacity at constant volume.

Comparison of Equations 32 and 33 indicates that $K$ should be equal to $\eta C_{v}$, although the experimental measurements indicate that $\mathrm{K}$ is slightly greater. Comparison of Equations 32 and 34 indicates that $\rho \mathrm{D} / \eta=1$, but, as might be expected, the experimental data indicate that the ratio should be greater than 1 . These differences are shown by Jeans to be caused by factors which are neglected in the simple kinetic theory. Jeans also shows that Equations 32 and 34 contain two sources of error, the first error arising from the assumption that the mean free path is the same for all velocities, and the second from neglect of the persistence of velocities.

Upon correcting $D$ and $\eta$ for persistence, Jeans found that:

$$
\rho \mathrm{D} / \eta=1.34
$$

The value of this quantity, the "dimensionless quantity" (see page 49), is in agreement with the experimental results $(1.35 \pm 0.05)$ and the calculated results of DeMarcus and: Starnes $^{42}(1.32)$.

Mean free path values obtained through the relationships listed above at standard conditions are presented in Table 28. Also given are values which were used in the calculations of the physical properties and constants at standard conditions. In the list of the mean free path values, it is apparent that values are of the same order of magnitude. The values obtained from viscosity and thermal conductivity data agree with those obtained from the dimensionless quantity. The mean free path values calculated from thermal conductivity and viscosity data are 13 and 30 percent lower, respectively, than those calculated using the dimensionless quantity. Values were also obtained from viscosity, thermal conductivity, and dimensionless quantity data at temperatures of $0^{\circ}, 30^{\circ}$ and $130^{\circ} \mathrm{C}$. for pressures ranging from 0.2 to 2.0 atmospheres. These values are presented in Table 29 and Figure 11.

\footnotetext{
*Jeans, J. H. The Dynamic Theory of Gases. 4th ed. London, Dover Publications, Inc., 1954.
} 


\section{INTERMOLECULAR FORCE MODELS}

A number of force models for $\mathrm{UF}_{6}$ molecules have been proposed by various investigators in their attempts todescribe the behavior of the vapor by correlating experimental values of the transport properties; i.e., viscosity, self-diffusion, and thermal conductivity. The force models and the values of the constants which were employed are listed. in Table 30 .

Even though on the basis of the kinetic theory of gases it appears that the dimensionless quantity, $\rho D / \eta$, should be equal to a constant, $\epsilon$, which is dependent on the forces between the molecules in a vapor, force laws based on values of the dimensionless quantity alone are likely to give ambiguous results. Amdur ${ }^{6}$ briefly summarized the reasons for the ambiguity as follows: "First at laboratory temperatures, the transport properties of gases depend upon molecular inter-actions which must be represented as a combination of attractive and repulsive forces. Second, it is possible to obtain.essentially the same $\rho D / \eta$ values for different molecular-force models which are not demonstrably equivalent." Since most of the force models which have been proposed for $U F_{6}$ are based, primarily, on viscosity data, the models and data based on them should be used with caution. Of the force models which have been proposed, the Lennard-Jones 6-12 model, fitted with force constants which were estimated from viscosity measurements, from empirical correlations, from the free-volume theory of liquids, and from existing estimates of the second virial coefficient, appears to describe the behavior of $\mathrm{UF}_{6}$ molecules most satisfactorily.

DeMarcus and Starnes ${ }^{42}$ employed the Lennard-Jones 6-12 force model to derive an approximate expression for the intermolecular potential between two $\mathrm{UF}_{6}$ molecules the mass centers of which are $R(\mathrm{~cm}$.$) apart:$

$$
\phi(R)=\frac{9.9937 \times 10^{-101}}{R^{12}}-\frac{4.9216 \times 10^{-57}}{R^{6}} \text { ergs }
$$

This expression was estimated from viscosity measurements obtained from empirical correlations, from the free-volume theory of liquids, and from existing estimates of the second virial coefficient. The expression is reported to be independent of isotopic species and of relative orientation of the two molecules. The dimensionless quantity, $\rho D / \eta$, was determined by using theoretically derived values of the parameters $\epsilon$ and $R_{0}$ of the Lennard-Jones 6-12 model in the form:

$$
\phi(R)=4 \epsilon\left[\left(R_{0} / R\right)^{12}-\left(R_{0} / R\right)^{6}\right] \text { ergs }
$$

For the values $\epsilon / \mathrm{k}=439^{\circ} \mathrm{K}$, and $\mathrm{R}_{\mathrm{O}}=5.2232 \times 10^{-8} \mathrm{~cm}$., the dimensionless quantity was determined to be 1.32. This value was found to be in agreement with the experimental results (1.36) which were calculated from the viscosity data of Myerson and Eicher ${ }^{116}$ and the $\rho D$ data of Ney and Armistead ${ }^{117}$. Values of theoretical viscosities, computed using the above values of $\epsilon / k$ and $R_{0}$ and the equation given by Hirschfelder, Bird, and Spots* for the viscosity of a single component gas, were found to compare favorably with the experimental viscosity values obtained by Myerson and Eicher.

McMillan ${ }^{14}$ applied the inverse force model, in which the interaction force has only one replusion term, $F=\mathrm{Xr}^{-9}$, in an attempt to explain the behavior of $\mathrm{UF}_{6}$ vapor between $40^{\circ}$ and $200^{\circ} \mathrm{C}$. From this force model, the viscosity can be represented by:

$$
\eta=\mathrm{AT}^{\mathrm{n}}=\frac{5}{8}\left(\frac{\mathrm{kmT}}{\pi}\right)^{1 / 2}\left(\frac{2 \mathrm{kT}}{\mathrm{X}}\right)^{2 / \nu-1} / \mathrm{A}_{2}{ }^{(\nu)} \Gamma\left(4-\frac{2}{\nu-1}\right)
$$

*Hirschfelder, J. O., Bird, R. D., and Spots, E. L. J. Chem. Phys, 16, 968(1948). 
Using the viscosity data reported by Myerson and Eicher, McMillan obtained $A=0.6163$ and $\mathrm{n}=0.933$, or:

$$
\eta=0.6163 \mathrm{~T}^{0.933}
$$

From Equation 40 and the equations for force and the potential energy of the inverse force model, McMillan obtained the values $\nu=5.6$ and $\epsilon=1.529$ or:

$$
\rho \mathrm{D} / \eta=1.529
$$

The value of $\rho \mathrm{D}$ at $30^{\circ} \mathrm{C}$. calculated from Equation 42 does not compare favorably with the experimental value.

Treating the potential energy function, $U(r)=\lambda r^{-8}$, of the inverse force model as having spherical symmetry, McMillan calculated the second virial coefficient, $B_{v}$, in the equation of state:

$$
P V=A_{V}+B_{V} V^{-1}+C_{V} V^{-2}
$$

by means of the expression:

$$
\mathrm{B}=\frac{2 \pi}{3} \Gamma\left[\frac{\mathrm{S}-3}{8}\right]\left[\frac{\lambda}{\mathrm{kT}}\right]^{3 / 8}
$$

in which $\mathrm{B}_{\mathrm{V}} / \mathrm{A}_{\mathrm{V}}=\mathrm{B} \nu_{\mathrm{o}}$ and $\nu_{\mathrm{O}}$ is the density of molecules for each cubic centimeter under normal conditions, resulting in:

$$
\log B_{V} / A_{V}=-1.383-0.653 \log T
$$

From Equation 45 , the value of $\mathrm{B}_{\mathrm{V}} / \mathrm{A}_{\mathrm{V}}$ at $0^{\circ} \mathrm{C}$. is of the order of $10^{-3}$, indicating that $\mathrm{UF}_{6}$ behaves as an ideal gas in the first approximation.

Kigoshi ${ }^{90}$ obtained estimates of the molecular diameter, the rigidity, and the Sutherland constant for $U_{F}$ vapor by fitting the experimental viscosity values to the Sutherland formula:

$$
\eta=\mathrm{C} \mathrm{T}^{3 / 2} /(\mathrm{T}+\mathrm{S})
$$

by using the constants $\mathrm{C}=28.44 \times 10^{-6}$ and $\mathrm{S}=566.8$

where:

$$
C=5 / 16 \sigma^{2}(\mathrm{~km} / \mathrm{h})^{1 / 2}
$$

From Equation 47, where $\mathrm{k}$ is the Boltzmann constant, $\sigma$ is the molecular diameter, and $m$ is the mass of the molecule, the value of the molecular diameter, $\sigma=4.29 \mathrm{~A}$, of $\mathrm{UF}_{6}$ was obtained. Assuming the observed viscosities are proportional to $\mathrm{T} S$, Kigoshi set $\mathrm{S}$ equal to 1.16 and determined the rigidity, $\nu$, of the molecule from the equation:

and

$$
\begin{aligned}
& S=1 / 2+2 /(\nu-1) \\
& \nu=4.03
\end{aligned}
$$

These values should be also used with caution, for as Amdur ${ }^{6}$ pointed out, the temperature variation of the coefficient of viscosity, $\eta \propto \mathrm{T}^{\left[\frac{1}{2}+2 /(\nu-1)\right]}$, for point-repelling molecules provides no better information about the law of force than does the ratio $\rho D / \eta$ or the temperature dependence of " $D$ " if it were known.

Cohen ${ }^{37}$ employed the repulsive force law, $f=\lambda_{n} / r^{n}$, where $\lambda_{n}$ is the force constant and $r$ is the distance between molecules, and the viscosity data which was then available to determine the values of the dimensionless quantity and the values of $n$. These values are listed in Table 30. Cohen also employed the attraction-repulsion force law, 
Table 30

\begin{tabular}{|c|c|c|c|c|c|c|c|}
\hline $\begin{array}{l}\text { Temperature } \\
\left({ }^{\circ} \mathrm{C} .\right)\end{array}$ & Force Model & $\rho \mathrm{D} / \eta$ & $\underline{\eta}$ & $\mathrm{s}$ & $\lambda\left(\right.$ erg cm..$\left.^{12}\right)$ & $\mu\left(\mathrm{erg} \mathrm{cm} . .^{6}\right)$ & Reference \\
\hline \multirow[t]{3}{*}{30} & \multirow{3}{*}{$\begin{array}{l}\text { Inverse Force } \\
\text { (Eq. 38) and the } \\
\text { Attractive-Repulsive } \\
\text { type (Eq. 39). }\end{array}$} & 1.31 & 20 & 29 & -- & -- & 38 \\
\hline & & 1.16 & -- & -- & -- & -- & 38 \\
\hline & & 1.18 & -- & - & -- & -- & 38 \\
\hline 30 to 200 & $\begin{array}{l}\text { Lennard-Jones 6-12 } \\
\text { (Eq. 40) }\end{array}$ & 1.32 & -- & -- & $9.9937 \times 10^{-101}$ & $4.9216 \times 10^{-57}$ & 42 \\
\hline 15 to 50 & Sutherland (Eq. 41) & -- & -- & 566.8 & -- & -- & 90 \\
\hline 40 to 200 & $\begin{array}{l}\text { Inverse Force } \\
\text { (Eq. 38) }\end{array}$ & 1.529 & 8 & -- & -- & -- & 114 \\
\hline 0 to 200 & Sutherland (Eq. 41) & -- & -- & 101 & -- & -- & 135 \\
\hline
\end{tabular}

$f=\lambda_{n} / r^{n}-\lambda_{3} / r^{5}$, where $\lambda_{n}$ and $\lambda_{3}$ are the force constants for attraction and repulsion, respectively. Using this force law, the viscosity can be represented by:

$$
\eta=\left(\mathrm{C} \mathrm{T}^{1 / 2} \mathrm{~b}\right) /\left(\mathrm{T}^{\mathrm{b}}+\mathrm{S}\right) \quad \text { (poise) }
$$

where $C$ is a constant, $S$ is the Sutherland constant, and $b=1 / 2+2 /(n-1)$. Taking $n=20$, Cohen found that $S=29$. The constant $C$ was chosen so that the viscosity values calculated from Equation 49 agree with those reported by Llewellyn. However, despite this agreement, Cohen felt that a repulsive force field varying as $1 / \mathrm{r}^{20}$ seemed rather "hard" for the $\mathrm{UF}_{6}$ molecule and therefore recommended further measurement of the transport properties. 


\section{THERMODYNAMIC PROPERTIES}

The thermodynamic properties of $\mathrm{UF}_{6}$ discussed here have been obtained mostly from primary literature sources. These properties, in some cases, have been determined directly by experimentation. An indirect method, using other related data, was resorted to in other cases.

The heat capacities of the solid and of the liquid have been measured from $14^{\circ}$ to $370^{\circ} \mathrm{K}$. These values are reported as being reliable within one percent. The entropies, enthalpies, and free energy functions of the solid and of the liquid have been calculated from the experimental values of the heat capacity.

The thermodynamic properties of the vapor have been determined over the range $100^{\circ}$ to $1000^{\circ} \mathrm{K}$. from vibrational spectra together with the interatomic distances using statistical mechanics. These properties have also been determined using the heats of vaporization and sublimation, and the third law addition of entropies. The original comparison 20 of the thermodynamic properties obtained by these two methods in the range from $273^{\circ}$ to $348^{\circ} \mathrm{K}$. revealed slight discrepancies, although a recent comparis on ${ }^{144}$ of these properties in the range from $273^{\circ}$ to $370^{\circ} \mathrm{K}$. using later and more precise data revealed a more favorable agreement. In the latter comparison a non-ideality parameter was used to define the gas imperfection.

The heats of vaporization and sublimation havebeen measured experimentally from $273^{\circ}$ to $370^{\circ} \mathrm{K}$. and have also been calculated from vapor pressure data using the clapeyron equation. The values obtained experimentally do not compare favorably with the calculated values which should be considered more reliable. From the heat values, the entropies of vaporization and sublimation have been calculated assuming that the heat change involved is both isothermal and reversible.

The heat of fusion has been measured calorimetrically and has also been calculated from the heats of vaporization and sublimation. The value obtained by measurement is in agreement with the calculated value.

Some of the basic thermodynamic properties have been covered in fairly recent compilations by others. These sources contain "selected" thermodynamic properties, with extrapolations to cover a larger temperature range. They contain useful applications of the thermodynamic data. Therefore, a few of them should be mentioned. The National Bureau of Standards circular, The Selected Values of Chemical Thermodynamic Properties ${ }^{29}$, contains a tabulation of the 'best' thermodynamic values of $U_{8}$ for such properties as the heats of transition, fusion and vaporization.

An Argonne National Laboratory survey, The Thermodynamic Properties of the Fluorides, Chlorides, and Oxides of the Elements to2500 ${ }^{\circ},{ }^{67}$ lists empirical heat capacity equations which are used to determine the free energy of formation of the various fluorides, chlorides, and oxides of the elements. The constants of the empirical equations were obtained either from experimental data or by some theoretical, semi-empirical approach. Other thermodynamic data relating to enthalpy, entropy, free energy functions, and the like were obtained by the appropriate integrations. The Argonne publication also contains diagrams showing the free energy of formation versus temperature from which stability relations existing between compounds of a given type can be quickly obtained. A less recent report, The Thermodynamic Properties of Uranium Halides, Oxides, Nitrides, and Carbides ${ }^{23}$, also contains some rather useful applications of the thermodynamic properties. 
The Carrier report, P. G. Thermodynamic Properties ${ }^{131}$, is an attempt at establishing a self-consistent set of thermodynamic data for the vapor to fit the various known isolated data. Assuming that $U F_{6}$ behaves nearly as a perfect gas, enthalpy, relative pressure, relative volume, specific heat, ratio of specific heats, viscosity, and acoustic velocity were derived and tabulated as a function of temperature.

\section{HEAT CAPACITY}

The heat capacity of solid and liquid $\mathrm{UF}_{6}$ which have been measured in the temperature range from $14^{\circ}$ to $370^{\circ} \mathrm{K}$. are represented, in part, by Equations 50 and 51 . These values, which are reliable to within one percent, are presented in Table 31 and Figures 12 and 13. Other less reliable values are listed in Table 32.

The heat capacity values of $\mathrm{UF}_{6}$ vapor have been determined by two methods: first, from thermodynamic functions of the solid and liquid and vapor pressure data utilizing the third law addition of entropies; and second, from the vibrational spectra using statistical mechanics. Although the more reliable values (listed in the first three columns of Table 33) obtained by using these two methods are in reasonable agreement, it should be kept in mind that even better agreement ${ }^{144}$ could be obtained if the most recent data reported were employed in the computations.

\section{HEAT CAPACITY OF THE SOLD AND THE LIQUID}

Brickwedde, Hoge, and Scott ${ }^{24}$ measured the heat capacity, $\mathrm{C}_{\mathrm{p}}$, of solid and liquid UF under its own vapor pressure from $14^{\circ}$ to $370^{\circ} \mathrm{K}$. using a special fluted copper calorimeter. The corrugations in the calorimeter allowed for a ten percent increase in the volume of the material at temperatures near its melting point. Vapor corrections to both the heat capacity and the heat of fusion values were applied according to the procedure outlined by Hoge*.

The vapor pressure data of Crist and Weinstock and those of Simon (see page 86) were found to intersect at $64.052^{\circ} \mathrm{C}$., the triple point temperature. At this temperature, the vapor pressure equations yield a triple point pressure of $1142 \mathrm{~mm}$. Hg. A maximum vapor pressure correction of 5 percent was determined near the triple point. Extrapolation of the molar heat capacity of $\mathrm{UF}_{6}$ from $14^{\circ}$ to $0^{\circ} \mathrm{K}$. was made on the basis of the Debye-Einstein specific heat functions. In considering the error arising from experimental measurements and from possible impurities, the authors felt that the $C_{p}$ data should be reliable to approximately one percent.

Kirshenbaum ${ }^{93}$ converted the units of the original heat capacity data which are joules / mole deg. to units of cal./mole deg. by use of the factor 4.1833 calories = 1 international joule. The values derived are presented in Table 31.

The heat capacity-temperature relationships of solid and liquid $U F_{6}$ determined from the enthalpy-temperature equations obtained by Kirshenbaum ${ }^{93}$ from the experimental data of Brickwedde and his co-workers are:

Solid $\left(250^{\circ}\right.$ to $\left.337.212^{\circ} \mathrm{K}.\right)$

$\mathrm{C}_{p}=\left[20.0827+161.158 \times 10^{-3} \mathrm{~T}+104.792 \times 10^{4} / \mathrm{T}^{2}\right] \mathrm{cal} . / \mathrm{mole} \mathrm{deg}$.

(deviates less than one percent from the experimental results for the stated temperature range)

*Hoge, H. J. J. Research Nat1. Bur. Standards 36,111 (1946). 


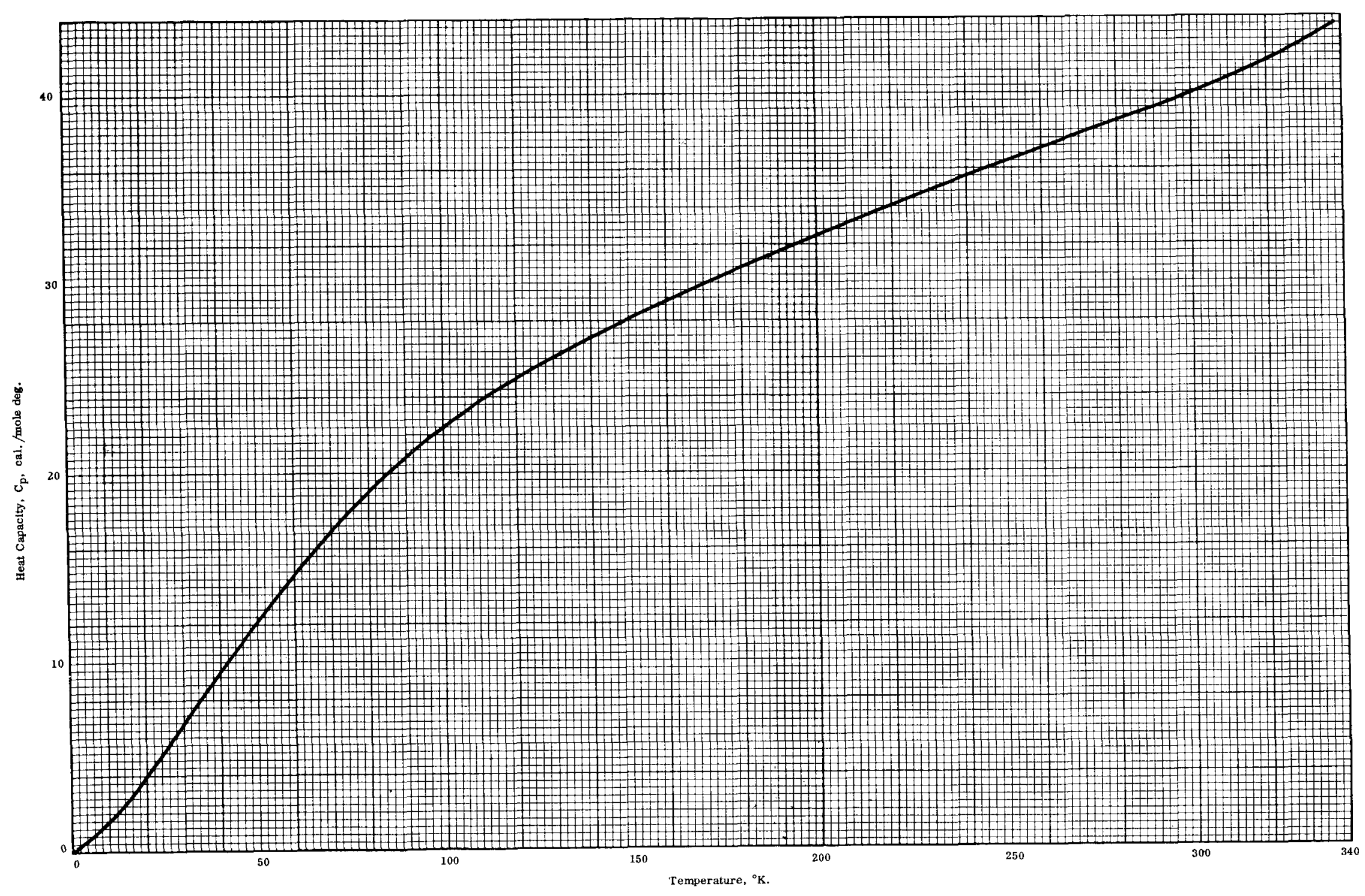

FIG. 12. HEAT CAPACITY OF THE SOLID 


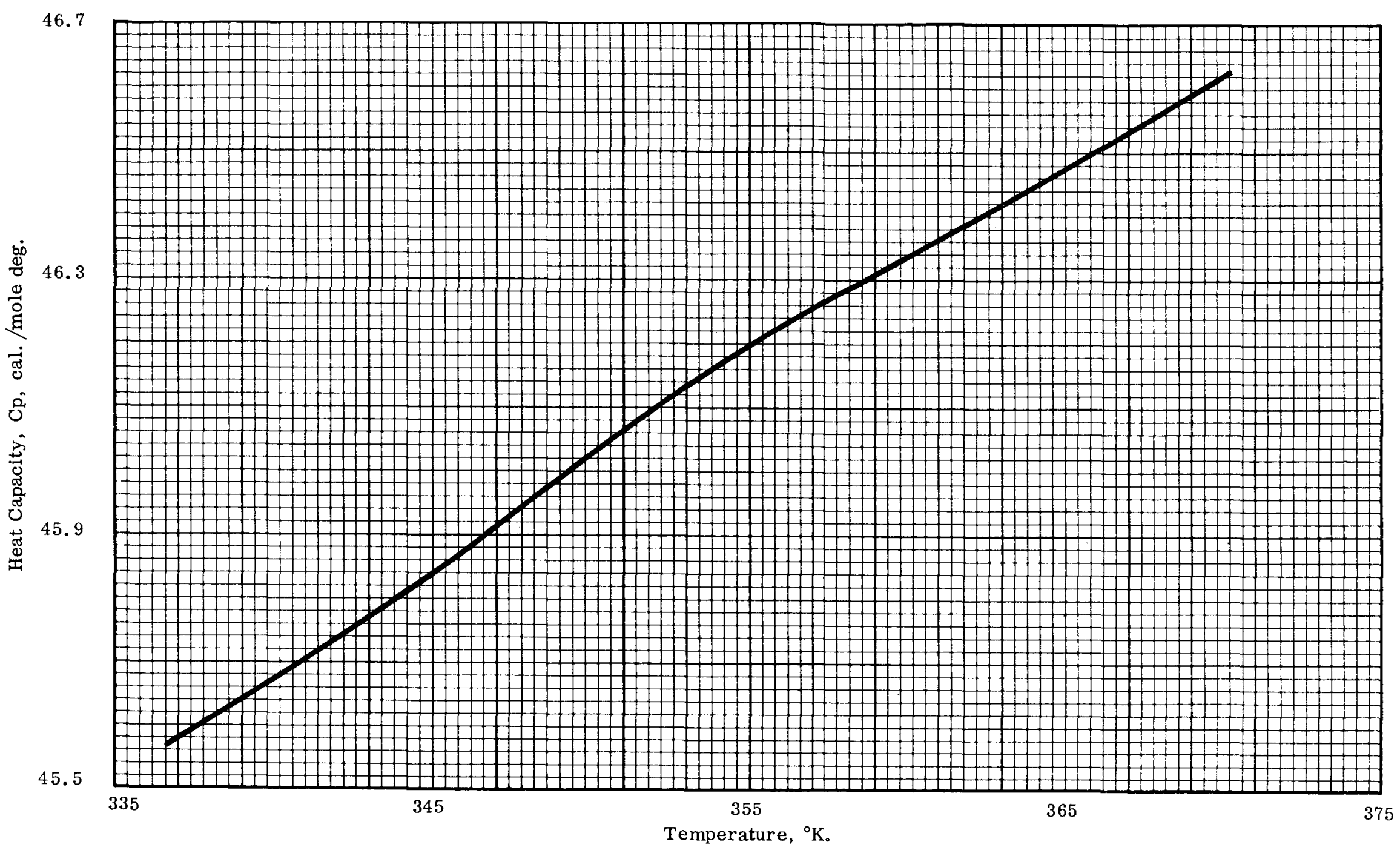

FIG. 13. HEAT CAPACITY OF THE LIQUD

(Reference 24) 
Table 31

THERMODYNAMIC PROPERTIES OF THE SOLID AND THE LIQUID

(Reference 88)

\begin{tabular}{|c|c|c|c|c|}
\hline $\begin{array}{c}\text { Temperature } \\
\left({ }^{\circ} \mathrm{K} .\right)\end{array}$ & $\begin{array}{c}\mathrm{Cp} \\
\left.\text { (cal. } / \text { mole }^{\circ} \mathrm{C} .\right)\end{array}$ & $\begin{array}{c}\mathbf{H}-\mathbf{H}_{\mathbf{O}} \\
\text { (cal. } / \mathrm{mole})\end{array}$ & $\begin{array}{c}\mathbf{S}-\mathbf{S}_{\mathrm{o}} \\
\left(\mathrm{cal} . / \mathrm{mole}^{\circ} \mathrm{C} .\right)\end{array}$ & $\begin{array}{l}\mathrm{T}\left(\mathrm{S}-\mathrm{S}_{\mathrm{o}}\right) \\
\text { (cal./mole) }\end{array}$ \\
\hline & & SOLm & & \\
\hline 0 & 0 & 0 & 0 & 0 \\
\hline 20 & 4.06 & 28.0 & 1.96 & 39 \\
\hline 25 & 5.53 & 52.0 & 3.04 & 76 \\
\hline 30 & 6.92 & 83.2 & 4.16 & 125 \\
\hline 35 & 8.27 & 121.1 & 5.33 & 187 \\
\hline 40 & 9.64 & 165.9 & 6.53 & 261 \\
\hline 45 & 11.00 & 217.5 & 7.72 & 347 \\
\hline 50 & 12.34 & 275.9 & 8.96 & 448 \\
\hline 55 & 13.66 & 304.9 & 10.21 & 562 \\
\hline 60 & 14.90 & 412.4 & 11.45 & 687 \\
\hline 65 & 16.07 & 489.8 & 12.69 & 825 \\
\hline 70 & 17.16 & 572.8 & 13.91 & 974 \\
\hline 75 & 18.22 & 661.4 & 15. 13 & 1,135 \\
\hline 80 & 19.20 & 754.9 & 16.35 & 1,308 \\
\hline 85 & 20.14 & 853.9 & 17.55 & 1,492 \\
\hline 90 & 20.99 & 956.2 & 18.72 & 1,685 \\
\hline 95 & 21.76 & 1,063 & 19.86 & 1,887 \\
\hline 100 & 22.49 & 1,174 & 20.99 & 2,099 \\
\hline 105 & 23.17 & 1,288 & 22.11 & 2,322 \\
\hline 110 & 23.82 & 1,405 & 23.21 & 2,553 \\
\hline 115 & 24.46 & 1,526 & 24.29 & 2,793 \\
\hline 120 & 25.08 & 1,650 & 25.34 & 3,041 \\
\hline 125 & 25.66 & 1,777 & 26.37 & 3,296 \\
\hline 130 & 26.23 & 1,907 & 27.39 & 3,561 \\
\hline 135 & 26. 77 & 2,039 & 28.40 & 3,834 \\
\hline 140 & 27.30 & 2,174 & 29.38 & 4,113 \\
\hline 145 & 27.80 & 2,312 & 30.33 & 4,398 \\
\hline 150 & 28.30 & 2,452 & 31.29 & 4,694 \\
\hline 155 & 28.78 & 2,595 & 32.22 & 4,994 \\
\hline 160 & 29.24 & 2,740 & 33.16 & 5,306 \\
\hline 165 & 29.71 & 2,887 & 34.04 & 5,617 \\
\hline 170 & 30.15 & 3,037 & 34.95 & 5,942 \\
\hline 175 & 30.60 & 3,189 & 35.83 & 6,270 \\
\hline 180 & 31.03 & 3,343 & $3: 69$ & 6,604 \\
\hline 185 & 31.42 & 3,499 & 37.55 & 6,947 \\
\hline 190 & 31.87 & 3,657 & 38.39 & 7,294 \\
\hline 195 & 32.27 & 3,818 & 39.23 & 7,650 \\
\hline 200 & 32.65 & 3,980 & 40.04 & 8,008 \\
\hline 205 & 33.05 & 4,144 & 40.85 & 8,374 \\
\hline 210 & 33.46 & 4,310 & 41.67 & 8,751 \\
\hline
\end{tabular}


Table 31 (Continued)

THERMODYNAMIC PROPERTIES OF THE SOLID AND THE LIQUID

(Reference 88)

\begin{tabular}{|c|c|c|c|c|}
\hline $\begin{array}{c}\text { Temperature } \\
\text { ('K.) }\end{array}$ & $\begin{array}{c}\mathrm{Cp} \\
\left.\text { (cal./mole }{ }^{\circ} \mathrm{C} .\right)\end{array}$ & $\begin{array}{c}\mathrm{H}-\mathrm{H}_{\mathrm{O}} \\
\text { (cal./mole) }\end{array}$ & $\begin{array}{c}S-S_{0} \\
\left.\text { (cal. } / \text { mole }^{\circ} \mathrm{C} .\right)\end{array}$ & $\begin{array}{c}\mathrm{T}\left(\mathrm{S}-\mathrm{S}_{\mathrm{o}}\right) \\
(\mathrm{cal} . / \mathrm{mole})\end{array}$ \\
\hline & & SOLID & & \\
\hline 215 & 33.78 & 4,479 & 42.45 & 9,127 \\
\hline 220 & 34.22 & 4,648 & 43.24 & 9,513 \\
\hline 225 & 34.60 & 4,820 & 44.01 & 9,902 \\
\hline 230 & 34.96 & 4,994 & 44.77 & 10,296 \\
\hline 235 & 35.34 & 5,170 & 45.51 & \\
\hline 240 & 35.70 & 5,348 & 46.28 & 11,107 \\
\hline 245 & 36.07 & 5,527 & 47.02 & 11,520 \\
\hline 250 & 36.43 & 5,708 & 47.74 & 11,935 \\
\hline 255 & 36.78 & 5,892 & 48.48 & 12,362 \\
\hline 260 & 37.14 & 6,067 & 49.20 & 12,792 \\
\hline 265 & 37.50 & 6,263 & 49.89 & 13,221 \\
\hline 270 & 37.86 & 6,451 & 50.61 & 13,665 \\
\hline 273. 16 & 38.08 & 6,571 & 51.05 & 13,942 \\
\hline 275 & 38.22 & 6,640 & 51.30 & 14,108 \\
\hline 280 & 38.56 & 6,833 & 51.99 & 14,557 \\
\hline 285 & 38.90 & 7,027 & 52.69 & 15,017 \\
\hline 290 & 39.24 & 7,223 & 53.36 & 15,474 \\
\hline 295 & 39.61 & 7,420 & 54.02 & 15,936 \\
\hline 298. 16 & 39.86 & 7,545 & 54.45 & 16,235 \\
\hline 300 & 40.00 & 7,619 & 54.69 & 16,407 \\
\hline 305 & 40.42 & 7,820 & 55.36 & 16,885 \\
\hline 310 & 40.87 & 8,023 & 56.03 & 17,369 \\
\hline 315 & 41.33 & 8,229 & 56.68 & 17,854 \\
\hline 320 & 41.80 & 8,437 & 57.35 & 18,352 \\
\hline 325 & 42.27 & 8,648 & 57.99 & 18,847 \\
\hline 330 & 42.77 & 8,860 & 58.64 & 19,351 \\
\hline 335 & 43.27 & 9,076 & 59.28 & 19,859 \\
\hline \multirow[t]{2}{*}{337.212} & 43.49 & 9,172 & 59.57 & 20,088 \\
\hline & \multicolumn{3}{|c|}{ LIQUID } & \\
\hline 337.212 & 45.59 & 13,760 & 73.17 & 24,674 \\
\hline 340 & 45.68 & 13,888 & 73.55 & 25,007 \\
\hline $\begin{array}{l}345 \\
350\end{array}$ & 45.84 & 14,118 & $\begin{array}{l}74.22 \\
74.89\end{array}$ & 25,606 \\
\hline 355 & 46.20 & 14,579 & $\begin{array}{l}74.89 \\
75.54\end{array}$ & $\begin{array}{l}26,212 \\
26,817\end{array}$ \\
\hline 360 & 46.33 & 14,811 & 76.18 & 27,425 \\
\hline 365 & 46.48 & 15,044 & 76.83 & 28,043 \\
\hline 370 & 46.62 & 15,278 & 77.45 & 28,657 \\
\hline
\end{tabular}


Liquid $\left(337.212^{\circ}\right.$ to $\left.370^{\circ} \mathrm{K}.\right)$

$$
\begin{aligned}
& \mathrm{Cp}=\left[17.954+65.028 \times 10^{-3} \mathrm{~T}+66.699 \times 10^{4} / \mathrm{T}^{2}\right] \mathrm{cal} . / \mathrm{mole} \mathrm{deg} . \\
& \mathrm{Cp}=\left[18.0855+0.126985 \mathrm{~T}-1.3476307 \times 10^{-1} \mathrm{~T}^{2}\right] \mathrm{cal} . / \mathrm{mole} \mathrm{deg} .
\end{aligned}
$$

(Values calculated from Equation 51 deviate less than 0.6 percent from the experimental values for the stated temperature range)

Equation 51a was obtained by fitting the actual heat capacity values to a temperature function. This equation is more representative of the experimental heat capacity values than is Equation 51.

Glassner ${ }^{67 *}$ expressed the experimental heat capacity data of solid $\mathrm{UF}_{6}$ by the equation:

$$
\mathrm{Cp}=\left[12.34+92.23 \times 10^{-3} \mathrm{~T}\right] \mathrm{cal} . / \text { mole deg. }
$$

which represents the experimental data within 0.2 percent in the temperature range $300^{\circ} \mathrm{K}$. to $337.212^{\circ} \mathrm{K}$.

Other reported values of the heat capacity of the solid and liquid found in the literature differ somewhat from those reported by Brickwedde and his co-workers. Llewellyn ${ }^{107}$ determined the heat capacity values of the solid and the liquid using a copper calorimeter. The results, which are reported to have an estimated error of one percent, deviate from the results of Brickwedde and his co-workers for the solid at $333^{\circ} \mathrm{K}$. and for the liquid at $373^{\circ} \mathrm{K}$. by approximately 5 percent. The heat capacity values of the solid reported by Llewellyn ${ }^{107}$ and others ${ }^{47}, 50$ are listed in Table 32 . Heat capacity values of the liquid in the temperature range $343^{\circ}$ to $373^{\circ} \mathrm{K}$. are expressed by the equation:

$$
\mathrm{Cp}=\left[47.3+0.347\left(\mathrm{t}^{\circ} \mathrm{C} .-70\right)\right] \mathrm{cal} . / \mathrm{mole} \mathrm{deg} \text {. }
$$

Values of the heat capacity obtained from Equation 53 are somewhat higher than those given by Brickwedde and his co-workers.

\section{HEAT CAPACITY OF THE VAPOR}

Bigeleisen and his co-workers ${ }^{20}$ and more recently Gaunt ${ }^{65}$ calculated the heat capacity of the vapor from the fundamental frequencies which were assigned to the vibrational spectra of $U F_{6}$. For calculation of the heat capacity from fundamental frequencies, the structure of $\mathrm{UF}_{6}$ was taken as that of a regular octahedron in which the uranium-tofluorine distance is $2.00 \AA$ and the symmetry number is 24 . Since the fundamentals assigned by Bigeleisen and his co-workers differ only slightly from those assigned by Gaunt, the thermodynamic functions calculated from the two sets of fundamentals are in agreement. Claassen, Weinstock, and $\mathrm{Malm}^{35}$ confirmed the thermodynamic functions obtained by Gaunt. Since they obtained, from the Raman spectrum, fundamentals which agreed very well with those determined by Gaunt, they found no need to revise Gaunt's thermodynamic calculations.

*Glassner stated in a private communication that values of the constants $a$ and $b$ for $\mathrm{UF}_{t}$ (solid) given on the last page of Table III of his report are incorrect. The correct values may be obtained by dropping the entire tabulation for columns $a, b, c$, and $d$ two lines, beginning with $\mathrm{UF}_{3}$. The insertions intended for $\mathrm{UF}_{3}$ are as follows:

solid

$$
\frac{\mathrm{a}}{20.8} \quad \frac{\mathrm{b}}{7.2} \quad \mathrm{c} \quad \stackrel{\mathrm{d}}{\mathbf{6 . 5 2 2}} \quad \frac{\mathrm{A}}{94.6}
$$

liquid 
Table 32

OTHER SOLID AND LIQUID HEAT CAPACITY VALUES

Temperature
$\left({ }^{\circ} \mathrm{K}.\right)$

213.2

223.2

233.2

253.2

273.2

293.2

303.2

313.2

323.2

333.2

343.2

353. 2

363. 2

373.2

\begin{tabular}{|c|c|}
\hline & \\
\hline $\begin{array}{l}\text { Llewellyn } \\
\text { (Ref. 107) }\end{array}$ & $\begin{array}{c}\text { Simon } \\
\text { (Ref. 135) }\end{array}$ \\
\hline
\end{tabular}

SOLID

29.5

34.2

34.6

30.4

35.7

31.7

37.0

33.5

39.0

36.2

38.0

41.8

40.5

--

44.0

44.5

\section{LIQUID}

47.4

48.1

48.8

49.5

However, it should be mentioned that Weinstock and his co-workers ${ }^{144}$ re-evaluated both the fundamental frequencies and the U-F distance. They found that the thermodynamic data calculated by using the new frequencies gave better comparisons than were made by earlier workers. Their calculations of the thermodynamic data based on the third law of thermodynamics were made using the vapor pressure data of oliver and his co-workers ${ }^{119}$ and a correction for the gas imperfection.

The heat capacity values determined by Gaunt ${ }^{65}$ were found to agree with the corrected experimental data of $\mathrm{Arms}^{135}$, who determined the heat capacity of the vapor using an apparatus of the type devised by Blackett, Henry, and Rideal*. The method used gives values which are relative to those of vapors of known heat capacity. Arms' results, however, were shown to be erroneous. Gaunt found that the errors in Arms' results were caused by neglect of a factor which depends on the nature of the vapor. By making the proper corrections and using the value $6.98 \mathrm{cal} . / \mathrm{mole} \mathrm{deg}$. for the heat capacity of air at $25^{\circ} \mathrm{C}$., Gaunt calculated the corrected experimental heat capacity value for $\mathrm{UF}_{6}$ at $25^{\circ} \mathrm{C}$. as $30.5 \mathrm{cal}$. / mole. This value compares favorably with the value of $30.9 \mathrm{cal} . / \mathrm{mole}$

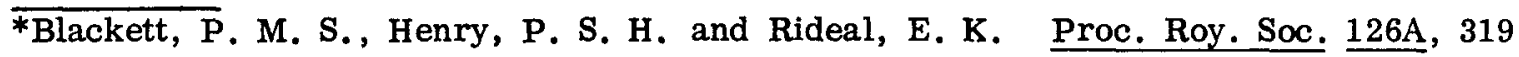
(1930). 
which was determined from the spectral data. Unfortunately, the data available to Gaunt were not sufficient for complete revision of the heat capacity values which were determined by Arms at other temperatures.

Booth, Callihan, and Haggstrom ${ }^{22}$ also measured the heat capacity of $\mathrm{UF}_{6}$ vapor by a continuous flow method similar to that described by Blackett, Henry, and Rideal. The investigation was conducted at $52.5^{\circ} \mathrm{C}$. and $12.7 \mathrm{~cm}$. $\mathrm{Hg}$. The measurement of the heat capacity was related to hydrogen and to air which at the conditions of the investigation have specific heats of $4.36 \times 10^{-5}$ and $4.29 \times 10^{-5} \mathrm{cal} . / \mathrm{deg}$., respectively. They reported a value of $29 \pm 1 \mathrm{cal} . / \mathrm{mole}$. Nordsieck ${ }^{22}$ also estimated the heat capacity of the vapor from the molecular data. Vibrational frequencies of $\mathrm{UF}_{6}$ were estimated by extrapolation from the known series of molecules of $\mathrm{SF}_{6}, \mathrm{SeF}_{6}$ and $\mathrm{TeF}_{6}$. The averagedistance, $\mathrm{d}$, from the central atom to fluorine was alsodetermined by extrapolation and found to be $1.98 \AA$. The structure of $\mathrm{UF}_{6}$ was assumed to be a regular octahedron. The values of the heat capacities along with the estimated deviation of the mean which were obtained by Nordsieck are presented in column 6 of Table 33 .

Duncan $^{44}$ calculated heat capacity values at various temperatures from estimated frequencies of Raman spectra, moments of inertia, and a symmetry number of 24 . These values are presented in column 8 of Table 33 .

Kirshenbaum ${ }^{93}$ derived Equation 54 for the heat capacity of $\mathrm{UF}_{6}$ vapor from thermodynamic functions and the vapor pressure-temperature relationships of the condensate:

$$
\mathrm{Cp} \text { (vapor) }=\left[32.43+7.936 \times 10^{-3} \mathrm{~T}-32.068 \times 10^{4} / \mathrm{T}^{2}\right] \mathrm{cal} . / \mathrm{mole} \mathrm{deg} .
$$

Values of the heat capacity are presented in column 4 of Table 33. The more reliable values are shown in Figure 14.

Table 33

HEAT CAPACITY OF THE VAPOR

\begin{tabular}{|c|c|c|c|c|c|c|c|}
\hline \multirow[b]{2}{*}{$\begin{array}{l}\text { Temperature } \\
\text { ('K.) }\end{array}$} & \multicolumn{7}{|c|}{$\mathrm{C}_{\mathrm{p}}$ (cal./mole deg.) } \\
\hline & $\begin{array}{l}\text { Bigeleisen } \\
\text { and Mayer* } \\
\text { (Ref. 20) } \\
\end{array}$ & $\begin{array}{c}\text { Gaunt }^{\dagger} \\
\text { (Ref. 65) }\end{array}$ & $\begin{array}{c}\text { Calculated from } \\
\text { Equation 54 } \\
\text { (Ref. 65) } \\
\end{array}$ & $\begin{array}{c}\text { Arms } \\
\text { (Ref. 135) } \\
\end{array}$ & $\begin{array}{c}\text { Nordsiek } \xi \\
\text { (Ref. 22) }\end{array}$ & $\begin{array}{l}\text { Booth, et al. I } \\
\text { (Rei. 22) } \\
\end{array}$ & $\begin{array}{l}\text { Duncan // } \\
\text { (Ref. 44) } \\
\end{array}$ \\
\hline 100 & 18.93 & 18.76 & & & & & \\
\hline 150 & 23.45 & 23.32 & & & & & \\
\hline 200 & 26.74 & 26.62 & & & & & \\
\hline 250 & & 29.12 & 29.28 & & & & \\
\hline 273 & 30.13 & 30.05 & 30.29 & & & & 29.7 \\
\hline 273.2 & & & & & $29.2 \pm 1.0$ & & \\
\hline 298 & 31.00 & 30.93 & 31.18 & & & & \\
\hline 298.2 & & & & $\begin{array}{l}33.5 \pm 1^{\ddagger} \\
(30.5)^{\#}\end{array}$ & & & \\
\hline 323 & 31.75 & 31.68 & 31.92 & & & & 31.4 \\
\hline 323.2 & & & & & $30.1 \pm 1.0$ & $29+1$ & \\
\hline 348 & 32.38 & 32.32 & 32.54 & $34.5 \bullet 1^{\ddagger}$ & & & \\
\hline 348.2 & & & & & $30.8 \pm 0.5$ & & \\
\hline 373 & 32.93 & & & & & & 32.8 \\
\hline 398 & & 33.36 & 33.56 & & & & \\
\hline 398.2 & & & & $35.5 \pm 1^{\ddagger}$ & & & \\
\hline 400 & 33.46 & 33.40 & & & & & \\
\hline 500 & 34.80 & 34.77 & 35.12 & & & & \\
\hline 650 & & & 36.83 & & & & \\
\hline 750 & 36.35 & & & & & & \\
\hline 1000 & 36.94 & & & & & & \\
\hline $\begin{array}{l}{ }_{\text {*Calculated fr }} \\
\text { †Calculated fr } \\
t_{\text {Experimental }}\end{array}$ & $\begin{array}{l}\text { ration spectra. } \\
\text { rared spectra. } \\
\text { s. }\end{array}$ & & $\begin{array}{l}\text { ected value calcula } \\
\text { nated from measur } \\
\text { ured relative to bo } \\
\text { lated from Raman }\end{array}$ & $\begin{array}{l}\text { Gaunt. } \\
\text { rational freo } \\
\text { irogen and ai } \\
\text { ra. }\end{array}$ & $\begin{array}{l}\text { es of } \mathrm{SF}_{6}, \mathrm{Se} \\
\text { t capacity val }\end{array}$ & $\mathrm{TeF}_{\mathrm{B}}$ and $U \mathrm{~F}_{\mathrm{B}}$. & \\
\hline
\end{tabular}




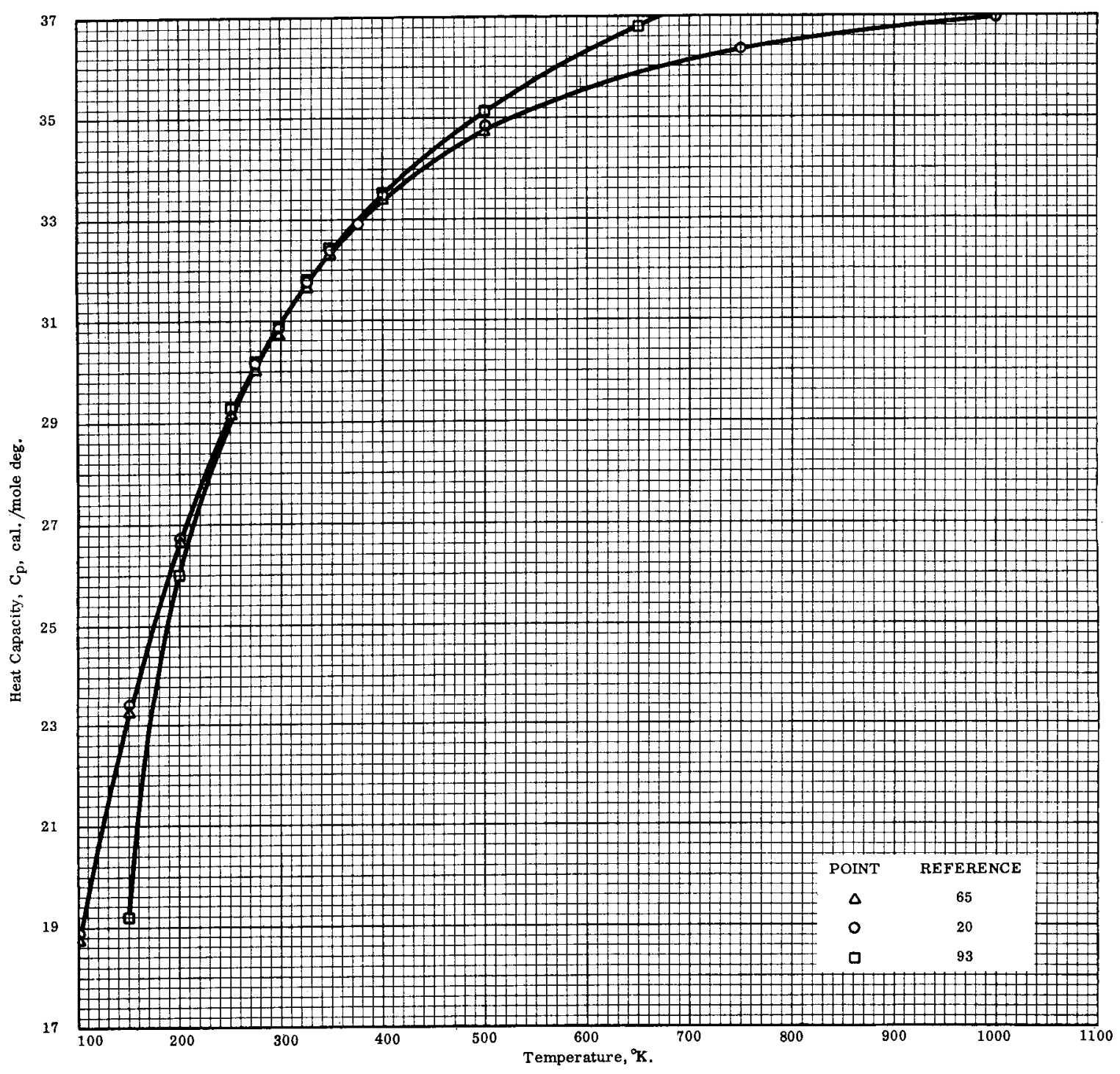

FIG. 14. CALCULATED HEAT CAPACITY OF THE VAPOR

\section{HEAT CAPACITY RATIO}

Values of the heat capacity ratio reported in the literature were estimated in two ways:

(1) from experimental values of the velocity of sound, $\mu$, using the equation:

$$
\mathrm{C}_{\mathrm{p}} / \mathrm{C}_{\mathrm{v}}=\mu^{2}(\partial \rho / \partial \mathrm{P})_{\mathrm{T}}
$$

where $P$ is the pressure and $\rho$ is the vapor density; and

(2) from the heat capacity at constant pressure, $C_{p}$, using the equation:

$$
C_{p} / C_{v}=c_{p} /\left(C_{p}-R\right)
$$

where $R$ is the gas constant. Equation 56 is based on the assumption that the behavior of $\mathrm{UF}_{6}$ vapor is the same as that predicted by the ideal gas law. 
Values of $\mathrm{C}_{\mathrm{p}} / \mathrm{C}_{\mathrm{v}}$ at $49.2^{\circ} \mathrm{C}$. obtained using Equation 55 are in agreement with those obtained using Equation 56 and are found to range between 1.062 and 1.067 .

The quantity $(\partial \rho / \partial \mathrm{P}) 49.2^{\circ} \mathrm{C}$. was experimentally determined at various pressures by Amphlett, Mullinger, and Thomas ${ }^{9}$. It was found that

$$
(\partial \mathrm{P} / \partial \rho)_{49.2^{\circ} \mathrm{C} .}=1.32 \times 10^{-8} \mathrm{sec} .{ }^{2} / \mathrm{cm} .^{2}
$$

which is nearly the same, at least within experimental error, as the value predicted by the kinetic theory of gases:

$$
(\partial \rho / \partial \mathrm{P})_{49.2 .{ }^{\circ} \mathrm{C} .}=1.314 \times 10^{-8} \mathrm{sec}^{2} / \mathrm{cm} .{ }^{2}
$$

Chackett ${ }^{34}$. determined the velocity of sound in $\mathrm{UF}_{6}$ vapor as $8,990 \mathrm{~cm}$. $/ \mathrm{sec}$. at $49.2^{\circ} \mathrm{C}$. with an estimated error of \pm 0.2 percent. Previously, a preliminary mean value of $8,870 \mathrm{~cm}$. $/ \mathrm{sec}$. was reported ${ }^{49}$. The latter value was determined at $49^{\circ} \mathrm{C}$. and at pressures of 326 and $539 \mathrm{~mm}$. Hg using a resonance tube 25 centimeters long and 1.6 centimeters in diameter. The former value was determined at $420 \mathrm{~mm}$. $\mathrm{Hg}$ using a similar tube, except that it was wider and longer. Using the value $\mu=8,990 \mathrm{~cm} . / \mathrm{sec}$. and assuming that $\mathrm{UF}_{6}$ vapor is ideal, Chackett found that:

$$
\begin{aligned}
\mathrm{C}_{\mathrm{p}} / \mathrm{C}_{\mathrm{v}} & =(8,990)^{2}\left(1.314 \times 10^{-8}\right) \\
& =1.062 \pm 0.5 \text { percent }
\end{aligned}
$$

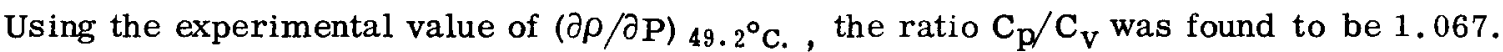
From the heat capacity value of $\mathrm{UF}_{6}$ vapor at $49.2^{\circ} \mathrm{C}$., which was obtained from the heat capacity equation of Kirshenbaum (see page 63) and Equation 51, it was found that $\mathrm{C}_{\mathrm{p}} / \mathrm{C}_{\mathrm{v}}=1.066$. This value compares favorably with the values given above. Booth and his co-workers reported that an average of the experimental and theoretical values of $\mathrm{C}_{\mathrm{p}}$ at $50^{\circ} \mathrm{C}$. yields a value of $\mathrm{C}_{\mathrm{p}} / \mathrm{C}_{\mathrm{v}}=1.073$.

\section{ENTHALPY}

The enthalpy values of the solid and of the liquid were calculated from the measured heat capacity values by integrating along the saturation curve. The values for the solid which are represented, in part, by Equation 61 and the values for the liquid which are represented by Equation 62 are presented in Table 31 and in Figure 15. The enthalpy of the vapor which was obtained from the calculated entropy function is expressed by Equation 63.

Brickwedde, Hoge, and Scott ${ }^{24}$ determined the enthalpies of solid and liquid $\mathrm{UF}_{6}$ by integrating

$$
\mathrm{dH}=\mathrm{C}_{\mathrm{sat}} \mathrm{dT}+\mathrm{VdP}
$$

along the saturation curve. $\mathrm{C}_{\mathrm{sat}}$ is the heat capacity of the condensed phase in equilibrium with the saturated vapor. Values of the enthalpies of the liquid and solid are presented in Table 31. Kirshenbaum ${ }^{93}$ fitted the enthalpy values of the solid and liquid which were calculated by Brickwedde and his co-workers to the following representative equations:

*The value actually reported by Chackett $(1.063 \pm 0.5$ percent) was found to contain a slight rounding-off error. Although this error falls within the estimated 0.5 percent error, for mathematical consistency the valuehas been changed to 1.062 for this report. 


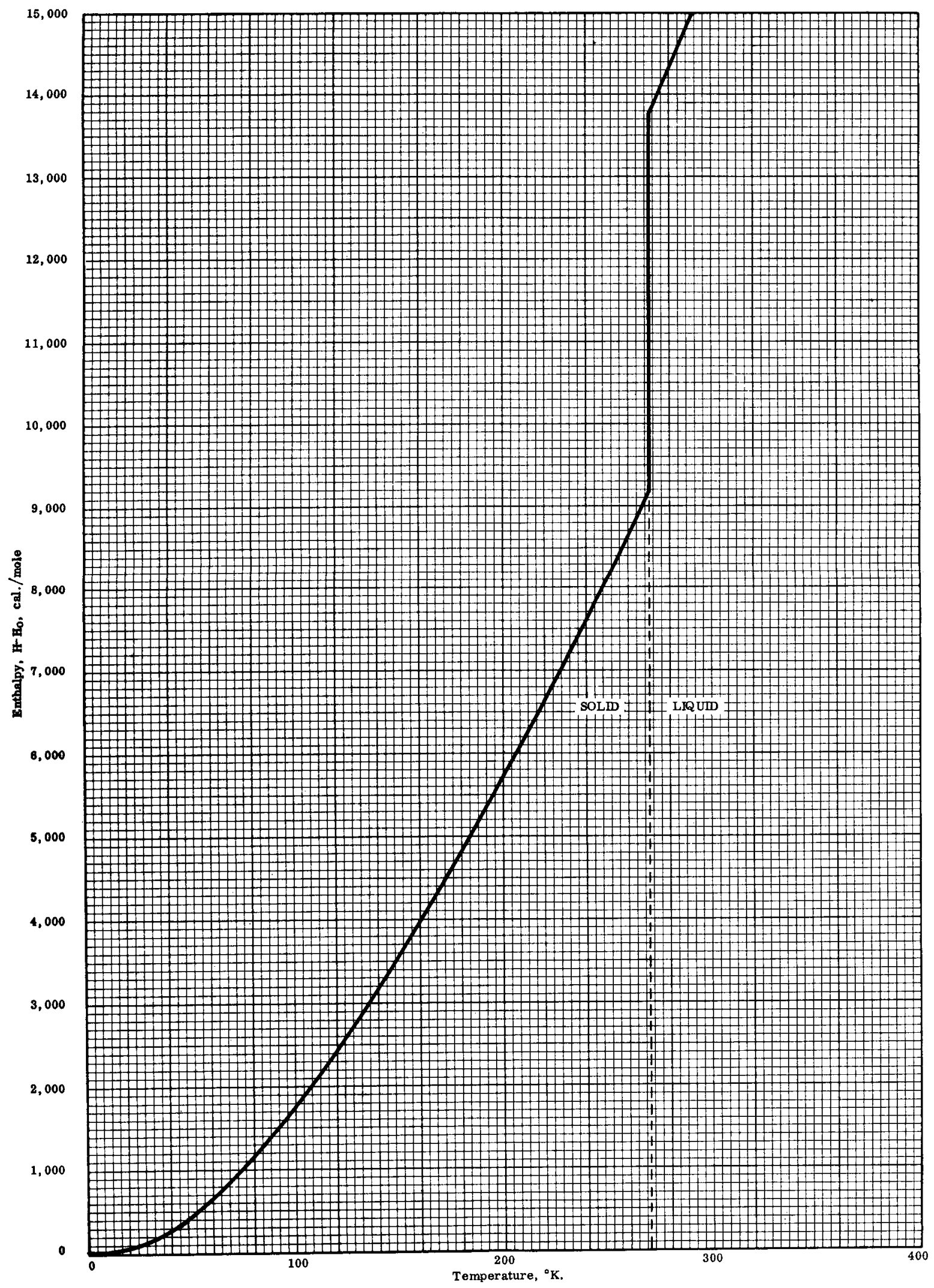

FIG. 15. ENTHALPY OF THE SOLID AND THE LIQUD (Reference 24) 
$\underline{\text { Solid }}$

$\mathrm{H}-\mathrm{H}_{\mathrm{O}}=9865-20.082 \mathrm{~T}+80.790 \times 10^{-3} \mathrm{~T}^{2}-104.7920 \times 10^{4} \mathrm{~T}^{-1} \mathrm{cal} . / \mathrm{mole} \mathrm{deg}$.

(deviates from experimental values by \pm 0.01 percent from $337.21^{\circ}$ to $265^{\circ} \mathrm{K}$. and by \pm 1 percent from $265^{\circ}$ to $225^{\circ} \mathrm{K}$.)

Liquid

$\mathrm{H}-\mathrm{H}_{\mathrm{O}}=5986.6+17.954 \mathrm{~T}+32.514 \times 10^{-3} \mathrm{~T}^{2}-66.6990 \times 10^{4} \mathrm{~T}^{-1} \mathrm{cal} . / \mathrm{mole} \mathrm{deg}$.

(deviates from experimental values by \pm 0.01 percent).

Vapor

$\mathrm{H}=8460+32.43 \mathrm{~T}+3.968 \times 10^{-3} \mathrm{~T}^{2}+32.0680 \times 10^{4} \mathrm{~T}^{-2} \mathrm{cal} . / \mathrm{mole} \mathrm{deg}$.

This equation was obtained from the entropy equation of the vapor which was derived from thermodynamic data and vapor pressure equations of the condensate.

\section{ENTROPY}

An approximate entropy diagram for $\mathrm{UF}_{6}$ was constructed by $\cdot$ Havlic ${ }^{73}$ from the critical data and the saturated vapor pressure data in the low temperature range. These data are given in a monograph by Katz and Rabinowitch ${ }^{88}$. The diagram shown by Havlicek is reproduced in Figure 16. This diagram should be used with caution, since it was determined using physical constants of uncertain value.

The entropy values of the solid and of the liquid were calculated by Brickwedde and his co-workers ${ }^{24}$ from the measured heat capacity values. Entropy values of the vapor were obtained from the vapor pressure data using the third law of thermodynamics and from the fundamental vibrational frequencies using statistical mechanics. These values, which are listed in Table 34, are found to be in reasonable agreement. However, as pointed out before, even better agreement could be obtained if the latest values of the necessary properties ${ }^{144}$ (fundamental vibration frequencies, vapor pressure data, etc.) and the non-ideality factor of the vapor are used in calculating the thermodynamic properties.

\section{ENTROPY OF THE SOLID AND OF THE LIQUD}

Brickwedde and his co-workers ${ }^{24}$ determined the entropies of solid and liquid $U F_{6}$ from the experimental values of the heat capacity by integrating the equation:

$$
\mathrm{dS}=(\mathrm{C} / \mathrm{T}) \mathrm{d} \mathbf{T} \text {. }
$$

Values of the entropy of the solid and of the liquid obtained from Equation 64 are presented in Table 33. Kirshenbaum ${ }^{93}$ fitted these values to the following representative equations :

Solid

$S-S_{O}=\left[126.082 \ln \mathrm{T}+0.16162 \mathrm{~T}-523,960 \mathrm{~T}^{-2}\right] \mathrm{cal} . / \mathrm{mole} \mathrm{deg}$.

(deviates from experimental results by \pm 0.01 percent

from $337.21^{\circ}$ to $273.16^{\circ} \mathrm{K}$.)

$\underline{\text { Liquid }}$

$\mathrm{S}-\mathrm{S}_{\mathrm{O}}=\left[-50.33+17.954 \ln \mathrm{T}+0.065028 \mathrm{~T}-333,490 \mathrm{~T}^{-2}\right] \mathrm{cal} . / \mathrm{mole} \mathrm{deg}$.

(deviates from experimental results \pm 0.01 percent). 


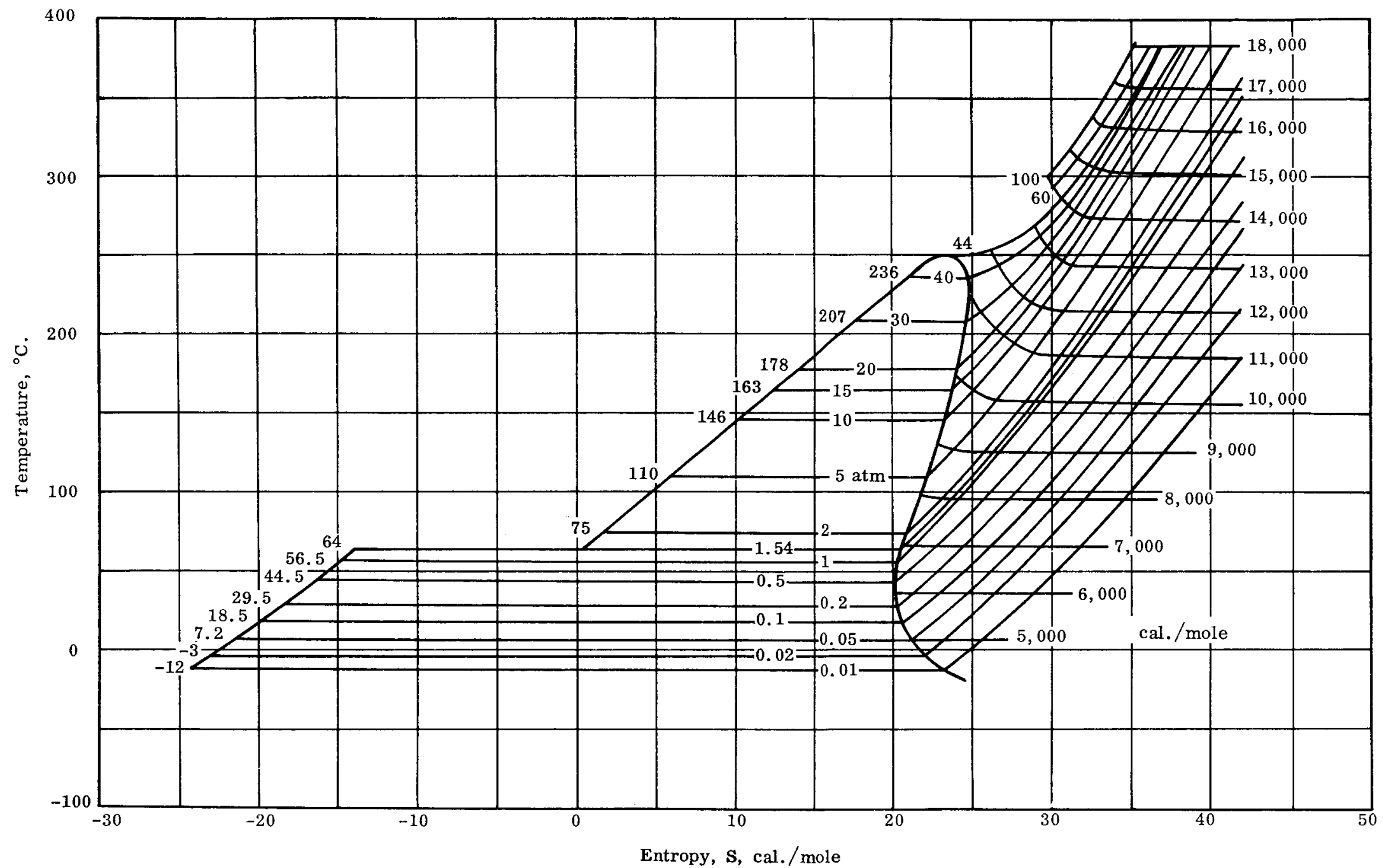

FIG. 16. AN APPROXIMATE ENTROPY DIAGRAM (Reference 73) 


\section{ENTROPY OF THE VAPOR}

Entropy values of the vapor, which were determined by various methods, are presented in Table 34. Kirshenbaum ${ }^{93}$ derived an expression, Equation 67, for the entropy of the vapor from thermodynamic data and vapor pressure equations of the condensate:

$\mathrm{S}_{(1 \mathrm{~atm} .)}=\left[74.69 \log \mathrm{T}+7.935 \times 10^{-3} \mathrm{~T}+16.034 \times 10^{4} \mathrm{~T}^{-2}-98.05\right] \mathrm{cal} . / \mathrm{mole} \mathrm{deg}$.

Values obtained from this equation are in reasonable agreement with those obtained from other sources. Approximate entropy values can be obtained from the curve given in Figure 17.

The entropy of the vapor has been calculated at one atmosphere for temperatures ranging from $0^{\circ}$ to $100^{\circ} \mathrm{C}$. using the third-law addition of entropies and Equation 68:

$$
\mathrm{S}^{\circ}=\mathrm{S}_{\mathrm{Sat}}+\Delta \mathrm{S}_{\mathrm{V}}+\Delta \mathrm{S}_{(\text {ideal-real) }}+\mathrm{R} \ln \mathrm{P}(\mathrm{atm} .)
$$

where $\Delta S_{(\text {ideal-real) }}=27 R P\left(T_{C}\right)^{3} / 32 P_{c}(T)^{3}$

The values of $S_{S a t}$ are those obtained by Brickwedde and his co-workers. The $\Delta S_{V}$ values were obtained from the calculated values of the heats of vaporization and sublimation based on Magnuson's non-ideality parameter and are listed in Table 36 and in Table 37 , respectively. The values of the critical constants and the vapor pressure data are those obtained by Oliver and his co-workers ${ }^{119}$.

Weinstock and Crist ${ }^{142}$ calculated the entropy of the vapor at several temperatures using measurements of the vapor pressure and a form of the Berthelot equation which incorporated values of the heat of fusion and the heat capacity at the triple point. The values of the various constants used in the calculations are: the triple point temperature, $T_{t}=$ $337.213^{\circ} \mathrm{K}$.; the heat of fusion, $\Delta \mathrm{H}_{\mathrm{f}}=4588 \mathrm{cal} . / \mathrm{mole}$; the heat capacity at the triple point, $\Delta \mathrm{c}_{\mathrm{p}}^{\mathrm{t}}=2.10 \mathrm{cal} . / \mathrm{mole}$; the critical temperature $\mathrm{T}_{\mathrm{c}}=518^{\circ} \mathrm{K}$; ; and the critical pressure, $p_{c}=36,000 \mathrm{~mm}$. Hg. Values of the entropy of the vapor determined by Weinstock and Crist are given in Table 34.

Masi ${ }^{113}$ calculated the entropy, $S^{\circ}$, of $U_{6}$ gas (ideal) at one atmosphere from the thirdlaw addition of entropies using entropy values which were calculated from the experimentally determined heats of vaporization and sublimation, using Equation 68 where the $S_{\text {sat }}$ values used were those obtained by Brickwedde and his co-workers except that values for the liquid were lowered by $0.05 \mathrm{cal} . / \mathrm{mole}$ deg., corresponding to a change in the heat of fusion from 4588 to $4570 \mathrm{cal}$./mole. For comparis on Masi obtained values of $\mathbf{S}^{\circ}$ for corresponding temperatures by interpolating in the table calculated by Bigeleisen and his co-workers ${ }^{20}$. These values are listed in parentheses in column 2 of Table 34.

Entropy values calculated from vibrational spectra compare favorably with those obtained by Weinstock and Crist from vapor pressure data. This comparison was first made by Bigeleisen and his co-workers. Entropy values calculated by Bigeleisen and his coworkens are given in column 2 of Table 34 ; those calculated by Gaunt ${ }^{65}$ are given in column 4; and those calculated by Duncan ${ }^{44}$ are given in column 6 .

\section{FREE ENERGY OF THE VAPOR}

The free energy function, $-\left(F^{\circ}-E_{0}^{\circ}\right) / T$, for $U_{6}$ vapor was calculated by Bigeleisen and others ${ }^{20}$ and more recently by Gaunt ${ }^{65}$. These values, as well as other values calculated by Bigeleisen and his co-workers such as for the thermodynamic properties determined on the basis of the spectral data, compare favorably with each other. Values of $-\left(F^{\circ}-E_{\circ}^{\circ}\right) / T$ in units of cal./mole deg. for temperatures between $100^{\circ}$ and $1000^{\circ} \mathrm{K}$. are presented in Table 35. 


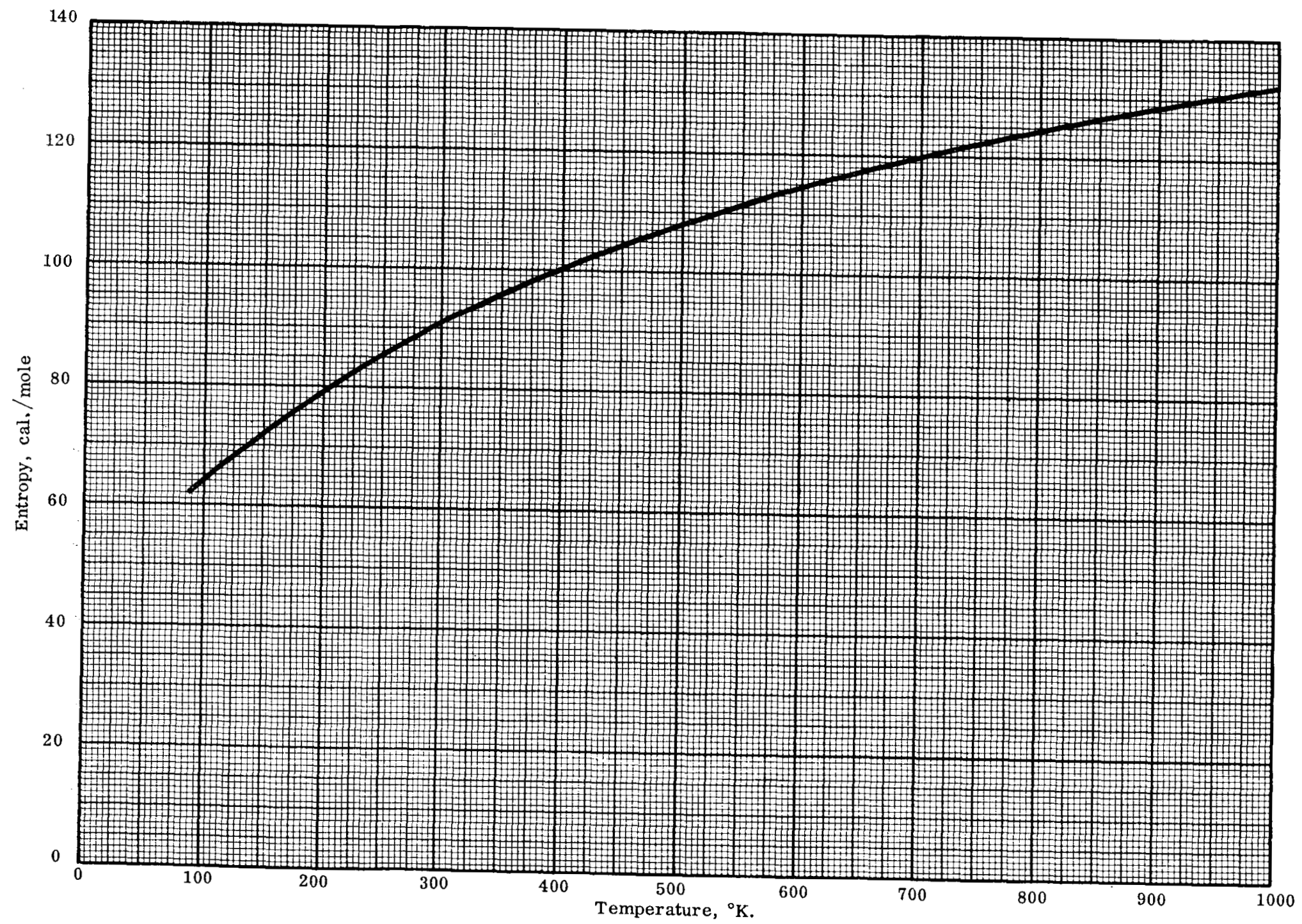

FIG, 17. ENTROPY OF THE VAPOR (Reference 20) 
Table 35

FREE ENERGY OF THE VAPOR

\begin{tabular}{|c|c|c|}
\hline \multirow[b]{2}{*}{$\begin{array}{c}\text { Temperature } \\
\left({ }^{\circ} \mathrm{K} .\right)\end{array}$} & \multicolumn{2}{|c|}{$-\left(\mathrm{F}^{\mathrm{O}}-\mathrm{E}_{\mathrm{O}}^{\mathrm{o}}\right) / \mathrm{T} \quad$ (cal./mole deg. $)$} \\
\hline & $\begin{array}{l}\text { Bigeleisen, et al. } \\
\text { (Ref. 20) }\end{array}$ & $\begin{array}{l}\text { Gaunt } \\
\text { (Ref. 65) }\end{array}$ \\
\hline 100 & 50.91 & 50.74 \\
\hline 150 & 56.41 & 56.18 \\
\hline 200 & 61.14 & 60.84 \\
\hline 250 & & 64.98 \\
\hline 273 & 67.08 & 66.75 \\
\hline 298 & 68.92 & 68.57 \\
\hline 323 & 70.69 & \\
\hline 348 & 72.33 & \\
\hline 350 & & 72.12 \\
\hline 373 & 73.93 & \\
\hline 400 & 75.65 & 72.25 \\
\hline 500 & 81.25 & 80.85 \\
\hline 750 & 92.99 & \\
\hline 1000 & 101.37 & \\
\hline
\end{tabular}

\section{HEATS OF VAPORIZATION AND OF SUBLIMATION}

The heats of vaporization and sublimation have been determined by two methods, one a direct calorimetric measurement and the other an indirect method based on vapor pressure data and the Clapeyron equation. Values obtained by these methods are not in the best agreement. Summaries of values for the heat of vaporization and the heat of sublimation are presented in Tables 36 and 37 respectively. Comparisons of the experimental values with values calculated on the basis of the most recent vapor pressure data are presented in Figures 18 and 19.

Masi $i^{113}$ measured the heats of sublimation and vaporization at temperatures between $4^{\circ}$ and $90^{\circ} \mathrm{C}$. From these data he calculated the entropies of vaporization and sublimation and the entropy of the ideal gas at one atmosphere (see page 70 ).

The apparatus, which consisted of a heavy-wall, nickel-plated calorimeter, was tested by obtaining a number of values for the heat of vaporization of water at various temperatures before the measurements were begun. The mean values at $60^{\circ}$ and $95^{\circ} \mathrm{C}$. were reported to be 0.05 and 0.07 percent smaller, respectively, than the values given by Osborne, Stimson and Ginnings*.

*Obsorne, N. S., Stimson, H. F. and Ginnings, D. C. J. Research Natl. Bur. Standards $\underline{23}, 256(1939)$. 
Table 36

\section{HEATS OF VAPORIZATION}

$\Delta \mathrm{H}_{\mathrm{v}}$ (kcal./mole)

\begin{tabular}{|c|c|c|c|c|c|c|c|}
\hline \multirow{3}{*}{$\begin{array}{c}\text { Temperature } \\
\left({ }^{\circ} \mathrm{K} .\right) \\
\end{array}$} & \\
\hline & \multicolumn{2}{|c|}{$\begin{array}{l}\text { Calculated on Basis of Vapor } \\
\text { Pressure Data of Oliver etal. }{ }^{19} \\
\text { and the Non-ideality Parameters } \\
\text { Proposed by }\end{array}$} & \multirow{2}{*}{$\begin{array}{l}\text { Weinstock } \\
\text { and Crist } \\
\text { (Ref. 142) }\end{array}$} & \multirow{2}{*}{$\begin{array}{c}\text { Simon } \\
\text { (Ref. 135)* }\end{array}$} & \multirow{2}{*}{$\begin{array}{c}\text { Kirshenbaum } \\
\text { (Ref. 93) }\end{array}$} & \multirow{2}{*}{$\begin{array}{c}\text { Masi } \\
\text { (Ref. 113) }\end{array}$} & \multirow{2}{*}{$\begin{array}{l}\text { Cohen } \\
\text { (Ref. 38) }\end{array}$} \\
\hline & Magnuson & Weinstock & & & & & \\
\hline 337.18 & 6.792 & & & & & & \\
\hline 337.21 & & & & $6.920 \pm 0.1$ & 7.038 & 6.859 & \\
\hline 338.16 & 6.764 & & & & & & 6.950 \\
\hline $\mathbf{3 4 0}$ & & & & & 7.000 & 6.817 & \\
\hline 343.16 & 6.699 & 6.634 & & 6.890 & & & 6.890 \\
\hline 345 & & & & & 6.933 & & \\
\hline 348 & & & 6.487 & & & & \\
\hline 348.16 & & & & & & & 6.820 \\
\hline $\mathbf{3 5 0}$ & & & & & 6.865 & 6.671 & \\
\hline 355 & & & & & 6.797 & & \\
\hline 353.16 & 6.542 & 6.470 & & & & & 6.740 \\
\hline 360 & & & & & 6.729 & 6.533 & \\
\hline 363.16 & 6.374 & 6.264 & & 6.670 & & & 6.570 \\
\hline 365 & & & & & 6.660 & & \\
\hline 368.16 & & & & & & & 6.460 \\
\hline 370 & & & & & 6.591 & 6.404 & \\
\hline 373.16 & 6.206 & 6.067 & & & 6.547 & & \\
\hline 383.16 & 6.042 & 5.867 & & 6.310 & & & \\
\hline 393.16 & 5.875 & 5.661 & & & & & \\
\hline 403.16 & 5.708 & 5.446 & & 5.800 & & & \\
\hline 413.16 & 5.536 & 5.219 & & & & & \\
\hline
\end{tabular}

*See also Llwellyn ${ }^{107}$.

Table 37

\section{HEAT OF SUBLIMATION}

\begin{tabular}{|c|c|c|c|c|c|c|c|}
\hline \multirow{2}{*}{$\begin{array}{c}\text { Temperature } \\
\left({ }^{\circ} \mathrm{K} .\right)\end{array}$} & \multicolumn{3}{|c|}{$\begin{array}{l}\text { Calculated on Basis of Vapor Pressure } \\
\text { Data of Oliver et al. } .^{19} \text { and the Non- } \\
\text { Ideality Parameters Proposed by }\end{array}$} & \multirow{2}{*}{$\begin{array}{l}\text { Weinstock } \\
\text { and Crist } \\
\text { (Ref. 142) }\end{array}$} & \multirow{2}{*}{$\begin{array}{c}\text { Simon } \\
\text { (Ref. 135)* }\end{array}$} & \multirow{2}{*}{$\begin{array}{c}\text { Kirshenbaum } \\
\text { (Ref. 93) }\end{array}$} & \multirow{2}{*}{$\begin{array}{c}\text { Masi } \\
\text { (Ref. 113) }\end{array}$} \\
\hline & Berthelot & Magnuson & Weinstock & & & & \\
\hline 198.16 & & & & & 12.20 & & \\
\hline 223.16 & & & & & 12.15 & & \\
\hline 248.16 & & & & & 12.08 & & \\
\hline 273 & & & & 12.22 & & & \\
\hline 273.16 & 12.086 & 12.082 & 12.080 & & 11.98 & 12.22 & 12.023 \\
\hline 275 & & & & & & 12.20 & \\
\hline 280 & & & & & & 12.16 & 11.988 \\
\hline 283.16 & 11.973 & 11.969 & 11.965 & & & & \\
\hline 285 & & & & & & 12.12 & \\
\hline 290 & & & & & & 12.08 & 11.929 \\
\hline 293.16 & 11.857 & 11.849 & 11.842 & & 11.87 & & \\
\hline 295 & & & & & & 12.04 & \\
\hline 298 & & & & 11.97 & & & \\
\hline 298.16 & $11.80^{\dagger}$ & & & & & 12.01 & 11.872 \\
\hline 300 & & & & & & 12.00 & 11.858 \\
\hline 303.16 & 11.764 & 11.753 & 11.739 & & & & \\
\hline 305 & & & & & & 11.95 & \\
\hline 310 & & & & & & 11.91 & 11.772 \\
\hline 313.16 & 11.676 & 11.660 & 11.636 & & 11.73 & & \\
\hline 315 & & & & & & 11.86 & \\
\hline 320 & & & & & & 11.81 & 11.666 \\
\hline 323 & & & & 11.58 & & & \\
\hline 323.16 & 11.574 & 11.547 & 11.506 & & & & \\
\hline 325 & & & & & & 11.76 & \\
\hline 329.7 & $11.50^{(1 \mathrm{a}}$ & a.) ${ }^{1}$ & & & & & \\
\hline 330 & & & & & & 11.71 & 11.537 \\
\hline 333.16 & 11.440 & 11.404 & 11.331 & & 11.53 & & \\
\hline 335 & & & & & & 11.65 & \\
\hline 337.18 & $\begin{array}{l}11.372 \\
11.38^{\dagger}\end{array}$ & & & & & & \\
\hline 337.21 & & & & & & 11.63 & 11.429 \\
\hline 338.16 & & & & & 11.47 & & \\
\hline
\end{tabular}

*See also Reference 107.

$\dagger$ Calculated by Oliver, et al. 


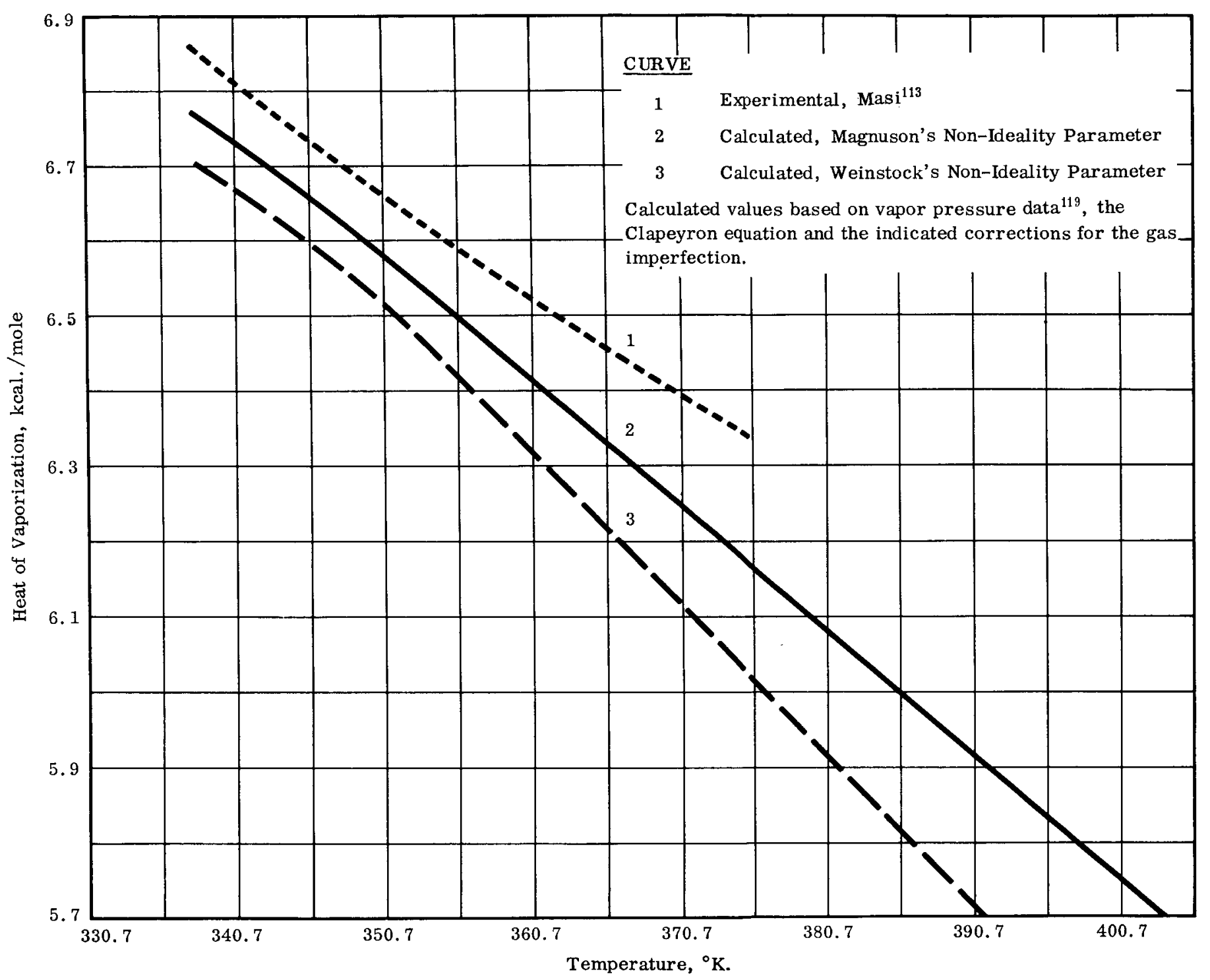

FIG. 18. HEATS OF VAPORIZATION 
The measured quantities, $\nu$, in the heat of vaporization experiments with $\mathrm{UF}_{6}$ were found by Masi to compare favorably with values of $\nu$ calculated from the Clapeyron equation and the vapor pressure data of Weinstock and Crist ${ }^{142}$. The vapor pressure data were reconciled with the measured heat data by using an equation of state of the form $\mathrm{PV}=\mathrm{RT}+\mathrm{BP}$, where the virial coefficient $\mathrm{B}_{\mathrm{cc}}=1082-\left(1.81 \times 10^{8}\right) \mathrm{T}^{-2} \mathrm{cc}$.

From the equations:

$$
\begin{array}{ll}
\text { Solid: } & \nu=\mathrm{RZ}(6581.2-1.9116 \mathrm{~T}) \\
\text { Liquid: } & \nu=\mathrm{RZ}(5678.2-6.2582 \mathrm{~T})
\end{array}
$$

where $\mathrm{Z}=1+(\mathrm{Bp} / \mathrm{RT})$

and the Clapeyron equation in the form:

$$
\Delta \mathrm{H}=\nu\left[1-\left(\mathrm{V}_{\mathrm{c}} / \mathrm{V}_{\mathrm{g}}\right)\right]
$$

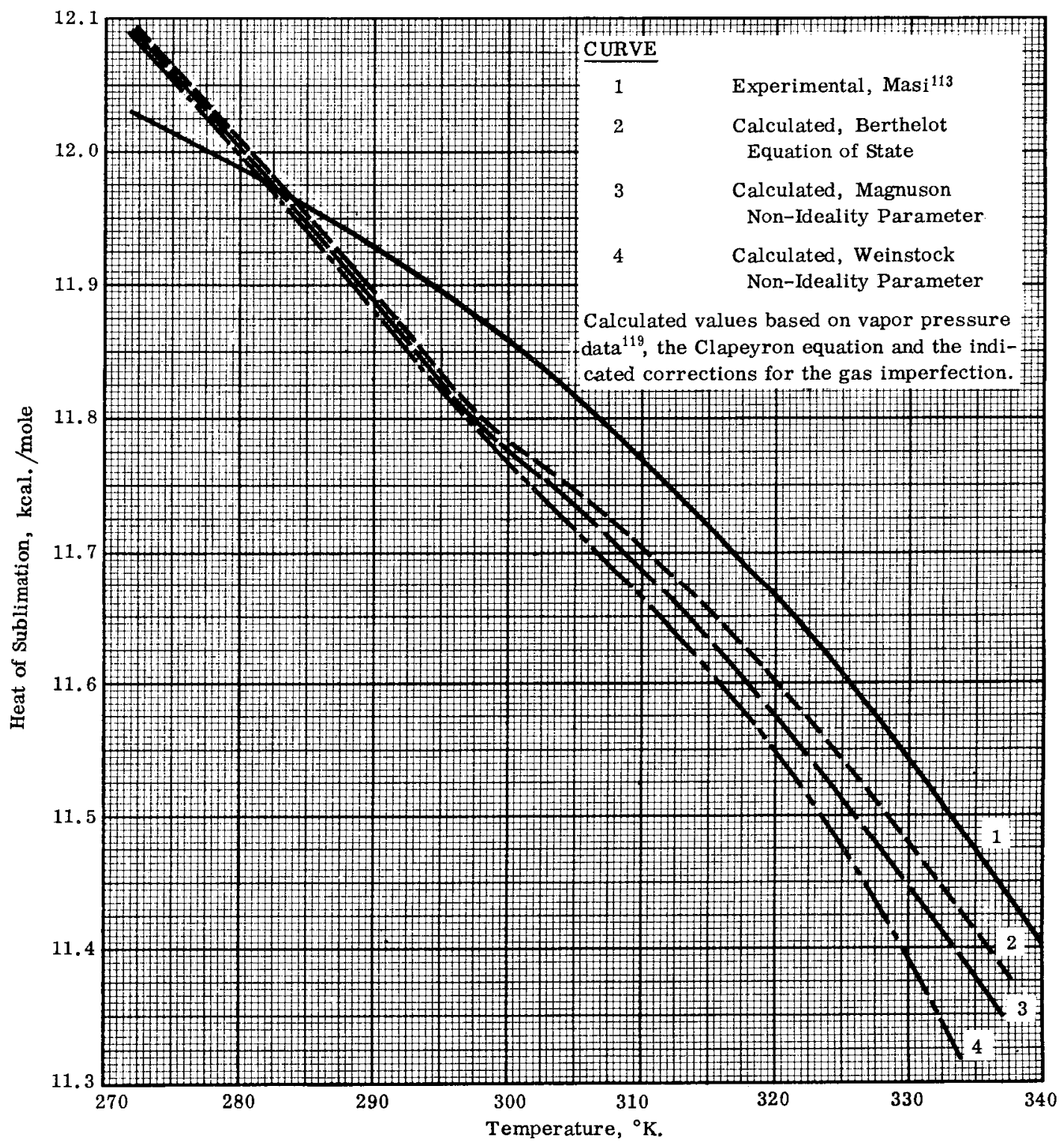

FIG. 19. HEATS OF SUBLIMATION 
he calculated the heats of vaporization and sublimation. The calculated values are tabulated in Tables 36 and 37 , respectively. Masi assigned a probability error of about one percent to the latent heat values. However, he also mentioned an unexplained phenomenon of an increasing difference between the third-law entropies and the spectroscopic entropies which were calculated by Bigeleisen and his co-workers.

The Clapeyron equation:

$$
\frac{\mathrm{dP}}{\mathrm{d} T}=\frac{\Delta \mathrm{H}}{\mathrm{T} \Delta \mathrm{V}}
$$

is applicable to the equilibrium between any two phases of one component and can be used to determine the heats of vaporization or sublimation whenever the vapor pressuretemperature relationships of a system are accurately known and the difference in the volumes of the two phases, $\Delta \mathrm{V}$, can be determined.

If the equilibrium under consideration is that between an ideal gas and the condensed phase, the equation of state of the ideal gas may be substituted to remove the volume term in Equation 72. The resulting equation is, of course, the Clausius-Clapeyron equation.

Heat values calculated using Equation 72 and the vapor pressure-temperature relationships reported by Oliver and his co-workers ${ }^{119}$ are listed in parentheses in the last columns of Tables 36 and 37. Vapor volumes needed for the determination of the heats of sublimation were calculated on the basis of Magnuson's proposed non-ideality parameter and the Berthelot equation; $V=[R T / P]\left[1+9 \mathrm{PT}_{\mathrm{c}} / 128 \mathrm{P}_{\mathrm{c}} \mathrm{T}\left(1-6 \mathrm{~T}_{\mathrm{c}}{ }^{2} / \mathrm{T}^{2}\right)\right]$ where $T_{c}=503.36^{\circ} \mathrm{K}$. and $P_{c}=45.5$ atmospheres. Volumes needed for the calculation of the heat of vaporization were determined in the same way using Weinstock's non-ideality parameters as well. The volumes of the liquid were calculated from the density values obtained by Wechsler and Hoge ${ }^{141}$. The volume of the solid was assumed to be constant over the $0^{\circ}$ to $60^{\circ} \mathrm{C}$. range and was calculated from the density value of 4.87 grams per cubic centimeter.

Oliver and his co-workers calculated the heat values from vapor pressure data, the Clapeyron equation, and the Berthelot equation. These values also are listed in the last column of Tables 36 and 37 .

In addition, other heat values have been calculated in a manner similar to that described above. Formulae representing the heats of vaporization reported, first by Simons ${ }^{135}$ and later by Llewellyn ${ }^{107}$, are as follows:

$$
\begin{aligned}
& \Delta \mathrm{H}_{\mathrm{V}}=\left[8890-0.0225 \mathrm{~T}^{2}+1.85 \mathrm{~T}\right] \mathrm{cal} . / \mathrm{mole} \mathrm{deg} . \\
& \Delta \mathrm{H}_{\mathrm{V}}=\left[6920-5.3(\mathrm{t}-65)-0.184(\mathrm{t}-65)^{2}\right] \mathrm{cal} . / \mathrm{mole} \mathrm{deg} .
\end{aligned}
$$

Equation 74 satisfies the condition that $\Delta \mathrm{H}_{\mathrm{V}}=0$ at the critical temperature $\left(t_{c}\right), 245^{\circ} \mathrm{C}$. Values of the heats obtained from these expressions are reported to agree with the experimental values of $\mathrm{Masi}^{113}$ to within two percent at $100^{\circ} \mathrm{C}$. These values are listed in Table 36. The heats of sublimation are expressed by the equation:

$$
\Delta H_{S}=\left[12,600-875,600 \mathrm{e}^{-2560 / T}-2 \mathrm{~T}\right] \text { cal./mole deg. }
$$

Values of the heats obtained from this expression are reported to agree with those obtained by Masi to within one percent and are shown in Table 37.

Kirshenbaum $^{93}$ also calculated the heats of vaporization and sublimation from vapor pressure data. He obtained the following representative equations:

$$
\Delta \mathrm{H}_{\mathrm{V}}=\left[2473.4+14.476 \mathrm{~T}-0.028546 \mathrm{~T}^{2}+987,670 \mathrm{~T}^{-1}\right] \text { cal. } / \text { mole deg. }
$$




$$
\Delta \mathrm{H}_{\mathrm{S}}=\left[-1405+52.512 \mathrm{~T}-0.076822 \mathrm{~T}^{2}+1,368,000 \mathrm{~T}^{-1}\right] \mathrm{cal} . / \mathrm{mole} \mathrm{deg} .
$$

Values obtained from these equations are also in agreement with those obtained experimentally by Masi. These values are also included in Tables 36 and 37 .

Weinstock and Crist ${ }^{142}$ calculated the heat of vaporization from the Clapeyron equation, except that they neglected the volume of the condensed phase. The quantity $\mathrm{dP} / \mathrm{dT}$ was calculated from vapor pressure expressions and the values of vapor volumes were determined from the Berthelot equation of state. These values too are found in Tables 36 and 37.

Cohen ${ }^{38}$ reported values for the heats of vaporization for the range between $65^{\circ}$ and $95^{\circ} \mathrm{C}$. These values were extrapolated as a function of temperature over the $60^{\circ}$ to $232^{\circ} \mathrm{C}$. range by utilizing the fact that $\Delta \mathrm{H}_{\mathrm{V}}=0$ at the critical point. Only the experimental values are given in this report. The extrapolated values can be found in the original work.

\section{HEAT OF VAPORIZATION AT $0^{\circ} \mathrm{K}$}

Weinstock, Weaver, and Malm ${ }^{144}$ evaluated the heat of vaporization, $\Delta \mathrm{H}_{\circ}^{\circ}$, at $0^{\circ} \mathrm{K}$. using two methods. One was based on the fundamental vibrational frequencies and utilized the methods of statistical mechanics. The other utilized vapor pressure data, the Clapeyron equation, and the third law of thermodynamics. In the case of their determinations based on statistical mechanics (Equation 78), using a virial coefficient $\mathrm{b}=3.6 \times 10^{3} \mathrm{~T}^{-2}$ cal. $\mathrm{mole}^{-1}(\mathrm{~mm} . \mathrm{Hg})^{-1}$ and the equation of state, $\mathrm{PV}=\mathrm{RT}+\mathrm{bP}$, instead of the Berthelot equation of state to define the non-ideality of the vapor, it was found that a constant value, $\Delta H_{o}^{\circ}=12,965 \pm 2$ cal. mole ${ }^{-1}$, was obtained from $280^{\circ}$ to $370^{\circ} \mathrm{K}$. In general, the agreement between the values of $\Delta \mathrm{H}_{\circ}^{\circ}$ obtained by the two methods was especially good when the gas imperfection was taken into account through use of the virial coefficient. A slight discrepancy at the lower pressure was accounted for by a slight systematic error in the vapor-pressure measurements of Oliver and his coworkers ${ }^{119}$ near $0^{\circ} \mathrm{C}$. (see Vapor Pressure, page 81 ).

Only the most recent data were used for the computations. The heat of vaporization at $0^{\circ} \mathrm{K}$. was evaluated using the fundamental vibrational frequencies proposed by the authors (see Table 13) and the relation

$$
\Delta H_{o}^{\circ}=-\left(F^{\circ}-H_{o}^{\circ}\right) g+\left(F-H_{o}^{\circ}\right)_{c}-R T \ln P-\left(F-F_{i d e a l}\right) g
$$

in which the free energy function of the ideal gas, $-\left(F^{\circ}-H_{\circ}^{\circ}\right) g$, was calculated by means of statistical mechanics using $1.994 \AA$ for the U-F distanc $e^{143}$ and in which the free energy function for the condensed phases, $\left(\mathrm{F}-\mathrm{H}_{\circ}^{\circ}\right)_{c}$, was taken from the heat capacity measurements of Brickwedde and his co-workers ${ }^{24}$. The vapor pressure equations and critical constants of Oliver and his co-workers were used in all the necessary calculations. The $\Delta \mathrm{H}_{\circ}^{\circ}$ calculated from Equation 78 was then compared to the values obtained from Equation 79:

$$
\Delta \mathrm{H}_{\circ}^{\circ}=\Delta \mathrm{H}-\left(\mathrm{H}^{\circ}-\mathrm{H}_{\circ}^{\circ}\right)_{\mathrm{g}}-\left(\mathrm{H}-\mathrm{H}_{\circ}^{\circ}\right)_{\mathrm{c}}-\left(\mathrm{H}-\mathrm{H}^{\circ}\right)_{\mathrm{g}}
$$

where the heats of vaporization and sublimation, $\Delta \mathrm{H}$, were evaluated using the vapor pressure equation of Oliver and his co-workers and the Clapeyron equation. Both the proposed equation of state and the Berthelot equation of state were used todetermine $\Delta \mathrm{H}$ values. The other thermodynamic quantities used in the equation were derived in a manner similar to that used above.

\section{ENTROPIES OF VAPORIZATION AND OF SUBLIMATION}

For a small reversible change, the entropy of sublimation or vaporization, dS, can be calculated by use of the following equation: 


$$
\mathrm{dS}=\frac{\mathrm{dq}}{\mathrm{T}}
$$

where dq is the heat absorbed. It must be emphasied that Equation 80 is applicable to the phase changes in which $d q$ is taken up isothermally and reversibly as the heat absorbed in the isothermal stage of a Carnot cycle.

Masi ${ }^{113}$ calculated the entropies of vaporization and of sublimation from the experimental heat values. The entropy values are given in Table 38 and Figure 20 along with values calculated from heat values determined from recent vapor pressure data and values calculated from heat values reported by Crist and Weinstock ${ }^{142}$.

\section{HEAT OF FUSION}

The heat of fusion of $\mathrm{UF}_{6}$ was determined calorimetrically by Brickwedde and his coworkers $^{24}$. They reported a value of 19,193 joule mole $^{-1}$ or $4588 \mathrm{cal}$. mole $\mathrm{c}^{-1}$. Oliver and his co-workers ${ }^{119}$ determined the heat of fusion, $\Delta \mathrm{H}_{\mathrm{f}}$, from the heat of vaporization, $\Delta H_{V}$, and the heat of sublimation, $\Delta H_{S}$, at the triple point in the straightforward manner:

$$
\begin{aligned}
\Delta \mathrm{H}_{\mathrm{f}} & =\Delta \mathrm{H}_{\mathrm{S}}-\Delta \mathrm{H}_{\mathrm{V}} \\
& =4.56 \mathrm{kcal} . \mathrm{mole}^{-1}
\end{aligned}
$$

Weinstock and his co-workers ${ }^{144}$ also calculated the heat of fusion in the same manner as described above, that is, from the difference between the calculated heats of sublimation and vaporization. The value, $4.555 \mathrm{kcal}$. mole ${ }^{-1}$, compares favorably with the measured value. All of the above-mentioned values are in agreement with the earlier results reported as $4.5 \pm 0.5 \mathrm{kcal}$. mole $\mathrm{e}^{-1}$ at $64.5^{\circ} \mathrm{C}$. by British workers $\mathrm{s}^{47,48,50,51,55}$. 
Table 38

ENTROPIES OF VAPORIZATION AND SUBLIMATION

\begin{tabular}{|c|c|c|c|}
\hline \multirow[b]{2}{*}{$\begin{array}{c}\text { Temperature } \\
\left({ }^{\circ} \mathrm{K} .\right)\end{array}$} & \multicolumn{3}{|c|}{ Entropy, s (cal./mole deg.) } \\
\hline & $\begin{array}{c}\text { Masi } \\
\text { (Ref. 113) }\end{array}$ & $\begin{array}{l}\text { Weinstock } \\
\text { and Crist } \\
\text { (Ref. 142) }\end{array}$ & $\begin{array}{c}\text { Calc. on Basis } \\
\text { of Data from } \\
\text { Oliver et al. } \\
\text { (Ref. 119) }\end{array}$ \\
\hline & & SUBLIMATIO & \\
\hline 273.16 & 44.02 & 44.77 & 44.25 \\
\hline 280 & 42.81 & & \\
\hline 283.16 & & & 42.28 \\
\hline 290 & 41.13 & & \\
\hline 293.16 & & & 40.45 \\
\hline 298 & & 40.18 & \\
\hline 298.16 & 39.82 & & \\
\hline 300 & 39.53 & & \\
\hline 303.16 & & & 38.81 \\
\hline 310 & 37.97 & & \\
\hline 313.16 & & & 37.28 \\
\hline 320 & 36.46 & & \\
\hline 323 & & 35.86 & \\
\hline 323.16 & & & 35.82 \\
\hline 330 & 34.96 & & \\
\hline 333.16 & & & 34.34 \\
\hline 337.18 & & & 33.73 \\
\hline 337.21 & 33.89 & & \\
\hline
\end{tabular}

\section{VAPORIZATION}

337.18

337.21

338.16

340

343.16

348

350

353.16

360

363.16

370

373.16

393.16

403.16

413.16

20.34

20.06

19. 99

20.05

19.52

19.06

18.64

18.53

18.15

17.55

17. 31

16.64

14.94

14.16

13.40 


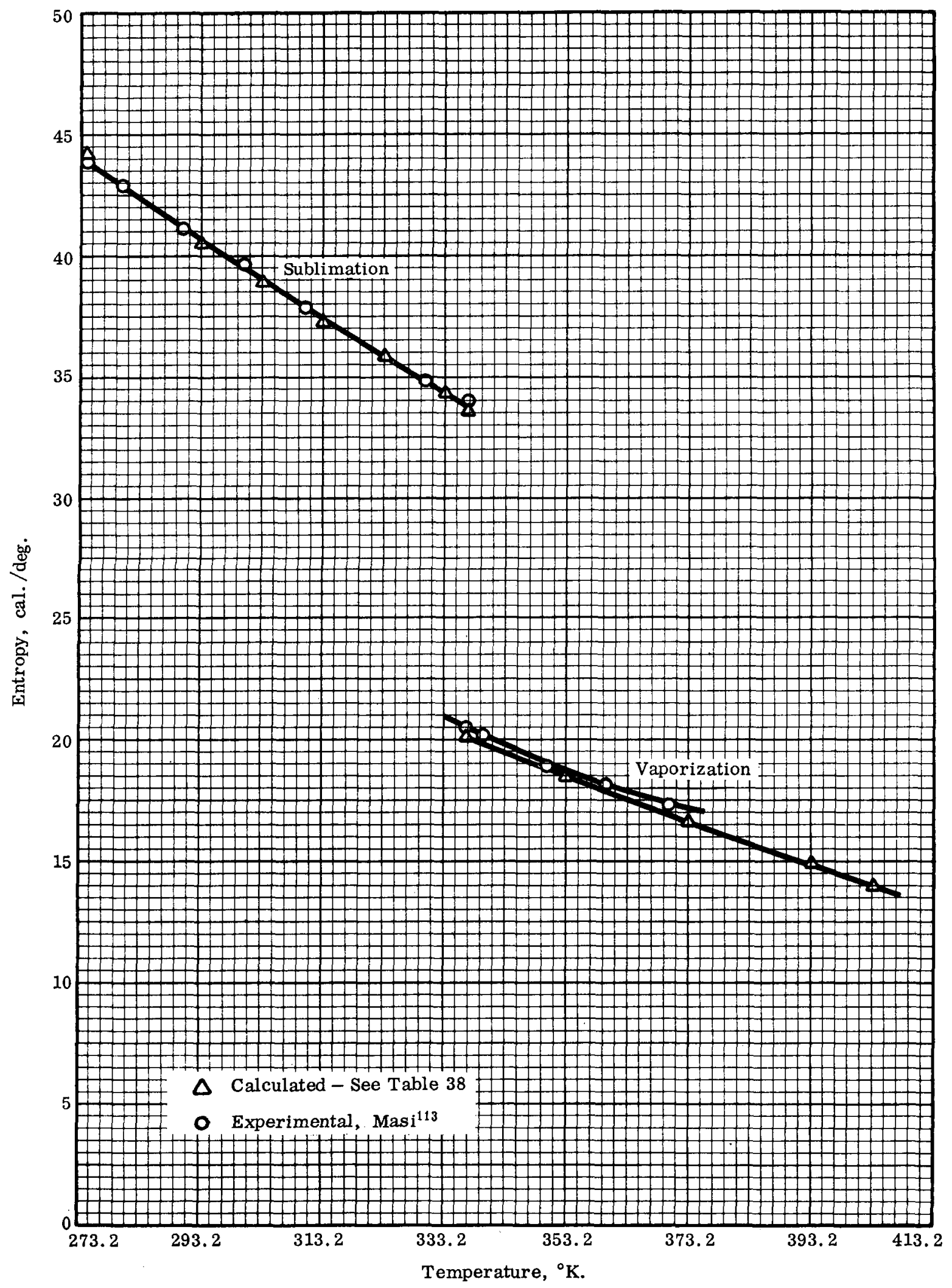

FIG. 20. ENTROPIES OF SUBLIMATION AND VAPORIZATION 


\section{PHASE RELATIONS}

\section{VAPOR PRESSURE}

The vapor pressure of $\mathrm{UF}_{6}$ has been investigated many times, especially in the low pressure range. Most of the early vapor pressure data appeared in the report literature of the atomic energy projects of the United States and Great Britain with summaries of the more reliable data appearing in the open literature. Of the more reliable data, those obtained by Oliver, Milton, and Grisard ${ }^{119}$ are the most extensive, covering temperatures ranging from $0^{\circ}$ to near the critical point, $230.2^{\circ} \mathrm{C}$. These data, which are accurately represented by three Antoine vapor pressure-temperature expressions, are found to compare favorably with other less extensive but, nevertheless, reliable data. However, Weinstock and his co-workers ${ }^{144}$ recently pointed out that a slight systematic error appears in the vapor-pressure measurements of Oliver and his co-workers near $0^{\circ} \mathrm{C}$. By using the Clapeyron equation and a value for $\Delta \mathrm{H}_{\circ}^{\circ}$ of $12,965 \mathrm{cal} . \mathrm{mole}^{-1}$, they calculated that the vapor-pressure of $\mathrm{UF}_{6}$ at $0^{\circ} \mathrm{C}$. is $17.70 \mathrm{~mm}$. $\mathrm{Hg}$. This compares favorably with the value $17.65 \mathrm{~mm}$. $\mathrm{Hg}$ obtained at the ice point which was reported to Weinstock by Plurien in a footnote in the previous article ${ }^{144}$.

The observed vapor pressure data for the solid are listed in Tables 39 and 40 while those for the liquid are listed in Table 41. The representative expressions for the recent reliable data along with some of the experimental methods used to obtain them, are presented below. Earlier data, mostly of a preliminary nature, are referred to and summarized by their representative equations in Table 42 .

Oliver and his co-worker $\mathrm{s}^{119}$ measured the vapor pressure of the solid from $0^{\circ}$ to $64.02^{\circ} \mathrm{C}$. by both static and ebulliometric methods. They measured the vapor pressure of the liquid from $64^{\circ} \mathrm{C}$. to the critical temperature by the ebulliometric method alone. The two methods of measuring pressure yielded results consistent within the experimental error (Tables 39 and 41). The temperatures were accurately measured within $\pm 0.01^{\circ} \mathrm{C}$, , but the accuracy of the ebulliometric pressure measurements depended upon the accuracy of the reference, the boiling point of water. This was taken from the Osborne-Meyers steam tables*.

The vapor pressure of the solid is represented by a modified Antoine equation, Equation 82 , which has an estimated uncertainty, based on a 95 percent confidence level, of \pm 0.05 percent. The vapor pressure of the liquid from $64^{\circ}$ to $116^{\circ} \mathrm{C}$. is represented by Equation 83 , and above $116^{\circ} \mathrm{C}$. by Equation 84 . The uncertainties of these equations are \pm 0.03 percent and \pm 0.3 percent, respectively at the same confidence level.

$$
\begin{aligned}
& \frac{\text { Solid, Vapor; } 0^{\circ} \text { to } 64^{\circ} \mathrm{C} .}{\log _{10} \mathrm{P}_{(\mathrm{mm} .)}=6.38353}+0.0075377 \mathrm{t}-942.76 /(\mathrm{t}+183.416) \\
& \frac{\text { Liquid, Vapor; } 64^{\circ} \text { to } 116^{\circ} \mathrm{C} .}{\log _{10} \mathrm{P}_{(\mathrm{mm} .)}=6.99464-1126.288 /(\mathrm{t}+221.963)} \\
& \frac{\text { Liquid, Vapor; } 116^{\circ} \mathrm{C} \text {. to critical point }}{\log _{10} \mathrm{P}_{(\mathrm{mm} .)}=7.69069-1683.165 /(\mathrm{t}+302.148)}
\end{aligned}
$$

\footnotetext{
*Osborne, N. S. and Meyers, C. H. J. Research Natl. Bur. Standards 13, 1-20(1934).
} 
Table 39

EXPERIMENTAL VALUES OF THE VAPOR PRESSURE OF THE SOLID

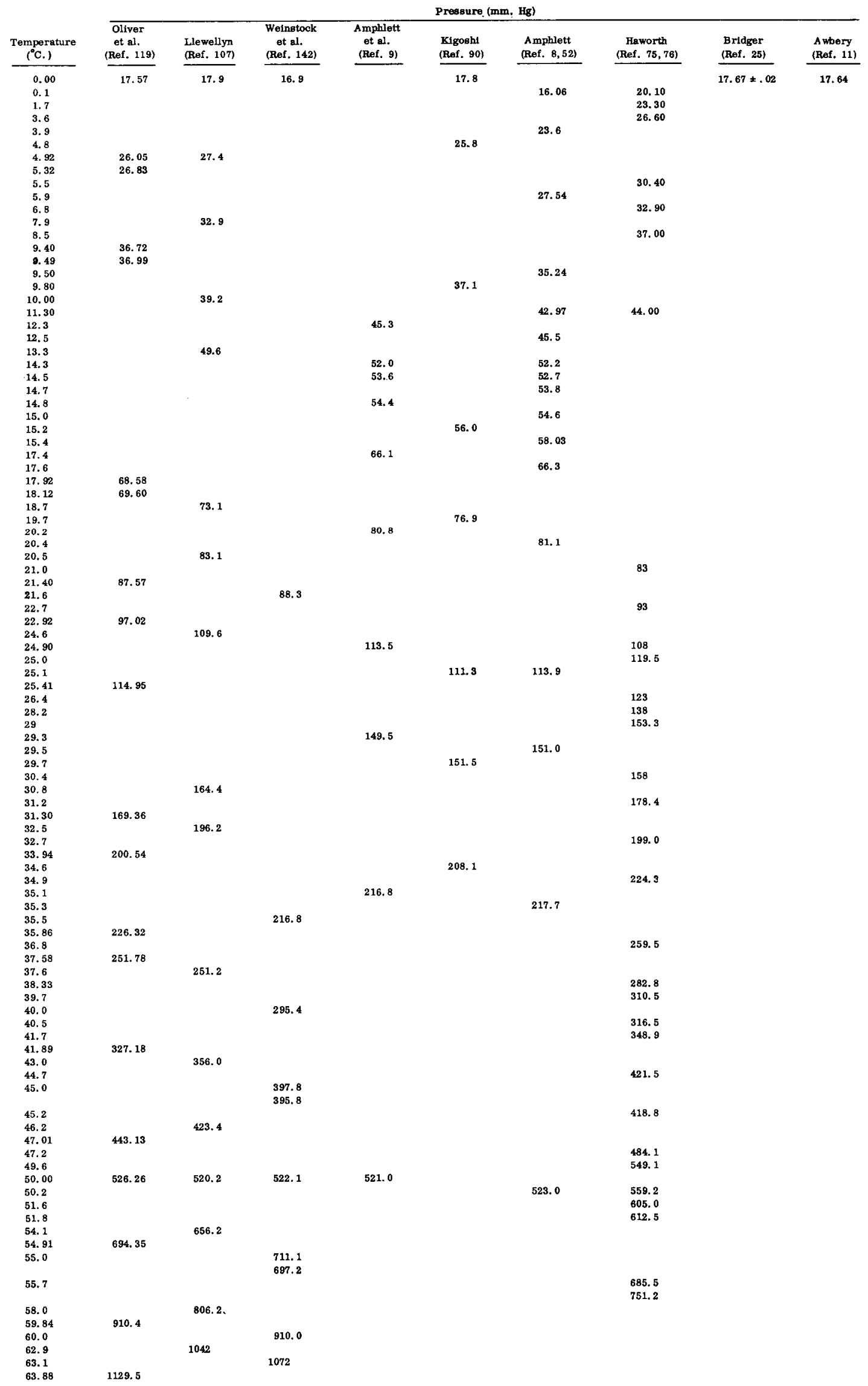


Table 40

VAPOR PRESSURE OF THE SOLID AT LOW TEMPERATURES

Pressure (mm. Hg)

Temperature

$\left({ }^{\circ} \mathrm{C}.\right)$

$-200$

$-183$

$-150$

$-100$

$-90$

$-80$

$-78$

$-70$

- 60

- 50

- 40

$-30$

$-25$

$-20$

$-15$

- 14

$-14.2$

$-13$

$-12.4$

$-11$

$-10$

$-5$

$-2$

$-\quad 1.5$

$-1$

0

\begin{tabular}{ll}
\hline $\begin{array}{c}\text { Awbery } \\
(\text { Ref. 11) }\end{array}$ & $\begin{array}{l}\text { Llewellyn* } \\
\text { (Ref. 107) }\end{array}$ \\
\hline $2 \times 10^{-25}$ & $10^{-26}$ \\
$9 \times 10^{-19}$ & $10^{-11}$ \\
$5 \times 10^{-11}$ & $4.3 \times 10^{-5}$ \\
$5.8 \times 10^{-5}$ & $3.0 \times 10^{-4}$ \\
& $1.7 \times 10^{-3}$
\end{tabular}

$2.8 \times 10^{-3}$

0.037

$8.2 \times 10^{-3}$

0.034

0.173

0.414

0.369

1.16

1. 949

3.136

3.11

4. 953

5.00

5.42

6.85

5.93

7. 80

7.08

7.73

11.9

15.2

17.80

16.5

17.9

*Calculated values. See Equation 91 ; see also Ref. 135.

$\dagger^{\dagger}$ Experimental values. 
Table 41

VAPOR PRESSURES OF THE LIQUID

Pressure (mm. Hg)

\begin{tabular}{|c|c|c|c|c|c|}
\hline $\begin{array}{c}\text { Temperature } \\
\left({ }^{\circ} \mathrm{C} .\right) \\
\end{array}$ & $\begin{array}{c}\text { Oliver et al. } \\
\text { (Ref. 119) }\end{array}$ & $\begin{array}{l}\text { Llewellyn } \\
\text { (Ref. 107) }\end{array}$ & $\begin{array}{l}\text { Weinstock } \\
\text { (Ref. 142) } \\
\end{array}$ & $\begin{array}{c}\text { Abelson* } \\
\text { (Ref. 1) } \\
\end{array}$ & $\begin{array}{l}\text { Awbery }{ }^{\dagger} \\
\text { (Ref. 11) } \\
\end{array}$ \\
\hline 64.2 & $1,145.2$ & & & & \\
\hline 64.7 & & & & & 1,157 \\
\hline 64.8 & & 1,161 & & & \\
\hline 65.0 & & & 1,169 & 1,189 & 1,169 \\
\hline 65.99 & $1,211.4$ & & & & \\
\hline 66.18 & $1,218.8$ & & & & \\
\hline 67.06 & $1,252.2$ & & & & \\
\hline 67.9 & & & 1,273 & & \\
\hline 68.59 & $1,313.1$ & & & & \\
\hline 69.55 & $1,352.2$ & & & & \\
\hline 69.7 & & 1,338 & & & \\
\hline 70.0 & & 1,350 & & & 1,369 \\
\hline 70.1 & & & 1,360 & & \\
\hline 70.2 & & & 1,366 & & \\
\hline & & & 1,370 & & 1,377 \\
\hline & & & 1,376 & & \\
\hline 70.79 & $1,404.3$ & & & & \\
\hline 71.86 & $1,450.4$ & & & & \\
\hline 72.8 & & 1,470 & & & \\
\hline 72.82 & $1,492.3$ & & & & \\
\hline 74.11 & $1,550.7$ & & & & \\
\hline 74.75 & $1,580.3$ & & & & \\
\hline 75.0 & & 1,566 & & & 1,594 \\
\hline 75.2 & & & 1,582 & & 1,603 \\
\hline 75.3 & & & 1,568 & & 1,608 \\
\hline 76.52 & $1,164.2$ & & & & \\
\hline 78.25 & $1,750.1$ & & & & \\
\hline 79.1 & & 1,752 & & & \\
\hline 80.0 & & & & 1,913 & 1,845 \\
\hline 80.19 & $1,849.2$ & & & & \\
\hline 80.3 & & & 1,830 & & \\
\hline & & & 1,838 & & 1,861 \\
\hline 82.0 & & 1,905 & & & \\
\hline 82.08 & $1,951.2$ & & & & \\
\hline 83.5 & & 1,970 & & & \\
\hline 83.87 & $2,050.8$ & & & & \\
\hline 85.0 & & 2,058 & & & 2,126 \\
\hline 85.4 & & & 2,087 & & 2,150 \\
\hline 85.54 & $2,147.8$ & & & & \\
\hline 86.63 & $2,212.8$ & & & & \\
\hline 87.20 & $2,247.0$ & & & & \\
\hline 88.84 & $2,348.7$ & & & & \\
\hline 89.3 & & 2,300 & & & \\
\hline 90.0 & & & & & 2,437 \\
\hline
\end{tabular}

*Values reported to have a probable error of 5 percent.

†Values calculated from Equation 105. 
Table 41 (Continued)

VAPOR PRESSURES OF THE LIQUD

\begin{tabular}{|c|c|c|c|c|c|}
\hline \multirow[b]{2}{*}{$\begin{array}{l}\text { Temperature } \\
\left({ }^{\circ} \mathrm{C} .\right)\end{array}$} & \multicolumn{5}{|c|}{ Pressure (mm. Hg) } \\
\hline & $\begin{array}{c}\text { Oliver et al. } \\
\text { (Ref. 119) } \\
\end{array}$ & $\begin{array}{l}\text { Llewellyn } \\
\text { (Ref. 107) } \\
\end{array}$ & $\begin{array}{l}\text { Weinstock } \\
\text { (Ref. 142) } \\
\end{array}$ & $\begin{array}{c}\text { Abelson* } \\
\text { (Ref. 1) } \\
\end{array}$ & $\begin{array}{l}\text { Awbery }{ }^{\dagger} \\
\text { (Ref. 11) }\end{array}$ \\
\hline 90.35 & $2,445.3$ & & & & \\
\hline 91.35 & $2,511.1$ & & & & \\
\hline 91.88 & $2,546.5$ & & & & \\
\hline 95.00 & & 2,648 & & & 2,781 \\
\hline 99.94 & $3,131.1$ & & & & \\
\hline 100.00 & & 2,985 & & 3,258 & 3,160 \\
\hline 108.07 & $3,818.4$ & & & & \\
\hline 116.03 & $4,596.8$ & & & & \\
\hline 118 & & & & 5,016 & \\
\hline 120 & & & & & 5,074 \\
\hline 124.17 & $5,512.3$ & & & & \\
\hline 133.19 & $6,669.7$ & & & & \\
\hline 137 & & & & 6,878 & \\
\hline 140 & & & & & 7,751 \\
\hline 141.44 & $7,888.6$ & & & & \\
\hline 149.50 & $9,226.0$ & & & & \\
\hline 157.83 & 10,773 & & & & \\
\hline 160 & & & & & 11,410 \\
\hline 170.64 & 13,528 & & & & \\
\hline 162 & & & 11,377 & & \\
\hline $\begin{array}{l}180 \\
180.57\end{array}$ & 15,986 & & & & 16,347 \\
\hline 188.85 & 18,294 & & & & \\
\hline 196.02 & 20,477 & & & & \\
\hline 199.85 & 21,735 & & & & \\
\hline 200 & & & & 22,755 & 22,988 \\
\hline 207.32 & 24,329 & & & & \\
\hline 213.82 & 26,779 & & & & \\
\hline 218.74 & 28,773 & & & & \\
\hline 220 & & & & & 31,954 \\
\hline 220.52 & 29,468 & & & & \\
\hline 224.76 & 31,409 & & & & \\
\hline 225.14 & 31,611 & & & & \\
\hline 225.57 & 31,781 & & & & \\
\hline 227.93 & 32,908 & & & & \\
\hline 228.38 & 33,260 & & & & \\
\hline 229.11 & 33,740 & & & & \\
\hline 230.2 & 34,580 & & & 37,235 & \\
\hline 240 & & & & & 44,168 \\
\hline 245 & & & & & 47,880 \\
\hline
\end{tabular}

*Values reported to have a probable error of 5 percent.

$\dagger$ Values calculated from Equation 105. 
Table 42

SUMMARY OF EARLIER DATA

ON VAPOR PRESSURE-TEMPERATURE RELATIONSHIPS

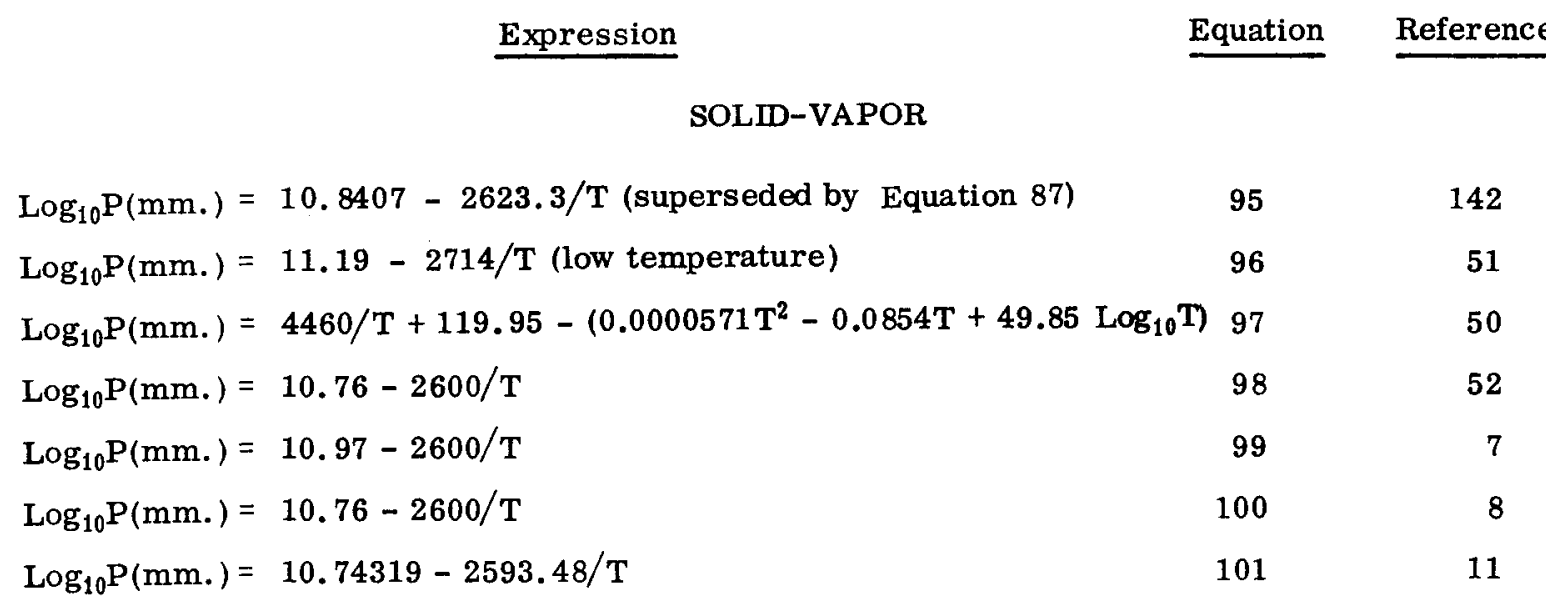

LIQUID-VAPOR

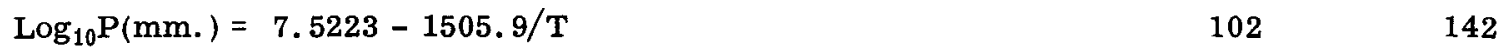

$\log _{10} \mathrm{P}(\mathrm{mm})=.7.73-1575 / \mathrm{T}$ (between $65^{\circ}$ and $\left.95^{\circ} \mathrm{C}.\right) \quad 103 \quad 51$

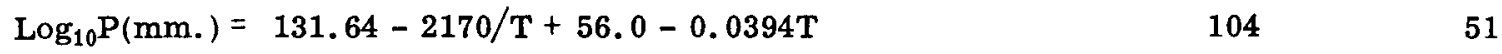

$\log _{10} \mathrm{P}(\mathrm{mm})=.17.81264-2916.9127+0.107489 \log _{10} \mathrm{~T}$

$-0.026137715 \mathrm{~T}+2.14125 \times 10^{-5} \mathrm{~T}^{2}$

105

10

Brooks and Wood ${ }^{27}$ fitted the liquid $\mathrm{UF}_{6}$ vapor pressure data of Oliver, Milton, and Grisard over the $64^{\circ}$ to $226^{\circ} \mathrm{C}$. range with a sixth-order polynomial in $1 / \mathrm{T}^{\circ} \mathrm{K}$. The equation which represents the data to \pm 0.0005 (standard deviation of $\ln P$ ) was used to calculate the vapor pressure of liquid $\mathrm{UF}_{\boldsymbol{B}}$ and the derivative of the vapor pressure with respect to temperature at integral values of the temperature. Some of the results are given in Table 43, although a more nearly complete tabulation of the results can be obtained directly from the primary literature source.

Grisard and Oliver compared the vapor pressures of normal $\mathrm{UF}_{6}$ and $\mathrm{UF}_{6}$ enriched to 92.93 weight percent $U^{235}$, in the temperature range $64^{\circ}$ to $92^{\circ} \mathrm{C}$. They found by a differential boiling point method that the average ratio of the vapor pressure of normal material to that of the enriched material was $1.000072 \pm 0.000018$.

Kigoshi ${ }^{90}$ measured the vapor pressure of solid $U_{6}$ which had been purified by a sublimation process. The measurements were made by a static method at the temperature interval $0^{\circ}$ to $34.6^{\circ} \mathrm{C}$. The results, listed in column 6 of Table 39, are expressed by the following equation:

Solid, Vapor; $0^{\circ}$ to $34.6^{\circ} \mathrm{C}$.

$$
\log _{10} P_{(m m .)}=10.023-(2486 / T)+0.0012 T
$$

where $T$ is the absolute temperature.

Amphlett, Mullinger, and Thomas ${ }^{9}$ measured the vapor pressure of solid $\mathrm{UF}_{6}$ from $12^{\circ}$ to $50^{\circ} \mathrm{C}$. by a null method, the deflection produced in a quartz spiral manometer being 
Table 43

\section{VAPOR PRESSURE OF THE LIQUID AND ITS DERIVATIVE} WITH RESPECT TO TEMPERATURE*

\section{(Reference 27)}

\begin{tabular}{c}
$\begin{array}{c}\text { Temperature } \\
\left({ }^{\circ} \mathrm{C} .\right)\end{array}$ \\
\hline 65 \\
70 \\
80 \\
90 \\
100 \\
110 \\
120 \\
130 \\
140 \\
150 \\
160 \\
170 \\
180 \\
190 \\
200 \\
210 \\
220
\end{tabular}

Pressure

(mm. Hg)

1174.3

1370.5

1839.3

2422.6

3135.1

3997.0

5025.9

6240.8

7663.7

9313.5

$11,210.0$

$13,379.0$

$15,840.0$

$18,626.0$

$21,768.0$

$25,313.0$

$29,314.0$
Derivative

$\mathrm{dp} / \mathrm{dt}$

(mm. Hg /deg.)

36.896

41.686

52.323

64.534

78.422

94.192

111.89

131.55

153.25

177.01

202.86

231.06

261.84

295.78

333.56

376.26

425.24

*For a more nearly complete listing see Ref. 27.

balanced by the admission of dry air and thebalancing pressure being read on a mercury manometer. The data, listed in column 5 of Table 39, are represented by the equation:

Solid, Vapor; $12^{\circ}$ to $50^{\circ} \mathrm{C}$.

$$
\log _{10} P_{(\mathrm{mm} .)}=10.74 .-2592 / \mathrm{T}
$$

Weinstock and Crist ${ }^{142}$ also used a null method to measure the vapor pressure of $\mathrm{UF}_{6}$ from 0 to $85^{\circ} \mathrm{C}$. Their results compare favorably with those of Amphlett and his coworkers $^{9}$. The apparatus used to make the measurements consisted of an all-metal system which contained a brass sylphon bellows and a multiple-type mercurydibutylphthalate manometer. Temperatures are reported to the nearest $0.1^{\circ} \mathrm{C}$., which the authors state introduces an error in the pressure of about $3 \mathrm{~mm}$. at $60^{\circ} \mathrm{C}$. and $5 \mathrm{~mm}$. at $85^{\circ} \mathrm{C}$. The data, listed in Tables 39 and 41 , are represented by the following equations: 
Solid, Vapor; $0^{\circ}$ to $64^{\circ} \mathrm{C}$.

$$
\log _{10} \mathrm{P}(\mathrm{mm} .)=-3.77962 \log _{10} \mathrm{~T}-(3023.479 / \mathrm{T})+21.87103
$$

Liquid, Vapor; $64^{\circ}$ to $85^{\circ} \mathrm{C}$.

$$
\log _{10} P_{(m m .)}=-3.72662 \log _{10} T-(2065.679 / T)+18.60033
$$

The constants of Equations 87 and 88 were adjusted to include the values for the heat of fusion $\left(\Delta \mathrm{H}_{\mathrm{f}}=4588 \mathrm{cal} . / \mathrm{mole}\right)$ and the triple point temperature which was obtained by Brickwedde, Hoge, and Scott. ${ }^{24}$

Masi ${ }^{113}$ reconciled his measured heats of vaporization with the vapor pressure data of Weinstock and Crist by using an equation of state of the form PV $=$ RT + BT where the virial coefficient is expressed as $\mathrm{B}_{\mathrm{cc}} .=1082-\left(1.81 \times 10^{8}\right) \mathrm{T}^{-2}$ cc. The reported vapor pressure equations are:

$$
\begin{aligned}
& \frac{\text { Solid, Vapor }}{\log _{10} P_{(m m .)}}=-(2858.2 / T)+16.3619-1.9116 \log _{10} T \\
& \frac{\text { Liquid, Vapor }}{\log _{10} P_{(m m .)}}=-(2466.0 / T)+26.1868-6.2582 \log _{10} T
\end{aligned}
$$

These equations were made to reproduce the heat of fusion $(4588 \mathrm{cal} . / \mathrm{mole})$ and the vapor pressure data of Weinstock and Crist.

Llewellyn ${ }^{107}$ reported vapor pressure data for temperatures from $-15^{\circ}$ to $100^{\circ} \mathrm{C}$. The vapor pressure data for the $0^{\circ}$ to $-15^{\circ} \mathrm{C}$. range are given in Table 40 and those for $0^{\circ}$ to $100^{\circ} \mathrm{C}$. are given in Tables 39 and 41 . These data are represented by the equations:

Solid, Vapor

$$
\log _{10} P_{(m m .)}=-2751 / T-75.0 e^{-2560 / T}-1.01 \log _{10} T+13.797
$$

Liquid, Vapor

$$
\log _{10} P_{(m m .)}=-1946 / T-0.00492 T+0.934 \log _{10} T+8.123
$$

Equations 91 and 92 have an estimated accuracy to 0.5 percent in the measured range.

Some of the earlier vapor pressure-temperature data, which appeared for the most part in early progress reports, were first summarized by Kirshenbaum ${ }^{93}$ and later reported by Katz and Rabinowitch ${ }^{88}$, by Murphy ${ }^{115}$, and by others. From the pressure-temperature data available to Kirshenbaum, he derived Equations 93 and 94 as being the best representation of all the then available experimental data.

$$
\begin{aligned}
& \frac{\text { Solid, Vapor }}{\log _{10} \mathrm{P}(\mathrm{mm} .)}=-57.7043-149,610 / \mathrm{T}^{2}+307.18 / \mathrm{T}+26.436 \log \mathrm{T}-0.016796 \mathrm{~T} \\
& \frac{\text { Liquid, Vapor }}{\log _{10} \mathrm{P}(\mathrm{mm} .)}=-10.7098-107,969 / \mathrm{T}^{2}-540.8 / \mathrm{T}+7.2876 \log \mathrm{T}-0.006241 \mathrm{~T}
\end{aligned}
$$

Equation 93 is reported by Kirshenbaum to represent the experimental data to \pm 0.5 percent and Equation 94 to represent the data in the temperature range $65^{\circ}$ to $90^{\circ} \mathrm{C}$. to \pm 0.4 percent.

Vapor pressure values of solid $\mathrm{UF}_{6}$ at very low temperatures (between $-200^{\circ}$ and $0^{\circ} \mathrm{C}$.) have been calculated by using Equation 91 . These and other experimental and calculated vapor pressure data for low temperatures are presented in Table 40. 
To complete as nearly as possible the record of literature findings on the vapor pressuretemperature relationships, a summary of some of the earlier data, consisting mostly of preliminary relationships, is shown in Table 42.

\section{SUBLIMATION POINT}

Since $U_{6}$ has a triple point pressure in excess of one atmosphere, it cannot be melted at atmospheric pressure nor can it have a normal boiling point. However, a sublimation point, the temperature at which the solid vapor pressure attains $760 \mathrm{~mm}$. $\mathrm{Hg}$, has often been referred to in the literature as the "boiling point."

The sublimation point at $760 \mathrm{~mm}$. Hg reported by Oliver and his co-workers ${ }^{119}$ compares favorably with the value reported by Crist and Weinstock ${ }^{142}$. These values, presented in Table 44, are in agreement with the other reported values also listed.

Table 44

\section{SUBLIMA TION TEMPERA TURE AT ONE ATMOSPHERE}

Temperature

$\left({ }^{\circ} \mathrm{C}.\right)$

56.54

56.5

$56.7 *$

56.76

56.2

\section{Reference}

11

71

* Calculated from vapor pressure Equation 86.

\section{TRIPLE POINT}

Brickwedde, Hoge, and Scott ${ }^{24}$ determined the melting point of $\mathrm{UF}_{6}$ containing 0.02 mole percent impurities. Oliver, Milton, and Grisard ${ }^{119}$. determined a value which is in agreement with that of Brickwedde and his co-workers for material of similar purity. They stated that although the uncertainty of the melting point determination is $\pm 0.05^{\circ} \mathrm{C}$., close agreement could be reached if a correction for the partial pressure of helium over the $\mathrm{UF}_{6}$ were applied to the results of Brickwedde and his co-workers. However, Weinstock and his co-workers ${ }^{144}$ report that solution of vapor pressure equations of oliver and his co-workers gives $64.05^{\circ} \mathrm{C}$. which is in agreement with the directly determined value of Brickwedde and his co-workers. These results, along with the pressure values at the triple point and the results of some of the earlier determinations, are presented in Table 45.

\section{CRITICAL CONSTANTS}

Considerable discrepancy exists between some of the earlier reported values of critical temperature, critical pressure, critical density, and molar volume. Some of these reported values were obtained experimentally while others were calculated from related physical properties. However, values of the critical constants determined more recently compare favorably with those calculated from the refined values of related physical 
Table 45

TRIPLE POINT TEMPERATURE AND PRESSURE

$\begin{array}{llcr}\begin{array}{c}\text { Temperature } \\ \left({ }^{\circ} \mathrm{C} .\right)\end{array} & \begin{array}{c}\text { Pressure } \\ (\mathrm{mm} . \mathrm{Hg})\end{array} & \underline{\text { Impurity }} & \frac{\text { Reference }}{64.02 \pm 0.05} \\ 64.052 & 1137.47 & 0.015 \text { (mole \%) } & 119 \\ 65.0 \pm 0.25 & 1133 \pm 7 & 0.02 \text { (mole \%) } & 24 \\ 64.8 \pm 0.4 & 1161 & & 142 \\ 64.5 \pm 0.3 & & 150 \mathrm{ppm} . & 48,107 \\ 64.45 & & & 11\end{array}$

properties. Comparisons indicate that the following values of the critical constants should be regarded as the most reliable: temperature $\left(\mathrm{T}_{\mathrm{c}}\right)=230.2^{\circ} \mathrm{C}$.; pressure $\left(\mathrm{P}_{\mathrm{C}}\right)=45.5$ atmospheres; density $\left(\rho_{\mathrm{c}}\right)=1.375$ grams per cubic centimeter; and molar volume $\left(\mathrm{V}_{\mathrm{c}}\right)=0.256$ liters. These and other experimental and calculated values of the critical constants are presented in Table 46.

Probably the most reliable of the critical temperature and pressure values found in literature are those of Oliver and his co-workers ${ }^{119}$ and those of workers in the U.S. liquid thermal diffusion project which are in agreement. Oliver and his associates started their vapor pressure system in an equilibrium state at temperature and pressure below the critical points. While they kept the heat input nearly constant, they increased the pressure until the critical pressure was exceeded. Plotting the pressure-temperature data as they were obtained, they estimated the critical values of the temperature and pressure at the point at which the slope, dp/dt, approached infinity. They estimated the critical temperature to be $230.2^{\circ} \mathrm{C}$. and the critical pressure to be 45.5 atmospheres from the break in the curve.

Whybrew, Tayman, and Kokulis ${ }^{147}$ determined the critical temperature visually by observing the disappearance of the liquid-gas meniscus as the liquid approached the critical temperature. The liquid-gas mixture was contained in a copper tube; disappearance of the meniscus was observed with the aid of an $x$-ray apparatus and a fluorescent screen. The meniscus was faint at $232.4^{\circ} \mathrm{C}$. and disappeared entirely at $232.8^{\circ} \mathrm{C}$. Therefore, the authors reported that the critical temperature fell between $232.4^{\circ}$ and $232.8^{\circ} \mathrm{C}$. From the amount and volume of $\mathrm{UF}_{6}$ contained in the tube, it was estimated that the critical density was close to 1.47 grams per cubic centimeter.

Brokaw $^{26}$ used the Cailletet-Mathias method (Law of Rectilinear Diameter) to determine the critical temperature and the critical density. In this method, the critical temperature, density, and molar volume are defined by the point of intersection of the straight line which represents the average of the liquid and vapor densities and the curve plotted from temperature against orthobaric density. As can be seen in Table 46, these values compare favorably with those determined by Oliver and his co-workers. It is also interesting to 
Table 46

CRITICAL CONSTANTS

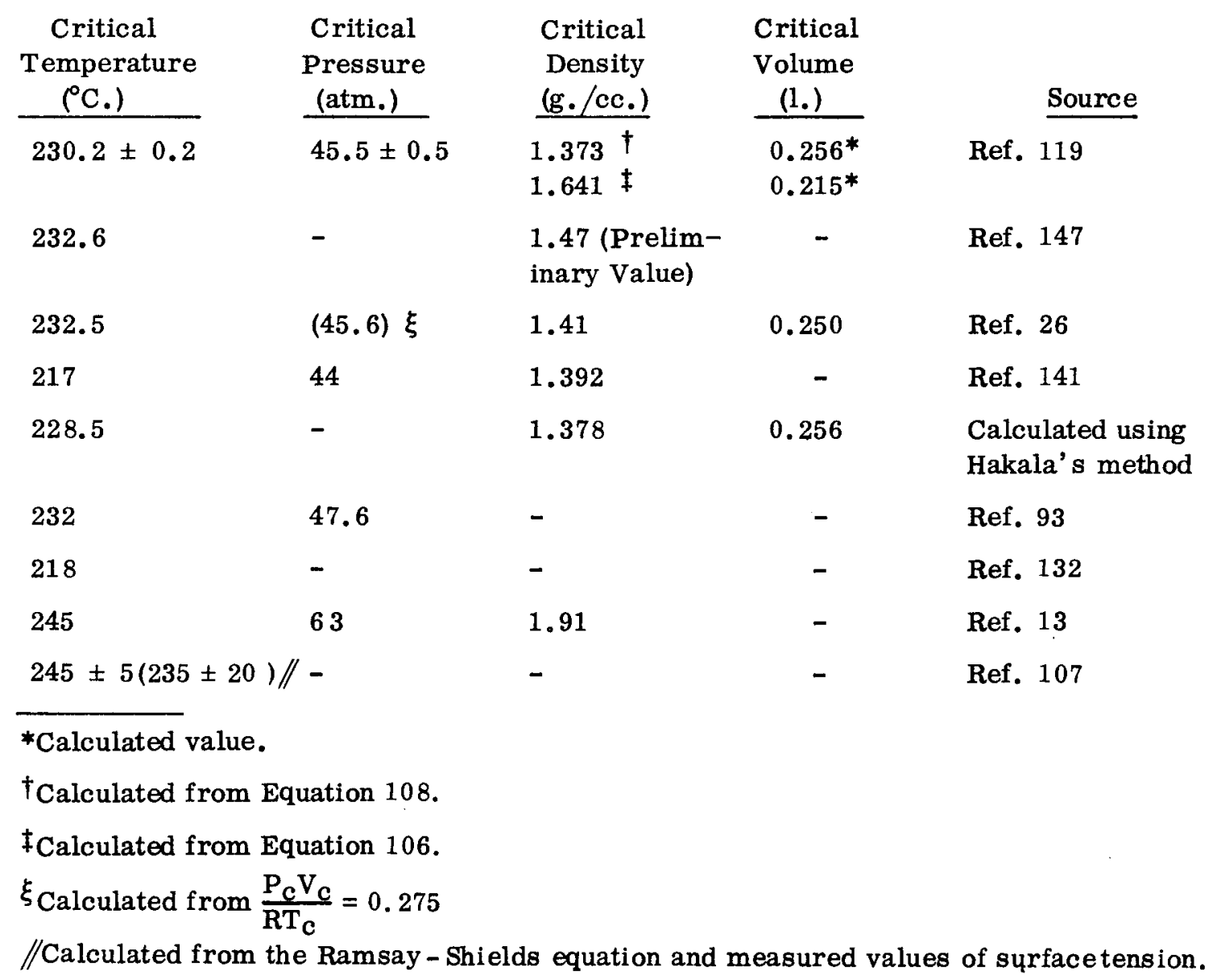

note that if these critical values are substituted into the van der Waals relation, $P_{c} V_{c} / R T_{c}=0.275$, we find that $P_{c}=45.6$ atmospheres, a value which is also in agreement with the value obtained by Oliver and his co-workers.

Hoge and Wechsler ${ }^{141}$ used the Cailletet-Mathias method to check the critical values proposed by Cohen ${ }^{93}$. Cohen had predicted a critical temperature of $232^{\circ} \mathrm{C}$. and a critical pressure of 700 pounds per square inch. Hoge and Wechsler employed the critical pressure value of 700 pounds per square inch in the vapor pressure equation proposed by Meyers* to determine the vapor densities. They found that the average density of the liquid and vapor approximated a linear function represented by the equation:

$$
\rho_{\mathrm{av}}=2.784-2.84 \times 10^{-3} \mathrm{~T}
$$

They were able to estimate the critical temperature by using the empirical equation of Cragoe and Myers ${ }^{141}$.

$$
\rho_{\mathrm{av}} / \rho_{\mathrm{c}}=1+\mathrm{m}\left(1-\mathrm{T} / \mathrm{T}_{\mathrm{c}}\right)
$$

Based on previous observations concerning other substances, they assumed $m=1$ and found that $\mathrm{T}_{\mathrm{c}}=490^{\circ} \mathrm{K}$. and $\rho_{\mathrm{c}}=1.392$ grams per cubic centimeter. Using these critical

*Myers, C. H. J. Research Natl. Bur. Standards 11, 691-701(1933). 
values and the van der Waals relationship, $\mathrm{P}_{\mathrm{c}} \mathrm{V}_{\mathrm{c}} / \mathrm{RT}_{\mathrm{c}}=0.275$, they obtained a critical pressure of 44 atmospheres. The authors did not place very much confidence in these values, since they were aware of the unusual behavior of $\mathrm{UF}_{6}$ in relation to other empirical correlations. Nevertheless, they did express the belief that the critical values fell below rather than above the values which were predicted by Cohen.

Llewellyn ${ }^{1}$ also determined the critical temperature of $\mathrm{UF}_{6}$ by slowly heating a sealed tube containing $\mathrm{UF}_{6}$ as both the liquid and as the vapor until the meniscus between the two phases just disappeared. The temperature of disappearance and reappearance $\left(245 \pm 5^{\circ} \mathrm{C}.\right)$, which was measured a number of times, was reported as the critical temperature. The critical temperature was also calculated from surface tension and viscosity data. From the Ramsay-Shields equation and measured values of the surface tension, a critical temperature value of $235 \pm 20^{\circ} \mathrm{C}$. was obtained. This value was also arrived at on the basis of the viscosity data. However, Llewellyn placed little confidence in the latter critical value because of the large extrapolation necessary for the determination.

Since more accurate information was available for the determination of the vapor densities, although only for a limited temperature range, it seems advisable to make new estimates of the critical constants. Therefore, an orthobaric density chart (Figure 21) was constructed for this report, and the Cailletet-Mathias method was employed for the determination of the critical density. In addition, a method recently proposed by Hakala* for the determination of critical density and critical temperature was utilized. Vapor density values needed for the methods mentioned above were computed by use of the Magnuson equation of state for $\mathrm{UF}_{6}$ at temperatures between $50^{\circ}$ and $140^{\circ} \mathrm{C}$. Liquid density values used in the calculations were those obtained by Hoge and Wechsler ${ }^{14}$.

For the orthobaric density plots (Figure 21), the liquid density - vapor density averages were fitted to a linear function of temperature by the method of least squares. The following equation represents the relationship:

$$
\rho_{\text {av }} \text { (g./cc.) }=1.999-2.719 \times 10^{-3} \mathrm{t}\left({ }^{\circ} \mathrm{C} .\right)
$$

Comparisons of the average densities, $\rho_{\text {av }}$, which were calculated at various temperatures with those obtained from Equation 108 are shown in Table 47. If in Equation 108 the temperature is equal to the critical temperature, the average density becomes the critical density. At the experimental critical temperatures, $230.2^{\circ} \mathrm{C}$. and $232.5^{\circ} \mathrm{C}$., the critical densities calculated from Equation 108 are 1.373 and 1.367 grams per cubic centimeter, respectively. These values are close to that estimated by Brokaw (1.41 grams per cubic and that calculated by Hakala's method.

In the methodproposed by Hakala, the liquiddensity, $\rho_{1}$, and the vapor density, $\rho_{\mathrm{v}}$, values were substituted in the following equation:

$$
\left(\rho_{1}+\rho_{\mathrm{v}}\right)=2 \rho_{\mathrm{c}}-\mathrm{a}\left(\rho_{1}-\rho_{\mathrm{v}}\right)^{10 / 3}
$$

where $\rho_{\mathrm{c}}$ is the critical density and $a$ is the characteristic constant. If the quantity $\left(\rho_{1}+\rho_{\mathrm{V}}\right)$ is plotted against $\left(\rho_{1}-\rho_{\mathrm{V}}\right)^{10 / 3}$, a straight line is obtained, the intercept of which defines the critical density. Equation 109 was derived by simultaneously solving the Kathyama-Eotvos, the Macleod, and the Cailletet-Mathias equations and, according to Hakala, can be used to extrapolate a straight line to the critical point even when low temperature data were used.

*Hakala, R. W. Chem. Eng. News 37, 43-4 (1959) March 16. 


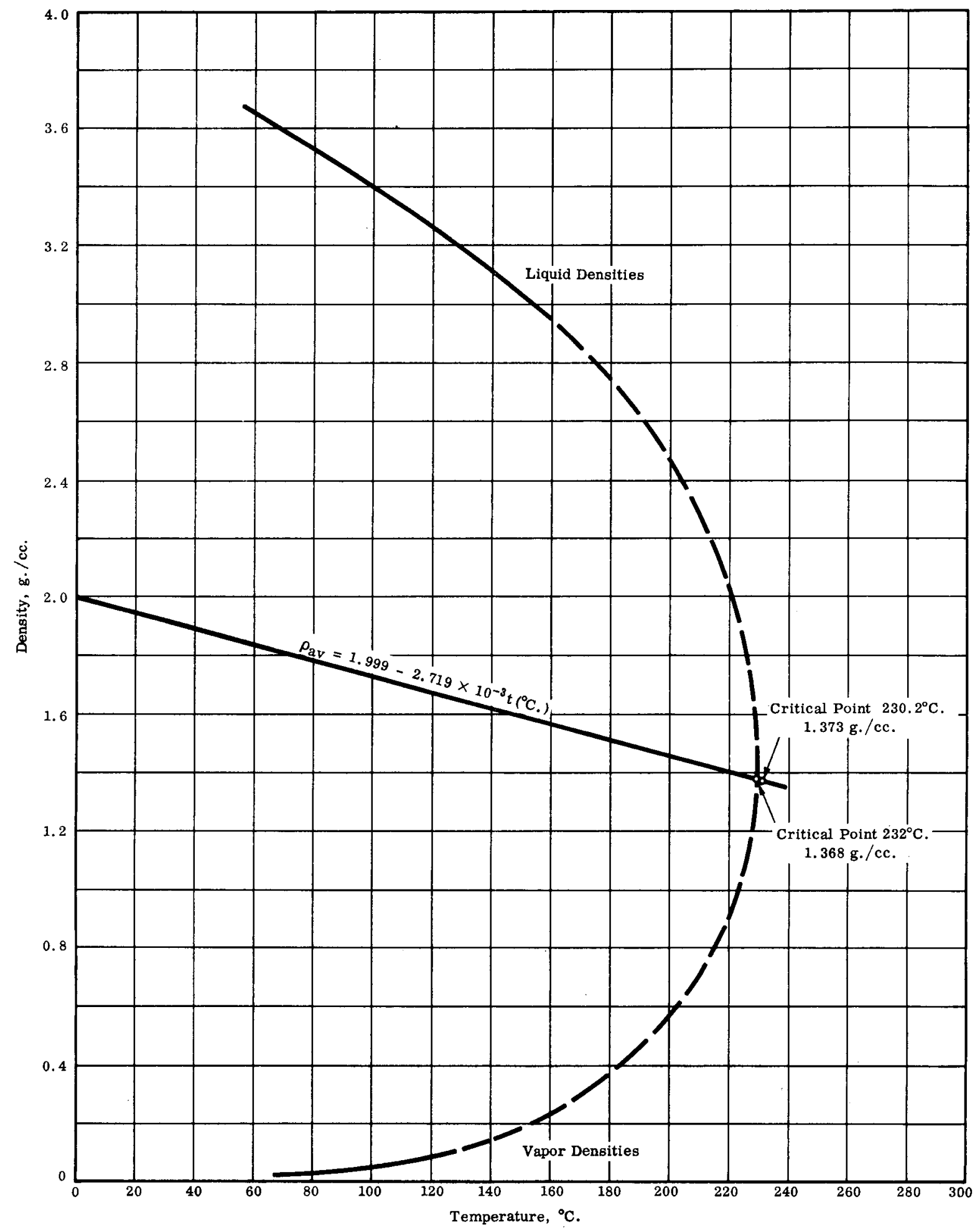

FIG. 21. ORTHOBARIC DENSITY CHART 
Table 47

CALCULATED VAPOR DENSITIES, AVERAGE OF VAPOR AND LIQUID DENSITIES, AND DEVIATIONS OF THE LATTER FROM EQUATION 108

\begin{tabular}{|c|c|c|c|c|c|}
\hline \multirow{2}{*}{$\begin{array}{c}\text { Temperature } \\
\text { (C.) }\end{array}$} & \multicolumn{4}{|c|}{ Density (g./ cc.) } & Difference \\
\hline & $\rho(1)$ & $\rho(v)$ & $\rho$ (av.) & $\rho($ av.)(Eq. 108) & $\rho($ av. $)-\rho$ (av.)(Eq. 108) \\
\hline 65 & 3.624 & 0.0206 & 1.822 & 1.822 & 0.000 \\
\hline 70 & 3.595 & 0.0238 & 1.809 & 1.809 & 0.000 \\
\hline 80 & 3.532 & 0.0313 & 1.782 & 1.781 & -0.001 \\
\hline 90 & 3.470 & 0.0407 . & 1.756 & 1.754 & -0.002 \\
\hline 100 & 3.404 & 0.0521 & 1.728 & 1.727 & -0.001 \\
\hline 110 & 3.332 & 0.0657 & 1.699 & 1.700 & +0.001 \\
\hline 120 & 3.263 & 0.0818 & 1.673 & 1.673 & 0.000 \\
\hline 130 & 3.192 & 0.1009 & 1.647 & 1.646 & -0.001 \\
\hline
\end{tabular}

The critical temperature can be obtained in a similar manner from an equation which has the same geometry as the one used to determine the critical densities:

$$
\mathrm{t}=\mathrm{t}_{\mathrm{c}}-\mathrm{k}\left(\rho_{1}-\rho_{\mathrm{v}}\right)^{10 / 3}
$$

Hakala refers to this equation as the Sugden-Verschaffelt equation. The values of $\left(\rho_{1}+\rho_{\mathrm{v}}\right)$ and $\left.\rho_{1}-\rho_{\mathrm{v}}\right)^{10 / 3}$ which are listed in Table 48 are plotted in Figure 22 for the determination of the critical density and in Figure 23 for the critical temperature. The critical density value, 1.378 grams per cubic centimeter, compares very well with those determined by use of the Law of Rectilinear Diameter. The critical temperature, $228.5^{\circ} \mathrm{C}$., is also in agreement with some of the experimental results.

Table 48

VALUES OF THE QUANTITIES

$$
\left(\rho_{1}+\rho_{\mathrm{v}}\right) \operatorname{AND}\left(\rho_{1}-\rho_{\mathrm{v}}\right)^{10 / 3}
$$

$\begin{array}{ccc}\text { Temperature }\left({ }^{\circ} \mathrm{C} .\right) & \frac{\left(\rho_{1}+\rho_{\mathrm{v}}\right)}{30} & \frac{\left(\rho_{1}-\rho_{\mathrm{v}}\right)^{10 / 3}}{3.563} \\ 90 & 3.511 & 65.15 \\ 100 & 3.456 & 60.80 \\ 110 & 3.401 & 56.36 \\ 120 & 3.345 & 51.84 \\ 130 & 3.289 & 47.33 \\ 140 & 3.234 & 42.83 \\ 160 & 3.127 & 38.84\end{array}$




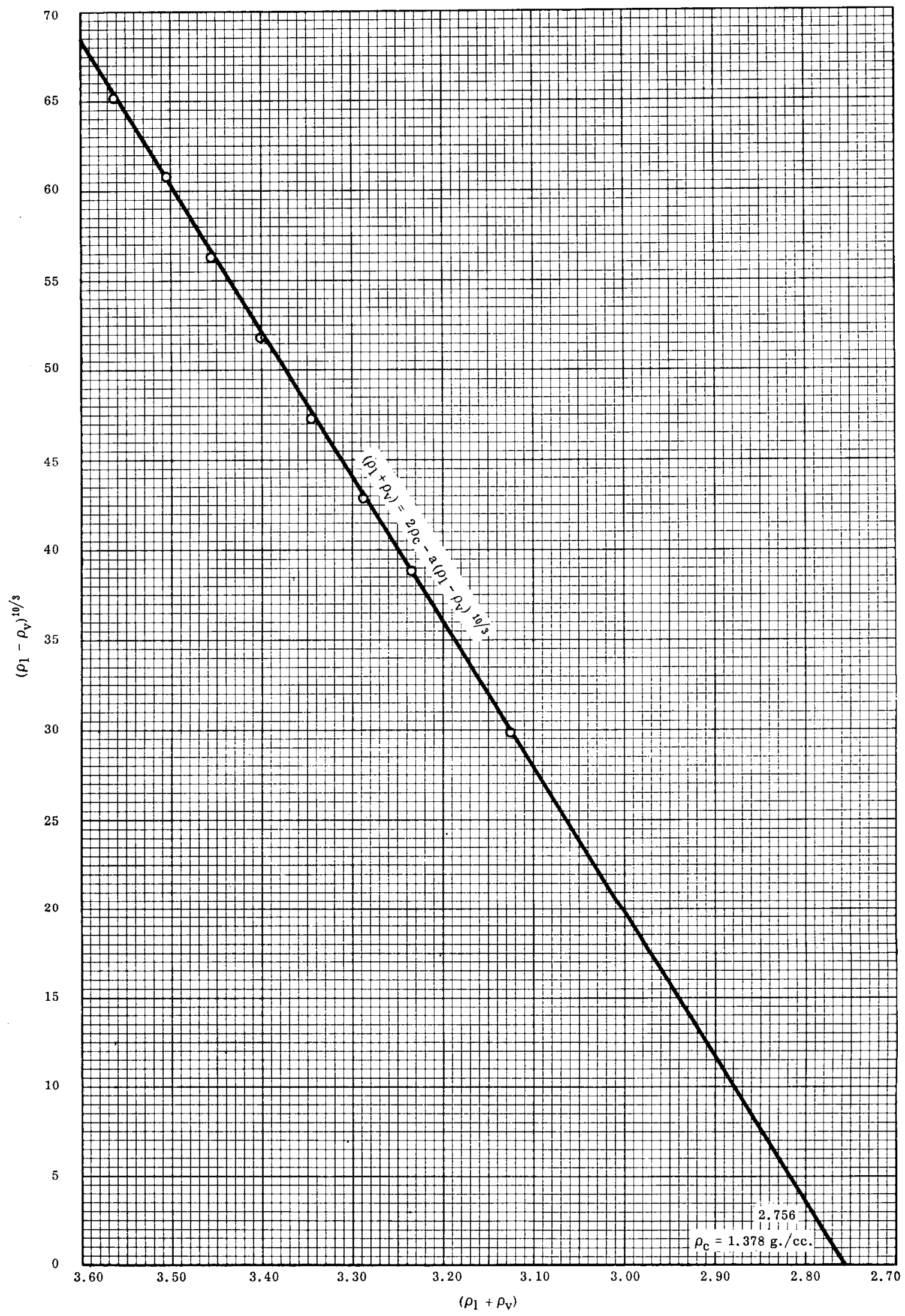

FIG. 22. GRAPHIC DETERMINATION OF CRITICAL DENSITY 


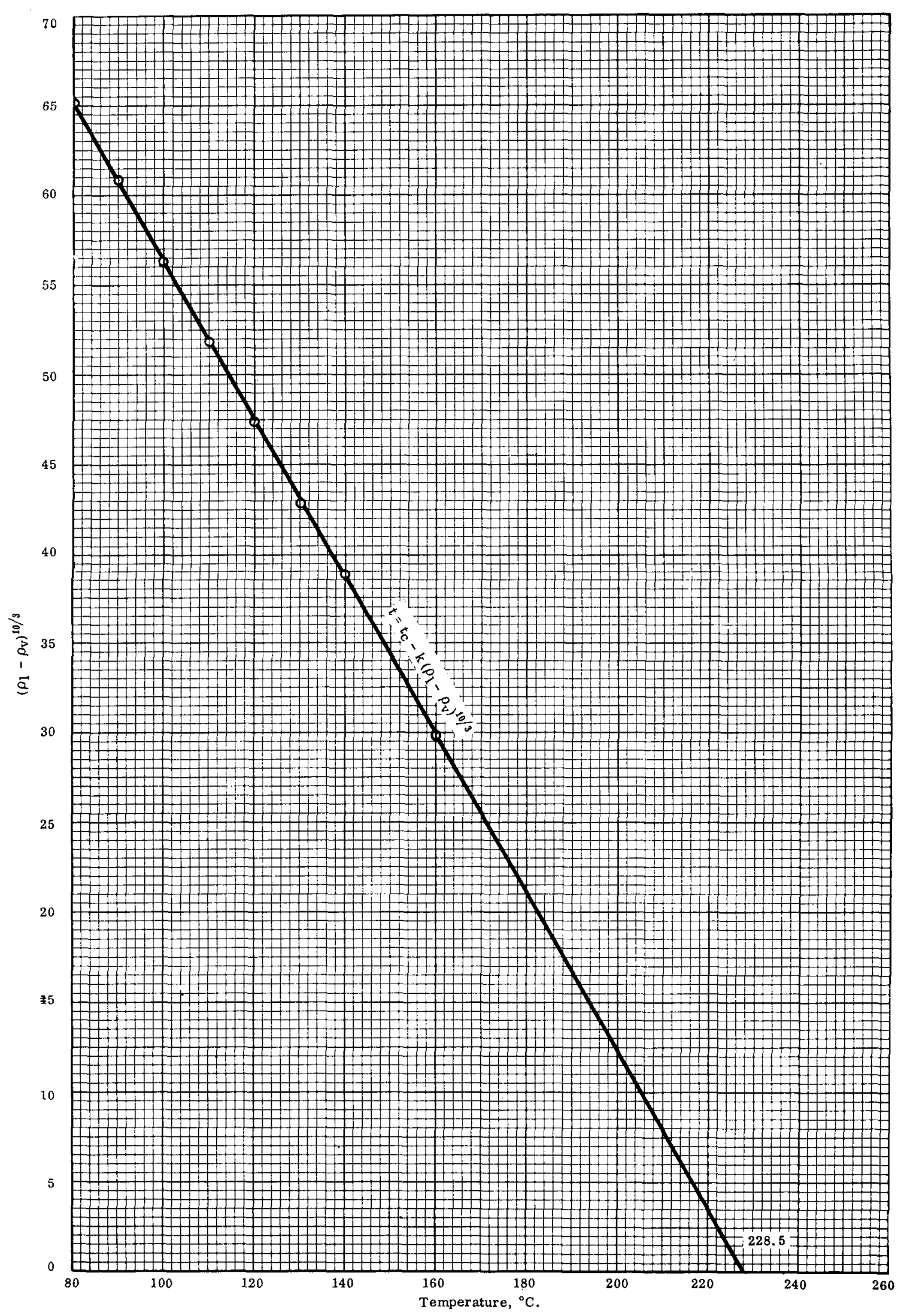

FIG. 23. GRAPHIC DETERMINATION OF CRITICAL TEMPERATURE 


\section{EQUATIONS OF STATE}

Early investigations of such things as the vapor density variations with pressure and temperature indicated that, within experimental error, the behavior of $\mathrm{UF}_{6}$ vapor does not deviate appreciably from that predicted by the simple gas laws. However, the more accurate pressure-volume-temperature experiments which were conducted somewhat later revealed deviations from ideality of as much as 3 percent at $60^{\circ} \mathrm{C}$. and atmospheric pressure. These findings were verified by the experimental dielectric constant studies and later by studies of the variations between the thermodynamic properties of $\mathrm{UF}_{6}$ as calculated from heat capacity and vapor pressure data with those calculated from the vibrational frequencies. Values of the non-ideality parameters which were computed from the thermodynamic data compare favorably with those deduced from the dielectric constant studies. Comparisons of these non-ideality parameters with those obtained from the Berthelot and the van der Waals equations of state can be made from the data presented in Table 49 and Figure 24.

Table 49

NON-IDEALITY PARAMETERS

\begin{tabular}{|c|c|c|c|c|c|c|c|c|}
\hline \multirow{3}{*}{$\begin{array}{c}\text { Temperature } \\
\left({ }^{\circ} \mathrm{C} .\right) \\
\end{array}$} & \multicolumn{7}{|c|}{ A (atm. $\left.{ }^{-1}\right)$} & \multirow{3}{*}{$\begin{array}{l}\text { Weinstock et al. } \\
\text { (Ref. 144) } \\
(1+\alpha)^{*}\end{array}$} \\
\hline & \multicolumn{2}{|c|}{ Magnuson (Ref. 110) } & \multirow{2}{*}{$\begin{array}{l}\text { Ackley and } \\
\text { Magnuson } \\
\text { (Ref. 2) } \\
\end{array}$} & \multirow{2}{*}{$\begin{array}{c}\text { Weinstock et al. } \\
\text { (Ref. 144) } \\
\text { Empirical }{ }^{\dagger} \\
\end{array}$} & \multirow{2}{*}{$\begin{array}{c}\text { Others } \\
\text { (Ref. 3) } \\
\end{array}$} & \multirow[b]{2}{*}{ Berthelot } & \multirow{2}{*}{$\begin{array}{c}\text { van der } \\
\text { Waals }\end{array}$} & \\
\hline & Experimental & Empirical & & & & & & \\
\hline 0.0 & & & & & & & & 0.9987 \\
\hline 44.0 & & & 0.027 & & & & & \\
\hline 25.0 & & & & & & & & 0.9936 \\
\hline 50.0 & & 0.0365 & & 0.0408 & & 0.0326 & 0.0182 & 0.9764 \\
\hline 53,2 & $0.0337 \pm .003$ & & & & & & & \\
\hline 60.0 & & 0.0333 & 0.032 & 0.0372 & $\begin{array}{l}0.0239^{\ddagger} \\
0.030 \xi\end{array}$ & 0.0297 & 0.0170 & \\
\hline 61.1 & $0.0351 \pm .0029$ & & & & & & & \\
\hline 70.0 & & 0.0305 & & & & & & \\
\hline 71.0 & $\begin{array}{l}0.0335 \pm .0009 \\
0.0313 \pm .0013\end{array}$ & & & & & & & \\
\hline 75.0 & & & & & & & & 0.9441 \\
\hline 78.4 & $0.0292 \pm .0008$ & & & & & & & \\
\hline 78.5 & $0.0294 \pm .0009$ & & & & & & & \\
\hline 79.3 & $0.0280 \pm .0013$ & & & & & & & \\
\hline 80.0 & $\begin{array}{l}0.0279 \pm .0013 \\
0.0288 \pm .0015 \\
0.0286 \pm .0013\end{array}$ & 0.0279 & & 0.0313 & & 0.0246 & 0.0149 & \\
\hline 90.0 & & 0.0257 & & & & & & \\
\hline 94.0 & & & 0.021 & & & & & \\
\hline 95.5 & $\begin{array}{l}0.0251 \pm .0006 \\
0.0251 \pm .0012\end{array}$ & & & & & & & \\
\hline 100.0 & & 0.0237 & & 0.0265 & & 0.0207 & 0.0131 & \\
\hline 110.0 & & 0.0219 & & & & & & \\
\hline 113.0 & $0.0200 \pm .0007$ & & & & & & & \\
\hline 114.2 & $\begin{array}{l}0.0197 \pm .0005 \\
0.0197 \pm .0007 \\
0.0187 \pm .0008\end{array}$ & & & & & & & \\
\hline 120.0 & & 0.0203 & & 0.0227 & & 0.0176 & 0.0117 & \\
\hline 130.0 & & 0.0188 & & & & & & \\
\hline 132.4 & $0.0183 \pm .0009$ & & & & & & & \\
\hline 132.5 & $0.0192 \pm .0009$ & & & & & & & \\
\hline 140.0 & & 0.0175 & & 0.0195 & & 0.0149 & 0.0104 & \\
\hline
\end{tabular}

* Ratio actual volume to ideal volume.

†Calculated on basis of non-ideality equation proposed by Weinstock et al., in which $\mathrm{b}=-\mathbf{3 . 6} \times 10^{3} \mathrm{cal}$. $/ \mathrm{mole}(\mathrm{mm}$. Hg)

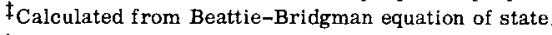

$\xi$ Calculated from the method of Brewer and Searcy. 


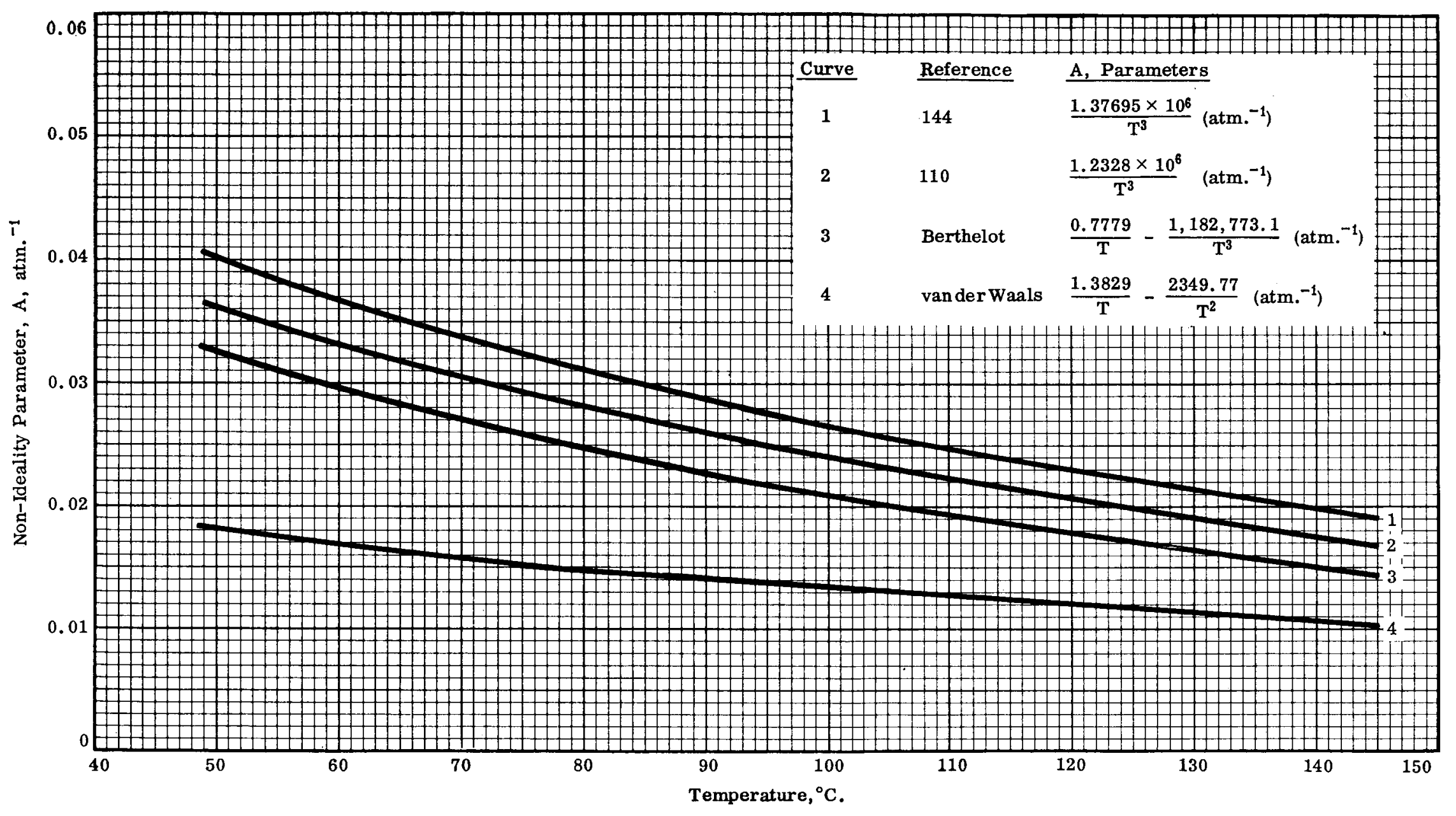

FIG. 24. NON-DEALITY PARAMETERS 
Ackley and Magnuson ${ }^{2}$, in their attempts to explain the behavior of certain $\mathrm{UF}_{6}$ adsorption is otherms, showed that $\mathrm{UF}_{6}$ vapor at pressures of the order of one atmosphere exhibited non-ideality. Their equation of state for $U_{6}$ vapor, $P(1+A P) V=N R T$, contains a non-ideality parameter, $\mathrm{A}$, which is only a function of temperature. Ackley evaluated $\mathrm{A}$ at $44^{\circ}, 60^{\circ}$ and $94^{\circ} \mathrm{C}$. by measuring the pressures of a quantity of gas corresponding to two different known volumes under approximately isothermal conditions. Magnuson confirmed the results at $61.1^{\circ} \mathrm{C}$. by utilizing microwave dielectric constant measurements. Other dielectric constant measurements ${ }^{108,109}$ of $U F_{6}$ vapor at 9400 megacycles per second did not show non-ideality effects, but these observations were accounted for by the low $\mathrm{UF}_{6}$ vapor pressures that were used (less than $40 \mathrm{~cm} . \mathrm{Hg}$ ).

Magnuson used a form of the Debye equation, which results when the dipole moment is considered zero:

$$
P_{m}=\frac{\epsilon-1}{\epsilon+2} M / P=\frac{4 \pi \alpha}{3} N_{0}
$$

The equation of state was put into the form representing the quantity $\mathrm{M} / \rho$ and combined with Equation 111 to obtain Equation 112 from which dielectric constant measurements taken at various pressures could be used to obtain the non-ideality parameter, A, and the molar polarization, $P_{m}$, at a particular temperature:

$$
\left[\frac{\epsilon-1}{\epsilon+2}\right]\left[\frac{1}{\mathrm{P}}\right]\left[\frac{\mathrm{P}_{0} \mathrm{~V}_{0} \mathrm{~T}}{\mathrm{~T}_{0}}\right]=\mathrm{P}_{\mathrm{m}}(1+\mathrm{AP})
$$

From the plot of the quantity $[(\epsilon-1) /(\epsilon+2)][1 / \mathrm{P}]$ against $\mathrm{P}$ at a constant temperature Magnuson obtained a straight line, the slope of which defined the parameter $A$ and the intercept of which defined the molar polarization $P_{m}$ at the given temperature. The slope and intercept were obtained by the least squares method and the limit of error is said to be at the 95 percent confidence level. Using an improved dielectric constant apparatus, Magnuson ${ }^{110}$ evaluated the non-ideality parameter A over the $53^{\circ}$ to $132.5^{\circ} \mathrm{C}$. range and expressed the results. as a function of temperature by means of the equation:

$$
\mathrm{A}\left(\mathrm{atm}^{-1}\right)=1.2328 \times 10^{6} \mathrm{~T}^{-3}\left({ }^{\circ} \mathrm{K} .\right)
$$

The equation of state for $\mathrm{UF}_{6}$ over the stated temperature range is then:

$$
\mathrm{PV} / \mathrm{RT}=1 /\left[1+\left(1.2328 \times 10^{6} \mathrm{~T}^{-3}\right)(\mathrm{P})\right]
$$

The van derWaals and Berthelot equations of state were put into the form PV/RT $=1+\mathrm{AP}$ to compare the A quantities with those calculated from Equation 111, where $A_{V}$ and $A_{b}$ are represented by Equations 115 and 116, respectively:

$$
\begin{aligned}
& A_{\mathrm{V}}=\mathrm{T}_{\mathrm{c}} / 8 \mathrm{P}_{\mathrm{c}} \mathrm{T}-\frac{24 \mathrm{~T}_{\mathrm{c}}^{2}}{64 \mathrm{P}_{\mathrm{c}} \overline{\mathrm{T}}^{2}} \quad \text { (van der Waals) } \\
& \mathrm{A}_{\mathrm{b}}=9 \mathrm{~T}_{\mathrm{c}} / 128 \mathrm{P}_{\mathrm{c}} \mathrm{T}-\frac{54 \mathrm{~T}_{\mathrm{c}}^{3}}{128 \mathrm{~T}^{3} \mathrm{P}_{\mathrm{c}}} \quad \text { (Berthelot) }
\end{aligned}
$$

The critical constants, $\mathrm{T}_{\mathrm{c}}=503.4^{\circ} \mathrm{K}$. and $\mathrm{P}_{\mathrm{c}}=45.5$ atmospheres, obtained by Oliver and his co-workers ${ }^{119}$ were used in the above expressions for $A$. When $A_{V}$ and $A_{b}$ are compared to the empirical values of $A$, which are shown in Figure 24, they are found to be somewhat lower in value, the Berthelot non-ideality parameter $A_{b}$ being more nearly representative of the empirical A values.

In addition to calculating the Berthelot $A_{b}$ value at $60^{\circ} \mathrm{C} .$, Ackley and Barber ${ }^{3}$, determined an $A$ value of 0.0239 atmosphere ${ }^{-1}$ by using the Beattie-Bridgman equation. Using the 
method of Brewer and Searcy*, they determined an A value of 0.030 atmosphere $^{-1}$. Here again the observation was made that $A$ values calculated from the various equations of state were found to be slightly lower than the experimentally determined values. Other remarks concerning values of $\mathrm{A}$ can be found in a number of other reports $31,98,99$.

Weinstock and his co-workers ${ }^{144}$ used a modified form of the Berthelot equation of state, $\mathrm{PV}=\mathrm{RT}+\mathrm{bP} / \mathrm{T}^{2}$, to express the behavior of the vapor. By using a modification of the procedure given by Busey and Giauque to determine the virial coefficient, $b$, from the heats of vaporization and sublimation, they obtained a value of $b=-3.6 \times 10^{3}$ cal. deg. ${ }^{2}$ $\mathrm{mm}^{-1} \mathrm{~mole}^{-1}$. Previously, Weinstock and $\mathrm{Malm}^{143}$ had determined the virial coefficient as $\mathrm{b}=-5.1 \times 10^{3} \mathrm{cal}$. deg. ${ }^{2} \mathrm{~mm} .^{-1} \mathrm{~mole}^{-1}$ using the same method. Putting the proposed equation of state into the form PV $/ R T=1+A P$, where $A_{W}=1.3769 \times 10^{6} / T^{3}$, the values of $A_{W}$ can be compared with other proposed non-ideality parameters which are presented in Table 49 and in Figure 24. The final value of A proposed by Weinstock and co-workers compares favorably with that proposed by Magnuson.

Weinstock and Crist ${ }^{142}$ had previously calculated the deviation from ideality by using the Berthelot equation and represented this deviation in terms of $(1+\alpha)$, the ratio of the actual volume to the ideal volume. The values of the critical constants used for substitution in the Berthelot equation were those listed by Kirshenbaum ${ }^{93}$; that is, $\mathrm{T}_{\mathbf{C}}=518^{\circ} \mathrm{K}$., $\mathrm{p}_{\mathrm{c}}=36,000 \mathrm{~mm}$. $\mathrm{Hg}$.

Oliver and his co-workers ${ }^{119}$ also expressed the deviation of $\mathrm{UF}_{6}$ from the ideal gas law by using the experimentally determined critical constants and the Berthelot equation. They reported deviations in AP of 0.0062 at $25^{\circ} \mathrm{C} ., 0.031$ at $56.54^{\circ} \mathrm{C}$, and 0.043 at $64.02^{\circ} \mathrm{C}$. At room temperature and pressures of the order of $100 \mathrm{~mm}$. $\mathrm{Hg}$, they found that $\mathrm{UF}_{6}$ vapor is essentially ideal.

An early attempt at establishing the behavior of $\mathrm{UF}_{6}$ vapor was made by Awbery ${ }^{12}$. He found that his data fit the Beattie and Bridgman equation of state:

$$
\frac{\mathrm{PV}}{\mathrm{RT}}=1+\mathrm{B} / \mathrm{V}+\mathrm{C} / \mathrm{N}^{2}+\mathrm{D} / \mathrm{N}^{3}
$$

where the virial coefficients, $B, C$, and $D$, are only functions of temperature. After determining $B, C$, and $D$ from tentative critical constants $\left(T_{c}=518^{\circ} \mathrm{K} . ; \rho_{c}=1.910 \mathrm{~g} . / \mathrm{cc}.\right)$ and correlating vapor pressure data with specific heats and other thermodynamic data, he obtained the following equation of state:

$$
\begin{aligned}
\frac{\mathrm{PV}}{\mathrm{RT}}=1 & +\frac{1}{\mathrm{~V}}\left[109.32-\frac{1.4870 \times 10^{5}}{\mathrm{~T}}-\frac{6.2599 \times 10^{9}}{\mathrm{~T}^{3}}\right] \\
& +\frac{1}{\mathrm{~V}^{2}}\left[-6.479396 \times 10^{7}+\frac{2.5386441 \times 10^{10}}{\mathrm{~T}}-\frac{6.84332 \times 10^{11}}{\mathrm{~T}^{3}}\right] \\
& +\frac{1}{\mathrm{~V}^{3}}\left[\frac{4.05603576 \times 10^{17}}{\mathrm{~T}^{3}}\right]
\end{aligned}
$$

Since the constants of the above equation were determined on the basis of preliminary data or data of unknown reliability, they can be considered approximations only.

Another early attempt at establishing the behavior of the vapor was made by Amphlett, Mullinger, and Thomas ${ }^{9}$. They found, within the limits of experimental error of vapor

*Brewer, L. and Searcy, A. W. J. Chem. Ed. 548-52(1949).

†Busey, R. H. and Giauque, W. F. J. Am. Chem. Soc. 75, 806-9(1953). 
density measurements ( 1 percent), that the molecular weight of $\mathrm{UF}_{6}$ was not systematically dependent upon temperature. They also found that the observed variation of the vapor density with pressure, $(\partial \rho / \partial \mathrm{p}) \mathrm{t}$, at $49.2^{\circ} \mathrm{C}$. is approximately that predicted by the kinetic theory for an ideal gas:

$$
\begin{aligned}
& \text { Experimental } \\
& (\partial \rho / \partial \mathrm{p})_{49.2^{\circ} \mathrm{C} .}=1.32 \pm 0.01 \times 10^{-8} \mathrm{sec} .{ }^{2} / \mathrm{cm}^{2}
\end{aligned}
$$

Theoretical

$$
(\partial \rho / \partial \mathrm{p})_{49.2^{\circ} \mathrm{C} .}=1.314 \times 10^{-8} \mathrm{sec} .{ }^{2} / \mathrm{cm} .{ }^{2}
$$

They therefore concluded that $\mathrm{UF}_{6}$ vapor, at ordinary temperatures, consists of single "undissociated" UF ${ }_{6}$ molecules and that the vapor pressure nearly obeys the simple gas laws. Results of the investigation reported by Llewellyn ${ }^{107}$ are the same.

\section{PHASE DIAGRAM}

The conditions of equilibrium between the three phases of $\mathrm{UF}_{6}$ are presented in Figure 25. The liquid-vapor equilibrium and the solid-vapor equilibrium utilized to construct the phase diagram were reported by Oliver and his co-workers ${ }^{119}$. The liquid-solid equilibrium (the change in melting point with change in pressure) was calculated from the Clausius-Clapeyron equation:

$$
\frac{\mathrm{dT}_{\mathrm{m}}}{\mathrm{dP}}=\frac{\mathrm{T}\left(\mathrm{V}_{1}-\mathrm{V}_{\mathrm{S}}\right)}{\Delta \mathrm{H}_{\mathrm{f}}}=0.0439 \mathrm{deg} . / \mathrm{atm} \text {. }
$$

where $\Delta H_{f}=4588 \mathrm{cal}$. $/$ mole and the volumes, $V_{1}$ and $V_{S}$, of the liquid and solid were obtained from density values given in this report.

\section{UF $_{6}$ BINARY EQUILIBRIUM SYSTEMS}

The solid-liquid and liquid-vapor equilibria of various $\mathrm{UF}_{6}$-fluorocarbon systems have been experimentally evaluated. Many of the earlier data have been summarized in other publications $^{62,101}$.

Most of the experimental equilibrium data have been compared to the equilibrium data predicted by Raoult's law. However, in most of the recent investigations, the experimental data also have been compared to equilibrium data calculated by the activity coefficient technique of Hildebrand, Wood, Scatchard, Flory, and Higgins. This technique, which is discussed in detail by Barber and his co-workers ${ }^{14}, 145$ utilizes the basic physical and thermodynamic properties of the pure components. From data relative to vapor pressure, heats of vaporization, molecular weights, and densities of the pure components, the activity coefficients and the phase composition of the system can be computed. In the case of $\mathrm{UF}_{6}$-fluorocarbon equilibrium, the experimental data compare better with the data predicted by the activity coefficient method than they do with data predicted by Raoult's law. The results calculated using Raoult's law are referred to as "ideal" while those calculated by the activity coefficient technique are referred to as "theoretical."

\section{SOLID AND LIQUD URANIUM HEXAFLUORIDE IN PERFECT SOLUTIONS}

Libby ${ }^{100}$ determined the solubility of vaporous and solid $U_{6}$ in perfect solutions using the vapor pressure data of Crist and Weinstock ${ }^{142}$ and the equation:

$$
\mathrm{Z}=\frac{\mathrm{N}}{(1-\mathrm{N})} \times \frac{35,200}{\mathrm{Y}}
$$




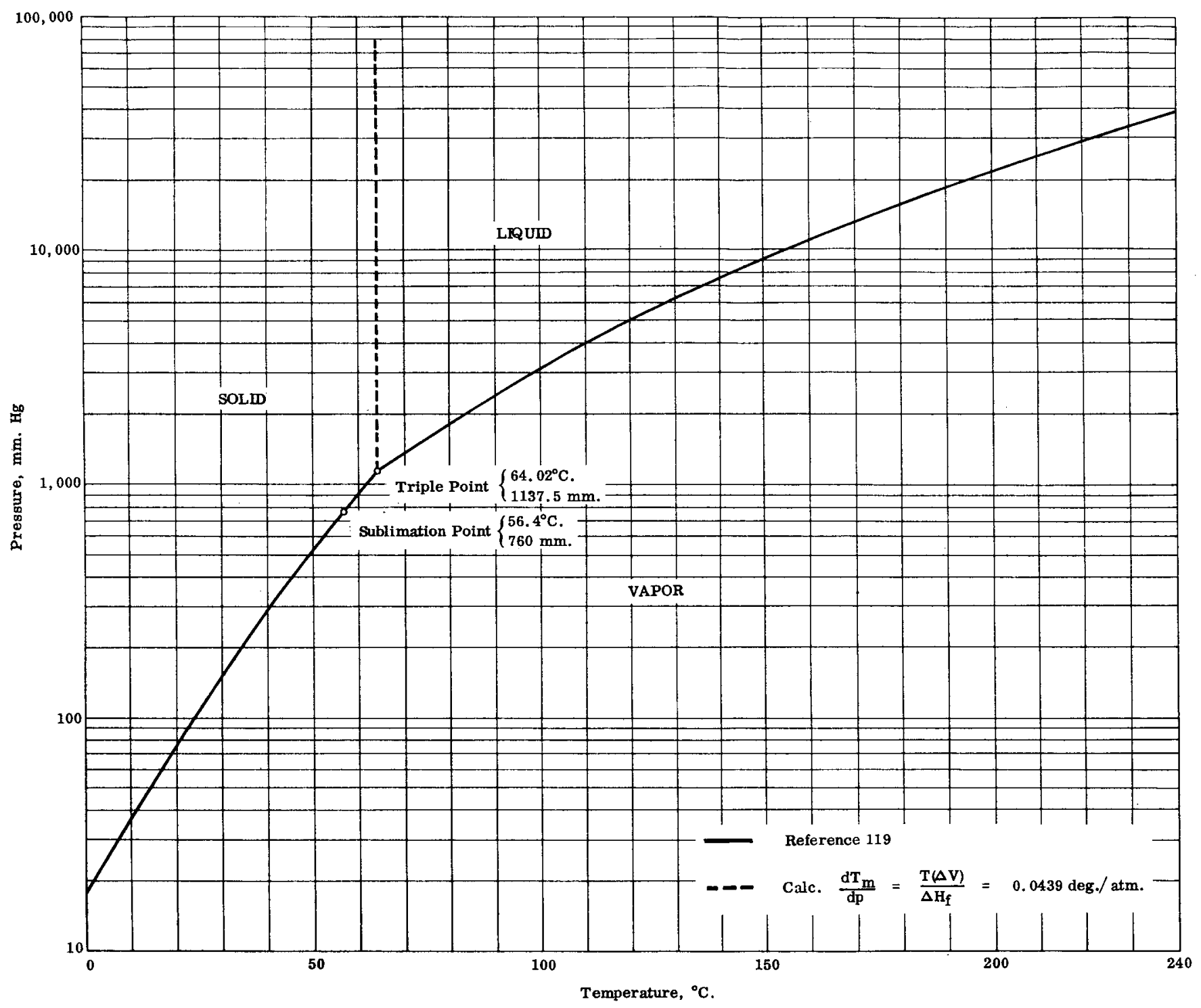

FIG. 25. PHASE DIAGRAM 
where $\mathrm{Z}$ is the solubility in grams per 100 grams of solvent of molecular weight $\mathrm{Y}$, and where $\mathrm{N}$, which is the mole fraction of $\mathrm{UF}_{6}$ at $100 \mathrm{~mm}$. $\mathrm{Hg}$ pressure in the saturated solution, can be calculated from the equation:

$$
\mathrm{N}=10(1486 / \mathrm{T}-4.44) / 11.70 \text {. }
$$

The solubilities of vaporous $U_{6}$ per 100 grams of solvent having a molecular weight $Y$ at $100 \mathrm{~mm}$. $\mathrm{Hg}$ pressure are given in the first part of Table 50 while those for solid $\mathrm{UF}_{6}$ are given in the second part.

\section{URANIUM HEXAFLUORIDE IN FLUOROCARBONS GD-727c AND GD-727h}

Kirshenbaum ${ }^{91}$ determined the solubility of $\mathrm{UF}_{6}$ in the fluorocarbons GD-727c and GD-727h (Dupont samples). Lubricating oil fraction GD- $727 \mathrm{c}$ was cut from $147^{\circ}$ to $157^{\circ} \mathrm{C} . / 10 \mathrm{~mm} . \mathrm{Hg}$ and was found to have an $\mathrm{F} / \mathrm{C}$ ratio of $1.73 / 1$, indicating a molecular weight of 900 . Fraction GD- $727 \mathrm{~h}$ was cut from $197^{\circ}$ to $207^{\circ} \mathrm{C}$. $/ 10 \mathrm{~mm}$. Hg. The experimental solubility values of $\mathrm{UF}_{6}$ in GD-727c and in GD-727h at various temperatures and pressures are presented in Table 51. These results agree with the calculated results obtained using Libby's formulae (Equations 122 and 123), although a better comparison (0 to 10 percent lower than ideal) can be obtained using a value of 1000 for the molecular weight of the oil.

Table 50

\section{SOLUBILITY IN PERFECT SOLUTIONS*}

(Reference 100)

Solubility of the vapor per 100 grams of solvent of $\mathrm{Y}$ molecular weight

\begin{tabular}{|c|c|c|c|c|c|c|c|c|c|}
\hline $\mathrm{Y}$ & $20^{\circ}$ & $30^{\circ}$ & $40^{\circ}$ & $50^{\circ}$ & $60^{\circ}$ & $70^{\circ}$ & $80^{\circ}$ & $90^{\circ}$ & $100^{\circ}$ \\
\hline 100 & 236 & 129.3 & 80.9 & 54.6 & 37.3 & 27.0 & 19.8 & 14.8 & 11.5 \\
\hline 200 & 118.0 & 64.65 & 40.45 & 27.30 & 18.65 & 13.5 & 9.90 & 7.40 & 5.75 \\
\hline 300 & 78.7 & 43.1 & 26.9 & 18.2 & 12.42 & 8.99 & 6.60 & 4.94 & 5.83 \\
\hline 400 & 59.0 & 32.3 & 20.2 & 13.6 & 9.33 & 6.75 & 4.95 & 3.70 & 2.87 \\
\hline 500 & 47.2 & 25.86 & 16.18 & 10.92 & 7.46 & 5.40 & 3.96 & 2.96 & 2.30 \\
\hline 600 & 39.3 & 21.6 & 13.50 & 9.10 & 6.21 & 4.50 & 3.30 & 2.47 & 1.92 \\
\hline 700 & 33.7 & 18.5 & 11.52 & 7.80 & 5.33 & 3.86 & 2.83 & 2.11 & 1.64 \\
\hline 800 & 29.5 & 16.2 & 10.12 & 6.84 & 4.66 & 3.38 & 2.47 & 1.85 & 1.44 \\
\hline 900 & 26.2 & 14.4 & 8.99 & 6.07 & 4.15 & 3.00 & 2.20 & 1.65 & 1.28 \\
\hline 1000 & 23.6 & 12.93 & 8.09 & 5.46 & 3.73 & 2.70 & 1.98 & 1.48 & 1.15 \\
\hline
\end{tabular}

Solubility of the solid per 100 grams of solvent of Y molecular weight

$\begin{array}{rccccc}\frac{Y}{100} & \frac{20^{\circ}}{177.2} & \frac{30^{\circ}}{280} & \frac{40^{\circ}}{462} & \frac{50^{\circ}}{919} & \frac{60^{\circ}}{3600} \\ 200 & 88.6 & 140 & 231 & 459.5 & 1800 \\ 300 & 59.07 & 93.3 & 154 & 306.3 & 1200 \\ 400 & 44.3 & 70.0 & 113 & 229.8 & 900 \\ 500 & 35.4 & 56.0 & 92.4 & 183.8 & 720 \\ 600 & 29.5 & 46.6 & 77.0 & 153.0 & 600 \\ 700 & 25.3 & 40.0 & 66.0 & 131.2 & 515 \\ 800 & 22.1 & 35.0 & 57.7 & 114.8 & 450 \\ 900 & 19.7 & 31.1 & 51.3 & 102.0 & 400 \\ 1000 & 17.7 & 28.0 & 46.2 & 91.9 & 360\end{array}$

* Temperature is in degrees Centigrade. 
Table 51

SOLUBILITY IN THE HYDROCARBONS

(Reference 91)

\begin{tabular}{|c|c|c|c|c|c|}
\hline $\begin{array}{c}\text { Temperature } \\
\left({ }^{\circ} \mathrm{C} .\right) \\
\end{array}$ & $\begin{array}{l}\text { Pressure } \\
(\mathrm{mm} . \mathrm{Hg}) \\
\end{array}$ & $\begin{array}{c}\text { Grams } \\
\mathrm{UF}_{6} / 100 \mathrm{~g} \text {. Oil } \\
\end{array}$ & $\begin{array}{c}\text { Temperature } \\
\text { ( } \mathrm{C} .) \\
\end{array}$ & $\begin{array}{l}\text { Pressure } \\
(\mathrm{mm} . \mathrm{Hg}) \\
\end{array}$ & $\begin{array}{r}\text { Gram } \\
\mathrm{UF}_{6} / 100 \\
\end{array}$ \\
\hline & & In GD & $727 \mathrm{c}$ & & \\
\hline 26 & 53 & 4.65 & 71 & 73 & 1.90 \\
\hline & 41 & 4.28 & & 48 & 1.03 \\
\hline & 38 & 3.90 & & 32 & 0.74 \\
\hline & 34 & 3.36 & & 19 & 0.57 \\
\hline & 28 & 2.96 & & 16 & 0.42 \\
\hline & 24 & 2.50 & & 12 & 0.33 \\
\hline & 17 & 1.86 & & 9 & 0.24 \\
\hline 51 & 97 & 4.62 & & 5 & 0.12 \\
\hline & 77 & 3.67 & 80 & 101 & 1.91 \\
\hline & 58 & 2.61 & & 69 & 1.43 \\
\hline & 39 & 1.90 & & 51 & 0.98 \\
\hline & 22 & 1.12 & & 35 & 0.68 \\
\hline & 14 & 0.64 & & 24 & 0.49 \\
\hline & & & & 14 & 0.26 \\
\hline & & & 100 & 98 & 0.91 \\
\hline & & & & 74 & 0.76 \\
\hline & & & & 42 & 0.44 \\
\hline & & & & 25 & 0.23 \\
\hline & & In GD & $727 \mathrm{~h}$ & & \\
\hline 76 & 80 & 1.09 & 106 & 53 & 0.63 \\
\hline & 45 & 0.68 & & 48 & 0.53 \\
\hline & 26 & 0.39 & & 30 & 0.36 \\
\hline & 15 & 0.23 & & 16 & 0.25 \\
\hline & & & & 13 & 0.16 \\
\hline
\end{tabular}

URANIUM HEXAFLUORIDE IN FLUOROCARBONS MFL (CHLOROTRIFLUOROETHYLENE LIQUD POLYMER) AND C-2144

The solubilities of $\mathrm{UF}_{6}$ in MFL (chlorotrifluoroethylene liquid polymer) lubrication oil, having the formula $\left(\mathrm{CF}_{2}=\mathrm{CFCl}\right)_{n}$ and a molecular weight of 770 , and in $\mathrm{C}-2144$, having the formula $\mathrm{CF}_{3}\left(\mathrm{CF}_{2}\right)_{19} \mathrm{CF}_{3}$, were experimentally determined ${ }^{149}$. The results are listed in Tables 52 and 53. It was found in the case of both solvents that the ratio of the measured solubility to the calculated solubility is less than one at low temperatures, but that it increases to a value of one at temperatures of $180^{\circ} \mathrm{F}$. and higher. It was pointed out $^{149}$, that the deviation of the solubility from that predicted by Raoult's law at the lower temperatures was probably due to association and, hence, to a higher average effective molecular weight. At the higher temperature the solutions appear to be ideal.

Gabbard and McHenry ${ }^{64}$ studied the vapor pressure relationship to the viscosity, density, and composition of a $U_{6}-$ chlorotrifluoroethylene liquid polymer solution. The vapor pressure measurements were made at $60^{\circ} \mathrm{C}$. from 0 to $650 \mathrm{~mm}$. Hg pressure. The solution was found to deviate from Raoult's law. The composition and vapor pressure 
Table 52

\section{SOLUBILITY IN MFL*}

(Reference 149)

\begin{tabular}{|c|c|c|c|c|}
\hline \multirow{2}{*}{$\begin{array}{c}\text { Temperature } \\
\text { of Oil } \\
\left({ }^{\circ} \mathrm{F} .\right) \\
\end{array}$} & \multirow{2}{*}{$\begin{array}{c}\mathrm{UF}_{6} \text { Partial } \\
\text { Pressure } \\
\text { (psia.) } \\
\end{array}$} & \multicolumn{2}{|c|}{ Solubility (lb. /gal.) } & \multirow{2}{*}{$\begin{array}{c}\text { Ratio } \\
\text { Measured/Calculated } \\
\end{array}$} \\
\hline & & Measured & Calculated & \\
\hline \multirow[t]{13}{*}{100} & .74 & 0.48 & 0.73 & 0.66 \\
\hline & .74 & 0.58 & 0.73 & 0.78 \\
\hline & .74 & 0.65 & 0.73 & 0.89 \\
\hline & 1.43 & 1.30 & 1.52 & 0.86 \\
\hline & 1.44 & 1.18 & 1.52 & 0.78 \\
\hline & 1.40 & 1.12 & 1.46 & 0.77 \\
\hline & 1.44 & 1.23 & 1.52 & 0.81 \\
\hline & 1.48 & 1.25 & 1.59 & 0.79 \\
\hline & 1.53 & 1.29 & 1.65 & 0.78 \\
\hline & 1.56 & 1.30 & 1.65 & 0.79 \\
\hline & 1.56 & 1.29 & 1.65 & 0.78 \\
\hline & 2.94 & 2.84 & 3.8 & 0.75 \\
\hline & 2.94 & 3.16 & 3.8 & $0.83 \mathrm{Av} .0 .79 \pm 0.08$ \\
\hline \multirow[t]{5}{*}{140} & 1.59 & 0.54 & 0.71 & 0.76 \\
\hline & 1.63 & 0.56 & 0.72 & 0.78 \\
\hline & 2.06 & 0.94 & 0.92 & 1.02 \\
\hline & 2.69 & 1.22 & 1.21 & 1.01 \\
\hline & 2.90 & 1.26 & 1.32 & $0.95 \mathrm{Av} \cdot 0.90 \pm 0.11$ \\
\hline \multirow[t]{13}{*}{180} & 1.62 & 0.43 & 0.35 & 1.23 \\
\hline & 1.62 & 0.35 & 0.35 & 1.00 \\
\hline & 1.62 & 0.36 & 0.35 & 1.03 \\
\hline & 1.62 & 0.37 & 0.35 & 1.06 \\
\hline & 1.62 & 0.41 & 0.35 & 1.17 \\
\hline & 1.43 & 0.41 & 0.31 & 1.32 \\
\hline & 1.47 & 0.37 & 0.33 & 1.12 \\
\hline & 1.93 & 0.41 & 0.42 & 0.98 \\
\hline & 2.17 & 0.50 & 0.45 & 1.11 \\
\hline & 2.22 & 0.45 & 0.49 & 0.92 \\
\hline & 2.40 & 0.49 & 0.53 & 0.92 \\
\hline & 2.51 & 0.61 & 0.54 & 1.13 \\
\hline & 2.85 & 0.61 & 0.62 & $0.98 \mathrm{Av} \cdot 1.07 \pm 0.10$ \\
\hline \multirow[t]{3}{*}{212} & 2.29 & 0.20 & 0.28 & 0.71 \\
\hline & 2.85 & 0.41 & 0.35 & 1.17 \\
\hline & 2.90 & 0.44 & 0.36 & $1.22 \mathrm{Av} .1 .03 \pm 0.22$ \\
\hline \multirow[t]{4}{*}{220} & 1.62 & 0.18 & 0.20 & 0.90 \\
\hline & 1.62 & 0.18 & 0.20 & 0.90 \\
\hline & 2.41 & 0.34 & 0.30 & 1.13 \\
\hline & 2.95 & 0.39 & 0.37 & $1.05 \mathrm{Av} .1 .00 \pm 0.10$ \\
\hline
\end{tabular}

*Molecular weight of MFL $(790 \pm 30)$ estimated from boiling point elevation. A value of 750 was used in calculations. 
Table 53

SOLUBILITY IN C-2144*

(Reference (149)

\begin{tabular}{|c|c|c|c|c|}
\hline \multirow{2}{*}{$\begin{array}{c}\text { Temperature } \\
\text { of Oil } \\
\left({ }^{\circ} \mathrm{F} .\right)\end{array}$} & \multirow{2}{*}{$\begin{array}{c}\mathrm{UF}_{6} \text { Partial } \\
\text { Pressure } \\
\text { (psia.) }\end{array}$} & \multicolumn{2}{|c|}{ Solubility (lb. /gal.) } & \multirow{2}{*}{$\begin{array}{c}\text { Ratio } \\
\text { Measured/Calculated }\end{array}$} \\
\hline & & Measured & Calculated & \\
\hline \multirow[t]{4}{*}{140} & 1.02 & 0.30 & 0.34 & 0.88 \\
\hline & 1.22 & 0.33 & 0.41 & 0.81 \\
\hline & 1.85 & 0.41 & 0.60 & 0.63 \\
\hline & 2.04 & 0.48 & 0.67 & 0.73 Av. $0.78 \pm 0.07$ \\
\hline 180 & 2.16 & 0.39 & 0.35 & 1.11 \\
\hline \multirow[t]{4}{*}{212} & 1.62 & 0.14 & 0.15 & 0.94 \\
\hline & 2.54 & 0.28 & 0.23 & 1.20 \\
\hline & 2.85 & 0.26 & 0.26 & 0.97 \\
\hline & 2.91 & 0.27 & 0.27 & $1.01 \mathrm{Av} .1 .03 \pm 0.08$ \\
\hline
\end{tabular}

*Molecular weight $(970 \pm 50)$ estimated by boiling point elevation of C-716. A value of 1018 was used for calculations.

were related by the Margule's equation. The results are listed in Table 54 and Figure 26.

Johns on also reports vapor pressure values for $\mathrm{UF}_{6}$ above a $U F_{6}-C_{21} F_{44}$ system. ${ }^{85}$

URANIUM HEXAFLUORIDE IN DICHLOROTETRAFLUOROETHANE

The solubility of $\mathrm{UF}_{6}$ in dichlorotetrafluoroethane (Freon-114) from $22^{\circ}$ to $64^{\circ} \mathrm{C}$. was experimentally determined by Barber, Posey, and Judkins ${ }^{14}$. They also determined a liquid-vapor isobar at 40 psia. The experimental results are shown in Figure 27 in which the solid, liquid, and vapor compositions are shown as functions of temperature. Both the liquid-solid and the liquid-vapor equilibria were calculated for the system over the $0^{\circ}$ to $100^{\circ} \mathrm{C}$. range.

In addition to calculating an ideal phase relationship using Raoult's law, Barber and his co-workers also calculated phase relationships using a theoretical method based on the work of Hildebrand* and others. ${ }^{14}$, 145 This method requires that vapor pressures, heats of vaporization, molecular weights, and densities of the pure components be known for calculation of the activity coefficients from which the equilibrium data can be determined. The calculated activity coefficients are plotted as a function of composition in Figure 28. The experimental, theoretical, and ideal solubilities are shown in Figure 29. The experimental and calculated liquid-vapor equilibria at 40 psia. are shown in Figure 30. In this figure the experimental concentration of the more volatile component (Freon-114) in the vapor is plotted as a function of the experimental concentration of the more volatile component in the liquid.

*Hildebrand, J. H. and Wood, S. E. J. Chem. Phys. 1, $817(1933)$. 
Table 54

VAPOR PRESSURE, COMPOSITION, AND DENSITY OF CHLOROTRIFLUOROETHYLENE LIQUID POLYMER AND URANIUM HEXAFLUORIDE SOLUTIONS AT $60^{\circ} \mathrm{C}$.

(Reference 64)

\begin{tabular}{|c|}
\hline $\begin{array}{l}\text { Vapor Pressure } \\
\text { (mm. Hg) }\end{array}$ \\
\hline 46 \\
\hline 52 \\
\hline 84 \\
\hline 136 \\
\hline 160 \\
\hline 174 \\
\hline 223 \\
\hline 225 \\
\hline 244 \\
\hline 260 \\
\hline 278 \\
\hline 278 \\
\hline 283 \\
\hline 325 \\
\hline 330 \\
\hline 347 \\
\hline 351 \\
\hline 351 \\
\hline 351 \\
\hline 351 \\
\hline 367 \\
\hline 375 \\
\hline 375 \\
\hline 375 \\
\hline 375 \\
\hline 402 \\
\hline 410 \\
\hline 410 \\
\hline 452 \\
\hline 484 \\
\hline 507 \\
\hline 532 \\
\hline 547 \\
\hline 558 \\
\hline 565 \\
\hline 581 \\
\hline 605 \\
\hline 630 \\
\hline 638 \\
\hline 638 \\
\hline 638 \\
\hline 649 \\
\hline
\end{tabular}

Composition

(mole percent $\left.\mathrm{UF}_{6}\right)$

4.9

6.3

9.9

24.2

27.8

31.4

31.1

36.1

38.7

38.0

37.9

37.4

38.9

39.8

40.7

41.0

41.5

42.9

44.6

49.2

53.2

55.9
Density

(g./cc.)

1.920

1.925

1.921

1.940

1.932

1.935

1.944

1.949

1.941

1.983

1.975

1.991

1.987

2.033

2.053

2.078

2. 097

2.136

2.130

2.163

2.196

2.187

2.188

2.222

2.246

2. 249

2. 241

2. 260

2. 262 


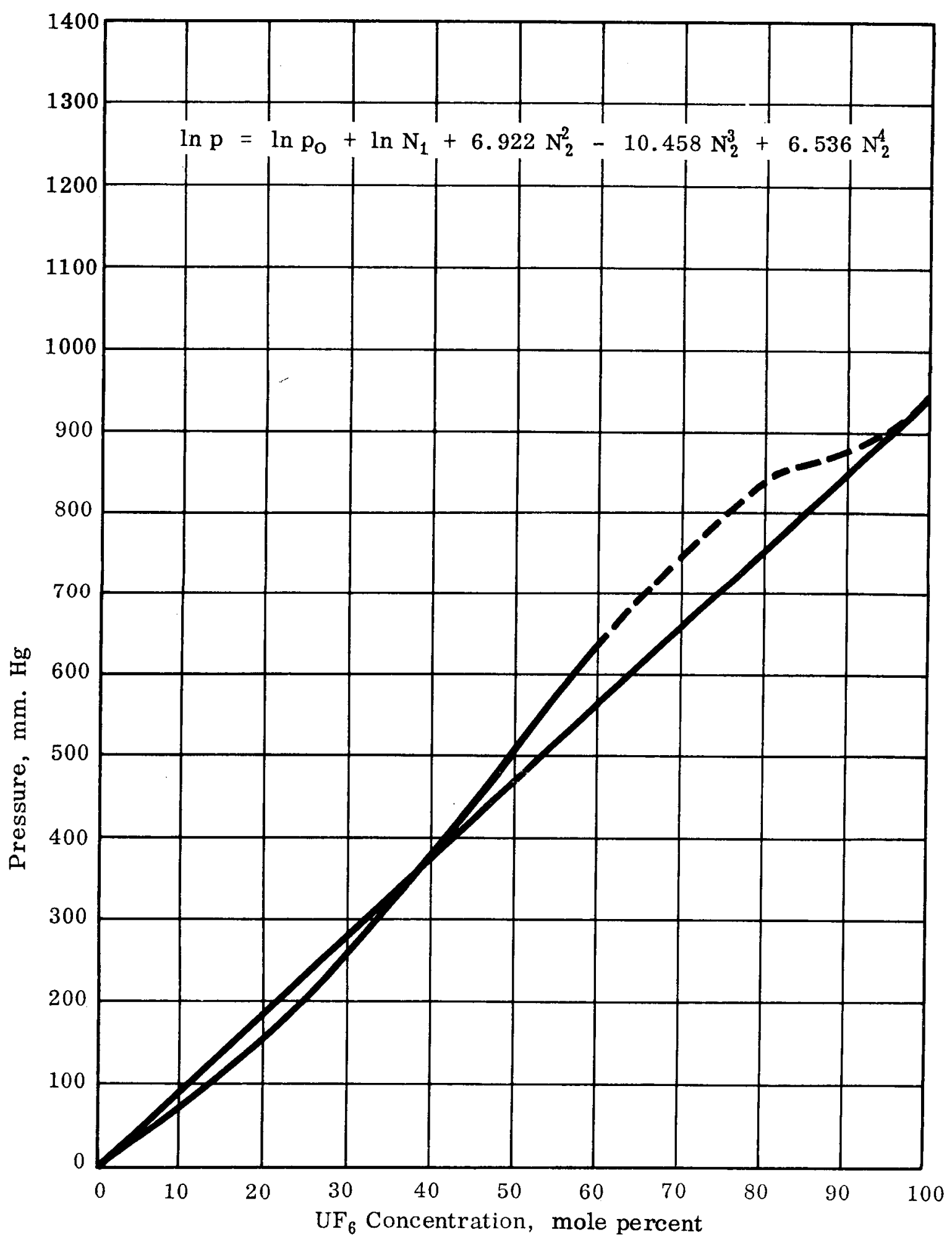

FYG. 26. COMPOSITION OF URANIUM HEXAFLUORIDE AND CHLOROTRIFLUOROETHYLENE POLYMER SOLUTIONS AS A FUNCTION OF THE EQUILIBRIUM PRESSURE OF URANIUM HEXAFLUORIDE AT $60^{\circ} \mathrm{C}$.

(Reference 125) 


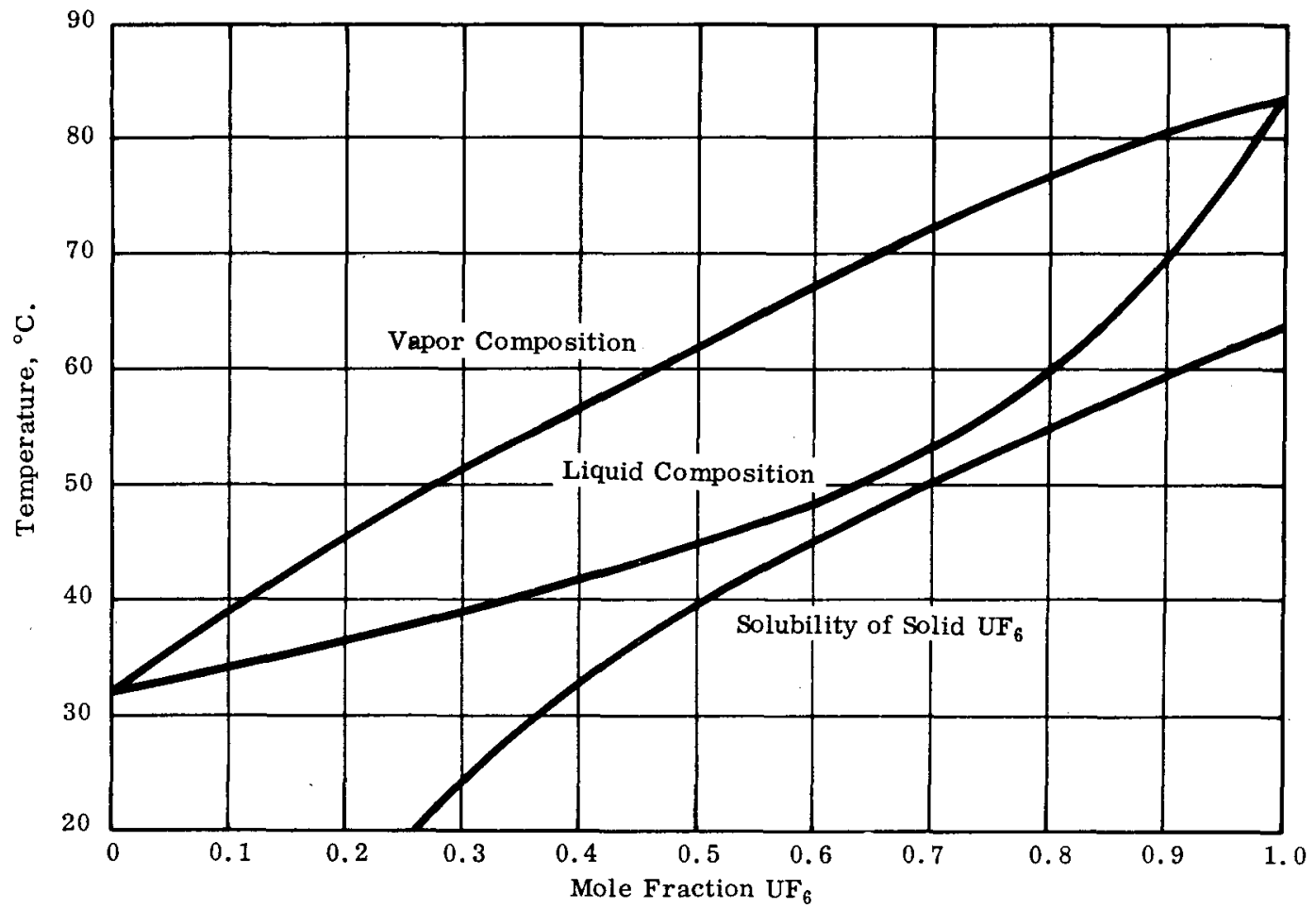

FIG. 27. VAPOR-LIQUID AND SOLID-LIQUID EQUILIBRIUM COMPOSITION OF THE URANIUM HEXAFLUORIDE-FREON-114 SYSTEM UNDER 40 PSIA. PRESSURE (Reference 14)

\section{URANIUM HEXAFLUORIDE IN PERFLUOROTRIBUTYLAMINE}

Jordon, Posey, and Rutledge ${ }^{86}$ determined the solid-liquid and liquid-vapor equilibria of the $\mathrm{UF}_{6}$-perfluorotributylamine system. The studies were conducted at $40 \mathrm{psia}$. and at temperatures ranging from $64^{\circ}$ to $220^{\circ} \mathrm{C}$. In addition, the solubility of $\mathrm{UF}_{6}$ in perfluorotributylamine was also determined at temperatures from $1^{\circ}$ to $64^{\circ} \mathrm{C}$. by slowly cooling solutions of known concentration until precipitation occurred. The experimental results were found to deviate from the results calculated from Raoult's law. However, there was less deviation from the results calculated by use of the activity coefficient technique. The experimental and calculated equilibria data are presented in Table 55

Table 55

\section{SOLUBILITY IN PERFLUOROTRIBUTYLAMINE}

Temperature

('C.)

0.94

11.31

19.87

30.90

38.24
Formula

Percent $\mathrm{UF}_{6}$

13.28

20.08

25.93

37.65

47.55
Temperature,

('C.)

48.47

53.85

58.17

59.50

64.02
Formula Percent UF $_{6}$

61.74

74.10

84.89

88.77

100.00 


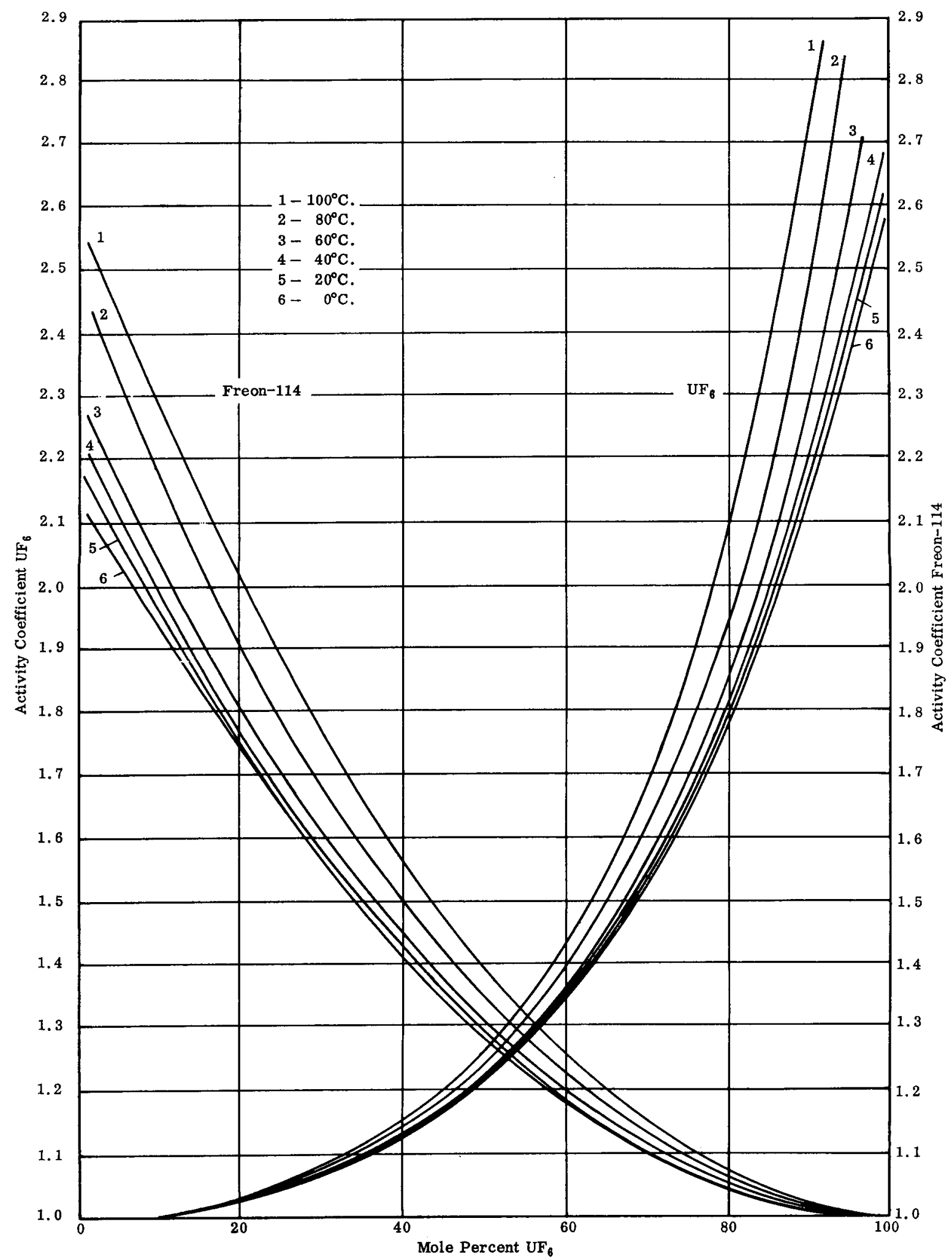

FIG. 28. ACTIVITY COEFFICIENT OF URANIUM HEXAFLUORDE IN FREON114 AS A FUNCTION OF COMPOSITION AT VARIOUS TEMPERATURES (Reference 14) 


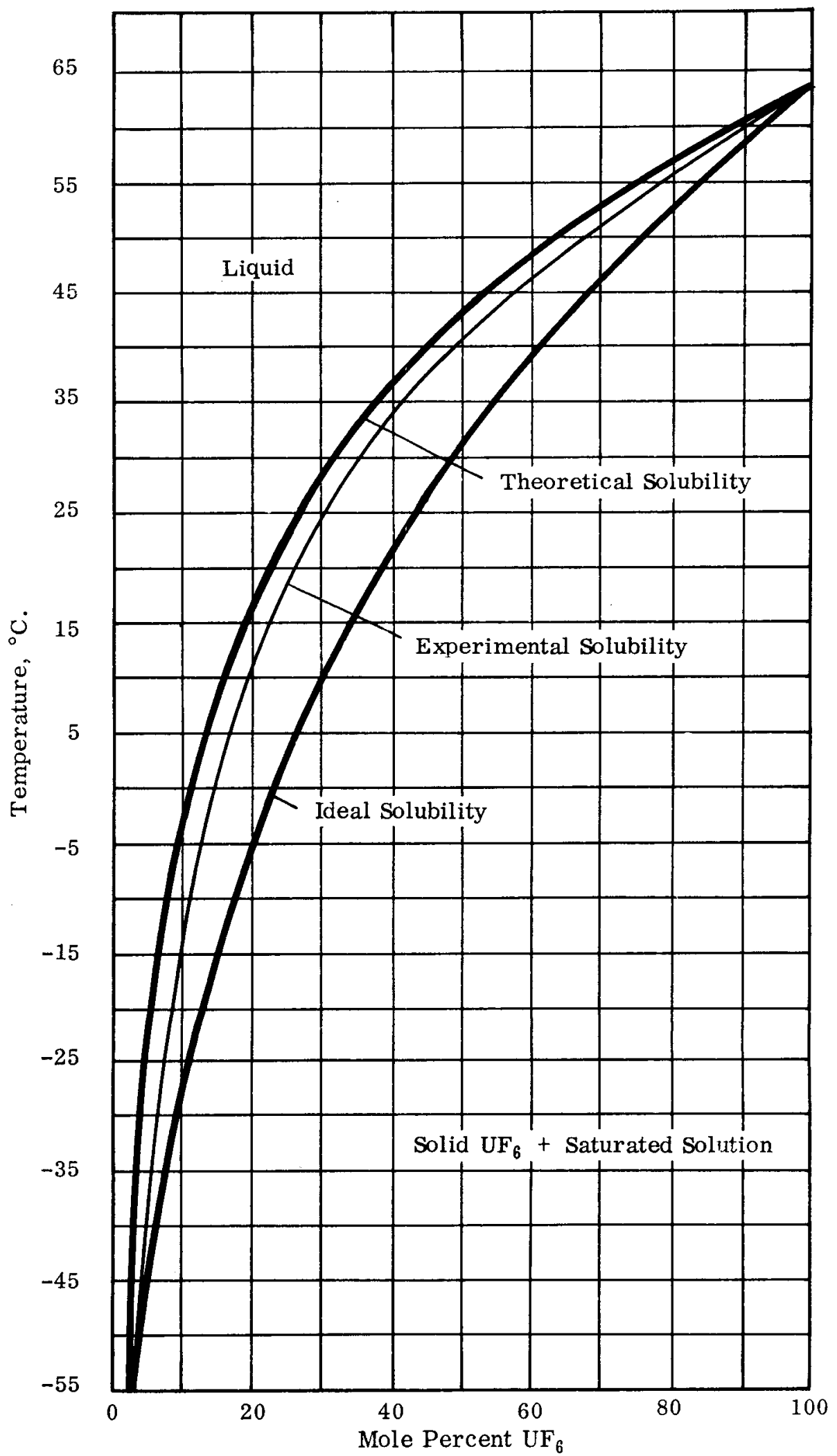

FIG. 29. SOLD - LIQUID EQUILIBRIUM OF THE URANIUM HEXAFLUORIDE FREON-114 SYSTEM

(Reference 14) 


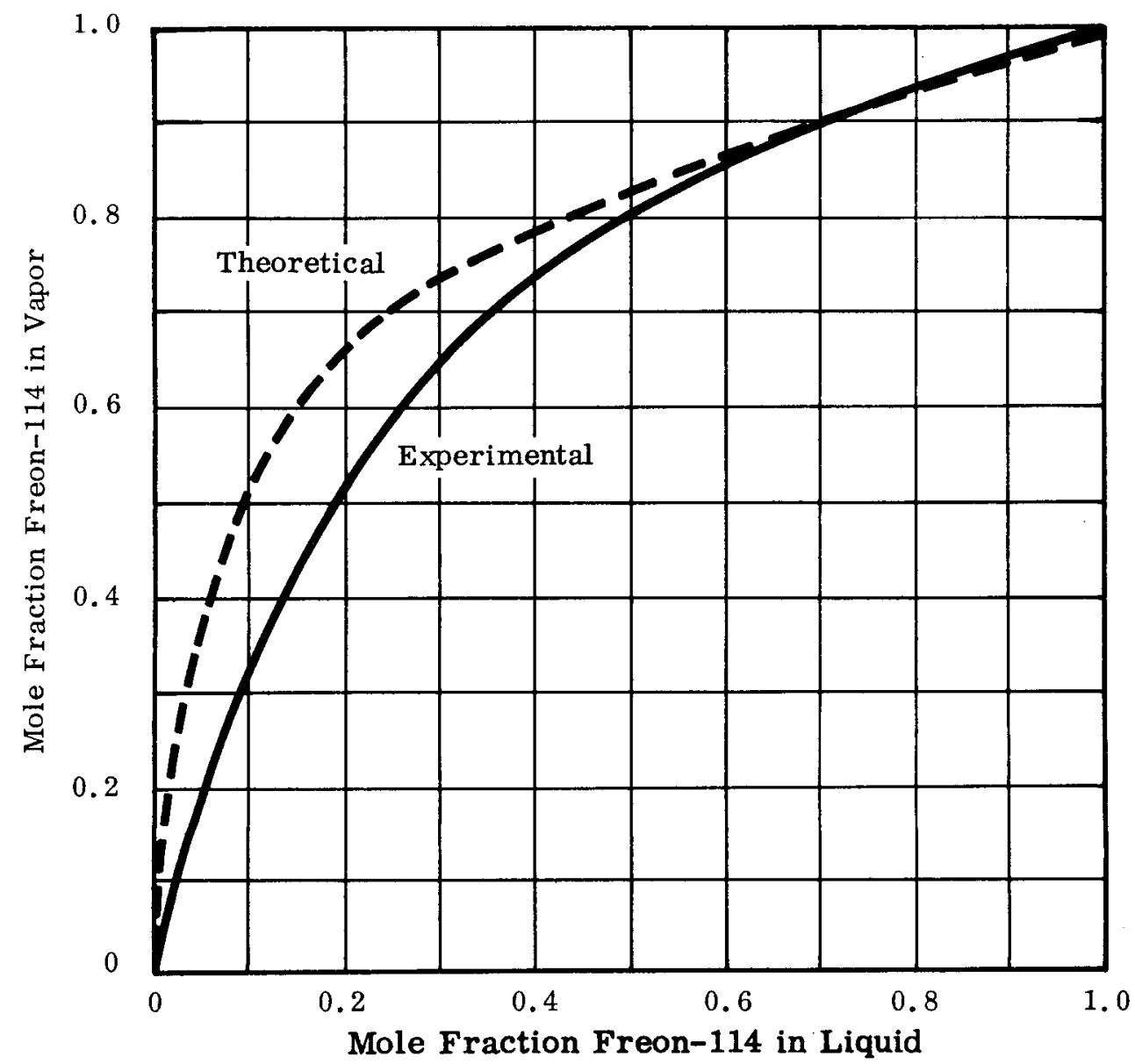

FIG. 30. LIQUID - VAPOR EQUILIBRIUM OF THE URANIUM HEXAFLUORIDE AND FREON-114 SYSTEM AT 40 PSIA. PRESSURE

(Reference 14)

and in Figure 31. A comparison of the calculated and experimental coefficients is given in Table 56. The experimental liquid-vapor equilibria at 40 psia. are presented in Table 57 and a comparison of the experimental data with the calculated data is presented in Figure 32.

\section{URANIUM HEXAFLUORIDE IN PERFLUOROISOPROPYL ETHER}

Kirshenbaum $^{62}$ (see also References 115 and 116) investigated the equilibria of the $\mathrm{UF}_{6}$ perfluoroisopropyl ether system. The results of the solubility studies of $\mathbf{U F}_{6}$ vapor in perfluoroisopropyl ether are presented in Table 58, while the results with solid $U_{6}$ in the same compound appear in Table 59.

\section{URANIUM HEXAFLUORIDE IN PERFLUORO- $n$-PENTANE AND IN} 1,2-DICHLOROHEXAFLUOROPROPANE

Posey and Barber ${ }^{126}$ calculated the liquid-vapor equilibria of the $U F_{6}$-perfluoro-npentane and $\mathrm{UF}_{6}-1,2$-dichlorohexafluoropropane systems by using the activity coefficient technique. The calculated activity coefficient, phase compositions, and total pressures for the $\mathrm{UF}_{6}$-perfluoro- $n$-pentane system at $60^{\circ}, 70^{\circ}, 80^{\circ}$, and $90^{\circ} \mathrm{C}$. are listed in Table 60 while those for the $\mathrm{UF}_{6}-1,2-$ dichlorohexafluoropropane system are given in Table 61 . 


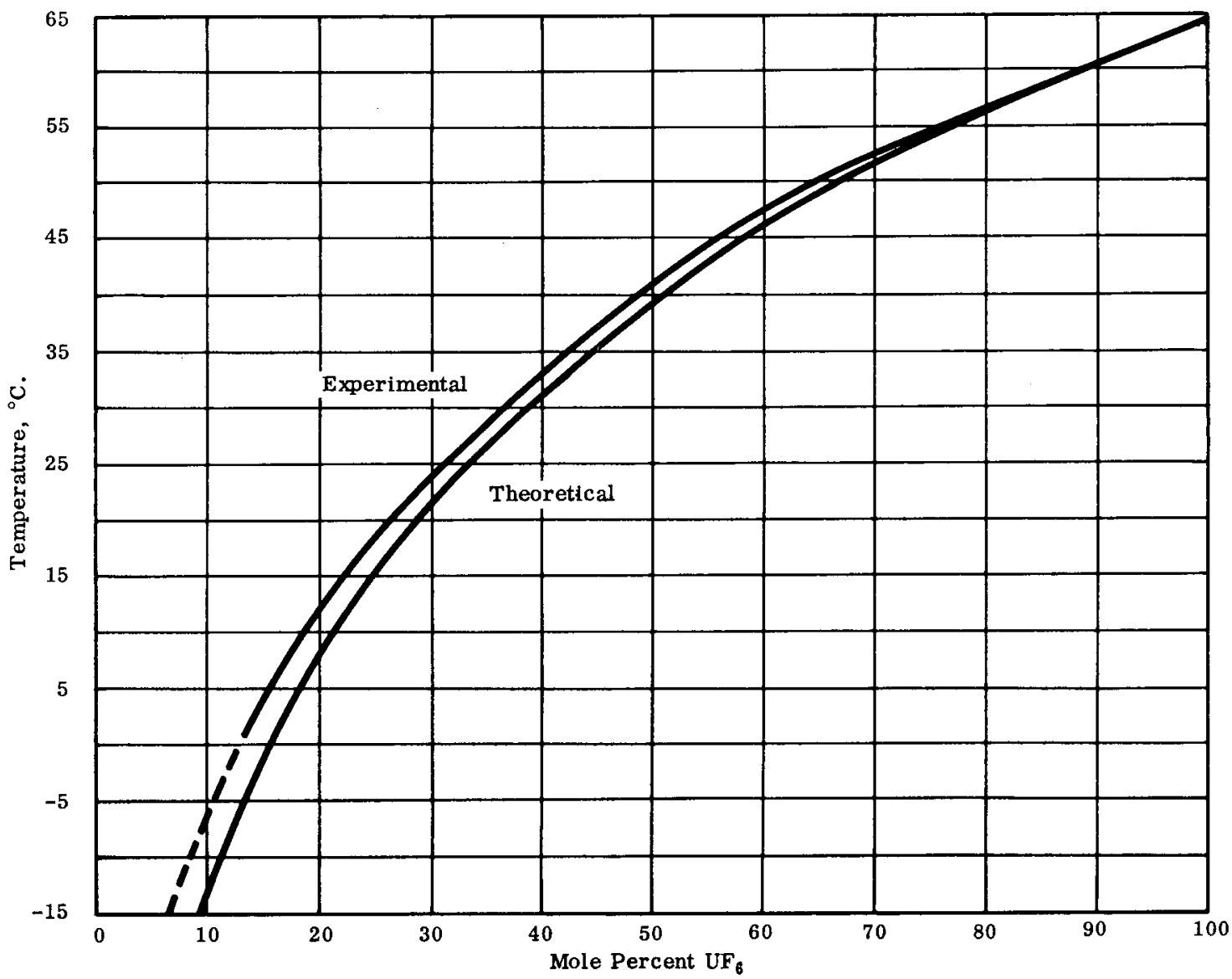

FIG. 31. SOLID - LIQUID EQUILIBRIUM OF THE URANIUM HEXAFLUORDE PERFLUOROTRIBUTYLAMINE SYSTEM

(Reference 86)

Table 56

ACTIVITY COEFFICIENTS IN PERFLUOROTRIBUTYLAMINE

(Reference 86)

Temperature

$\left({ }^{\circ} \mathrm{C}.\right)$

$-20$

0

20

40

60

64 $\underline{\text { Experimental* }}$

2.400

1.650

1.380

1.200

1.020

1.000
Theoretical ${ }^{\dagger}$

1.513

1.346

1.236

1.154

1.031

1.000

*Calculated by using "smoothed" data

†Calculated by using the activity coefficient method. 
Table 57

LIQUID-VAPOR EQ UILIBRIUM OF THE URANIUM HEXAFLUORIDEPERFLUOROTRIBUTYLAMINE SYSTEM

(Reference 86)

\begin{tabular}{|c|c|c|c|c|}
\hline \multirow{2}{*}{$\begin{array}{c}\text { Pressure } \\
\text { (psia.) } \\
\end{array}$} & \multirow{2}{*}{$\begin{array}{c}\text { Boiling Temperature } \\
\left({ }^{\circ} \mathrm{C} .\right) \\
\end{array}$} & \multicolumn{2}{|c|}{ Composition (mole percent $\mathrm{UF}_{6}$ ) } & \multirow{2}{*}{$\begin{array}{l}\text { Corrected Boiling } \\
\text { Point at } 40 \text { psia. }\end{array}$} \\
\hline & & Liquid & Vapor & \\
\hline 39.9 & 84.0 & 89.1 & 99.3 & 84.1 \\
\hline 40.9 & 90.0 & 55.0 & 96.9 & 89.2 \\
\hline 42.6 & 93.2 & 46.4 & 98.6 & 90.8 \\
\hline 39.7 & 95.4 & 29.1 & 98.9 & 95.7 \\
\hline 39.9 & 109.5 & 15.3 & 96.5 & 109.6 \\
\hline 39.9 & 119.6 & 13.2 & 94.5 & 119.7 \\
\hline 40.5 & 139.9 & 16.3 & 92.2 & 139.4 \\
\hline 40.4 & 182.9 & 9.87 & 69.3 & 182.5 \\
\hline 40.0 & 200.6 & 4.35 & 47.8 & 200.6 \\
\hline 39.9 & 209.2 & 0.88 & 15.1 & 209.3 \\
\hline 39.9 & 219.6 & 0.00 & 0.0 & 219.7 \\
\hline
\end{tabular}

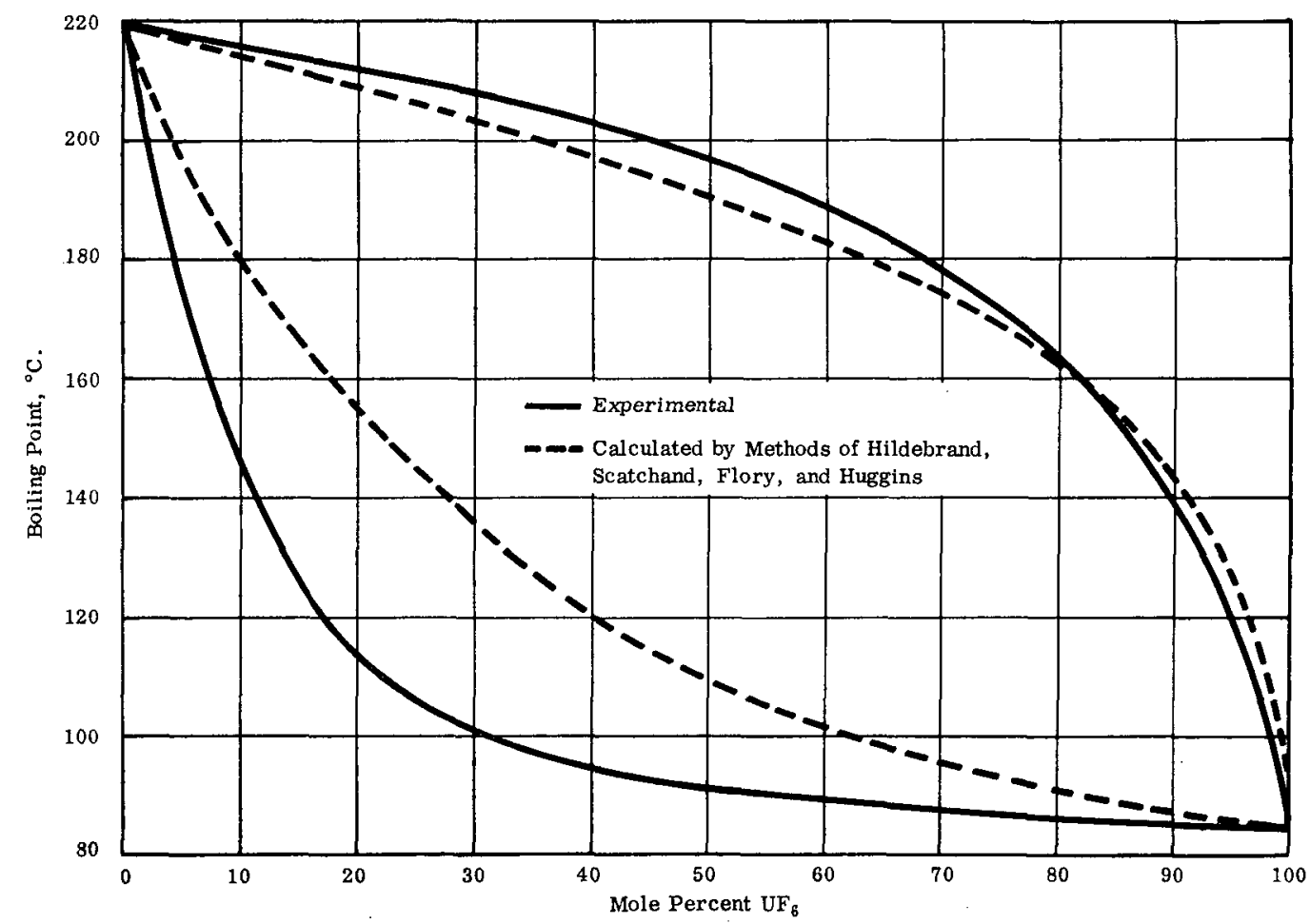

FIG. 32. LIQUID - VAPOR EQUILIBRIUM OF THE URANIUM HEXAFIUORIDE AND PERFLUOROTRIBUTYLAMINE SYSTEM AT 40 PSIA. PRESSURE (Reference 86) 
Table 58

\section{SOLUBILITY OF THE VAPOR IN PERFLUOROISOPROPYL ETHER}

(Reference 62)

\begin{tabular}{|c|c|c|c|c|c|c|}
\hline $\begin{array}{l}\text { Temperature } \\
\left({ }^{\circ} \mathrm{C} .\right)\end{array}$ & $\begin{array}{c}\text { Total } \\
\text { Pressure } \\
\text { (mm. Hg) }\end{array}$ & $\begin{array}{l}\text { Pressure } \\
\text { of } \mathrm{UF}_{\mathrm{B}}^{*} \\
(\mathrm{~mm} . \mathrm{Hg})\end{array}$ & $\begin{array}{l}\text { Grams } \mathrm{UF}_{6} / \\
100 \mathrm{~g} . \\
\text { Solvent }\end{array}$ & $\begin{array}{c}\text { Mole } \\
\text { Fraction } \\
\mathrm{UF}_{6}\end{array}$ & $\begin{array}{c}\text { Raoult's } \\
\text { Mole Fraction } \\
\text { UF }_{6}\end{array}$ & $\gamma \mathrm{UF}_{6}$ \\
\hline 0.0 & 110.1 & 10.1 & 6.9 & 0.065 & 0.122 & 1.88 \\
\hline 10.0 & 175.5 & 24.5 & 11.7 & 0.105 & 0.188 & 1.79 \\
\hline 20.0 & 271.0 & 57.0 & 19.7 & 0.165 & 0.262 & 1.59 \\
\hline 30.0 & 406.7 & 96.7 & 21.2 & 0.176 & 0.292 & 1.65 \\
\hline 30.0 & 423.5 & 139.0 & 33.0 & 0.249 & 0.524 & 2.10 \\
\hline 40.0 & 594.4 & 149.0 & 21.2 & 0.176 & 0.269 & 1.53 \\
\hline 40.0 & 626.5 & 243.0 & 41.3 & 0.293 & 0.487 & 1.66 \\
\hline 50.0 & 848.5 & 221.0 & 21.2 & 0.176 & 0.314 & 1.78 \\
\hline 50.0 & 904.8 & 367.0 & 41.3 & 0.293 & 0.520 & 1.78 \\
\hline
\end{tabular}

$\overline{\text { *Assuming } \gamma}$ ether $=1$.

Table 59

SOLUBILITY OF THE SOLID IN PERFLUOROISOPROPYL ETHER

(Reference 62)

Temperature

$\left({ }^{\circ} \mathrm{C}.\right)$

0

10

20

30

40

50
Mole Fraction $\mathrm{UF}_{6}$

0.0645

0.102

0.159

0.246

0.356

0.514
Raoult's

Mole Fraction $\mathrm{UF}_{6}$

0.21

0.31

0.37

0.46

0.58

0.76 $\frac{\gamma \mathrm{UF}_{6}}{3.26}$

3. 04

2. 33

1.87

1.63

1.48 
Table 60

LIQUID-VAPOR EQUILIBRIUM OF THE URANIUM HEXAFLUORIDE PERFLUORO- $n$-PENTANE SYSTEM

(Reference 126 )

\begin{tabular}{|c|c|c|c|c|c|c|c|c|c|c|c|c|}
\hline \multirow{2}{*}{$\begin{array}{l}\text { Mole Fraction } \\
\mathrm{UF}_{6} \text { in Liquid }\end{array}$} & \multicolumn{4}{|c|}{ Activity Coefficient of $U F_{6}$} & \multicolumn{4}{|c|}{ Mole Fraction $\mathrm{UF}_{6}$ in Vapor } & \multicolumn{4}{|c|}{ Total Pressure (mm. Hg) } \\
\hline & $60^{\circ} \mathrm{C}$ & $70^{\circ} \mathrm{C}$ & $80^{\circ} \mathrm{C}$. & $90^{\circ} \mathrm{C}$. & $60^{\circ} \mathrm{C}$. & $70^{\circ} \mathrm{C}$. & $80^{\circ} \mathrm{C}$. & $90^{\circ} \mathrm{C}$. & $60^{\circ} \mathrm{C}$ & $70^{\circ} \mathrm{C}$. & $80^{\circ} \mathrm{C}$. & $90^{\circ} \mathrm{C}$. \\
\hline 0.00 & -- & -- & - & & 0.00 & 0.00 & 0.00 & 0.00 & 2084 & 2767 & 3606 & 4622 \\
\hline 0.01 & 2.508 & 2.445 & 2.332 & 2.163 & 0.012 & 0.012 & 0.012 & -- & 2088 & 2773 & 3613 & 4657 \\
\hline 0.05 & 2.420 & 2.365 & 2.259 & 2.082 & 0.058 & 0.058 & 0.057 & 0.017 & 2103 & 2794 & 3637 & 4681 \\
\hline 0.10 & 2.313 & 2.264 & 2.169 & 1.922 & 0.109 & 0.110 & 0.109 & 0.108 & 2116 & 2812 & 3659 & 4697 \\
\hline 0.20 & 2.103 & 2.066 & 1.990 & 1.611 & 0.198 & 0.200 & 0.199 & 0.198 & 2124 & 2827 & 3674 & 4614 \\
\hline 0.40 & 1.712 & 1.692 & 1.650 & 1.330 & 0.328 & 0.334 & 0.336 & 0.338 & 2084 & 2779 & 3612 & 4414 \\
\hline 0.60 & 1.373 & 1.366 & 1.347 & 1.105 & 0.413 & 0.421 & 0.430 & 0.438 & 1994 & 2662 & 3457 & 4086 \\
\hline 0.80 & 1.116 & 1.114 & 1.110 & 1.031 & 0.480 & 0.492 & 0.509 & 0.524 & 1861 & 2482 & 3210 & 3702 \\
\hline 0.90 & 1.034 & 1.033 & 1.032 & 1.008 & 0.552 & 0.566 & 0.587 & 0.607 & 1685 & 2250 & 2908 & 3277 \\
\hline 0.95 & 1.009 & 1.009 & 1.009 & 1.000 & 0.653 & 0.667 & 0.689 & 0.708 & 1467 & 1969 & 2560 & 2648 \\
\hline 1.00 & 1.000 & 1.000 & 1.000 & 1.000 & 1.000 & 1.000 & 1.000 & 1.000 & $999^{*}$ & 1370 & 1840 & 2422 \\
\hline
\end{tabular}

*Extrapolated from the vapor pressure curve for $\mathrm{UF}_{6}$. 
Table 61

PRESSURE - COMPOSITION EQUILIBRIUM OF THE URANIUM HEXAF LUORDE 1,2 -DICHLOROHEXAF LUOROPROPANE SYSTEM

(Reference 126)

Mole Fraction $\mathrm{UF}_{6}$

\begin{tabular}{|c|c|c|c|}
\hline Liquid & Vapor & $\begin{array}{c}\text { Total Pressure } \\
(\mathrm{mm} . \mathrm{Hg})\end{array}$ & $\begin{array}{c}\text { Activity Coefficient } \\
U_{6} \text { in Liquid } \\
\end{array}$ \\
\hline 0 & 0 & 456.6 & $--\cdots-$ \\
\hline 0.10 & 0.084 & 458 & 1.777 \\
\hline 0.20 & 0.158 & 446 & 1.631 \\
\hline 0.40 & 0.284 & 422 & 1.380 \\
\hline 0.60 & 0.384 & 379 & 1.119 \\
\hline 0.80 & 0.544 & 336 & 1.052 \\
\hline 0.90 & 0.669 & 296 & 1.014 \\
\hline 1.00 & 1.000 & 217 & 1.000 \\
\hline
\end{tabular}

The phase compositions of the $\mathrm{UF}_{6}$-perfluoro- $n$-pentane system at $60^{\circ}, 70^{\circ}, 80^{\circ}$ and $90^{\circ} \mathrm{C}$. are presented in Figure 33. The authors pointed out that an azeotrope formation is indicated by the calculated results.

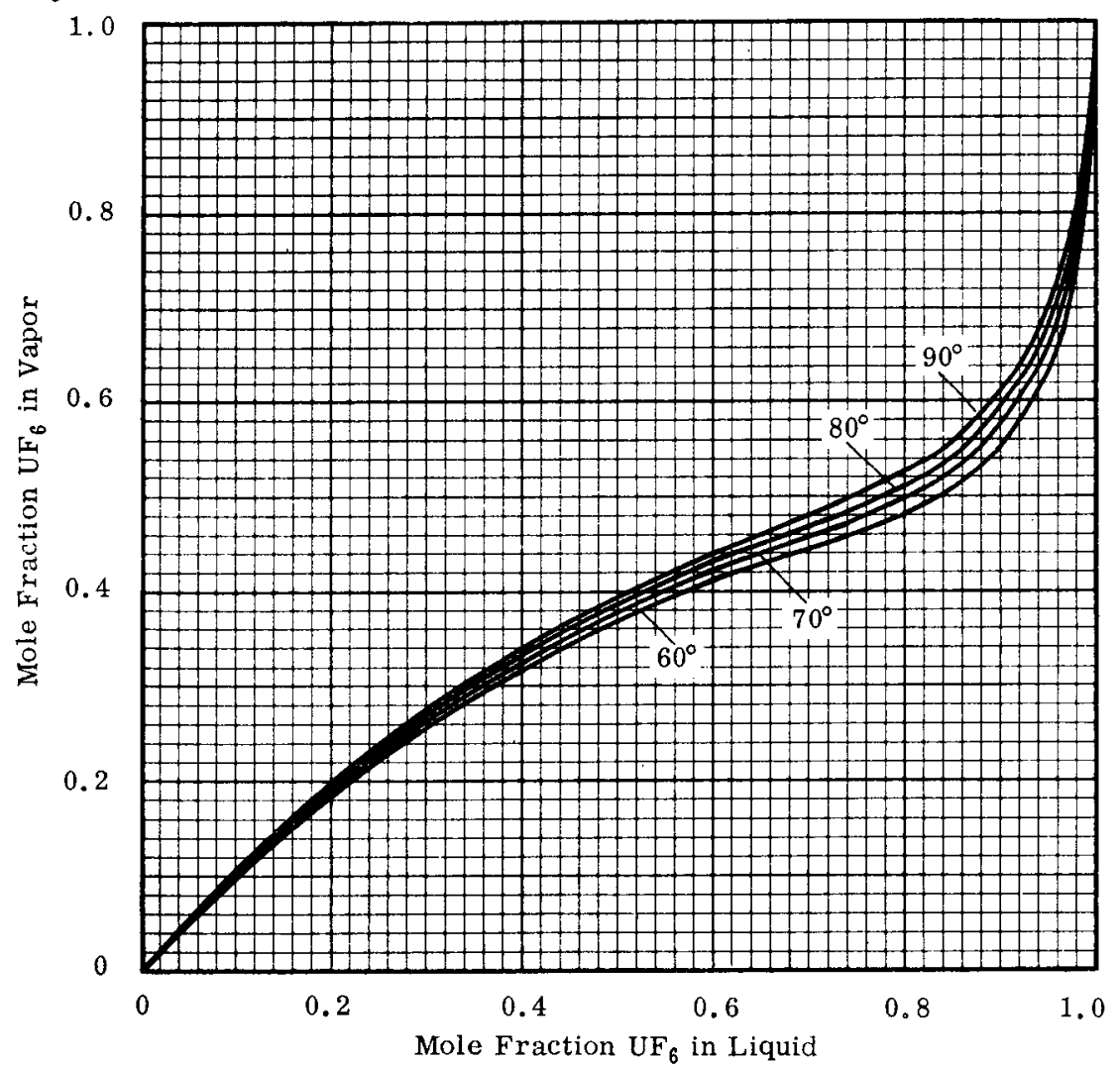

FIG. 33. LIQUID - VAPOR EQUILIBRIUM OF THE URANIUM HEXAFLUORIDE-PERFLUORO- $n$-PENTANE SYSTEM 
URANIUM HEXAFLUORIDE, IN PERFLUOROHEPTANE

Haendler and Barber ${ }^{T 2}$ investigated the liquid-vapor equilibrium of the $U F_{6}$-perfluoroheptane system at $1520 \mathrm{~mm}$. Hg. The results are listed in Table 62. It was noted that the experimental difficulties encountered in the measurement of this system were such that extreme accuracy could not be claimed. A temperature-composition diagram of the system is presented in Figure 34 .

Table 62

EQUILIBRIUM DATA OF THE URANIUM HEXAFLUORIDE PERFLUOROHEPTANE SYSTEM

(Reference 72)

Temperature

$\left({ }^{\circ} \mathrm{C}.\right)$

105.3

103.8

101.8

101.0

99.1

98. 7

82.8

80.8

78.9

78.0

77.2

76.4

75.8

75.2

73.8

73.6
Mole Percent $\mathrm{UF}_{6}$

Liquid $\quad$ Vapor

0

1.50

3.95

4.89

7.47

7.59

44.9

56.1

65.6

72.4

75.7

80.0

84.0

91.5

97.8

100.0

0

6.85

13.4

16.3

23.2

24.1

70.9

76.5

82.1

85.2

87.8

90.9

92.4

93.1

99.2

100.0
2.28

1.76

1.74

1.68

1.72

1.24

1.14

1.06

1.02

1.04

1.04

1.03

0.97

1.01

1.00 


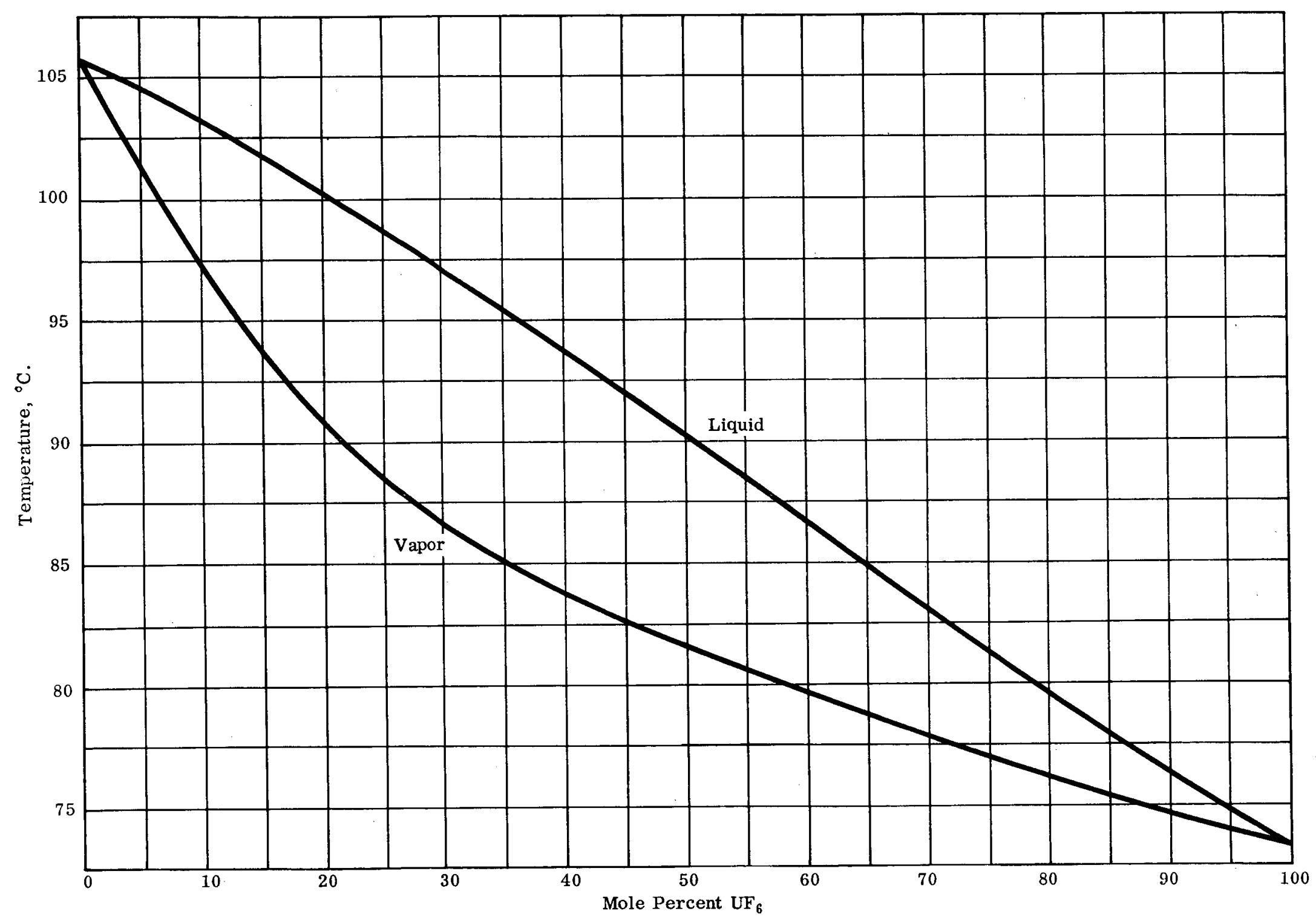

FIG. 34. LIQUD - VAPOR EQUILIBRIUM OF THE URANIUM HEXAFLUORIDEPERFLUOROHEPTANE SYSTEM (Reference 72) 
Kuykendall, Jones, Rapp, and Barbe ${ }^{95}$ experimentally determined the solid-liquid equilibrium for temperatures ranging from $32^{\circ}$ to $64^{\circ} \mathrm{C}$. for the $\mathrm{UF}_{6}-2,2,3$-trichloroheptafluorobutane system. In addition, the liquid-vapor equilibria were calculated at 30 to 40 psia. using the activity coefficient method.

The results of the solubility, studies are presented in Table 63 and Figure 35 . The agreement between the experimental and theoretical values are reported as being good. The theoretical values were calculated using the activity coefficient technique. The calculated liquid-vapor equilibrium data are presented in Table 64. The compositiontemperature diagrams for 30 and 40 psia. are presented in Figures 36 and 37, respectively.

The solution densities of the $\mathrm{UF}_{6}-2,2,3$-trichloroheptafluorobutane system were determined experimentally and the values fitted to the expression:

$$
\ln \rho=\alpha(\mathrm{m})+\beta(\mathrm{m})(\mathrm{X}) \mathrm{g} \cdot / \mathrm{cc} \text {. }
$$

where $\rho$ is the solution density, $m$ is the concentration of $\mathrm{UF}_{6}$ in mole percent, $\mathrm{X}$ is $10^{3} / \mathrm{T}^{\circ} \mathrm{K}$. and $\alpha(\mathrm{m})$ and $\beta(\mathrm{m})$ are expressed by the following equations :

$$
\begin{aligned}
& \alpha(\mathrm{m})=0.12698+3.73352 \times 10^{-3} \mathrm{~m}+1.95458 \times 10^{-5} \mathrm{~m}^{2} \\
& \beta(\mathrm{m})=0.12603+7.40421 \times 10^{-4} \mathrm{~m}
\end{aligned}
$$

A comparison of the experimental and calculated densities is given in Table 65.

\section{URANIUM HEXAFLUORDE IN C-816 (PERFLUORODIMETHYLCYCLOHEXANE)}

Hodgson $^{79}$ found that at temperatures below $-30^{\circ} \mathrm{C}$, a mixture of 8.5 mole percent $\mathrm{C}_{8} \mathrm{~F}_{16}$ and 91.5 mole percent $\mathrm{UF}_{6}$ was a "free-flowing solid," while at temperatures above $-30^{\circ} \mathrm{C}$., the mixture tended to cake. At room temperature the solid resembled damp salt. Vapor composition data are consistent with complete miscibility above the melting point of the mixture $\left(58.3^{\circ} \mathrm{C}.\right)$ and immiscibility below the melting point.

Gabbard, Bernstein, and Amis ${ }^{63}$ studied the vapor-liquid equilibrium of the $\mathrm{UF}_{6}-\mathrm{C}_{8} \mathrm{~F}_{16}$ system at approximately 40 psia. A summary of the results is shown in Table 66. A comparis on of the experimental data with calculated results (based on Raoult's law) appears in Figure 38. Data for a temperature-composition diagram (Figure 39) were obtained from the smooth curve of Figure 38. These data were found to compare favorably with the experimental data. The activity coefficients of $\mathrm{UF}_{6}$ and $\mathrm{C}_{8} \mathrm{~F}_{16}$ were calculated using the modification of Margule's method and are presented in Figure 40 which also contains the experimental values. The values used in the activity coefficient calculations were taken from the smooth curve in Figure 38.

Johnson ${ }^{85}$ utilized the vapor pressure data of $\mathrm{UF}_{6}$ above its solutions in $\mathrm{C}_{8} \mathrm{~F}_{16}$ and $\mathrm{C}_{22} \mathrm{~F}_{44}$ (see also Reference 115) to make an extrapolation of the partial pressure of $\mathrm{UF}_{6}$ above these solutions through Raoult's and Henry's laws.

\section{URANIUM HEXAFLUORIDE IN HYDROGEN FLUORIDE}

The solid-liquid, liquid-liquid, and liquid-vapor equilibria of the $\mathrm{UF}_{6}-\mathrm{HF}$ system have been experimentally determined. Rutledge, Jarry, and Davis 39, 133 investigated the solid-liquid and liquid-liquid portions of the equilibria over the $-85^{\circ}$ to $105^{\circ} \mathrm{C}$. range while Jarry, Rosen, Hale, and Davis ${ }^{40,83}$ investigated the liquid-vapor equilibria over the $40^{\circ}$ to $105^{\circ} \mathrm{C}$. range. Since the variation of the molecular weight of hydrogen 
Table 63

SOLUBILITY IN 2, 2,3-TRICHLOROHEPTAFLUOROBUTANE

(Reference 95)

\begin{tabular}{cccc}
$\begin{array}{c}\text { Temperature } \\
\left({ }^{\circ} \mathrm{C} .\right)\end{array}$ & \multicolumn{3}{c}{ Solubility (mole percent UF $)^{\text {) }}$} \\
\cline { 1 - 3 } 32.4 & $\frac{\text { Theoretical }}{\text { Experimental }}$ & $\frac{44.5}{\text { Ideal }}$ \\
37.5 & 42.3 & 51.0 & 49.5 \\
38.4 & 48.6 & 52.3 & 55.9 \\
44.3 & 50.2 & 61.5 & 57.0 \\
45.9 & 59.5 & 64.0 & 65.3 \\
54.1 & 62.0 & 80.0 & 67.8 \\
55.9 & 80.1 & 83.5 & 81.3 \\
64.0 & 82.4 & 100.0 & 84.5
\end{tabular}

Table 64

CALCULATED LIQUID-VAPOR EQUILIBRIUM AT PRESSURES OF 30 AND

40 PSIA. FOR THE URANIUM HEXAFLUORIDE-2, 2, 3 -

TRICHLOROHEPTAF LUOROBUTANE SYSTEM

(Reference 95)

Mole Percent UF

Temperature of Boiling ( $\left.{ }^{\circ} \mathrm{C}.\right)$ in Liquid

0.0

10.0

20.0

30.0

40.0

50.0

60.0

70.0

80.0

90.0

100.0
40 psia.

134.2

125.2

117.1

110.5

104.9

99.9

96.1

92.5

89.5

86.5

84.1
Mole Percent UF 6 in Vapor

\begin{tabular}{rr}
\hline 30 psia. & 40 psia. \\
\hline 0.0 & 0.0 \\
29.6 & 28.8 \\
49.2 & 48.2 \\
62.9 & 61.7 \\
72.8 & 71.7 \\
80.1 & 79.3 \\
85.7 & 85.2 \\
90.0 & 89.7 \\
93.6 & 93.4 \\
97.0 & 96.8 \\
100.0 & 100.0
\end{tabular}




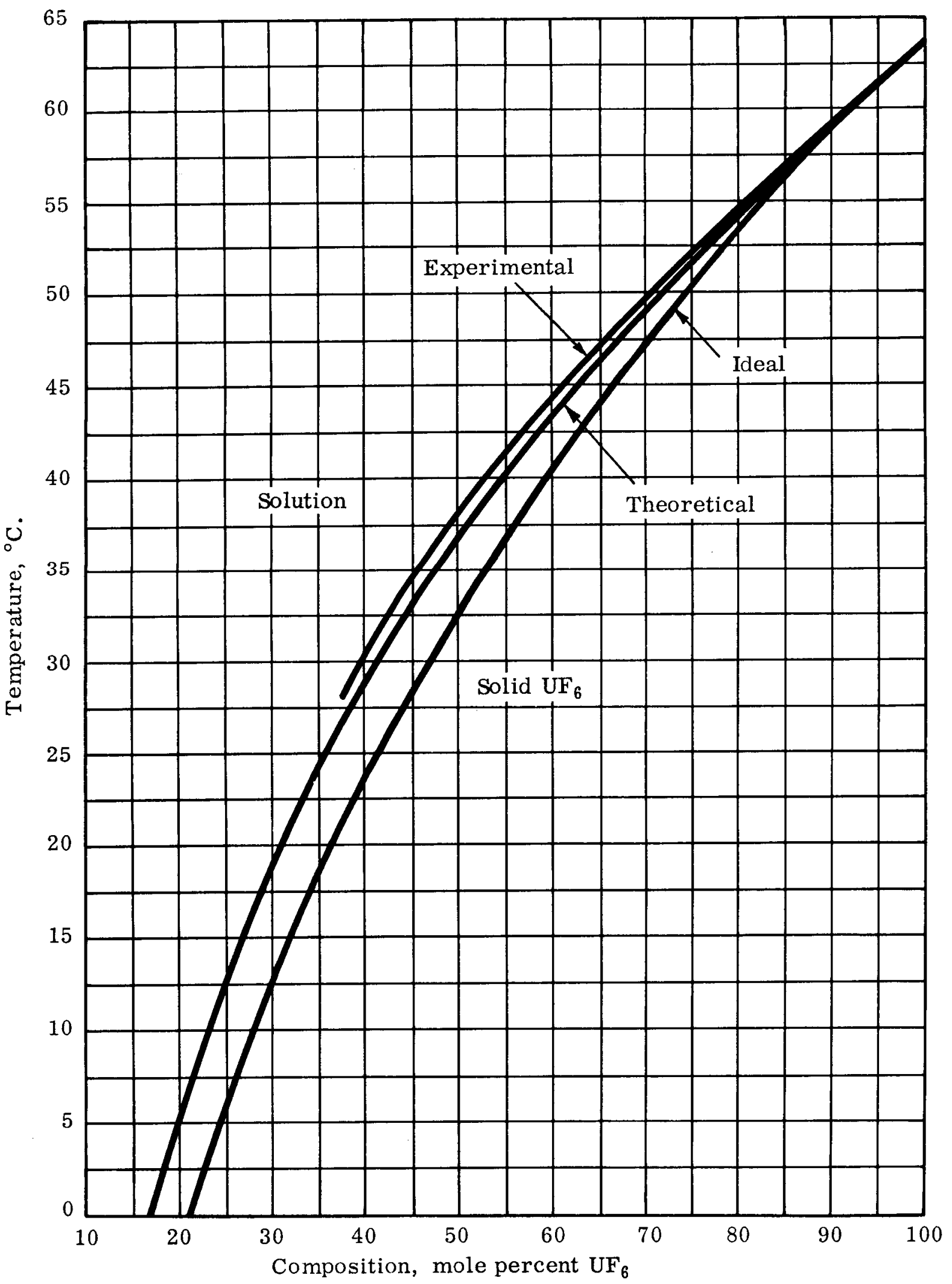

FIG. 35. SOLD - LIQUD EQUILIBRIUM OF THE URANIUM HEXAFLUORIDE2, 2, 3-TRICHLOROHEPTAFLUOROBUTANE SYSTEM (Reference 95) 


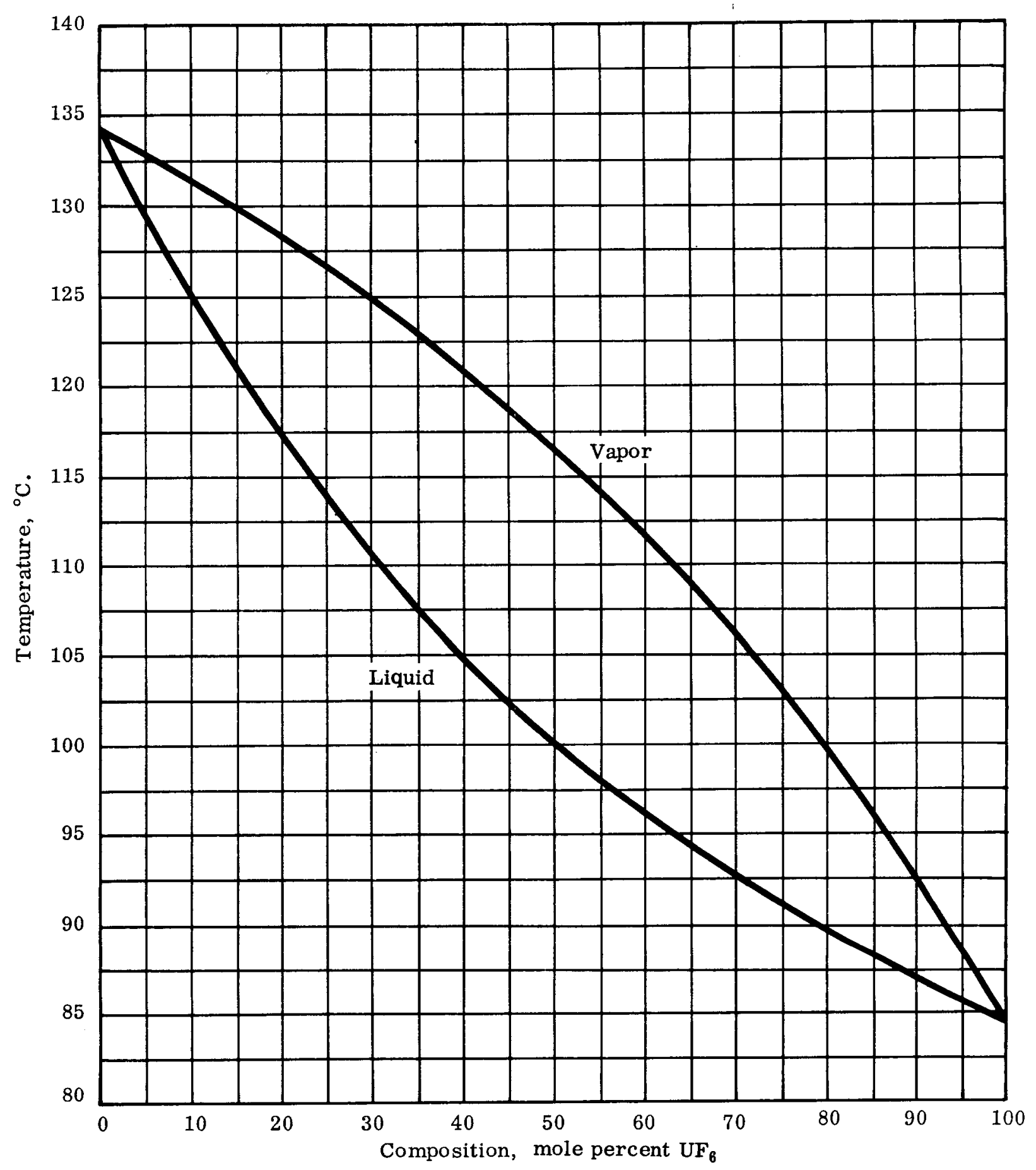

FIG. 36. VAPOR - LIQUD EQUILIBRIUM OF THE URANIUM HEXAFLUORIDE 2, 2, 3-TRICHLOROHEPTAFLUOROBUTANE SYSTEM AT 30 PSIA. PRESSURE

(Reference 95) 


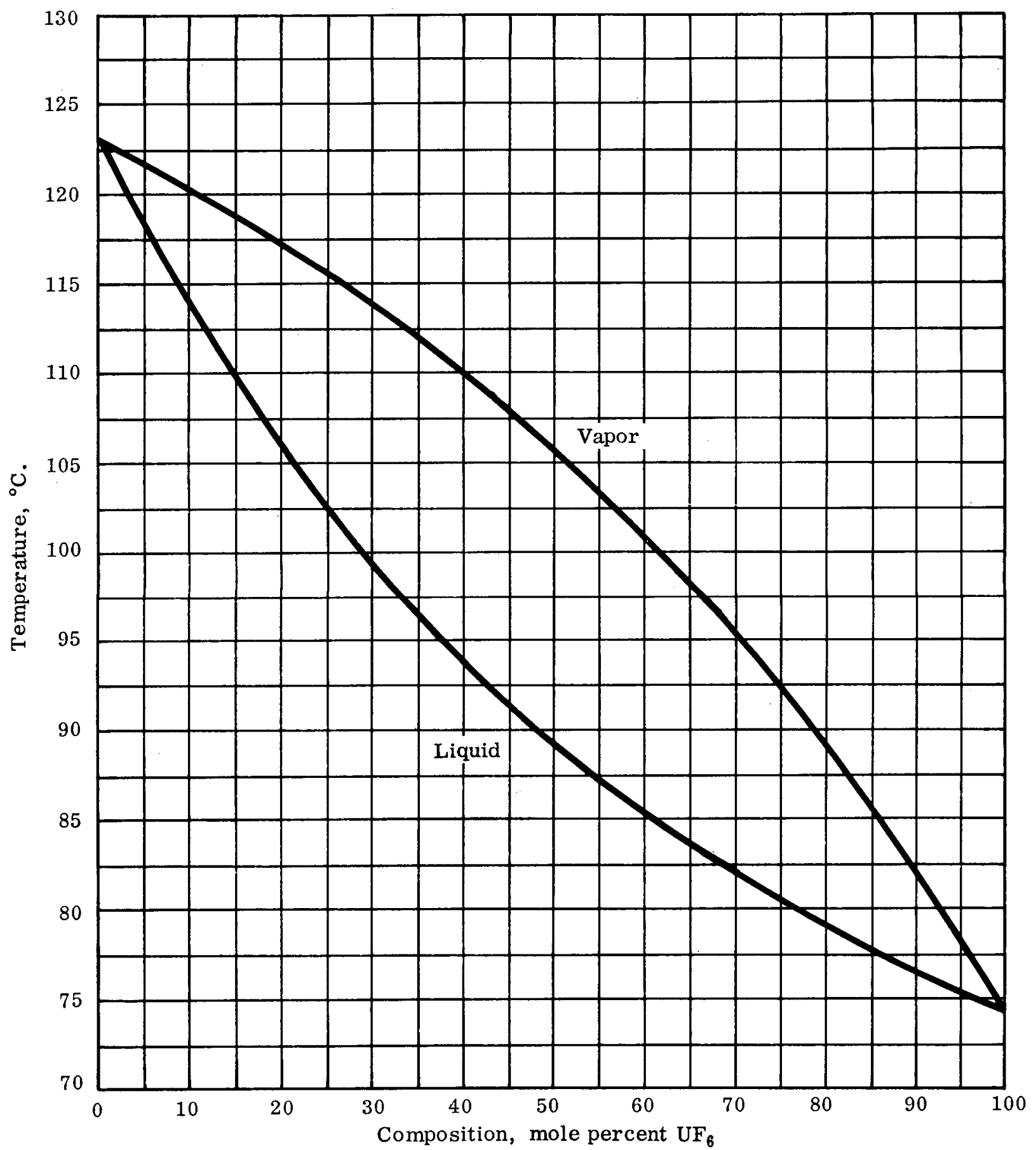

FIG. 37. VAPOR - LIQUID EQUILIBRIUM OF THE URANIUM HEXAFLUORIDE2,2,3-TRICHLOROHEPTAFLUOROBUTANE SYSTEM AT 40 PSIA. PRESSURE

(Reference 95) 
Table 65

SOLUTION DENSITY OF THE

URANIUM HEXAF LUORIDE-2, 2, 3-TRICHLOROHE PTAFLUOROBUTANE SYSTEM, EXPERIMENTAL AND CALCULATED RESULTS

(Reference 95)

\begin{tabular}{|c|c|}
\hline $\begin{array}{c}\text { Temperature } \\
\left({ }^{\circ} \mathrm{C} .\right) \\
\end{array}$ & $\begin{array}{c}\text { Composition } \\
\text { (mole percent } \mathrm{UF}_{6} \text { ) }\end{array}$ \\
\hline 25.2 & 16.97 \\
\hline 35.0 & 16.97 \\
\hline 45.0 & 16.97 \\
\hline 50.2 & 16.97 \\
\hline 35.0 & 28.32 \\
\hline 45.0 & 28.32 \\
\hline 49.8 & 28.32 \\
\hline 55.0 & 28.32 \\
\hline 44.0 & 37.60 \\
\hline 52.0 & 37.60 \\
\hline 58.0 & 37.60 \\
\hline 64.0 & 37.60 \\
\hline 52.0 & 45.45 \\
\hline 56.0 & 45.45 \\
\hline 60.0 & 45.45 \\
\hline 64.0 & 45.45 \\
\hline 56.0 & 60.49 \\
\hline 58.0 & 60.49 \\
\hline 60.0 & 60.49 \\
\hline 62.0 & 60.49 \\
\hline 64.0 & 60.49 \\
\hline 66.0 & 60.49 \\
\hline 58.0 & 72.21 \\
\hline 60.0 & 72.21 \\
\hline 62.0 & 72.21 \\
\hline 64.0 & 72.21 \\
\hline 59.0 & 86.24 \\
\hline 60.0 & 86.24 \\
\hline 62.0 & 86.24 \\
\hline 64.0 & 86.24 \\
\hline 66.0 & 86.24 \\
\hline
\end{tabular}

Experimental
Density

(g./cc.)

1. 944

1.916

1.888

1.874

2.065

2. 036

2.025

2.008

2.181

2. 156

2.137

2.119

2.297

2.282

2.269

2.256

2.567

2.558

2.551

2.542

2.535

2.528

2.822

2. 813

2.804

2. 795

3.196

3. 190

3.179

3. 169

3.158
Calculated Density (g./cc.)

1.936

1.907

1.880

1. 867

2.066

2.035

2. 021

2.006

2.188

2.162

2.143

2.126

2.289

2. 275

2. 262

2. 249

2.568

2.560

2.552

2.544

2.537

2.529

2.830

2. 821

2. 811

2. 804

3.209

3.203

3.192

3. 182

3. 171 $\underline{\text { Deviation }}$

$-0.008$

$-0.009$

$-0.008$

$-0.007$

$+0.001$

$-0.001$

$-0.004$

$-0.002$

$+0.007$

$+0.006$

$+0.006$

$+0.007$

$-0.008$

$-0.007$

$-0.007$

$-0.007$

$+0.001$

$+0.002$

$+0.001$

$+0.002$

$+0.002$

$-0.001$

$+0.008$

$+0.008$

$+0.007$

$+0.009$

$+0.013$

$+0.013$

$+0.013$

$+0.013$

$+0.013$ 
Table 66

\section{SUMMARY OF VAPOR-LIQUID EQUILIBRIUM DATA FOR THE SYSTEM} URANIUM HEXAF LUORIDE-PERF LUORODIMET HY LCYC LOHEXANE*

(Reference 79)

\begin{tabular}{|c|c|c|c|c|c|}
\hline \multirow{2}{*}{$\begin{array}{c}\text { Average Pressure } \\
\text { (psia.) } \\
\end{array}$} & \multicolumn{2}{|c|}{$\begin{array}{c}\text { Average Composition } \\
\left.\text { (mole percent } \mathrm{UF}_{6}\right) \\
\end{array}$} & \multicolumn{3}{|c|}{ Average Temperature $\left({ }^{\circ} \mathrm{C}.\right)$} \\
\hline & Liquid & Vapor & Liquid & Vapor & Condensing Vapor \\
\hline 39.8 & 99.7 & 100.1 & 84.8 & 85.1 & 84.9 \\
\hline 40.3 & 96.4 & 98.5 & 85.5 & 85.8 & 85.3 \\
\hline 40.5 & 91.7 & 96.0 & 86.3 & 86.6 & 85.7 \\
\hline 40.0 & 82.0 & 93.4 & 86.9 & 86.9 & 85.3 \\
\hline 39.8 & 75.0 & 90.4 & 87.8 & 87.8 & 85.1 \\
\hline 39.9 & 72.7 & 90.6 & 88.6 & 88.3 & 84.7 \\
\hline 40.3 & 58.3 & 84.9 & 93.3 & 92.9 & 85.0 \\
\hline 40.2 & 55.2 & 84.1 & 93.9 & 93.5 & 85.7 \\
\hline 40.0 & 48.1 & 79.0 & 97.4 & 97.3 & 86.3 \\
\hline 40.2 & 47.7 & 79.6 & 97.3 & 97.3 & 86.3 \\
\hline 40.1 & 37.2 & 73.9 & 100.8 & 100.8 & 86.0 \\
\hline 40.3 & 29.3 & 67.5 & 106.8 & 106.8 & 86.0 \\
\hline 39.8 & 19.5 & 62.3 & 113.8 & 113.7 & 85.5 \\
\hline 40.4 & 12.3 & 51.1 & 122.0 & 122.0 & 89.7 \\
\hline 40.2 & 7.8 & 32.3 & 126.9 & 126.8 & 88.2 \\
\hline 40.4 & 5.2 & 24.7 & 128.9 & 129.7 & 91.8 \\
\hline 39.1 & 1.9 & 9.7 & 134.3 & 134.8 & 119.0 \\
\hline 39.4 & 0.0 & 0.0 & 138.5 & 140.0 & 136.5 \\
\hline 36.9 & 96.1 & 97.6 & & & \\
\hline 40.6 & 65.4 & 88.5 & & & \\
\hline 39.2 & 55.7 & 85.7 & & & \\
\hline 40.3 & 50.3 & 83.4 & & & \\
\hline 38.0 & 43.2 & 78.9 & & & \\
\hline 38.2 & 33.8 & 72.9 & & & \\
\hline 40.7 & 17.6 & 57.1 & & & \\
\hline 39.3 & 11.5 & 46.0 & & & \\
\hline 39.6 & 8.6 & 35.2 & & & \\
\hline 39.8 & 0.0 & 0.0 & & & \\
\hline
\end{tabular}

*Each value represents an average of from 6 to 10 samples. 


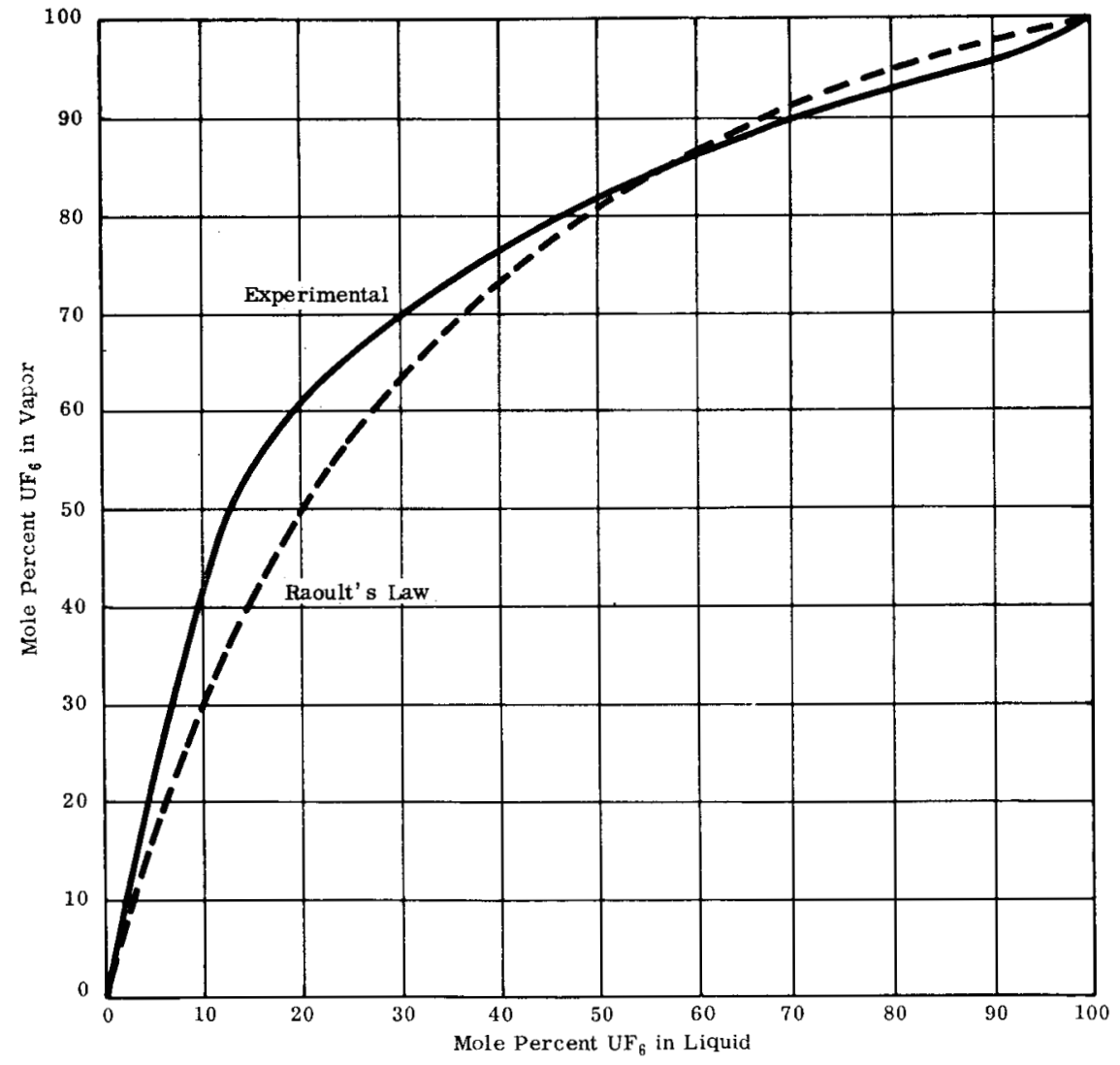

FIG. 38. VAPOR - LIQUID EQUILIBRIUM OF THE URANIUM HEXAFLUORIDEPERFLUORODIMETHYLCYCLOHEXANE SYSTEM AT $40 \pm 1$ PSIA. PRESSURE (Reference 63)

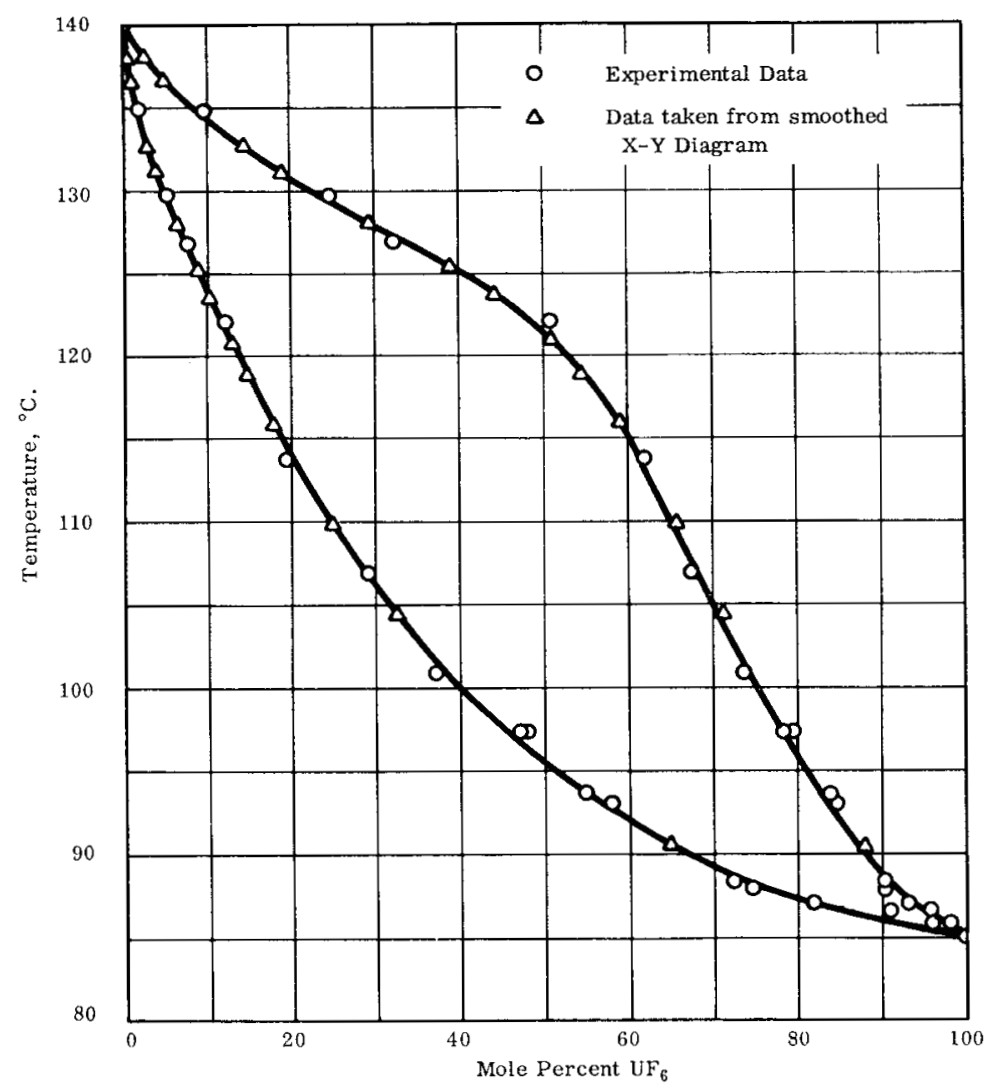

FIG. 39. TEMPERATURE - COMPOSITION DIAGFAM OF THE URANIUM HEXA FLUORIDE - PERFLUORODIMETHYLCYCLOHEXANE SYSTEM AT $40 \pm 1$ PSIA. PRESSURE (Reference 63) 


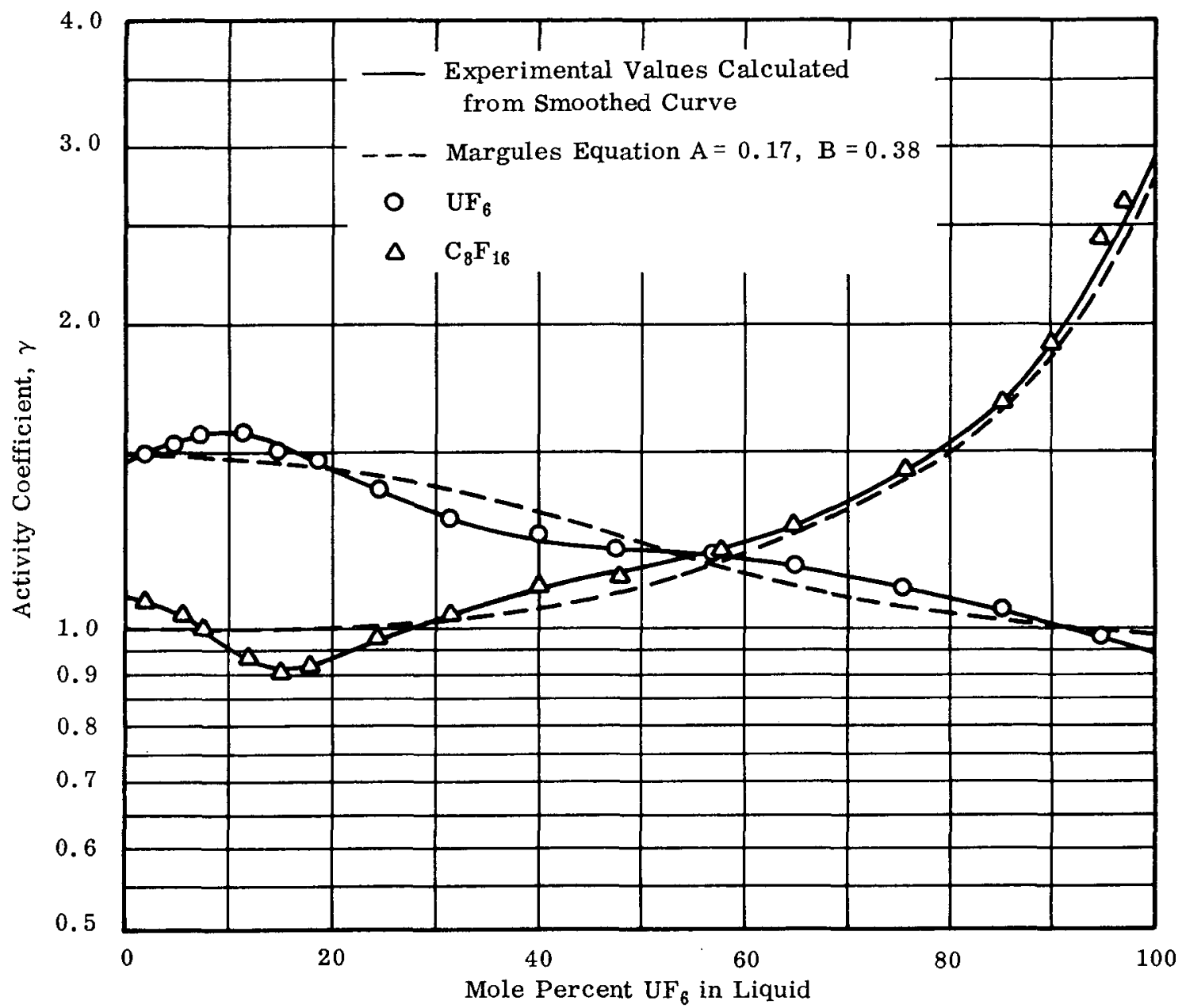

FIG. 40. COMPARISON OF EXPERIMENTAL AND CALCULATED ACTIVITY COEFFICIENTS AS A FUNCTION OF MOLE PERCENT URANIUM HEXAFLUORIDE

(Reference 63)

fluoride with temperature, pressure, and concentration was not determined, all the equilibria of this system were expressed in terms of formula percent. The solidliquid-and liquid-liquid data are presented in Table 67 and Figure 41, while the liquidvapor data are given in Table 68 and Figure 42.

A cryoscopic constant of $0.0820^{\circ}$ per 0.01 formula percent hydrogen fluoride was calculated by Rutledge and his co-workers from the vapor pressure data of $\mathrm{UF}_{6}$ obtained by Oliver and his co-workers ${ }^{119}$. In Figure 41 it is readily seen that hydrogen fluoride is very soluble in $\mathrm{UF}_{6}$. At $61.2^{\circ} \mathrm{C}$. hydrogen fluoride dissolves to the extent of about 20 formula percent at one end of the miscibility gap, or 90 formula percent at the other. As the solution temperature is increased to $101^{\circ} \mathrm{C}$., there is complete miscibility. The results obtained in the region of the miscibility gap by Rutledge and his co-workers are in agreement with those obtained by Jarry and his group. Both investigations revealed extensive deviations from ideal solution theory. This is indicated by the calculated activity coefficients shown in Table 68. 
Table 67

FREEZING POINTS AND LIQUID-LIQUID SOLUBILITIES OF THE URANIUM HEXAFLUORDE-HYDROGEN FLUORIDE SYSTEM

\begin{tabular}{|c|c|c|c|}
\hline \multicolumn{4}{|c|}{ (Reference 133) } \\
\hline $\begin{array}{c}\text { Formula } \\
\text { Percent } \mathrm{UF}_{6}\end{array}$ & $\begin{array}{c}\text { Eutectic } \\
\text { Temperature } \\
\left({ }^{\circ} \mathrm{C} .\right) \\
\end{array}$ & $\begin{array}{c}\text { Freezing } \\
\text { Temperature } \\
\text { (ㄷ.) } \\
\end{array}$ & $\begin{array}{c}\text { Miscibility Gap } \\
\text { Temperature } \\
\left({ }^{\circ} \mathrm{C} .\right) \\
\end{array}$ \\
\hline 0.00 & & -83.6 & \\
\hline 0.16 & & -5.0 & \\
\hline 0.24 & & -5.1 & \\
\hline 0.27 & & -5.0 & \\
\hline 0.32 & & -5.2 & \\
\hline 0.41 & & -5.0 & \\
\hline 0.45 & & 0.0 & \\
\hline 0.48 & & -0.1 & \\
\hline 0.781 & & 5.0 & \\
\hline 0.98 & & 25.0 & \\
\hline 1.593 & & 26.5 & \\
\hline 3.04 & & 44.3 & \\
\hline 3.93 & & 50 & \\
\hline 4.20 & & 52 & \\
\hline 5.39 & & 55 & \\
\hline 6.24 & & 55 & \\
\hline 6.67 & & 59.12 & \\
\hline 6.90 & -84.18 & & \\
\hline 7.95 & & 58 & \\
\hline 8.32 & & 60.25 & \\
\hline 8.51 & & 59 & \\
\hline 9.45 & & 60.55 & \\
\hline 10.28 & & & 69 \\
\hline 10.38 & & & 69 \\
\hline 11.92 & & 60.96 & \\
\hline 12.20 & & & 78 \\
\hline 16.29 & & & 83 \\
\hline 19.85 & & & 87.9 \\
\hline 23.39 & & & 90.3 \\
\hline 24.52 & & 61.16 & \\
\hline 28.58 & & & 97.2 \\
\hline 29.13 & & & 93.2 \\
\hline 39.38 & & & $98.8+$ \\
\hline 49.97 & & & 100.5 \\
\hline 53.14 & & & 99.9 \\
\hline 53.53 & -85.13 & & \\
\hline 55.02 & & 61.14 & \\
\hline 55.40 & & & 95.7 \\
\hline 56.77 & & 61.25 & \\
\hline 57.09 & & & 95 \\
\hline 58.45 & & & 98 \\
\hline 61.35 & & & 90.5 \\
\hline 62.03 & & & 93.5 \\
\hline 64.49 & & & 87.5 \\
\hline 65.21 & -85.06 & & \\
\hline 66.70 & & & 83 \\
\hline
\end{tabular}


Table 67 (Continued)

FREEZING POINTS AND LIQUID-LIQUID SOLUBILITIES OF THE URANIUM HEXAFLUORIDE-HYDROGEN FLUORIDE SYSTEM

(Reference 133)

Eutectic

Formula

Percent $\mathrm{UF}_{6}$

67.13

69.35

70.44

72.54

72.96

81.56

82.03

83.06

87.73

90.46

91.09

94.15

95.06

95.77

96.47

96.47

98.45

99.63

100.00

$\left({ }^{\circ} \mathrm{C}.\right)$

$-85.10$

$-84.99$

$-85.10$
Freezing

Temperature

( $\left.{ }^{\circ} \mathrm{C}.\right)$

$\left({ }^{\circ} \mathrm{C}\right.$.

61.56

61.95

62.3

62.45

62.51

62.39

62.53

63.09

63.76

64.02

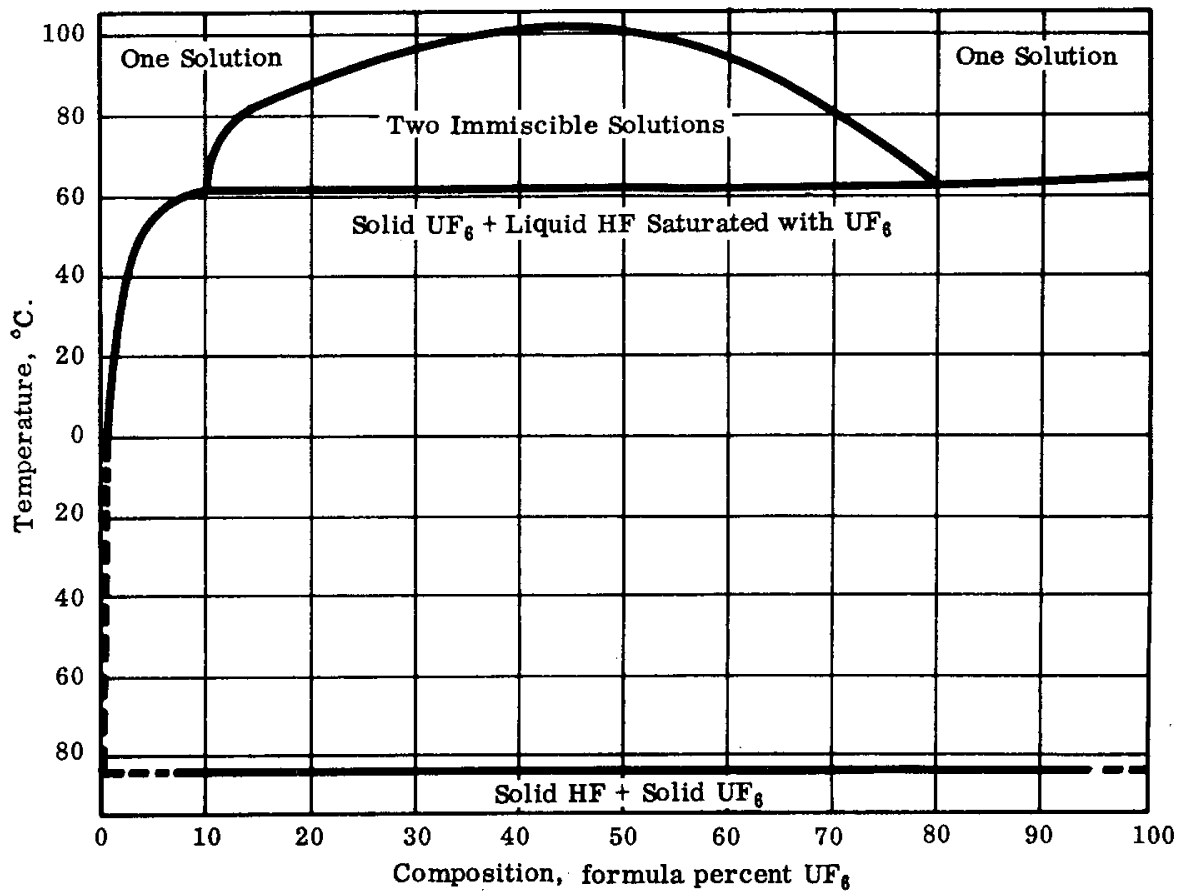

FIG. 41. PHASE DIAGRAM OF THE URANIUM HEXAFLUORDEHYDROGEN FLUORIDE SYSTEM (Reference 133) 
Table 68

LIQUID-VAPOR EQUILIBRIUM DATA FOR THE URANIUM HEXAFLUORIDE HYDROGEN FLUORIDE SYSTEM

(Reference 133)

\begin{tabular}{|c|c|c|c|c|c|c|}
\hline \multirow{2}{*}{$\begin{array}{l}\text { Temperature } \\
\left({ }^{\circ} \mathrm{C} .\right)\end{array}$} & \multirow{2}{*}{$\begin{array}{l}\text { Pressure } \\
\text { (cm.) } \\
\end{array}$} & \multicolumn{2}{|c|}{$\begin{array}{c}\text { Composition* } \\
\text { (formula percent } \mathrm{UF}_{6} \text { ) }\end{array}$} & \multirow{2}{*}{$\begin{array}{c}\text { Separation } \\
\text { Factor } \\
(\mathrm{HF})_{\mathrm{V}} /\left(\mathrm{UF}_{6}\right)_{\mathrm{V}} \\
(\mathrm{HF})_{1} /\left(\mathrm{UF}_{6}\right)_{1}\end{array}$} & \multicolumn{2}{|c|}{$\begin{array}{c}\text { Activity } \\
\text { Coefficient } \\
\text { in Solution } \\
\end{array}$} \\
\hline & & Liquid & Vapor & & $\gamma \mathbf{U F}_{6}$ & $\gamma \mathrm{HF}$ \\
\hline 40.89 & 156.0 & 0.00 & 0.00 & -- & - & 1.000 \\
\hline 40.89 & 179.6 & 2.74 & 6.85 & 0.383 & 8.76 & 1.103 \\
\hline 40.89 & 51.3 & 100.00 & 100.00 & -- & 1.00 & - \\
\hline 50.90 & 214.0 & 0.00 & 0.00 & -- & - & 1.000 \\
\hline 50.90 & 244.7 & 2.47 & 7.45 & 0.315 & 10.03 & 1.085 \\
\hline 50.90 & 258.3 & 3.81 & 9.09 & 0.396 & 8.37 & 1.141 \\
\hline 50.90 & 73.6 & 100.00 & 100.00 & -- & 1.00 & -- \\
\hline 59.66 & 275.0 & 0.00 & 0.00 & -- & -- & 1.000 \\
\hline 59.56 & 314.4 & 1.64 & 7.54 & 0.205 & 14.62 & 1.075 \\
\hline 59.75 & 343.8 & 5.78 & 11.59 & 0.468 & 6.97 & 1.173 \\
\hline 59.66 & 98.9 & 100.00 & 100.00 & -- & 1.00 & -- \\
\hline 66.87 & 340.0 & 0.00 & 0.00 & -- & -- & 1.000 \\
\hline 66.99 & 382.7 & 1.89 & 7.17 & 0.249 & 11.66 & 1.065 \\
\hline 67.01 & 412.7 & 4.07 & 12.48 & 0.298 & 10.16 & 1.107 \\
\hline 66.92 & 429.6 & 7.40 & 14.01 & 0.491 & 6.53 & 1. 173 \\
\hline 66.97 & 431.1 & -- & 13.99 & -- & -- & -- \\
\hline 66.79 & 424.5 & 7.42 & 13.96 & 0.494 & 6.41 & 1. 160 \\
\hline 66.97 & 430.5 & 7.67 & 15.14 & 0.466 & 6.82 & 1. 164 \\
\hline 66.83 & 428.3 & 8.27 & 14.40 & 0.536 & 5.99 & 1.176 \\
\hline 66.87 & 423.1 & 77.72 & 15.33 & 19.27 & 0.670 & 4.73 \\
\hline 66.85 & 422.6 & 78.86 & 14.96 & 21.21 & 0.643 & 5.00 \\
\hline 66.74 & 360.8 & 91.45 & 24.70 & 32.61 & 0.782 & 9.35 \\
\hline 66.81 & 360.1 & 92.53 & 25.10 & 36.96 & 0.784 & 10.62 \\
\hline- & -- & 91.93 & - & 33.99 & 0.789 & 9.83 \\
\hline 66.92 & 262.0 & 98.50 & 46.73 & 74.86 & 0.998 & 27.4 \\
\hline 66.87 & 124.5 & 100.00 & 100.00 & -- & 1.000 & -- \\
\hline 72.47 & 396.0 & 0.00 & 0.00 & - & -- & 1.000 \\
\hline 72.48 & 442.5 & 1.83 & 7.38 & 0.234 & 12.82 & 1.054 \\
\hline 72.28 & 442.8 & 2.55 & 8.00 & 0.301 & 9.41 & 1.056 \\
\hline 72.50 & 482.6 & 4.26 & 13.13 & 0.294 & 10.07 & 1.106 \\
\hline 72.48 & 498.4 & 7.44 & 15.04 & 0.454 & 6.82 & 1.155 \\
\hline 72.48 & 503.6 & 10.84 & 16.15 & 0.629 & 5.19 & 1. 191 \\
\hline 72.48 & 499.8 & 73.48 & 16.40 & 14.12 & 0.755 & 3.98 \\
\hline 72.62 & 494.7 & 77.62 & 16.93 & 17.02 & 0.731 & 4.64 \\
\hline 72.28 & 409.1 & 93.57 & 28.40 & 36.69 & 0.841 & 11.50 \\
\hline 72.62 & 286.7 & 98.43 & 51.15 & 59.88 & 1.009 & 22.5 \\
\hline 72.47 & 147.7 & 100.00 & 100.00 & -- & 1.000 & - \\
\hline
\end{tabular}

*Compositions calculated on the basis of association of HF in samples equivalent to a molecular weight of 20.35 . 
Table 68 (Continued)

LIQUID-VAPOR EQUILIBRIUM DATA FOR THE URANIUM HEXAFLUORIDE HYDROGEN FLUORIDE SYSTEM

(Reference 133)

\begin{tabular}{|c|c|c|c|c|c|c|}
\hline \multirow{2}{*}{$\begin{array}{l}\text { Temperature } \\
\left({ }^{\circ} \mathrm{C} .\right)\end{array}$} & \multirow{2}{*}{$\begin{array}{l}\text { Pressure } \\
\text { (cm.) }\end{array}$} & \multicolumn{2}{|c|}{$\begin{array}{c}\text { Composition* } \\
\text { (formula percent } \mathrm{UF}_{6} \text { ) }\end{array}$} & \multirow{2}{*}{$\begin{array}{c}\text { Separation } \\
\text { Factor } \\
(\mathrm{HF})_{\mathrm{V}} /\left(\mathrm{UF}_{6}\right)_{\mathrm{V}} \\
(\mathrm{HF})_{1} /\left(\mathrm{UF}_{6}\right)_{1}\end{array}$} & \multicolumn{2}{|c|}{$\begin{array}{l}\text { Activity } \\
\text { Coefficient } \\
\text { in Solution }\end{array}$} \\
\hline & & Liquid & Vapor & & $\gamma \mathrm{UF}_{6}$ & $\gamma \mathrm{HF}$ \\
\hline 84.46 & 538.0 & 0.00 & 0.00 & -- & -- & 1.000 \\
\hline 84.45 & 597.3 & 1.55 & 6.07 & 0.244 & 11.21 & 1.059 \\
\hline 84.49 & 652.1 & 3.60 & 11.60 & 0.285 & 10.08 & 1.112 \\
\hline 84.40 & 681.9 & 7.36 & 16.00 & 0.417 & 7.11 & 1.149 \\
\hline 84.47 & 688.2 & 11.05 & 17.75 & 0.517 & 5.30 & 1.183 \\
\hline 84.38 & 688.6 & 11.32 & 17.81 & 0.589 & 5.20 & 1.186 \\
\hline 84.38 & 686.6 & 65.78 & 17.80 & 8.88 & 0.892 & 3.07 \\
\hline 84.55 & 678.4 & 73.12 & 17.56 & 12.77 & 0.782 & 3.87 \\
\hline 84.53 & 543.5 & 93.74 & 33.33 & 29.95 & 0.927 & 10.8 \\
\hline 84.53 & 364.7 & 98.96 & 58.75 & 66.81 & 1.039 & 26.9 \\
\hline 84.46 & 208.5 & 100.00 & 100.00 & -- & 1.000 & - \\
\hline 92.30 & 656.0 & 0.00 & 0.00 & -- & -- & 1.000 \\
\hline 92.28 & 718.8 & 1.50 & 6.15 & 0.232 & 11.45 & 1.044 \\
\hline 92.28 & 789.2 & 3.50 & 11.22 & 0.287 & 9.83 & 1.111 \\
\hline 92.30 & 830.5 & 6.91 & 16.95 & 0.364 & 7.91 & 1.129 \\
\hline 92.30 & 840.6 & 11.24 & 18.51 & 0.558 & 5.38 & 1.176 \\
\hline 92.30 & 837.9 & 61.67 & 18.70 & 6.99 & 0.987 & 2.71 \\
\hline 92.37 & 821.8 & 71.17 & 19.19 & 10.40 & 0.861 & 3.51 \\
\hline 92.30 & 637.6 & 93.94 & 35.45 & 28.23 & 0.935 & 10.4 \\
\hline 92.28 & 421.1 & 99.53 & 62.43 & 127.4 & 1.026 & 51.3 \\
\hline 92.30 & 257.5 & 100.00 & 100.00 & - & 1.000 & -- \\
\hline 104.74 & 886.0 & 0.00 & 0.00 & -- & - & 1.000 \\
\hline 104.77 & 962.4 & 1.18 & 5.24 & 0.216 & 12.13 & 1.042 \\
\hline 104.73 & $1,051.3$ & 3.22 & 10.73 & 0.277 & 9.93 & 1.095 \\
\hline 104.60 & 804.6 & 94.92 & 40.85 & 27.06 & 0.983 & 10.6 \\
\hline 104.87 & 524.8 & 99.56 & 66.44 & 114.3 & 0.993 & 45.2 \\
\hline 104.74 & 352.5 & 100.00 & 100.00 & - & 1.000 & -- \\
\hline
\end{tabular}

*Compositions calculated on the basis of association of $\mathrm{HF}$ in samples equivalent to a molecular weight of 20.35 . 


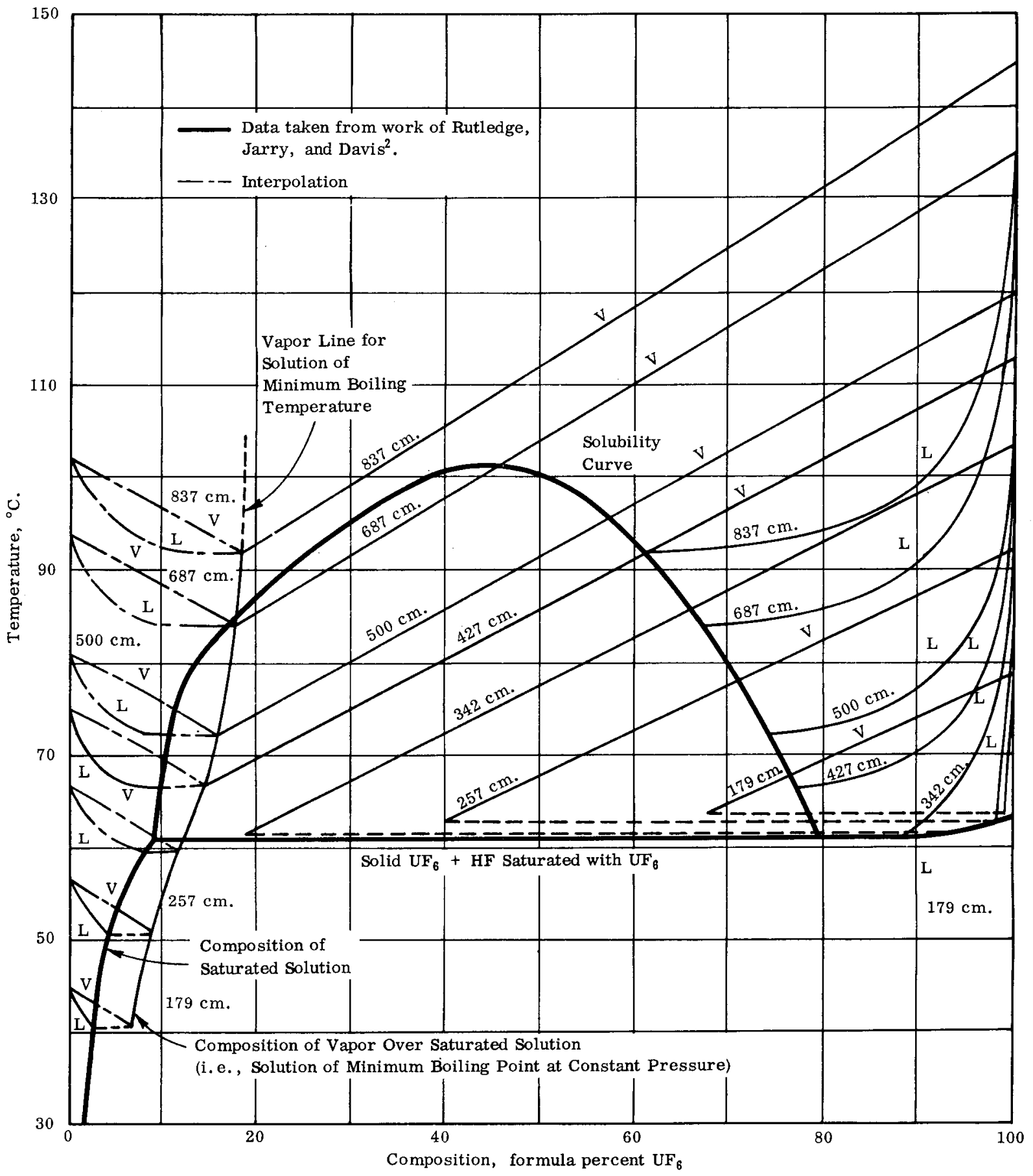

FIG. 42. SUMMARY OF LIQUID - VAPOR EQUILIBRIUM IN THE URANIUM HEXAFLUORDE - HYDROGEN FLUORDE SYSTEM

(Reference 133) 
URANIUM HEXAFLUORIDE IN BROMINE FLUORIDES (BrF $\mathrm{AND}_{3} \mathrm{BrF}_{5}$ )

Fischer and Vogel ${ }^{60,138}$ reported that the solid-liquid equilibria at temperatures ranging from $0^{\circ}$ to $64^{\circ} \mathrm{C}$. of the $\mathrm{UF}_{6}-\mathrm{BrF}_{3}$ and $\mathrm{UF}_{6}-\mathrm{BrF}_{5}$ systems are of simple eutectic types. Data for solid-liquid equilibria of the $\mathrm{UF}_{6}-\mathrm{BrF}_{3}$ system are shown in Table 69 and in Figure 43. Table 70 presents a comparison of the experimentalactivity coefficient values with those theoretically obtained using the method described by Barber and Wendolkowski ${ }^{145}$. The $\mathrm{UF}_{6}-\mathrm{BrF}_{3}$ system exhibits positive deviation from ideality. Data for the $\mathrm{UF}_{6}-\mathrm{BrF}_{5}$ system are presented in Table 71 and in Figure 44 . It was found that these data (solid curve of Figure 44) show little deviation from ideality (dotted curve) as calculated by Barber and Wendolkowski.

A preliminary investigation of the $\mathrm{UF}_{6}-\mathrm{BrF}_{3}$ system was made by Kirshenbaum ${ }^{94}$ at $-125^{\circ} \mathrm{C}$. He observed only that $\mathrm{UF}_{6}$ is sparingly soluble in liquid $\mathrm{BrF}_{3}$.

The liquid-vapor equilibrium of the $\mathrm{UF}_{6}-\mathrm{BrF}_{5}$ system has also been investigated by Ellis and Johnson ${ }^{58}$ and re-investigated by Liimatainen ${ }^{102}$. The results of these two investigations are in conflict. Ellis and Johnson found that the system exhibits complete miscibility over the $68^{\circ}$ to $80^{\circ} \mathrm{C}$. range and has a single maximum vapor pressure azeotrope at a composition corresponding to a mole fraction of $0.1 \mathrm{UF}_{6}$. The results are presented in Figure 45. Liimatainen found that when a $10 \mathrm{~mm}$. $\mathrm{Hg}$ partial pressure of elemental fluorine is introduced to the system, the binary liquid-vapor equilibrium shows positive deviations from ideality and that the system does not have an azeotrope. Data calculated using the theory of regular solutions (activity coefficient technique) also indicate that

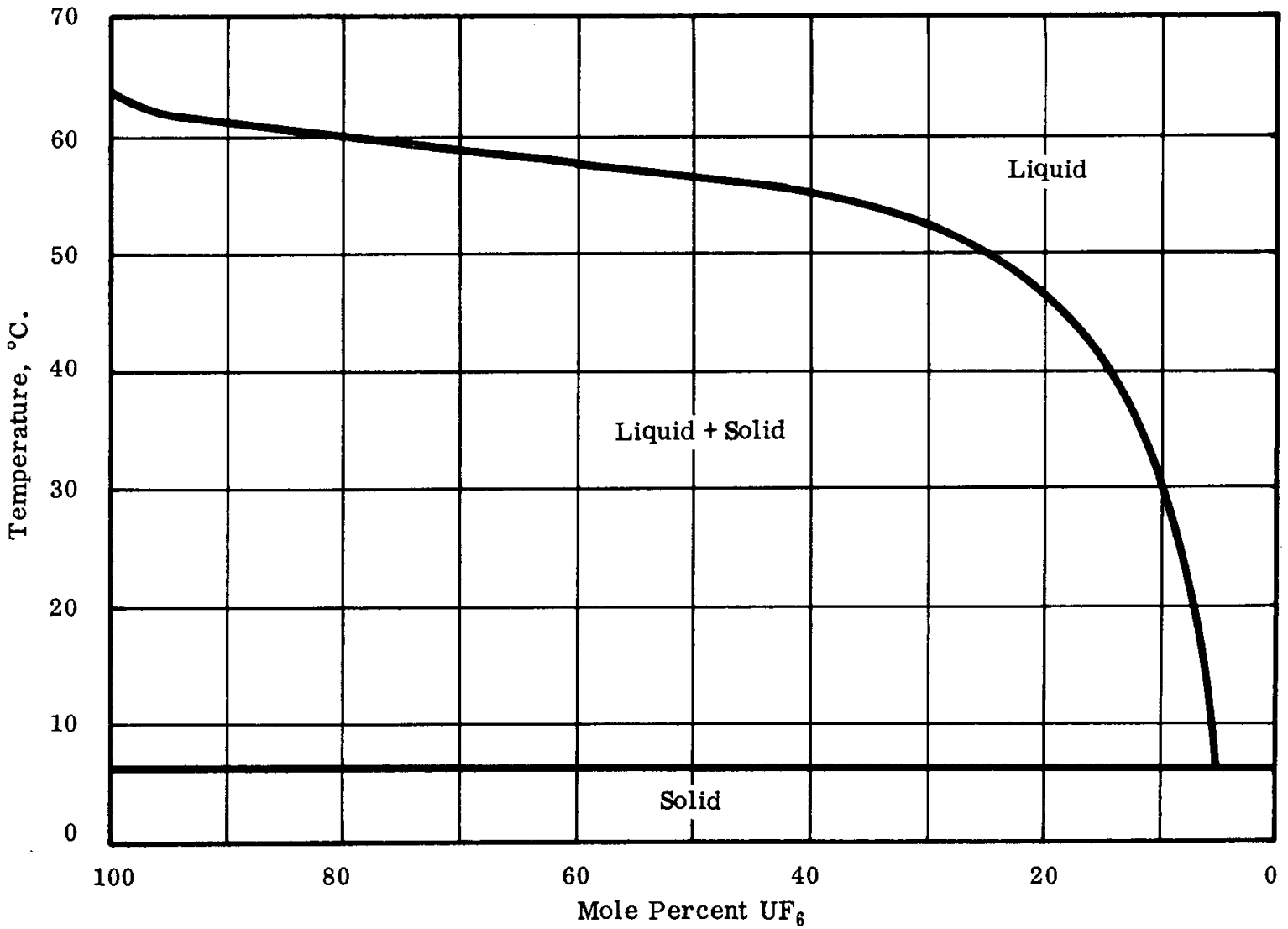

FIG. 43. SOLID - LIQUID EQUILIBRIUM OF THE URANIUM HEXAFLUORIDEBROMINE TRIFLUORIDE SYSTEM

(Reference 60) 
Table 69

SOLID-LIQUID EQUILIBRIUM OF THE URANIUM HEXAFLUORIDEBROMINE TRIFLUORIDE SYSTEM

(Reference 60)

\begin{tabular}{c} 
Mole \\
Percent \\
UF $_{6}$ \\
\hline 100 \\
96.4 \\
93.4 \\
90.4 \\
88.8 \\
85.7 \\
83.1 \\
81.8 \\
81.0 \\
80.2 \\
76.8 \\
72.9 \\
69.5 \\
67.0 \\
63.1 \\
58.8 \\
56.3 \\
53.9 \\
51.9 \\
48.7 \\
45.4 \\
41.1 \\
38.2 \\
35.6 \\
30.2 \\
29.1 \\
24.8 \\
19.5 \\
19.3 \\
14.7 \\
13.4 \\
9.9 \\
8.5 \\
8.4 \\
7.6 \\
6.0 \\
5.1 \\
2.6 \\
0
\end{tabular}

\begin{tabular}{|c|c|}
\hline \multicolumn{2}{|c|}{ Univariant Point } \\
\hline Cooling & Thaw \\
\hline Curve & Curve \\
\hline
\end{tabular}

62.3

62.8

61.7

61.6

61.4

$--$

$61.0 \pm 0.2$

60.7

60.0

$--$

$60.4 \pm 0.2$

60.6

60.0

60.2

$60.0 \pm 0.1$

--

60.0

$--$

$59.6 \pm 0.3$

59.6

59.1

58.6

59.3

58.4

57.9

57.7

$--$

58.4

58.0

$57.3 \pm 0.2$

$-$

56.9

--

$56.7 \pm 0.1$

$-$

$56.5 \pm 0.1$

$-$

55.9

$-$

55.1

$-$

$-$

55.0

53.3

$51.8 \pm 0.4$

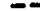

51.9

52.2

48.8

48.9

46.5

46.5

45.4

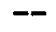

--

$\begin{array}{ll}-- & 38.9\end{array}$

$-$

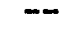

27.1

$-$

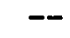

$-$

$=$

16.3

$-$

$8.7 \pm 0.1$

7.1

\begin{tabular}{|c|c|c|}
\hline \multicolumn{2}{|c|}{ Invariant Point } & \multirow[b]{2}{*}{$\begin{array}{l}\text { Solid } \\
\text { Phase }\end{array}$} \\
\hline $\begin{array}{l}\text { Cooling } \\
\text { Curve }\end{array}$ & $\begin{array}{l}\text { Thaw } \\
\text { Curve }\end{array}$ & \\
\hline $64.0 \pm 0.1$ & -- & $\mathrm{UF}_{6}$ \\
\hline-- & $\rightarrow-$ & $\mathrm{UF}_{6}$ \\
\hline-- & -- & $\mathrm{UF}_{6}$ \\
\hline-- & -- & $\mathrm{UF}_{6}$ \\
\hline-- & -- & $\mathrm{UF}_{6}$ \\
\hline-- & -- & $\mathrm{UF}_{6}$ \\
\hline-- & -- & $\mathrm{UF}_{6}$ \\
\hline-- & -- & $\mathrm{UF}_{6}$ \\
\hline-- & -- & $\mathrm{UF}_{6}$ \\
\hline-- & 5.6 & $\mathrm{UF}_{0}$ \\
\hline-- & -- & $\mathrm{UF}_{6}$ \\
\hline-- & 6.0 & $\mathrm{UF}_{6}$ \\
\hline-- & -- & $\mathrm{UF}_{6}$ \\
\hline-- & -- & $\mathrm{UF}_{6}$ \\
\hline-- & 6.2 & $\mathrm{UF}_{6}$ \\
\hline 6.4 & 6.5 & $\mathrm{UF}_{6}$ \\
\hline-- & -- & $\mathrm{UF}_{6}$ \\
\hline 6.3 & -- & $\mathrm{UF}_{6}$ \\
\hline-- & -- & $\mathrm{UF}_{6}$ \\
\hline-- & -- & $\mathrm{UF}_{6}$ \\
\hline 6.1 & -- & $\mathrm{UF}_{6}$ \\
\hline 6.3 & -- & $\mathrm{UF}_{6}$ \\
\hline-- & -- & $\mathrm{UF}_{6}$ \\
\hline 6.1 & -- & $\mathrm{UF}_{6}$ \\
\hline-- & -- & $\mathrm{UF}_{6}$ \\
\hline-- & -- & $\mathrm{UF}_{6}$ \\
\hline-- & -- & $\mathrm{UF}_{6}$ \\
\hline-- & -- & $\mathrm{UF}_{6}$ \\
\hline-- & -- & $\mathrm{UF}_{6}$ \\
\hline 6.3 & - & $\mathrm{UF}_{6}$ \\
\hline-- & -- & $\mathrm{UF}_{6}$ \\
\hline 6.5 & -- & $\mathrm{UF}_{6}$ \\
\hline-- & -- & $\mathrm{UF}_{6}$ \\
\hline 6.5 & - & $\mathrm{UF}_{6}$ \\
\hline 6.4 & - & $\mathrm{UF}_{6}$ \\
\hline-- & -- & $\mathrm{UF}_{6}$ \\
\hline 6.4 & - & $\mathrm{UF}_{6}$ \\
\hline 6.7 & 6.3 & $\mathrm{BrF}_{3}$ \\
\hline-- & -- & $\mathrm{BrF}_{3}$ \\
\hline
\end{tabular}


Table 70

ACTIVITY COEFFICIENTS IN BROMINE TRIFLUORIDE

(Reference 60)

\begin{tabular}{|c|c|c|c|c|c|c|}
\hline \multirow{2}{*}{$\begin{array}{c}\text { Temperature } \\
\text { ( } \mathrm{C} .)\end{array}$} & \multicolumn{3}{|c|}{ Experimental } & \multicolumn{3}{|c|}{ Hildebrand Theoretical } \\
\hline & \multicolumn{2}{|c|}{ Mole Fraction $\mathrm{UF}_{6}$} & Activity Coefficient $\mathrm{UF}_{6}$ & \multicolumn{2}{|c|}{ Mole Fraction $\mathrm{UF}_{6}$} & Activity Coefficient $\mathrm{UF}_{\mathrm{B}}$ \\
\hline 64 & \multicolumn{2}{|c|}{1.00} & 1.0 & \multicolumn{2}{|c|}{1.0} & 1.00 \\
\hline 63 & \multicolumn{2}{|c|}{0.980} & 1.0 & \multicolumn{2}{|c|}{0.978} & 1.00 \\
\hline 62 & \multicolumn{2}{|c|}{0.946} & 1.01 & \multicolumn{2}{|c|}{0.955} & 1.00 \\
\hline 61 & \multicolumn{2}{|c|}{0.877} & 1.07 & \multicolumn{2}{|c|}{0.912} & 1.02 \\
\hline 60 & \multicolumn{2}{|c|}{0.795} & 1.16 & \multicolumn{2}{|c|}{0.855} & 1.08 \\
\hline 58 & \multicolumn{2}{|c|}{0.630} & 1.40 & \multicolumn{2}{|c|}{0.665} & 1.33 \\
\hline 56 & \multicolumn{2}{|c|}{0.465} & 1.80 & \multicolumn{2}{|c|}{0.411} & 2.05 \\
\hline 52 & & & 2.67 & & & 5.05 \\
\hline 50 & & & 2.96 & & & 6.83 \\
\hline 40 & & & 4.22 & & & 21.2 \\
\hline 30 & & & 4.98 & & & 41.8 \\
\hline 20 & & & 5.64 & & & 74.0 \\
\hline 10 & & & 5.66 & & & 106.0 \\
\hline & & & Table 71 & & & \\
\hline & SOLID & $\begin{array}{l}\text { ID EQUT } \\
\text { BROI }\end{array}$ & $\begin{array}{r}\text { ILIBRIUM OF THE } \\
\text { MINE PENTAFLUO } \\
\text { (Reference 60) }\end{array}$ & $\begin{array}{l}\text { URANIL } \\
\text { ORIE S }\end{array}$ & $\begin{array}{l}\text { EXAFI } \\
\mathrm{M}\end{array}$ & UORIDE - \\
\hline & Mole & Univa & ariant Point & Invar & oint & \\
\hline & $\begin{array}{l}\text { Percent } \\
\text { UF }_{\mathbb{6}}\end{array}$ & $\begin{array}{c}\text { Freezing } \\
\text { Curve } \\
\end{array}$ & $\begin{array}{l}\text { Thaw } \\
\text { Curve }\end{array}$ & $\begin{array}{c}\text { Freezing } \\
\text { Curve }\end{array}$ & $\begin{array}{l}\text { Thaw } \\
\text { Curve } \\
\end{array}$ & $\begin{array}{c}\text { Solid } \\
\text { Phase } \\
\end{array}$ \\
\hline & 100.0 & -- & -- & 63.9 & -- & $\mathrm{UF}_{6}$ \\
\hline & 92.32 & 58.8 & 59.4 & -- & -- & $\mathrm{UF}_{6}$ \\
\hline & 89.52 & 57.3 & -- & -- & -- & $\mathrm{UF}_{6}$ \\
\hline & 84.67 & 54.6 & 54.2 & -- & -66.7 & $\mathrm{UF}_{6}$ \\
\hline & 81.23 & 53.2 & 53.5 & -- & -- & $\mathrm{UF}_{6}$ \\
\hline & 66.40 & 45.6 & -- & -- & -66.1 & $\mathrm{UF}_{6}$ \\
\hline & 56.81 & 39.0 & -- & - & -65.8 & $\mathrm{UF}_{6}$ \\
\hline & 50.07 & 34.0 & 34.1 & - & -63.5 & $\mathrm{UF}_{6}$ \\
\hline & 41.68 & 26.7 & -- & - & -- & $\mathrm{UF}_{6}$ \\
\hline & 34.35 & 18.5 & -- & - & -63.5 & $\mathrm{UF}_{6}$ \\
\hline & 25.18 & 7.7 & -- & - & -63.8 & $\mathrm{UF}_{6}$ \\
\hline & 18.81 & -3.1 & -2.9 & -- & -63.2 & $\mathrm{UF}_{6}$ \\
\hline & 13.32 & -18.3 & - & -- & $\rightarrow$ & $\mathrm{UF}_{6}$ \\
\hline & 10.53 & -28.7 & -- & -- & -63.2 & $\mathrm{UF}_{6}$ \\
\hline & 7.51 & -40.1 & -- & -- & -63.2 & $\mathrm{UF}_{6}$ \\
\hline & 5.78 & -49.5 & -- & -- & -63.5 & $\mathrm{UF}_{6}$ \\
\hline & 4.81 & -- & -- & -- & -63.5 & $\mathrm{UF}_{6}$ \\
\hline & 2.43 & -- & -- & -- & -63.5 & $\mathrm{BrF}_{5}$ \\
\hline & 0.00 & -- & -- & -61.3 & -61.3 & $\mathrm{BrF}_{5}$ \\
\hline
\end{tabular}




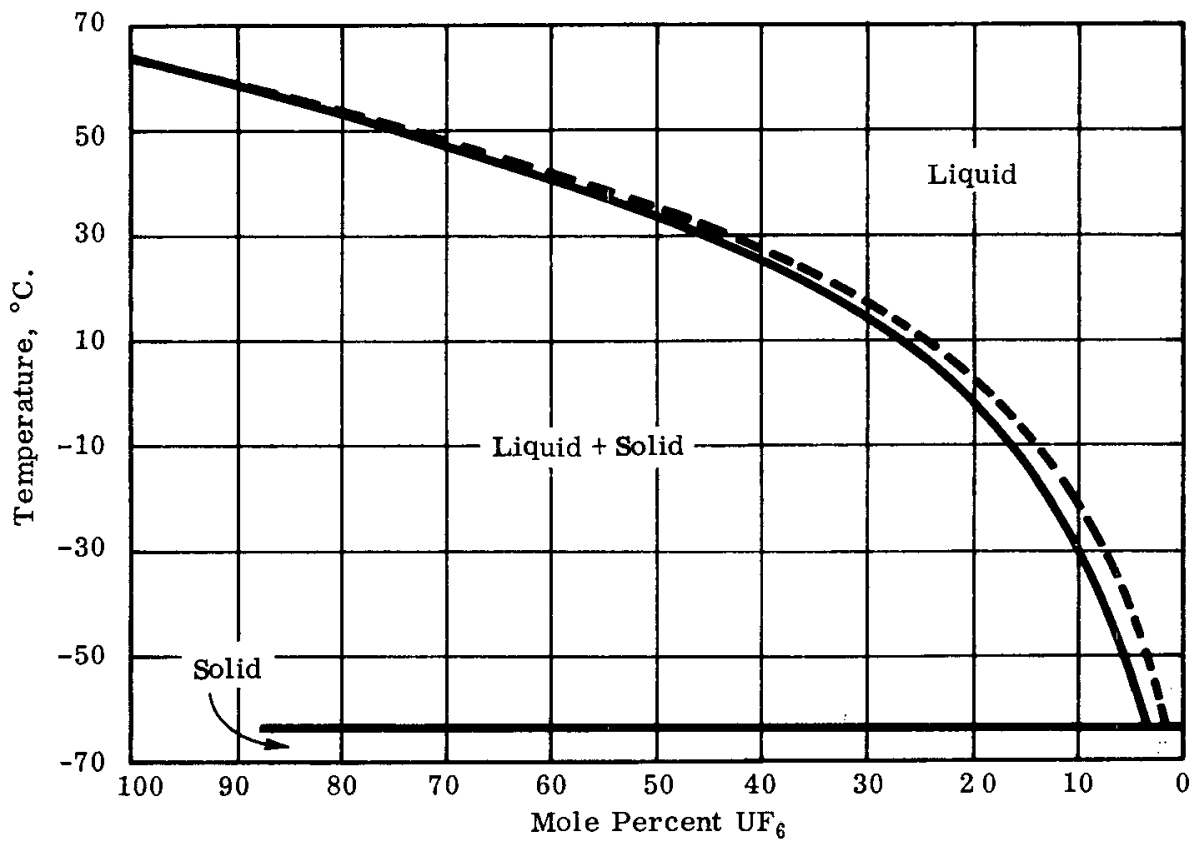

FIG. 44. SOLID - LIQUID EQUILIBRIUM OF THE URANIUM HEXAFLUORIDEBROMINE PENTAFLUORIDE SYSTEM

(Reference 60)

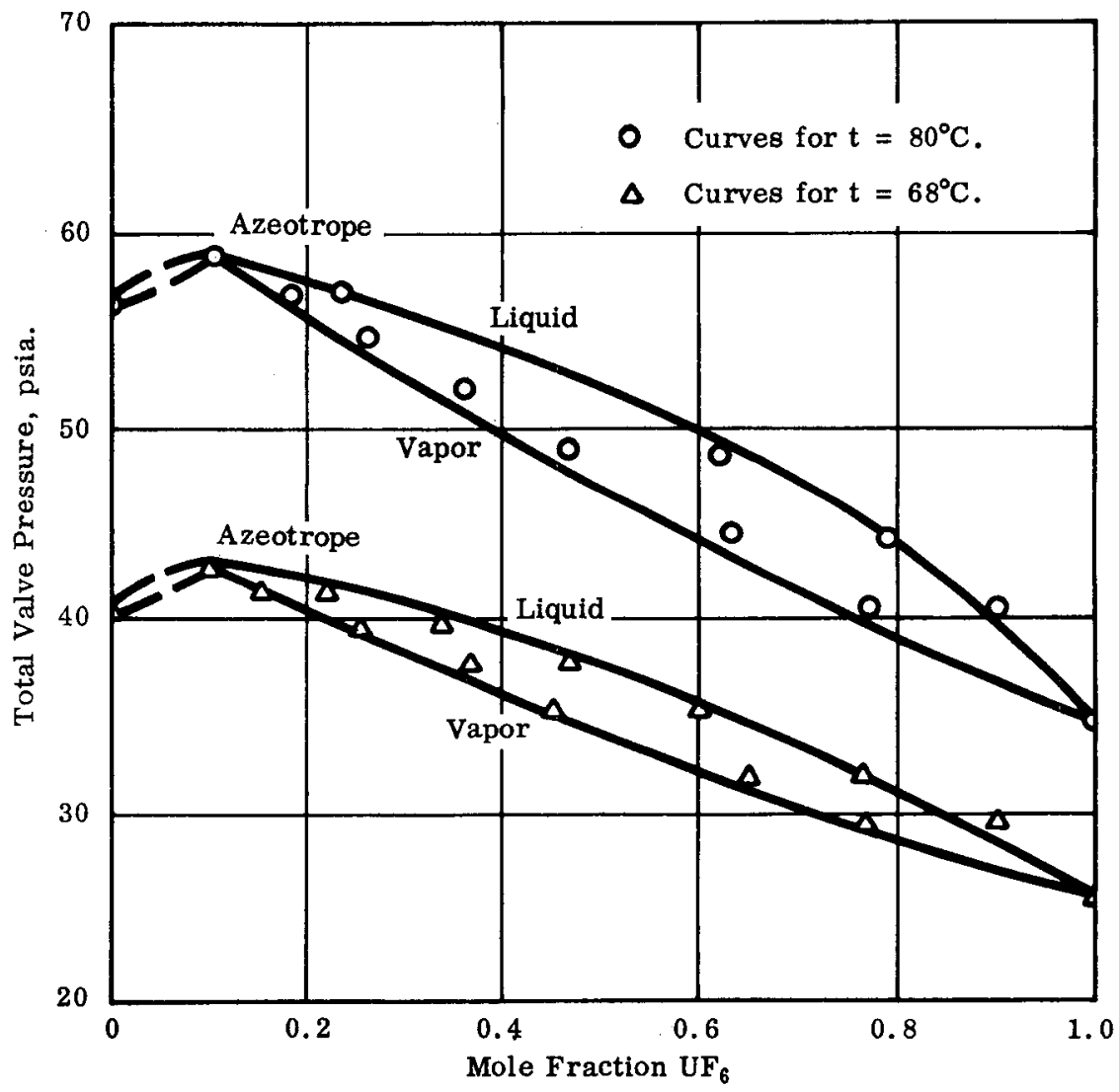

FIG. 45. PRESSURE - COMPOSITION DIAGRAM OF THE URANIUM HEXAFLUORIDE - BROMINE PENTAFLUORIDE SYSTEM (Reference 58) 
the liquid-vapor equilibrium in the $\mathrm{UF}_{6}-\mathrm{BrF}_{5}$ system shows small positive deviations from ideality with no azeotrope. The experimental liquid-vapor equilibrium data for the $\mathrm{UF}_{6}-\mathrm{BrF}_{5}$ system at the $70^{\circ} \mathrm{C}$. i sotherm are presented in Table 72 and Figure 46 while those at the $90^{\circ} \mathrm{C}$. is otherm are presented in Table 73 and in Figure 47.

Table 72

VAPOR-LIQUID EQUILIBRIUM DATA FOR THE URANIUM HEXAFLUORIDE BROMINE PENTAFLUORIDE SYSTEM

$.70^{\circ} \mathrm{C}$. Isotherm

(Reference 102)

\begin{tabular}{|c|c|c|c|c|c|c|}
\hline \multicolumn{2}{|c|}{ Mole Percent $\mathrm{BrF}_{5}$} & \multirow{2}{*}{$\begin{array}{l}\text { Temperature } \\
\text { (C.) }\end{array}$} & \multirow{2}{*}{$\begin{array}{l}\text { Pressure } \\
(\mathrm{mm} . \mathrm{Hg})\end{array}$} & \multirow{2}{*}{$\begin{array}{c}\text { Relative } \\
\text { Volatility }\end{array}$} & \multicolumn{2}{|c|}{ Activity Coefficient } \\
\hline Liquid & Vapor & & & & $\mathrm{BrF}_{5}$ & $\mathrm{UF}_{6}$ \\
\hline 2.1 & 4.2 & 69.4 & 1380 & 2.04 & 1.44 & 1.00 \\
\hline 9.3 & 14.8 & 69.3 & 1429 & 1.68 & 1.19 & 1.00 \\
\hline 19.4 & 28.0 & 69.9 & 1564 & 1.62 & 1.17 & 1.02 \\
\hline 22.5 & 32.0 & 69.7 & 1582 & 1.62 & $\cdot 1.17$ & 1.03 \\
\hline 23.1 & 30.7 & 69.6 & 1569 & 1.47 & 1.08 & 1.05 \\
\hline 40.0 & 50.2 & 69.4 & 1683 & 1.51 & 1.11 & 1.03 \\
\hline 40.6 & 50.4 & 69.7 & 1708 & 1.49 & 1.10 & 1.05 \\
\hline 46.1 & 55.9 & 69.6 & 1731 & 1.49 & 1.09 & 1.05 \\
\hline 57.2 & 63.8 & 69.5 & 1778 & 1.32 & 1.03 & 1.12 \\
\hline 67.5 & 72.2 & 69.7 & 1836 & 1.25 & 1.02 & 1.16 \\
\hline 76.7 & 79.4 & 69.6 & 1854 & 1.17 & 1.00 & 1.21 \\
\hline 78.2 & 82.8 & 69.5 & 1870 & 1.34 & 1.03 & 1.09 \\
\hline 80.1 & 83.3 & 69.6 & 1887 & 1.24 & 1.02 & 1.18 \\
\hline 88.0 & 88.4 & 69.4 & 1890 & 1.04 & 1.00 & 1.36 \\
\hline 88.0 & 89.1 & 69.4 & 1885 & 1.11 & 1.00 & 1.28 \\
\hline 92.4 & 93.0 & 69.5 & 1909 & 1.09 & 1.00 & 1.30 \\
\hline 92.8 & 93.3 & 69.1 & 1880 & 1.08 & 1.00 & 1.31 \\
\hline 93.2 & 93.7 & 69.3 & 1888 & 1.09 & 1.00 & 1.30 \\
\hline 93.4 & 94.9 & 69.5 & 1896 & 1.31 & 0.97 & 1.09 \\
\hline 93.8 & 94.3 & 69.3 & 1904 & 1.10 & 1.01 & 1.30 \\
\hline 94.2 & 94.3 & 69.3 & 1902 & 1.03 & 1.00 & 1.37 \\
\hline 96.2 & 96.8 & 69.4 & 1913 & 1.21 & 1.01 & 1.20 \\
\hline 98.5 & 98.6 & 69.6 & 1915 & 1.06 & 1.00 & 1.35 \\
\hline
\end{tabular}




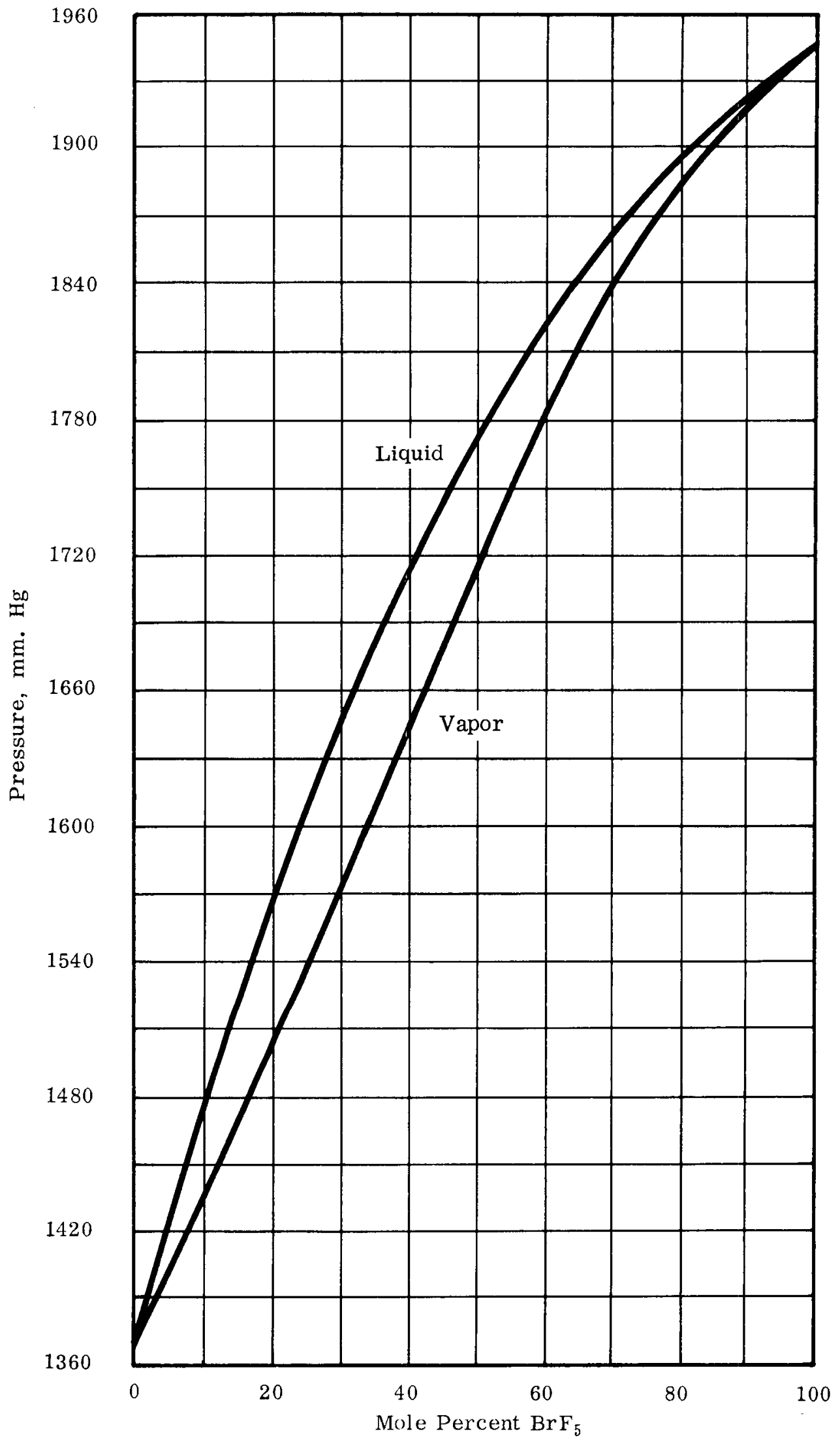

FIG. 46. PRESSURE - COMPOSITION DIAGRAM FOR THE URANIUM HEXAFLUORIDE - BROMINE PENTAFLUORDE SYSTEM AT $70^{\circ} \mathrm{C}$. (Reference 102) 
Table 73

VAPOR-LIQUID EQUILIBRIUM DATA FOR THE URANIUM HEXAFLUORIDE BROMINE PENTAFLUORIDE SYSTEM

$90^{\circ} \mathrm{C}$. Isotherm

(Reference 102)

\begin{tabular}{|c|c|c|c|c|c|c|}
\hline \multicolumn{2}{|c|}{ Mole Percent $\mathrm{BrF}_{5}$} & \multirow{2}{*}{$\begin{array}{c}\text { Temperature } \\
\left.\text { ( }{ }^{\circ} \mathrm{C} .\right)\end{array}$} & \multirow{2}{*}{$\begin{array}{l}\text { Pressure } \\
\text { (mm. Hg) }\end{array}$} & \multirow{2}{*}{$\begin{array}{l}\text { Relative } \\
\text { Volatility }\end{array}$} & \multicolumn{2}{|c|}{ Activity Coefficients } \\
\hline Liquid & Vapor & & & & $\mathrm{BrF}_{5}$ & $\mathrm{UF}_{6}$ \\
\hline 2.1 & 4.6 & 89.8 & 2472 & 2.28 & 1.64 & 1.00 \\
\hline 8.9 & 13.8 & 89.5 & 2558 & 1.65 & 1.18 & 1.01 \\
\hline 25.6 & 35.2 & 89.7 & 2790 & 1.58 & 1.14 & 1.01 \\
\hline 41.0 & 47.8 & 88.6 & 2889 & 1.32 & 1.04 & 1.10 \\
\hline 42.6 & 48.8 & 89.4 & 2967 & 1.29 & 1.02 & 1.11 \\
\hline 47.5 & 55.0 & 89.1 & 2991 & 1.35 & 1.05 & 1.08 \\
\hline 50.7 & 57.3 & 89.2 & 3022 & 1.30 & 1.03 & 1.20 \\
\hline 70.6 & 75.0 & 89.6 & 3212 & 1.25 & 1.01 & 1.13 \\
\hline 79.8 & 81.8 & 89.7 & 3281 & 1.14 & 1.00 & 1.23 \\
\hline 81.4 & 81.8 & 89.1 & 3218 & 1.03 & 0.97 & 1.34 \\
\hline 88.2 & 88.6 & 89.2 & 3272 & 1.04 & 0.99 & 1.31 \\
\hline 92.8 & 93.3 & 89.3 & 3301 & 1.08 & 1.00 & 1.33 \\
\hline 93.6 & 94.0 & 89.3 & 3304 & 1.07 & 1.00 & 1.30 \\
\hline
\end{tabular}

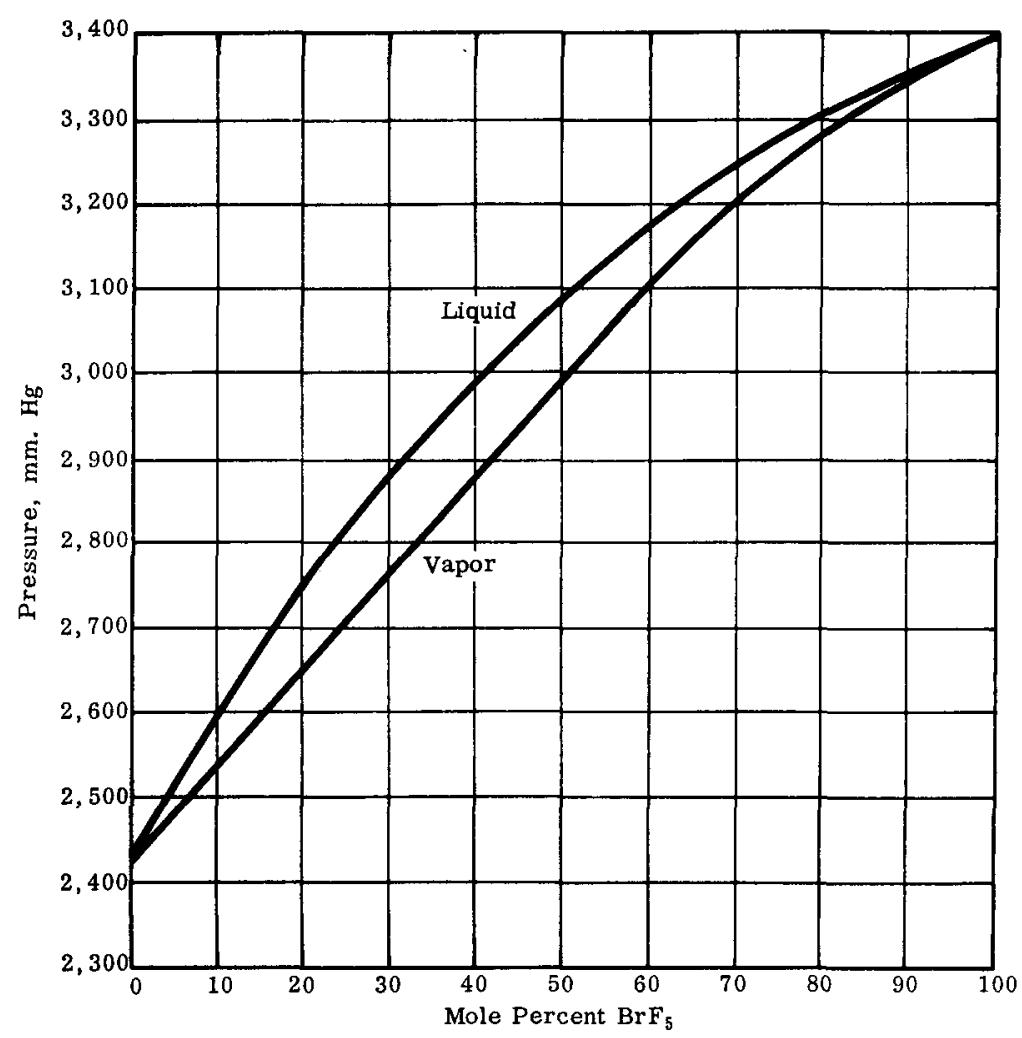

FIG. 47. PRESSURE - COMPOSITION DIAGRAM FOR THE URANIUM HEXAFLUORIDE - BROMINE PENTAFLUORIDE SYSTEM AT $90^{\circ} \mathrm{C}$. (Reference 102) 


\section{URANIUM HEXAFLUORIDE IN CHLORINE TRIFLUORIDE $\left(\mathrm{ClF}_{3}\right)$}

Wendolkowski and Barber ${ }^{145}$ investigated the solid-liquid equilibria of the $\mathrm{UF}_{6}-\mathrm{ClF}_{3}$ system over the entire composition range. The results of this investigation are presented in Figure 48. The data used in the plots of Figure 48 are average values which were obtained from a family of cooling and warming curves. At $-77.4^{\circ} \mathrm{C}$. and 0.4 mole percent $\mathrm{UF}_{6}$, the $\mathrm{UF}_{6}$ and chlorine trifluoride form a binary eutectic, and at $-83.1^{\circ} \mathrm{C}$. the chlorine trifluoride exhibits enantiotropy. The actual solubility was found to be less than ideal and shows positive deviation from Raoult's law. The experimental solubilities, the ideal solubilities, and the theoretical activity coefficients of $\mathrm{UF}_{6}$ calculated using the activity coefficient method appear in Table 74 .

The liquid-vapor equilibrium of the $\mathrm{UF}_{6}-\mathrm{ClF}_{3}$ system was investigated by Ellis, ${ }^{56,57}$ by McGill and Barber, ${ }^{15}$ and by Kuykendall ${ }^{96}$. A discrepancy exists between the conclusions of Ellis and those of the other investigators. Ellis found that the phase diagrams for the liquid-vapor equilibria in the $\mathrm{UF}_{6}-\mathrm{ClF}_{3}$ system show that no azeotropic mixture exists. At $67^{\circ} \mathrm{C}$. the components are completely miscible, but at $75^{\circ} \mathrm{C}$. a partial miscibility region appears between the composition range from 0.3 to 0.5 mole fraction $\mathrm{UF}_{6}$. On the other hand, Kuykendall found that the system displayed complete miscibility. This is in agreement with the data obtained by McGill and Barber.

Table 74

SOLUBILITY AND ACTIVITY COEFFICIENTS IN CHLORINE TRIFLUORIDE SOLUTION

(Reference 145)

Composition of Saturated Solution

Temperature
(C.)

64

60

50

40

30

20

10

0

$-10$

$-20$

$-30$ (mole percent $\mathrm{UF}_{6}$ )

$\begin{array}{ccc}\text { Experimental } & \frac{\text { Ideal }}{100.0} & \frac{\text { Theoretical }}{100.0}\end{array}$

90.0

67.7

48.2

33.0

22.3

15.6

10.5

6.8

4.4

2.9

92.0

92.0

73.5

57.6

46. 7

44.2

36.3

33.0

27.8

24.6

21.0

18.1

15.8

13.2

12.4

10.2

9.1

7.3

1.23

1.03

1.42

1.06

1.63

1.10

1.78

1.13

2.00

1.16

2.32

1.20

2. 81

1.22

3.14

1.25 


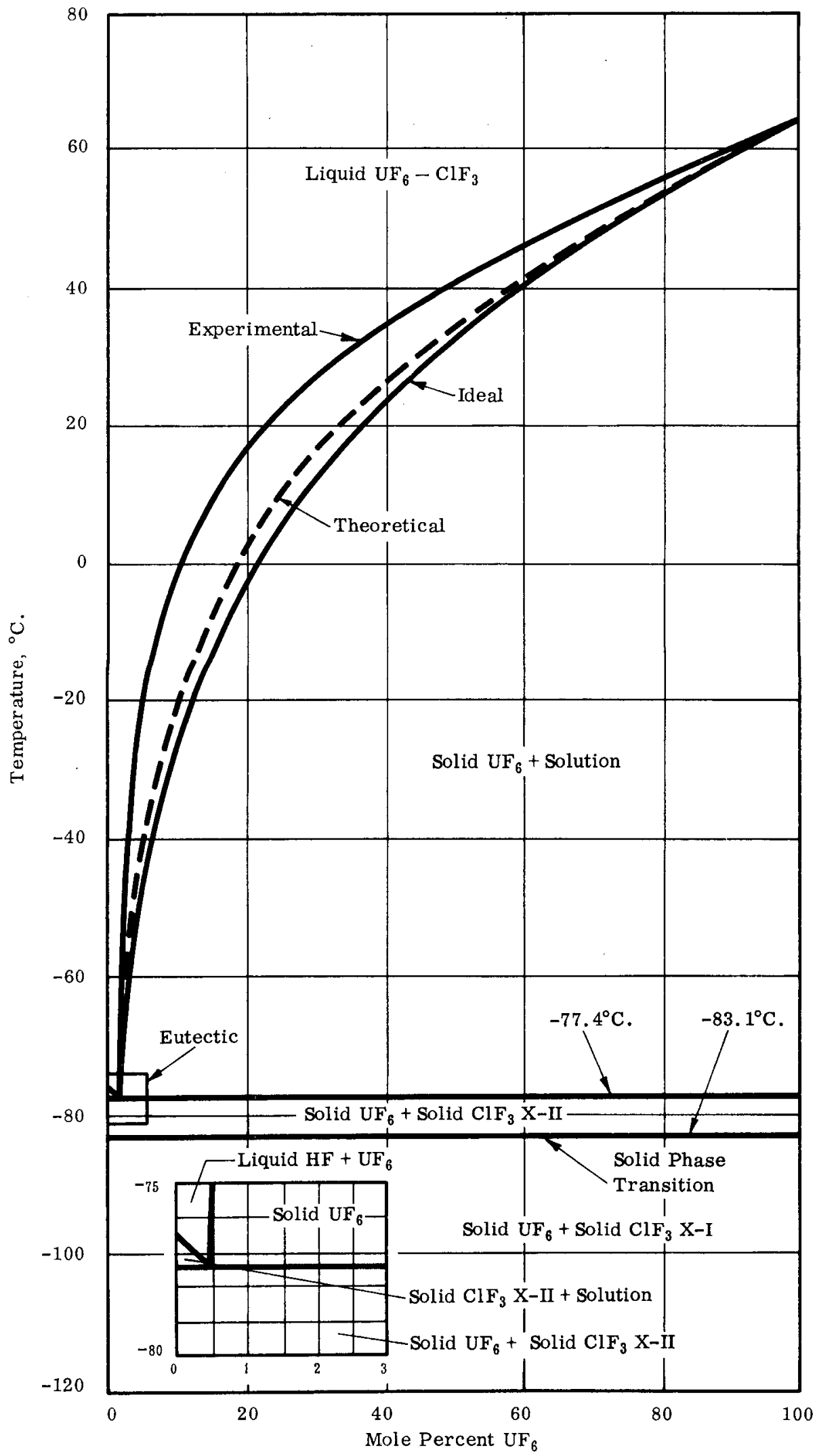

FIG. 48. SOLID - LIQUID EQUILIBRIUM OF THE URANIUM HEXAFLUORIDECHLORINE TRIFLUORIDE SYSTEM

(Reference 145 
McGill and Barber ${ }^{15}$ investigated the liquid-vapor equilibrium of the $\mathrm{UF}_{6}-\mathrm{ClF}_{3}$ system at total pressures of $1.5,2.0,2.5$ and 3.0 atmospheres (absolute) by means of a nickel othmer-type equilibrium still. They found that the system is a simple azeotropic one, but at pressures of 2.5 atmospheres or less the liquid curves intersect the solubility curve for the system. The results obtained by McGill and Barber on the $\mathrm{UF}_{6}-\mathrm{ClF}_{3}$ system are summarized in Table 75 . The composition diagram for the system is given in Figure 49. The activity coefficients of $\mathrm{UF}_{6}$ in $\mathrm{ClF}_{3}$ calculated from the use of Raoult's laws are listed at various concentration in Table 76 . The results obtained by Ellis are presented in Table 77 and Figure 50.

Recently, Kuykendall ${ }^{96}$ obtained data which are in direct conflict with the conclusions of Ellis and which are consistent with the data obtained by McGill and Barber. Kuykendall obtained the vapor pressures for the $\mathrm{UF}_{6}-\mathrm{ClF}_{3}$ system at approximately $76^{\circ}, 83^{\circ}$, and $92^{\circ} \mathrm{C}$. over the entire composition range. The results obtained by Kuykendall are presented in Table 78. Figure 51 shows the discrepancy between the results of Kuykendall and those of Ellis.

Table 75

LIQUD-VAPOR EQUILIBRIUM DATA ON THE URANIUM HEXAFLUORIDE CHLORINE TRIFLUORIDE SYSTEM

(Reference 15)

\begin{tabular}{|c|c|c|c|}
\hline \multirow{2}{*}{$\begin{array}{l}\text { Total Pressure* } \\
(\mathrm{mm} . \mathrm{Hg})\end{array}$} & \multirow{2}{*}{$\begin{array}{l}\text { Temperature } \\
\left({ }^{\circ} \mathrm{C} .\right)\end{array}$} & \multicolumn{2}{|c|}{$\left(\right.$ mole percent $\left.\mathrm{ClF}_{3}\right)$} \\
\hline & & Liquid & Vapor \\
\hline 1144 & 25.0 & 86.0 & 93.5 \\
\hline 1145 & 24.9 & 85.7 & 93.1 \\
\hline 1533 & 32.9 & 82.7 & 92.5 \\
\hline 1530 & 37.7 & 56.1 & 77.0 \\
\hline 1908 & 38.9 & 80.9 & 90.7 \\
\hline 1910 & 46.0 & & 68.7 \\
\hline 1913 & 51.9 & & 60.1 \\
\hline 2275 & 79.5 & 1.0 & 10.0 \\
\hline 2274 & 70.0 & 6.9 & \\
\hline 2280 & 61.5 & & 44.6 \\
\hline 2276 & 64.3 & 15.5 & 40.8 \\
\hline 2275 & 58.6 & 21.4 & 57.5 \\
\hline 2288 & 48.6 & 47.4 & 82.7 \\
\hline 2285 & 47.3 & 58.3 & 84.6 \\
\hline 2280 & 45.5 & 69.3 & 86.5 \\
\hline 2297 & 50.4 & 41.0 & \\
\hline
\end{tabular}

* Pressures corrected for atmospheric pressure and temperature. 
Table 76

ACTIVITY COEFFICIENTS

IN CHLORINE TRIFLUORIDE SOLUTION

(Reference 15)

\section{Concentration}

(mole percent $\mathrm{UF}_{6}$ )

10

20

30

40

50

60

70

80

90

\section{Activity Coefficient}

2.17

1.63

1.55

1.37

1.26

1.27

1.32

1.37

1.32

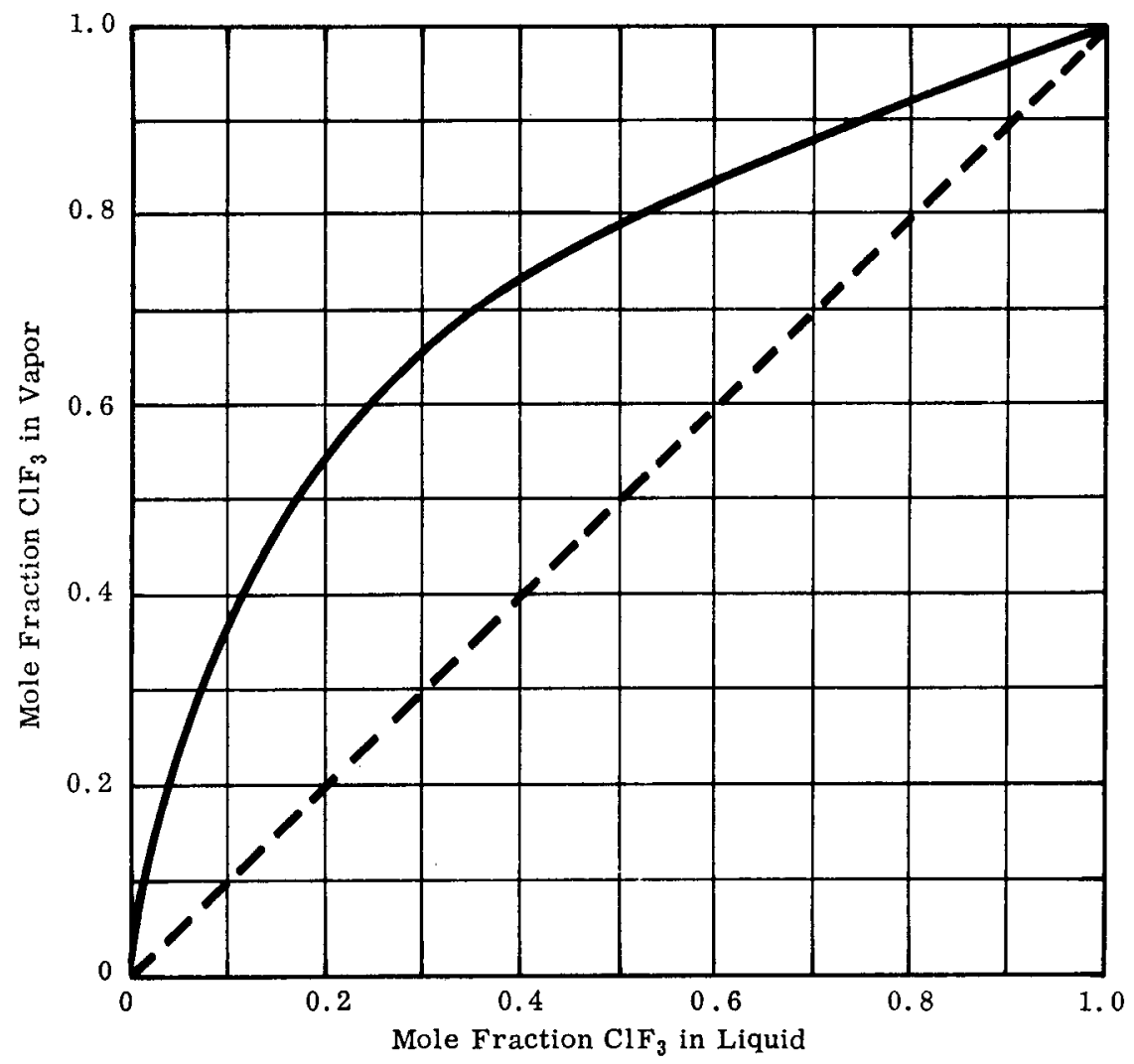

FIG. 49. DIAGRAM OF THE URANIUM HEXAFLUORIDE CHLORINE TRIFLUORIDE SYSTEM

(Reference 15) 
Table 77

LIQUID-VAPOR EQUILIBRIUM IN THE URANIUM HEXAFLUORIDE CHLORINE TRIFLUORIDE SYSTEM

(Reference 56)

\begin{abstract}
Gross Composition (mass estimate as mole fraction $\mathrm{UF}_{6}$ )
\end{abstract}

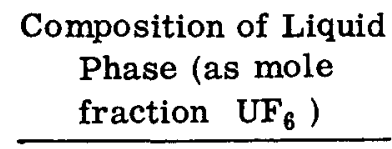

0.000

0.188

0.298

0.512

0.505

0.603

0.675

0.790

0.875

0.945

1.0
Vapor Composition (as mole fraction $\mathrm{UF}_{6}$ )

0.000

0.075

0.132

0.138

0.139

0.150

0.220

0.455

0.595

0.725

1. 0
Total Vapor Pressure (psia.)

132. 7

121.2

109.7

109.7
0.93

1.0

30.6

\section{MISCELLANEOUS BINARY URANIUM HEXAFLUORIDE PHASE RELATIONSHIPS}

Bernhardt and his co-workers ${ }^{19}$ determined the solubility of fluorine, oxygen, and nitrogen in solid and liquid $\mathrm{UF}_{6}$. The determinations were made at temperatures between $30^{\circ}$ and $90^{\circ} \mathrm{C}$. It was found that, at a 95 percent confidence level, the average mole percent of fluorine which dissolves in solid $U F_{6}$ in the range from $.50^{\circ} \mathrm{C}$. to the melting point is $0.058 \pm 0.020$. The mole percentages of nitrogen and axygen dissolved in solid $\mathrm{UF}_{6}$ over the same temperature range are $0.055 \pm 0.025$ and $0.068 \pm 0.050$, respectively, while the corresponding percentages in liquid $\mathrm{UF}_{6}$ are $0.093 \pm 0.103$ and $0.165 \pm 0.031$. These solubilities correspond to calculated activity coefficients for fluorine, nitrogen and oxygen of $0.24 \pm 0.08,0.47 \pm 0.88$, and $0.25 \pm 0.07$, respectively. 


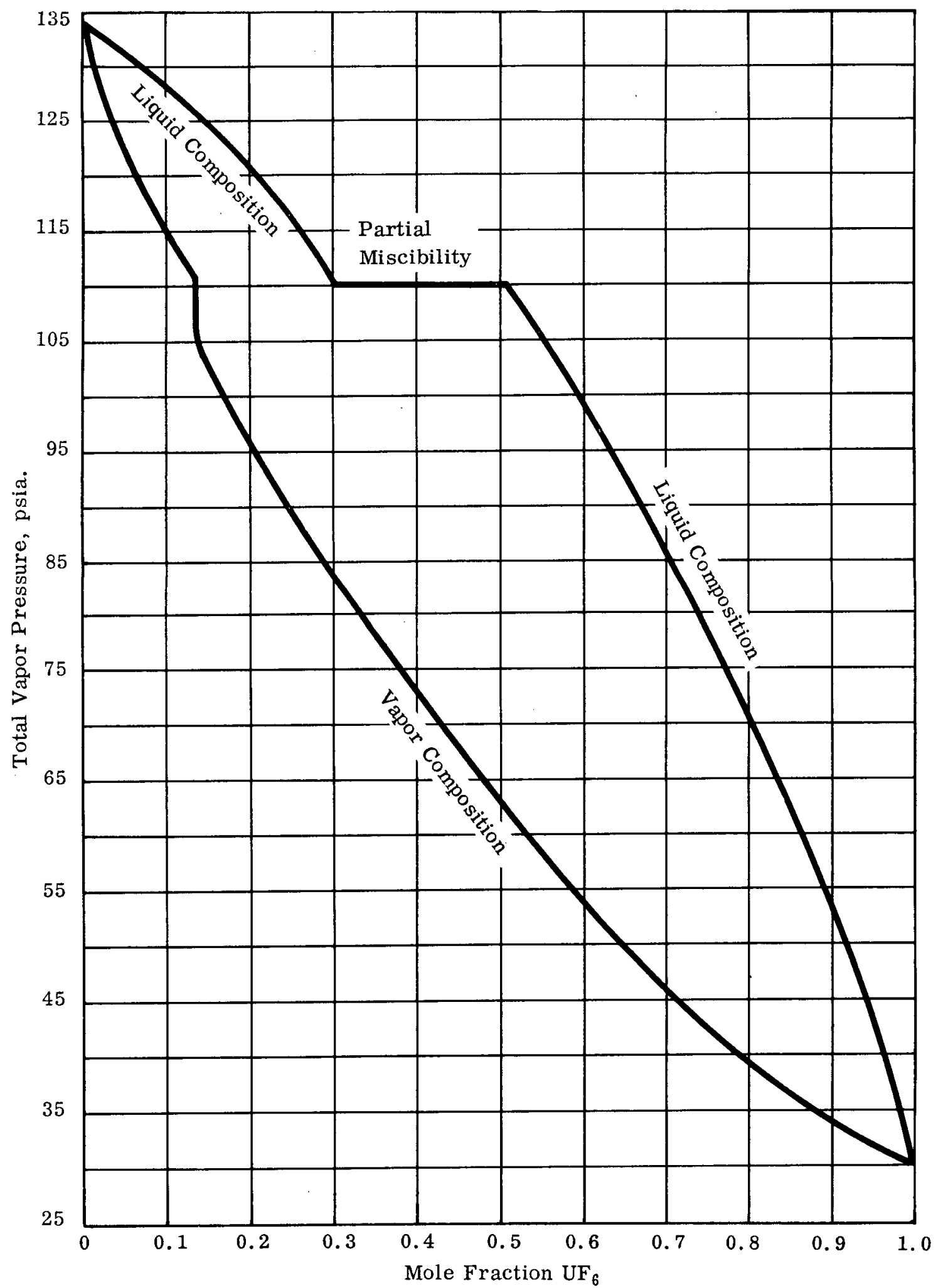

FIG. 50. LIQUID - VAPOR EQUILIBRIUM IN THE URANIUM HEXAFLUORIDECHLORINE TRIFLUORIDE SYSTEM AT $75^{\circ} \mathrm{C}$.

(Reference 56) 
Table 78

VAPOR PRESSURE DATA FOR THE URANIUM HEXAFLUORIDECHLORINE TRIF LUORIDE SYSTEM

(Reference 96)

\begin{tabular}{c}
$\begin{array}{c}\text { Total Pressure } \\
\text { (psia.) }\end{array}$ \\
\hline 35 \\
44 \\
54 \\
91 \\
107 \\
130 \\
98 \\
115 \\
143 \\
108 \\
127 \\
154 \\
117 \\
137 \\
164 \\
124 \\
137 \\
146 \\
122 \\
141 \\
167 \\
105 \\
129 \\
134 \\
96 \\
111 \\
127 \\
\end{tabular}

\begin{tabular}{c}
$\begin{array}{c}\text { Temperature } \\
\left.\text { ( }{ }^{\circ} \text { C. }\right)\end{array}$ \\
\hline 77.0 \\
84.0 \\
92.6
\end{tabular}

76.5

83.2

92.0

76.5

83.2

92.0

76.5

83.2

92.0

76.5

83.2

92.0

76.5

80.0

83.2

76.5

83.2

90.6

67.8

75.0

76.5

65.0

70.0

75.0
Gross Composition (mole fraction $\mathrm{UF}_{6}$ )

1.0000

1.0000

1.0000

0.5749

0.5749

0.5749

0.4681

0.4681

0.4681

0.3791

0. 3791

0.3791

0.3456

0.3456

0.3456

0.2394

0.2394

0.2394

0.1970

0.1970

0.1970

0.0000

0.0000

0.0000

0.0000

0.0000

0.0000 


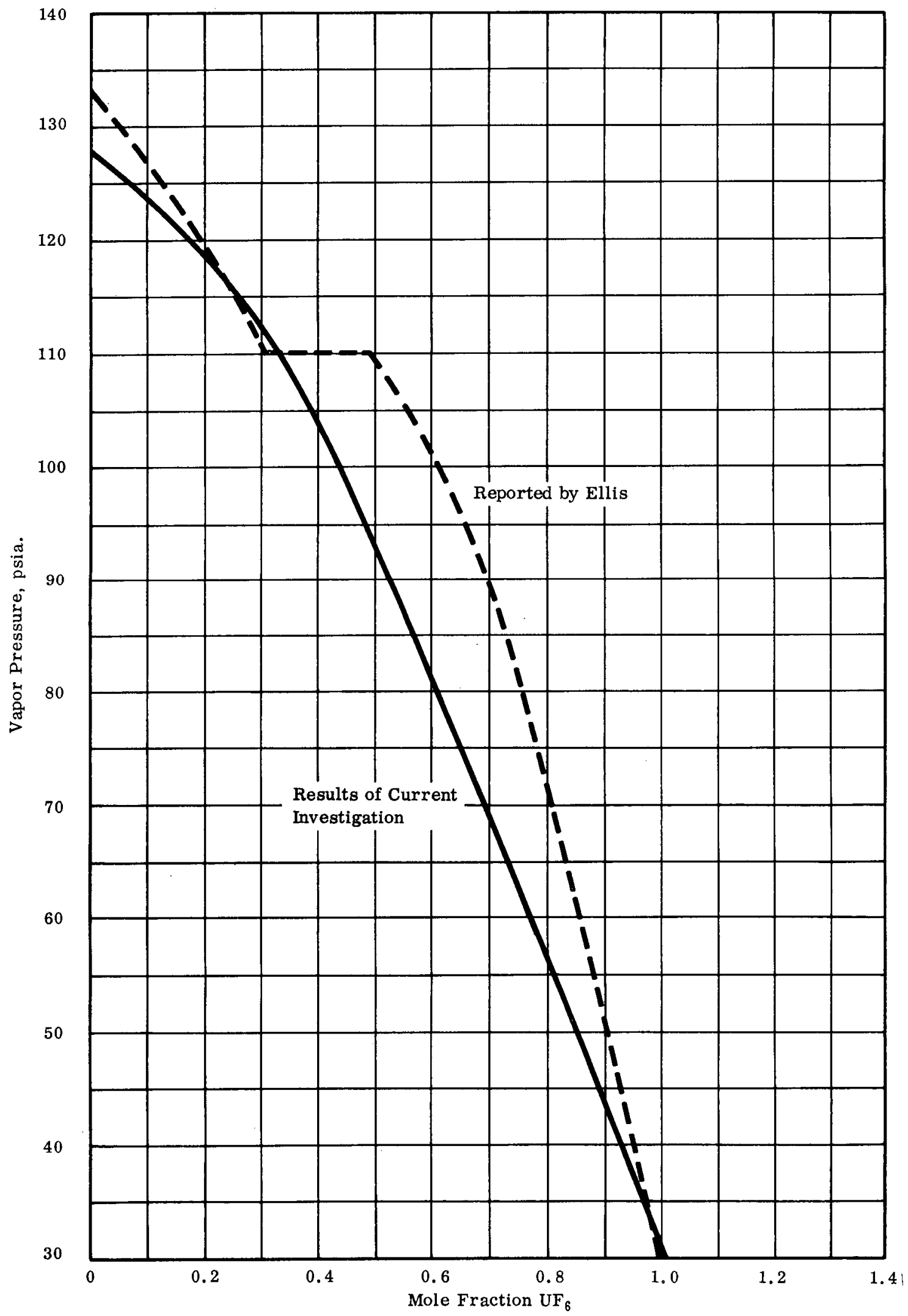

FIG. 51. VAPOR PRESSURE - COMPOSITION DIAGRAM FOR THE URANIUM HEXAFLUORIDE - CHLORINE TRIFLUORIDE SYSTEM

(Reference 96) 


\section{UF $_{6}$ TERNARY EQUILIBRIUM SYSTEMS}

\section{URANIUM HEXAFLUORIDE - CHLORINE TRIF LUORIDE - HYDROGEN FLUORIDE}

Rutledge and Davis ${ }^{134}$ constructed the solid-liquid and the liquid-liquid equilibria of the ternary system $\mathrm{UF}_{6}-\mathrm{ClF}_{3}-\mathrm{HF}$ from the experimental data on the binary systems of these three components. A ternary eutectic was found at $-91^{\circ} \mathrm{C}$. and a composition of 0.0 to 0.2 formula percent $\mathrm{UF}_{6}, 19.5$ formula percent $\mathrm{ClF}_{3}$, and 80.5 formula percent $\mathrm{HF}$. At a composition of 49 formula percent $\mathrm{UF}_{6}, 13$ mole percent $\mathrm{ClF}_{3}$, and 38 formula percent $\mathrm{HF}$ at a temperature of $53^{\circ} \mathrm{C}$., a miscibility gap begins in which two liquids are saturated with solid $\mathrm{UF}_{6}$. This miscibility gap exists up to about $101^{\circ} \mathrm{C}$.

Rowlinson ${ }^{130}$ calculated the liquid-vapor equilibria for the ternary system $\mathrm{UF}_{6}-\mathrm{ClF}_{3}-\mathrm{HF}$ from a knowledge of the three binary systems using the statistical theory of solutions. The binary equilibria data which were used by Rowlinson are the same as those used by Rutledge and Davis.

URANIUM HEXAFLUORDE - 2, 2, 3-TRICHLOROHEPTAFLUOROBUTANE PERF LUORODIMET HYLCYCLOHEXANE

Capps and Burke ${ }^{33}$ obtained some preliminary data concerning the liquid-vapor equilibrium for the $\mathrm{UF}_{6}-2,2,3$-trichloroheptafluorobutane - perfluorodimethylcyclohexane ternary system. Samples of the liquid and the condensed vapor which were withdrawn from a modified Othmer-type equilibrium still were analyzed by infrared spectroscopy. The results are listed in Table 79. The authors point out that the ratio of perfluorodimethylcyclohexane to 2, 2,3-trichloroheptafluorobutane tends to approach the azeotropic composition ratio in going from the liquid to the vapor phase. 
LIQUID-VAPOR EQUILIBRIUM OF THE URANIUM HEXAFLUORIDETRICHLOROHE PTA F LUOROBUTANE-PERF LUORODIMETHYLCYCLOHEXANE SYSTEM

(Reference 33)

Mole Percent

Liquid-Vapor

Sample Pair

\section{1}

2

3

4

5

6

7

8

9

10

11

\begin{tabular}{|c|c|c|c|}
\hline \multicolumn{2}{|c|}{ Trichloroheptafluorobutane } & \multicolumn{2}{|c|}{ Perfluorodimethylcyclohexane } \\
\hline Liquid & Vapor & Liquid & Vapor \\
\hline 44.7 & 30.8 & 42.0 & 23.0 \\
\hline 51.2 & 33.4 & 29.3 & 19.2 \\
\hline 45.0 & 23.5 & 26.7 & 13.4 \\
\hline 37.8 & 19.4 & 37.3 & 15.7 \\
\hline 32.8 & 17.6 & 52.9 & 20.7 \\
\hline 26.9 & 19. 7 & 57.8 & 27.5 \\
\hline 25.0 & 6.6 & 50.8 & 9.6 \\
\hline 36.5 & 14.6 & 40.1 & 13.0 \\
\hline 35.9 & 13.3 & 38.8 & 12.4 \\
\hline 25.9 & 9.6 & 27.3 & 9.7 \\
\hline 22.6 & 5.5 & 25.0 & 6.6 \\
\hline
\end{tabular}

Uranium Hexafluoride

Liquid Vapor

13.248 .4

$19.5 \quad 47.4$

$28.2 \quad 63.0$

$25.0 \quad 64.9$

$\begin{array}{ll}14.3 & 61.7\end{array}$

$\begin{array}{ll}15.3 & 52.8\end{array}$

$24.2 \quad 83.8$

$23.3 \quad 72.4$

$22.9 \quad 74.4$

$\begin{array}{ll}46.8 & 80.8\end{array}$

$\begin{array}{ll}52.4 & 87.8\end{array}$ 


\section{BIBLIOGRAPHY}

1. Data on Physical Properties of Uranium Hexafluoride Excerpted from NRL-O-1977 by Philip Abelson. U.S. Naval Research Labs. Jan. 4, 1943. (A-3126) Official Use Only

2. Ackley, R. D. and Magnuson, D. W. The Non-Ideality of Uranium Hexafluoride Vapor, Parts I and II. Carbide and Carbon Chemicals Co. ${ }^{*}$ Dec. 28, 1951. (K-840;AECD-3475) Unclassified

3. Ackley, R. D. and Barber, E. J. Additional Calculations and Comments on Uranium Hexafluoride Non-Ideality. Carbide and Carbon Chemical Co. Nov. 18, 1953. (KLI-2683) Secret

4. Agron, P. A. and Taylor, A. H. The Thermal Conductivity of Uranium Hexafluoride. SAM Labs. Feb. 17, 1945. (CL-48-2-71; MDDC-1747) Unclassified [See also Ref. 1]

5. Agron, P.A. Thermal Conductivity of $\left[\mathrm{UF}_{6}\right]$. SAM Labs. [Feb. 1949 ] (KZ-2161) Unclassified

6. Amdur, I. "Determination of the Molecular Law of Force from Self-Diffusion Coefficients." Phys. Rev. 72, 642-3(1947).

7. Amphlett, C. B. and Thomas, L. F. Determination of the Vapour Pressure of $\left[\mathrm{UF}_{6}\right]$ between $0^{\circ}$ and $15^{\circ} \mathrm{C}$. Univ. of Birmingham, England. Nov. 17, 1941. (BR-8) Declassified

8. Amphlett, C. B. The Vapour Pressure of $\left[\mathrm{UF}_{6}\right]$ from $12^{\circ}$ to $50^{\circ} \mathrm{C}$. Univ. of Birmingham, England. June 30, 1942. (BR-186) Declassified

9. Amphlett, C. B., Mullinger, L. W. and Thomas, L. F. "Some Physical Properties of Uranium Hexafluoride." Trans. Faraday Soc. 44, 927-36(1948).

10. Awbery, J. H. The Vapour Pressure of Liquid $\left[\mathrm{UF}_{6}\right]$. Dept. of Scientific and Industrial Research, Great Britain. Sept. 1943. (BR-300) Declassified

11. Awbery, J. H. Vapour Pressure of Solid [UF $\left.F_{6}\right]$. Dept. of Scientific and Industrial Research, Great Britain. Oct. 4, 1943. (BR-302) Declassified

12. Awbery, J. H. An Equation of State for $\left[\mathrm{UF}_{6}\right]$ Vapour. Dept. of Scientific and Industrial Research, Great Britain. Dec. 21, 1943. (BR-362) Declassified

13. Awbery, J. H. The Critical Constants of $\left[\mathrm{UF}_{6}\right]$. Dept. of Scientific and Industrial Research, Great Britain [Sept. 1943] (BR-290) Declassified

14. Barber, E. J., Posey, J, C. and Judkins, J. H. Phase Equilibria of the System Uranium Hexafluoride - Freon-114. Carbide and Carbon Chemicals Co. Nov. 4, 1953. (K-1075) Confidential

15. Barber, E. J. and McGill, R. M. Phase Equilibria of the Ternary System: Uranium Hexafluoride - Chlorine Trifluoride - Hydrogen Fluoride, Part IV, LiquidVapor Equilibria of the Binary System Uranium Hexafluoride - Chlorine Trifluoride. Carbide and Carbon Chemicals Co. Feb. 26, 1954. (K-1102) Declassified

*The Carbide and Carbon Chemicals Company is now known as the Union Carbide Nuclear Company. 
16. Bauer, S. H. and Palter, R. Analysis of X-ray Powder Diffraction Data on Crystalline Uranium Hexafluoride. Cornell Univ. Oct. 2, 1946. (MDDC-364) Unclassified

17. Bauer, S. H. The Structure of $\left[\mathrm{UF}_{6}\right]$. Cornell Univ. Mar. 5, 1956. (XD-252) Secret

18. Bauer, S. H. "The Structure of Uranium Hexafluoride as Determined by the Diffraction of Electrons on the Vapor." J. Chem. Phys. 18, 27-41(1950). [See also errata; J. Chem. Phys. 18, 994(1950) and letter from Fumi, F. G. and Castellan, G. W. "On the Molecular Structure of Uranium Hexafluoride." J. Chem. Phys. 18, 762(1950)]

19. Bernhardt, H. A., Bishop, W. H., Capps, R. H. and Weisblatt, H。 B. Solubility of Oxygen, Nitrogen and Fluorine in Uranium Hexafluoride. Carbide and Carbon Chemicals Co. Sept. 10, 1949. (AECD-2734) Declassified

20. Bigeleisen, J., Mayer, M. G., Stevenson, P. C. and Turkevich, J. "Vibrational Spectrum and Thermodynamic Properties of Uranium Hexafluoride Gas." J. Chem. Phys. 16, 442-5(1948). [Also reported in MDDC-1181 and A-1269]

21. Blatt, W. N. "Appendix C: Viscosity of Liquid Uranium Hexafluoride." in P.H. Abelson, et al., ed. Liquid Thermal Diffusion. Technical Information Service Extension, AEC. Aug. 1958. (TD-5229) Declassified

22. Booth, E. T., Callihan, D., Haggstrom, E. and Nordsieck, A. Specific Heat of $\mathrm{UF}_{6}$. SAM Labs. [Dec. 1941] (A-87) Unclassified

23. Brewer, L., Bromley, L. A., Gilles, P. W. and Lofgren, N. L. The Thermodynamic Properties and Equilibria at High Temperatures of Uranium Halides, Oxides, Nitrides, and Carbides. Univ. of California Radiation Lab. ${ }^{*}$ Sept. 20, 1945. (CC-3234) Unclassified [Data also reported earlier in BC-82; MDDC-1543]

24. Brickwedde, F. G., Hoge, H. J. and Scott, R. B. "The Low Temperature Heat Capacities, Enthalpies, and Entropies of $U F_{4}$ and $U_{6} . "$ J. Chem. Phys. 16 , 429-36(1948). [Also reported in A-607]

25. Bridger, G. W. The Vapour Pressure of $\left[\mathrm{UF}_{6}\right]$. Dept. of Scientific and Industrial Research, Great Britain. Dec. 1, 1944. (BR-539) Declassified

26. Brokaw, G. Y. "Appendix B: Pressure - Temperature - Volume Characteristics of Uranium Hexafluoride." in P. H. Abelson, et al., ed. Liquid Thermal Diffu sion. Technical Information Service Extension, AEC. Aug. 1958. (TID-5229) Declassified

27. Brooks, A. A. and Wood, P. Vapor Pressure Tables for Liquid Uranium Hexafluoride. Union Carbide Nuclear Co. Nov. 21, 1957 . (K-722; AECD-3470 and Addendum 1) Declassified

28. Brown, H. S. The Preparation, Properties and Handling of Uranium Hexafluoride $\left(\mathrm{UF}_{6}\right)$. Metallurgical Labs., Univ. of Chicago. Jan. 8, 1943. (CC-408; A-448) Secret

29. Burke, T. G., Smith, D. F. and Nielsen, A. H. "Molecular Structure of MoF 6 , $W_{6}$ and $U F_{6}$ from Infrared and Raman Spectra." J. Chem. Phys. 20, 447-54(1952).

*Now known as the Ernest O. Lawrence Radiation Laboratory. 
30. Burns, J. F., McKnown, H. S. and Asbury, I. The Electrical Resistivity and Dielectric Constant of Liquid Uranium Hexafluoride. Carbide and Carbon Chemicals Co. Aug. 10, 1949. (K-482) Unclassified

31. Burton, D. W. Effect of Non-Ideality of Gases upon Compressor Performance Calculations. Union Carbide Nuclear Co. Mar. 3, 1959. (KOA-520) Confidential

32. Califano, S. "Force Constant for Hexafluorides $\mathrm{XF}_{6}$. " Atti. Accad. Naz. Lincei Rend., Classe sci. fis., Mat. e Nat. 25, 284-91(1958).

33. Capps, R. H. and Burke, T. G. Liquid-Vapor Equilibrium of Ternary System 2, 2,3-Trichloroheptafluorobutane - Perfluorodimethylcyclohexane - Uranium Hexafluoride. Carbide and Carbon Chemicals Co. Dec. 29, 1954. (KLI-3355) Confidential

34. Chackett, K. F. Redetermination of the Velocity of Sound in $\mathrm{UF}_{6}$ Vapour. Univ. of Birmingham, England [June, 1942] (BR-185) Declassified

35. Claassen, H. H., Weinstock, B. and Malm, J. G. "Raman Spectrum of UF 6 ." J. Chem. Phys. 25, 426-7(1956).

36. Claassen, H. H. "Force Constants of Metal Hexafluorides." J. Chem. Phys. 30, 968-72(1959).

37. Cohen, K. Bi-Weekly Report for the Period November 15-30, 1943; K-25 Project. SAM Labs. Dec. 4, 1943. (M-466) Declassified

38. Cohen, K. Theoretical Considerations on Liquid Thermal Diffusion Experiments. SAM Labs. Feb. 5, 1943. (A-531) Unclassified

39. Davis, W. Jr. Solubility and Phase Relations in the System HF-UF . Carbide $^{-}$ and Carbon Chemicals Co. June 11, 1951. (KLI-964) Secret

40. Davis, W. Jr. and Kobisk, E. H. Analysis of Uranium Hexafluoride - Hydrogen Fluoride Solutions by Freezing Point Determination, Errors Caused by LiquidVapor Equilibrium. Carbide and Carbon Chemicals Co. Apr. 5, 1955. (KLI3438; AECD-4234) Unclassified

41. DeMarcus, W. C. and Hopper, E. H. The Kinematic Viscosity of Mixtures of C 816- $\mathrm{UF}_{6}$. Carbide and Carbon ChemicaIs Co. Feb. 22, 1954. (KD-869) Secret

42. DeMarcus, W. C. and Starnes, M. P. The Intermolecular Interaction of $\mathrm{UF}_{6}$ Molecules. Carbide and Carbon Chemicals Co. June 23, 1954. (K-1114) Declassified

43. Duncan, A. B. F. Spectra of Uranium Compounds in the Vapor Phase. Columbia Univ. Feb. 15 to Mar. 15, 1943. (A-565) Declassified

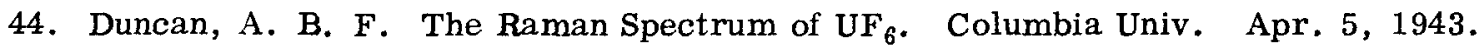
(A-580) Declassified [Also reported in A-584]

45. Dieke, G. H. and Duncan, A. B. F. Spectroscopic Properties of Uranium Compounds. New York, McGraw-Hill, 1949. (National Nuclear Energy Series, Div. III, Vol. 2)

46. Directorate of Tube Alloys Data Sheets.. Dept. of Scientific and Industrial Research, Great Britain. (LRG-64) Restricted Circulation 
47. Directorate of Tube Alloys Progress Report for November and December 1941. Dept. of Scientific and Industrial Research, Great Britain. (B-36) Restricted Circulation

48. Directorate of Tube Alloys Progress Report for January 1942. Dept. of Scientific and Industrial Research, Great Britain. (B-37) Restricted Circulation

49. Directorate of Tube Alloys Progress Report for February 1942 . Dept. of Scientific and Industrial Research, Great Britain. (B-38) Restricted Circulation

50. Directorate of Tube Alloys Progress Report for March 1942. Dept. of Scientific and Industrial Research, Great Britain. (B-55) Restricted Circulation

51. Directorate of Tube Alloys Progress Report for May 1942. Dept. of Scientific and Industrial Research, Great Britain. (B-3) Restricted Circulation

52. Directorate of Tube Alloys Progress Report for June 1942. Dept. of Scientific and Industrial Research, Great Britain. (B-79) Restricted Circulation

53. Directorate of Tube Alloys Progress Report for June 1944. Dept. of Scientific and Industrial Research, Great Britain. (LRG-33) Restricted Circulation

54. Directorate of Tube Alloys Progress Report for September 1942. Dept. of Scientific and Industrial Research, Great Britain. (B-100) Restricted Circulation

55. Directorate of Tube Alloys Progress Report for November 1942. Dept. of Scientific and Industrial Research, Great Britain. (B-117) Restricted Circulation

56. Ellis, J. F. Liquid-Vapour Equilibria of the System Uranium HexafluorideChlorine Trifluoride. Division of Atomic Energy (Production), Great Britain. July 3, 1953. (Risley-5197) Declassified

57. Ellis, J. F. and Johnson, K. D. B. "The Fluorides of Uranium, I. Liquid-Vapour Equilibria in the Systems Uranium Hexafluoride - Chlorine Trifluoride and Uranium Hexafluoride - Bromine Pentafluoride." J. Inorg. Nucl. Chem. $\underline{6}, 194-8(1958)$.

58. Ellis, J. F., Brooks, L. H. and Johnson, K. D. B. "The Fluorides of Uranium, II. Distillation of Mixtures of Corrosive Volatile Fluorides Including Uranium Hexafluoride." J. Inorg. Nucl. Chem. 6, 199-206(1958).

59. Feldman, S. M. Bibliography on the Physical Properties of Uranium Hexafluoride. SAM Labs. June 16, 1943. (100-ZR-33) Secret

60. Fischer, J. and Vogel, R. C. "Phase Equilibria in the Condensed System Uranium Hexafluoride-Bromine Trifluoride and Uranium Hexafluoride-Bromine Pentafluoride." J. Am. Chem. Soc. 76, 4829-32(1954). [Also reported in ANL-5167 and in ANL-5213]

61. Fowler, R. D., Anderson, H. C. and Weber, C. E. The Determination of the Viscosity of Gaseous $\mathrm{UF}_{6}$. National Defense Research Committee, OSRD. Nov. 15, 1942. (A-1398) Declassified

62. Gabbard, J. L., Gibson, J. D., Faloon, A. V., Rapp, K. E., Frey, S. E. and Walker, D. V. Fluorocarbons and Fluoroorganic Compounds; Section II. Carbide and Carbon Chemicals Co. Aug. 2, 1948. (K-220, Section II) Confidential

63. Gabbard, J. L., Bernstein, S. and Amis, E. S. Vapor-Liquid Equilibrium of the Uranium Hexafluoride - Perfluorodimethylcyclohexane $\left(\mathrm{C}_{8} \mathrm{~F}_{16}\right)$ System. Carbide and Carbon Chemicals Co. Sept. 27, 1948. (K-271) Confidential 
64. Gabbard, J. L. and McHenry, R. E. Viscosity, Density and Composition of Uranium Hexafluoride and Chlorotrifluoroethylene Liquid Polymer Solutions. Carbide and Carbon Chemicals Co. July 15, 1949. (K-436) Confidential

65. Gaunt, J. "The Infrared Spectra and Molecular Structure of Some Group 6 Hexafluorides." Trans. Faraday Soc. $49,1122-31(1953)$. [Also reported in AEREC/R-900]

66. Gaunt, J. "The Force Constants and Bond Lengths of Some Inorganic Hexafluorides." Trans. Faraday Soc. 50, 546(1954).

67. Glassner, A. The Thermodynamic Properties of the Fluorides, Chlorides, and Oxides of the Elements to $2500^{\circ} \mathrm{K}$. Argonne National Lab. [1958] (ANL-5750) Unclassified

68. Glauber, R. and Schomaker, V. "The Theory of Electron Diffraction." Phys. Rev. 89, 667-71(1953). [See also Hoerni, J. A., and Ibers, J. A. "Complex Amplitudes for Electron Scattering by Atoms." Phys. Rev. 91, 1182-5(1953)]

69. Greenspan, J., Roach, K. and Riseman, J. Thermal Conductance of $\left[\mathrm{UF}_{6}-\mathrm{N}_{2}\right]$ Mixtures. Kellex Corp. Aug. 12, 1945. (A-4038) Secret

70. Grisard, J. W. and Oliver, G. D. The Vapor Pressure Difference of Normal and Enriched Uranium Hexafluoride. Carbide and Carbon Chemicals Co. Nov. 31, 1951. (K-830) Secret

71. Grosse, A. V. Chemical Properties of Uranium Hexafluoride, $\mathrm{UF}_{6}$. Columbia Univ. June 25, 1941 . (A-83) Secret

72. Haendler, H. M. and Barber, E. J. Liquid-Vapor Equilibrium of the System $\mathrm{UF}_{6}-$ Perfluoroheptane. SAM Labs. May 24, 1943. (A-710) Declassified

73. Havlice, F. I. "An Approximate Entropy Diagram for Uranium Hexafluoride." Z. Naturforsch. 11a, 99(1956).

74. Hawkins, N. J., Mattraw, H. C. and Carpenter, D. R. Infrared Spectrum of UF 6 at Elevated Temperatures. Knolls Atomic Power Lab. Feb. 1, 1954. (KAPL1041). Unclassified

75. Haworth, W. N. Vapour Pressure of [UF $\left.{ }_{6}\right]$. Univ. of Birmingham, England. [June, 1941] (B-9) Declassified

76. Haworth, W. N. Vapour Pressure of $\mathrm{UF}_{6}$. Univ. of Birmingham, England. [Oct. 1941] (B-18) Restricted Circulation

77. Henkel, P. and Klemm, W. "Magnetochemical Investigations, XII. The Magnetic Behavior of Some Liquid Fluorides." Z. anorg. u. allgem. Chem. 222, 70-2 (1935).

78. Hicks, J. F. G. Visit to Oak Ridge, No. 6. SAM Labs. Dec. 27, 1944. (M-1460) Secret

79. Hodgson, M. A. E. Melting Point and Solid-Vapour Equilibrium Data of a Mixture $8.5 \% \mathrm{C}_{8} \mathrm{~F}_{16}$ and $91.5 \%\left[\mathrm{UF}_{6}\right]$. Dept. of Scientific and Industrial Research, Great Britain. Oct. 23, 1944. (BR-524) Restricted Circulation 
80. Hoard, J. L. and Stroupe, J. D. The Structure of Crystalline Uranium Hexafluoride. Cornell Univ. Mar. 1, 1944. (A-1242) Unclassified

81. Hoard, J. L. and Stroupe, J. D. The Structure of Crystalline Uranium Hexafluoride. Cornell Univ. June 30, 1944. (A-1296) Unclassified

82. Jacobsohn, B. A. Compilation of Process Gas Constants and Formulae. SAM Labs. July 19, 1943. (A-763) Secret

83. Jarry, R. L., Rosen, F. D., Hale, C. F. and Davis, W. Jr. "Liquid-Vapor Equilibrium in the System Uranium Hexafluoride - Hydrogen Fluoride." J. Phys. Chem. 57, 905-9(1953). [Also reported in K-872; AECD-3469]

84. Johnson, H. Bibliography on the Physical Properties of Uranium Hexafluoride. SAM Labs. July 18, 1944 . (A-1297) Secret

85. Johnson, J. W. Extrapolated Partial Pressure of $\mathrm{UF}_{6}$ above Its Solution in $\mathrm{C}_{8} \mathrm{~F}_{16}$ and $\mathrm{C}_{21} \mathrm{~F}_{44}$. Fairchild Engine and Airplane Corp. Nov. 29, 1948. (NEPA-SCR28) Secret

86. Jordan, G. S., Posey, J. C. and Rutledge, G. P. Liquid-Vapor and Solid-Vapor Equilibria of the System Uranium Hexafluoride-Perfluorotributylamine. Carbide and Carbon Chemicals Co. Oct. 28, 1953. (K-1073) Confidential

87. Kaplan, R. E. Physical Properties of $\left[\mathrm{UF}_{6}\right]$ from Data Available in Library. SAM Labs. July 10,1945 . (KZ-1538) Secret

88. Katz, J. J. and Rabinowitch, E. The Chemistry of Uranium. New York, McGraw Hill. 1951. (National Nuclear Energy Series, Div. VIII, Vol. 5)

89. Katz, J. J. and Rabinowitch, E., ed. Chemistry of Uranium (Collected Papers). Books I and II. Technical Information Service Extension, AEC. 1958. (TID-5290) Unclassified

90. Kigoshi, K. "On the Viscosity of the Uranium Hexafluoride." Bull. Chem. Soc. (Japan) $23,67-8(1950)$.

91. Kirshenbaum, A. D. Solubility of $\mathrm{UF}_{6}$ in GD-727c and GD-727h. SAM Labs. Mar. 20, 1943. (A-572) Declassified

92. Kirshenbaum, A. D. Viscosity of Liquid $U_{6}$ at $70^{\circ} \mathrm{C}$. SAM Labs. June $10,1943$. (A-732) Unclassified

93. Kirshenbaum, I. Physical Properties of Uranium Hexafluoride. SAM Labs. Oct. 26, 1943. (A-753 and Addendum I) Declassified

94. Kirshenbaum, I. A New Method of Separation. SAM Labs. Feb. 16, 1944. (M-709) Confidential

95. Kuykendall, W. C., Jones, C. G., Rapp, K. E. and Barber, E. J. Density, Solubility, and Phase Relations of the System Uranium Hexafluoride - 2, 2, 3Trichloroheptafluorobutane. Carbide and Carbon Chemicals Co. Feb. 13, 1957. (K-1303) Confidential

96. Kuykendall, W. C. Vapor Pressure Measurements for the System $\mathrm{UF}_{6}-\mathrm{ClF}_{3}$. Carbide and Carbon Chemicals Co. Nov. 26, 1954. (K-1298) Declassified 
97. Lane, J. A. and Howe, M. E. "Chapter II. Physical and Chemical Properties." R. S. Mulliken, et al., ed. Project Handbook. Metallurgical Labs., Univ. of Chicago. May, 1945. (CL-697; MDDC-95) Declassified

98. Levey, R. P. A Comparison of Non-Ideality Data for $\mathrm{UF}_{6}$ and a Proposed System for Determining New Constants. Carbide and Carbon Chemicals Co. Aug. 7, 1952. (KDD-425) Secret

99. Levey, R. P. Estimation of Dynamic K-25 Hidden Inventory. Carbide and Carbon Chemicals Co. June 17, 1953. (K-1033) Secret

100. Libby, W. F. Theoretical Solubility of Gaseous and Solid [UF 6 ] in Perfect Solutions. SAM Labs. Mar. 16, 1943. (A-574) Declassified

101. Libby, W. F. Chemistry of the Diffusion Process. SAM Labs. Oct. 1945. (A-3649) Secret

102. Liimatainen, R. C. Vapor-Liquid Equilibrium in the System Bromine Pentafluoride - Uranium Hexafluoride. Argonne National Lab. May, 1959. (ANL-6003) Unclassified

103. Linnett, J. W. and Simpson, C. J. S. M. "The General Force Field of Some Hexafluorides." Trans. Faraday Soc. 55, 857-66(1959).

104. Lipkin, D. and Weisman, S. I. Photochemistry of Systems Containing Uranium Compounds. Univ. of California, Radiation Lab. Dec. 17, 1942. (A-520) Declassified

105. Llewellyn, D. R. The Thermal Conductivity of Mixtures of Air and Uranium Hexafluoride. Oxford Univ. Nov. 19, 1943. (BR-357) Declassified

106. Llewellyn, D. R. The Viscosity of Air and [UF 6 ] Mixtures. Oxford Univ. May 10, 1944. (BR-427; Research Note No. 12) Declassified

107. Llewellyn, D. R. "Some Physical Properties of Uranium Hexafluoride." J. Chem. Soc. 28-36(1953).

108. Magnuson, D. W. Studies in Molecular Structure. Carbide and Carbon Chemicals Co. July 27, 1951. (K-787) Unclassified

109. Magnuson, D. W. "The Dielectric Constant of Uranium Hexafluoride Vapor at $9400 \mathrm{mc} / \mathrm{sec}$." J. Chem. Phys. 19, 1614(1951). [Also reported in K-689; AECD3175]

110. Magnuson, D. W. "Microwave Dielectric Constant Measurements." J. Chem. Phys. 24, 344-7(1955) [Also reported in $\mathrm{K}-1118$ ]

111. Mann, J. E. The Physical Properties of $\mathrm{UF}_{6}$. Div. of Atomic Energy (Production), Risley, England. Nov. 16, 1953. (RDB(R)/TN-17) Unclassified

112. Martin, A. E. and Amphlett, C. B. Determination of the Ultra-Violet Absorption of [ $\left.\mathrm{UF}_{6}\right]$ Vapour. Univ. of Birmingham, England. Nov. 30, 1942 . (BR-188)Declassified

113. Masi, J. F. "The Heats of Vaporization of Uranium Hexafluoride." J. Chem. Phys. 17, 755-8(1949). [Also reported in AECD-2288]

114. McMillan, J. A. Treatment of Gaseous Uranium Hexafluoride by Means of an Inverse Molecular Force Model. Argentina. Comision Nacional de Energia Atomica. 1954. (Physics Series, Vol. 1, No. 3) [See Translation, Goodyear Atomic Corp. April, 1954 (GAT-T-646)] 
115. Murphy, G. M. The Chemistry of the Diffusion Process. Oak Ridge, Technical Information Service Extension, AEC, 1952. (National Nuclear Energy Series, Div. II, Vol. 6) Secret

116. Myerson, A. L. and Eicher, J. H. "The Viscosity of Gaseous Uranium Hexafluoride." J. Am. Chem. Soc. 74, 2758-61(1952) [Also reported in M-2518]

117. Ney, E. P. and Armistead, F. C. "The Self-Diffusion Coefficient of Uranium Hexafluoride." Phys. Rev. $\underline{71}, 14-9(1947)$.

118. Nier, A. O. The Determination of the Coefficient of Thermal Diffusion of Uranium Hexafluoride. Univ. of Minnesota. May 28, 1941. (A-41) Unclassified

119. Oliver, G. D., Milton, H. T. and Grisard, J. W. "The Vapor Pressure and Critical Constants of Uranium Hexafluoride." J. Am. Chem. Soc. 75, 2827-9 (1953) [Also reported in K-722; AECD-3470]

120. Pasquier, L. P. and Lenihan, W. S., eds. Technical Data Book. Vol, II. Carbide and Carbon Chemicals Co. Aug. 7, 1947. (A-4739) Secret

121. Pistorius, C. W. F. T. "Potential Field and Force Constants of Octahedral Molecules." J. Chem. Phys. 29, 1328-32(1958).

122. Present, R. D. A Report on Fleischmann's Measure of the Viscosity and Thermal Conductivity of Process Gas. Carbide and Carbon Chemicals Co. June 7, 1945. (M-2511) Declassified

123. Priest, H. F. Measurement of the Density of Liquid Uranium Hexafluoride. Columbia Univ. Mar. 29, 1942. (A-139; MDDC-176) Declassified

124. Priest, H. F. and Priest, G. L. Determination of Densities of Several [UF ${ }_{6}$ ] Compounds. SAM Labs. Aug. 10, 1942. (A-257;MDDC-609) Declassified

125. Priest, H. F. The Measurement of the Surface Tension of $U_{6}$ at Two Temperatures. SAM Labs. Aug. 1, 1942. (KZ-6580) Secret

126. Posey, J. C. and Barber, E. J. Miscellaneous Studies of Fluorocarbons and Fluorocarbon - Uranium Hexafluoride Systems. Carbide and Carbon Chemicals Co. Dec. 28, 1953. (K-1089) Secret

127. Roberts, L. E. J. Viscosity of $\left[\mathrm{UF}_{6}\right]$ Vapour at Room Temperature. Oxford Univ., Great Britain. [July, 1944] (Br-468; Oxford Research Note 14) Declassified

128. Rosen, N. and Whybrew, W. E. "Appendix D: Measurement of Diffusion Coefficient of Uranium Hexafluoride." in P. H. Abelson, et al., eds. Liquid Thermal Diffusion. Technical Information Service Extension, AEC. Aug. 1958. (TD5229) Declassified

129. Rossini, F. D., Wagman, D. D., Evans, W. H., Levine, S. and Jaffe, I. The Selected Values of Chemical Thermodynamic Properties. National Bureau of Standards. Feb. 1, 1952. (N.B.S. Circular 500)

130. Rowlinson, J. S. A Calculation of the Liquid-Vapour Equilibrium in the Ternary System Uranium Hexafluoride - Chlorine Trifluoride - Hydrogen Fluoride. Ministry of Supply, Division of Atomic Energy (Production), Research and Development Branch, Capenhurst, Great Britain. Sept. 1953. (R. \& D. B. (Cap) TN 96). Declassified 
131. Rush, D. Thermodynamic Properties of Process Gas. Carrier Corp. Mar. 27, 1941. (KH-16) Unclassified

132. Rutledge, G. P. Correlation of Critical Temperature with Thermal Expansion of Liquid Uranium Hexafluoride. Carbide and Carbon Chemicals Co. July 15, 1949. (AECD-3264) Unclassified

133. Rutledge, G. P., Jarry, R. L. and Davis, W. Jr. "Freezing Point Diagram and Liquid-Liquid Solubilities of the System Uranium Hexafluoride - Hydrogen Fluoride." J. Phys. Chem. 57, 541-4(1953). [Also reported in AECD-3469]

134. Rutledge, G. P. and Davis, W. Jr. "Solid-Liquid and Liquid-Liquid Equilibria of the Ternary System Uranium Hexafluoride - Chlorine Trifluoride - Hydrogen Fluoride." J. Phys. Chem. 63, 166-9(1959). [Also reported in K-975]

135. Simon, F. Physical Properties of Uranium Hexafluoride. Oxford Univ., Great Britain. July 23, 1943. (100XR-2214) Restricted Circulation

136. Sheremet'ev, G. D. “Optical Properties of Uranium Hexafluoride, I. Spectra in the Visible and Near-Ultraviolet Regions." Optika i Specktroskopiya 1, 181-9 (1956). [See translation, Goodyear Atomic Corp. July 15, 1959. (GAT $-\bar{Z}-4077$ )]

137. Smyth, C. P. and Hannay, N. B. The Dipole Moment and Molecular Structure of Uranium Hexafluoride. Princeton Univ. Oct. 1, 1944. (A-2130; MDDC-441) Declassified [Also in TD-5290, see reference 89]

138. Stein, L. and Vogel, R. C. Refractive Indexes of the Systems $U_{6}-B_{6} F_{3}$ and $\mathrm{UF}_{6}-\mathrm{BrF}_{5}$. Argonne National Lab. May 25, 1953. (ANL-5051) Declassified [Also see report ANL-4941]

139. Tilk, W. and Klemm, W. "Magnetochemical Investigations, XXXI. Paramagnetism of the Compounds of Sexivalent Chromium, Molybdenum, Tungsten and Uranium." Z. anorg. u. allgem. Chem. 240, 355-68(1939).

140. Wechsler, M. T. and Hoge, H. J. Density of Solid $\left[\mathrm{UF}_{6}\right]$ near the Triple Point and the Expansivity of the Liquid from the Triple Point to $92^{\circ} \mathrm{C}$. National Bureau of Standards. Feb. 25, 1943. (A-465) Unclassified

141. Wechsler, M. T. and Hoge, H. J. "Density of Uranium Hexafluoride." J. Chem. Phys. 17, 617-9(1949). [Also reported in A-1591, AECD-2301]

142. Weinstock, B. and Crist, R. H. "The Vapor Pressure of Uranium Hexafluoride." J. Chem. Phys. 16, 436-41(1948). [Also reported in 2R-152; MDDC-1295. Preliminary data reported in A-571]

143. Weinstock, B. and Malm, J. G. Some Recent Studies with Hexafluorides. Proceedings of the 2nd International Conference on the Peaceful Uses of Atomic Energy, Geneva. 1958. Vol. 28. Paper No. P/942, p. 195.

144. Weinstock, B., Weaver, E. E. and Malm, J. G. "Vapour-Pressures of $\mathrm{NpF}_{6}$ and $\mathrm{PuF}_{6}$; Thermodynamic Calculations with $\mathrm{UF}_{6}, \mathrm{NpF}_{6}$ and $\mathrm{PuF}_{6} . "$ J. Inorg. Nuclear Chem. 11, 104-14(1959).

145. Wendolkowski, W. S. and Barber, E. J. "Solid-Liquid Equilibria of the System Uranium Hexafluoride - Chlorine Trifluoride." J. Phys. Chem. 62, 750-2(1957). [Also reported in $\mathbf{K}-846$ ] 
146. White, J. R. and Cameron, A. E. "The Critical Ionization Potentials of Uranium Hexafluoride and Hydrogen Fluoride." Phys. Rev. 71, 907(1947). [Also reported in AECD-3689]

147. Whybrew, W. E., Tayman, J. H. and Kokulis, P. N. "Appendix A: Critical Temperature Measurement of Uranium Hexafluoride." in P. H. Abelson, et al., eds. Liquid Thermal Diffusion. Technical Information Service Extension, AEC. Aug. 1958. (TW-5229) Declassified

148. General Properties of Process Gas. Kellex Corp. 1943. (TID-5278) Declassified

149. Solubility of $\left[\mathrm{UF}_{6}\right]$ in MFL and C-2144. Monthly Status Report; Jersey City Research Lab. May 1 - June 15, 1945. Kellex Corp. (A-3498) Secret 


\section{LIST OF SYMBOLS}

a

A

$\mathrm{A}_{\mathrm{V}}$

B

B

$\mathrm{B}_{\mathrm{V}}$

$\overline{\mathbf{c}}$

C

C

$\mathrm{Cp}_{\mathrm{t}}$

$\Delta \mathrm{C}_{\mathrm{p}}$

$\mathrm{C}_{\text {sat }}$

$\mathrm{C}_{\mathrm{V}}$

$\mathrm{C}_{\mathrm{V}}$

D

D

E

$\mathrm{E}_{\mathrm{o}}^{\circ}$

F

$\mathbf{F}^{\circ}$

$\mathrm{h}$

$\mathrm{H}$

$\mathrm{H}_{\mathrm{o}}$

$\Delta \mathrm{H}_{\mathrm{f}}$

$\Delta \mathrm{H}_{\mathrm{S}}$

$\Delta \mathrm{H}_{\mathrm{V}}$

k

k

$\mathrm{k}_{\mathrm{X}} ; \mathrm{k}_{\mathrm{x}, \mathrm{y}}$

K

I

$\mathrm{m}$

m
Empirical constant

Non-ideality parameter, $1 / \mathrm{T}^{3}$

First virial coefficient, atm. liters/mole

Empirical constant

Virial coefficient, liters

Second virial coefficient, atm. liter $^{2} / \mathrm{mole}$

Mean velocity, cm./sec.

Empirical constant

Virial coefficient, liter $\mathrm{s}^{2}$

Heat capacity at constant pressure, cal./mole deg.

Heat capacity at constant pressure at the triple point, cal./mole

Heat capacity of condensed phase in equilibrium with saturated vapor, cal./mole deg.

Heat capacity at constant volume, cal./mole deg.

Third virial coefficient, atm. liters $\mathrm{s}^{3} / \mathrm{mole}$

Self-diffusion coefficient, $\mathrm{cm} .2 / \mathrm{sec}$.

Virial coefficient, liters ${ }^{3}$

Energy content, cal./mole deg.

Energy content at absolute zero (zero-point energy), cal./mole

Free energy, cal./mole deg.

Free energy of a perfect gas, cal./mole deg.

Planck's constant, erg sec.

Enthalpy, cal./mole deg.

Enthalpy at standard state, cal./mole

Heat of fusion, cal./mole

Heat of sublimation, cal./mole

Heat of vaporization, cal./mole

Boltzmann constant, erg/deg.

Empirical constant

Force constants, $10^{5}$ dynes $/ \mathrm{cm}$.

Thermal conductivity, cal./cm. sec. ${ }^{\circ} \mathrm{C}$.

Mean free path, $\mathrm{cm}$.

Empirical constant

Mass of the molecule, grams 
M

$\mathrm{n}$

n

$\mathrm{n}$

N

$\mathrm{p}$

$\mathrm{P}$

$\mathrm{P}_{\mathrm{m}}$

$\mathbf{r}$

$\mathrm{R}$

$R_{\mathrm{o}}$

S

$\mathbf{S}$

$\mathbf{S}^{\circ}$

$\mathrm{S}_{\mathrm{o}}$

t

$t_{c}$

$t_{f}$

$\mathrm{T}$

$\mathrm{T}_{\mathrm{c}}$

$\mathrm{V}$

$\mathrm{V}_{\mathrm{C}}$

$\mathrm{V}_{\mathrm{C}}$

$V_{g}$

$\mathrm{V}_{\mathbf{f}}$

$\mathrm{X}$

$\mathrm{X}$

$\epsilon$

$\epsilon$

$\eta$

$\lambda$

$\mu$
Molecular weight, grams

Empirical constant

Refractive index

Number of molecules per unit volume

Avogadro number

Pressure, mm.

Pressure, atm.

Molar polarization, cc.

Distance between atoms or molecules, $\mathrm{cm}$.

Gas constant, atm. 1iter $/$ mole ${ }^{\circ} \mathrm{K}$.

Empirical constant (Lennard-Jones 6-12 parameter)

Sutherland's constant

Entropy, cal./mole deg.

Entropy of perfect gas, cal./mole deg.

Entropy at standard state, cal./mole

Temperature, degrees centigrade

Critical temperature, degrees centigrade

Triple point temperature, degrees centigrade

Temperature, degrees Kelvin

Critical temperature, degrees Kelvin

Volume, liters

Critical volume, liters

Volume of condensed phase, liters

Volume of vapor phase, liters

Volume of vapor at triple point, liters

Mole fraction

Repulsion force constant, g. $/$ sec. $^{2}$

Empirical constant (Lennard-Jones Model 6 12)

Dielectric constant

Viscosity, poise or g. $/ \mathrm{cm}$. sec.

Force constant

Empirical constant 
$\nu_{\mathrm{O}}$

$\rho$ or $\rho_{\mathrm{V}}$

$\rho_{1}$

$\rho_{\mathrm{c}}$

$\sigma$

Fundamental vibrational frequency, $\mathrm{cm} \cdot{ }^{-1}$

Rigidity of the molecule

Density of the molecule, grams/cc.

Density of the vapor, grams/cc.

Density of the liquid, grams/cc.

Critical density, grams/cc.

Molecular diameter, angstroms, $\AA$ 
DISTRIBUTION

Internal

K. E. Beu

M. M. Bruno

R. W. Brown

D. B. Crandall

F. E. Croxton

M. M. Earnhardt

V. S. Emler

C. J. Evans

D. H. Francis

D. C. Goodland

R. A. Holthaus

G. F. Kauffman

F. A. Koehler

M. F. Line

W. C. McCluggage

C. A. Mentges

C. R. Milone

J. B. Mitchelson

R. P. Nugent
A. S. Ostroski
L. E. Owen
B. W. Penland
G. H. Reynolds
P. R. Seufzer
B. W. Shugert
R. L. Smith
R. B. Stambaugh
H. Steinhauer
C. L. Stewart
C. D. Tabor
W. H. Taylor
C. F. Trivisonno
F. S. Voss
A. H. Wernecke
F. E. Woltz
S. J. Zangri

Central Files (20)

\section{External}

United Kingdom Atomic Energy Authority (Capenhurst Works) Attention:

R. Alexander

R. F. Bailey

R. W. M. D' Eye

J. F. Ellis

W. Fletcher

E. V. Garner

G. R. E. Goeghegan

A. G. Hamlin

D. B. B. Janisch
A. C. Mason

I. K. Mason

W. K. Matthews

D. H. Morris

E. G. Murphy

J. V. L. Parry

J. V. Shennan

G. E. Steele

Also distributed in accordance with TID-4500 (15th Ed.) 